\title{
The Turning Point
}

Localizing the motor performance deficit in Turner Syndrome

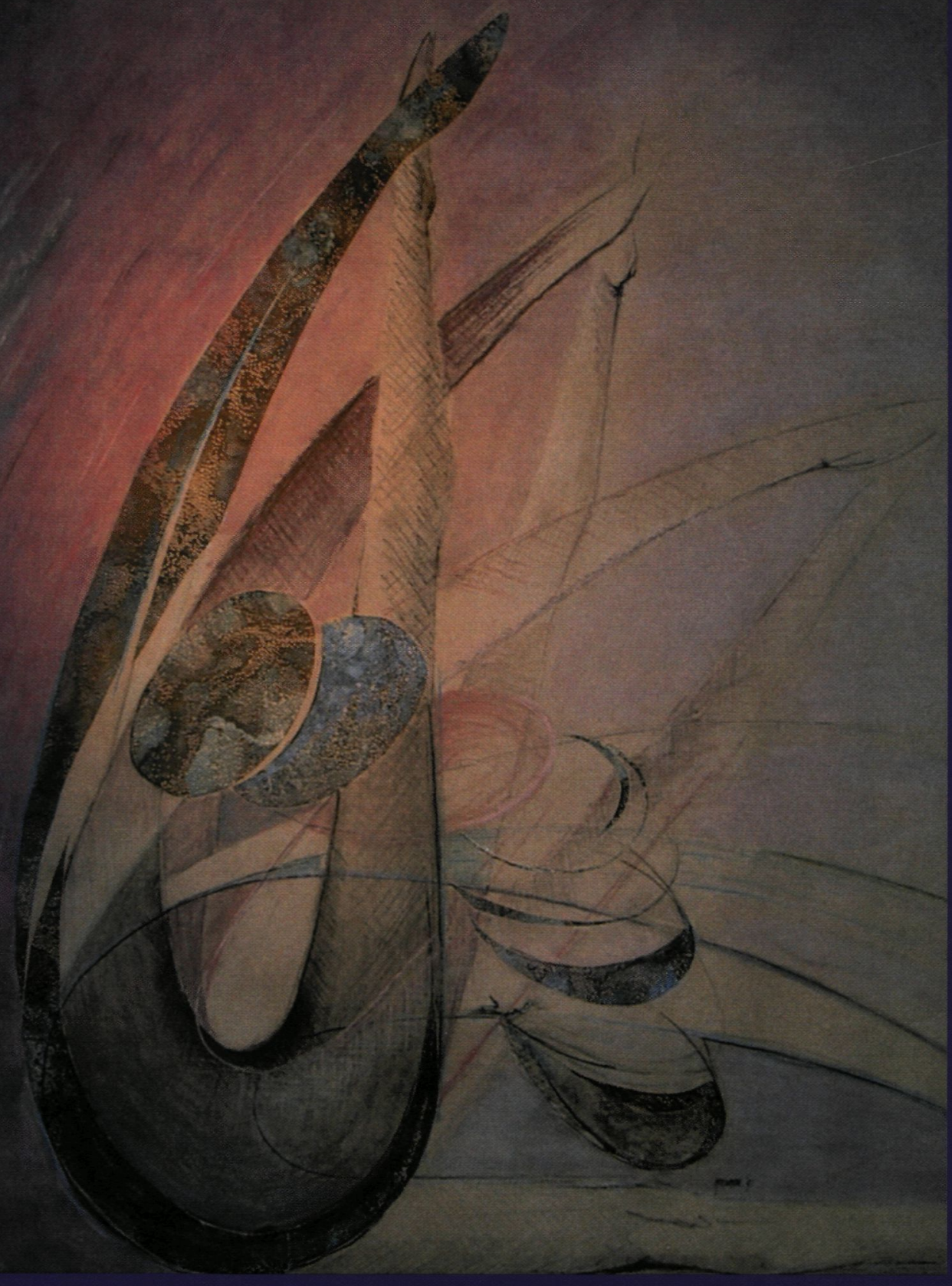

M.W.G. Nithuis-van der Sanden 



\section{The Turning Point}

\section{Localizing the motor performance deficit in Turner Syndrome}

M.W.G. Nijhuis - van der Sanden 
Cover Design: Jeanne Schouten

Printed by Ponsen \& Looijen BV, Wageningen, The Netherlands

Publication of this thesis was supported by:

Huisartsenpraktijk D.W.A.M. Jungst, Almelo

Koninklijk Genootschap voor Fysiotherapie, Amersfoort

Nederlandse Vereniging voor Kinderfysiotherapie, Amersfoort

Pharmacia B.V., Woerden

ISBN: $90-9016708-0$

(C2003. M.W.G.Nijhuis - van der Sanden, Nijmegen, The Netherlands. 


\title{
The Turning Point
}

\section{Localizing the motor performance deficit in Turner Syndrome}

\author{
een wetenschappelijke proeve op het gebied van de \\ Medische Wetenschappen
}

\section{Proefschrift}

\begin{abstract}
ter verkrijging van de graad van doctor aan de Katholieke Universiteit Nijmegen op gezag van de Rector Magnificus Prof. dr. C.W.P.M. Blom, volgens besluit van het College van Decanen in het openbaar te verdedigen op donderdag 24 april 2003
\end{abstract} des namiddags om 3.30 uur precies door

Maria Wilhelmina Geertruda Nijhuis - van der Sanden geboren op 28 april 1952 te Eindhoven. 
Promotores: Prof. dr. R.C.A. Sengers Prof. dr. G.P. van Galen

Copromotores: Dr. P.A.T.M. Eling

Dr. B.C.M. Smits - Engelsman

Manuscriptcommissie: Prof. dr. H.G. Brunner

Prof. dr. H. Bekkering

Prof. dr. J.E. Duysens 


\section{Het fietsje}

Lang liep ik met het fietsje aan de hand. Het fietsen zelf leek faliekant te falen. Dat er aan mij geen eer viel te behalen Was het gevolg van een te goed verstand.

Eer een impuls uit wielen of pedalen zo dacht ik- in mijn denkdoos was beland en doorgegeven naar mijn voet of hand zat ik allang tegen lantarenpalen.

Denkend ik kan het niet, kon ik het niet. De tranen van mijn voetgangersverdriet Deden het nickel al een beetje roesten. Mijn ouders overlegden wat ze moesten. Toen dacht ik: domoor, denk toch niet zo, zeg! En reed als razend op mijn fietsje weg.

Kees Stip

In: D. Welsink: Lachen in een leeuw. Verzamelde gedichten. (1994). Amsterdam, uitgeverij Bert Bakker. 

Voor alle kinderen, die wel een steuntje in de rug kunnen gebruiken 



\section{Contents}

Chapter 1 General introduction and outline of the thesis 11

Chapter 2 A review of neuropsychological and motor studies in 21 Turner Syndrome

Submitted

Chapter 3 Motor performance in girls with Turner syndrome.

Developmental Medicine and Child Neurology, 42, 685-690, 2000

Chapter 4 Low elementary movement speed is associated with poor motor skill in Turner's syndrome.

Developmental Neuropsychology, 22(3), 643-670, 2003

Chapter 5 Decreased movement speed in girls with Turner

Syndrome: A problem in motor planning or muscle initiation?

Submitted

Chapter 6 Slow motor performance in girls with Turner

Syndrome is not related to increased neuromotor noise.

In press, Motor Control

Chapter 7 General Discussion and Conclusion

Summary

Nederlandse Samenvatting

Dankwoord

Curriculum Vitae

List of publications 



\title{
General introduction and outline of the thesis
}

\author{
Maria W. G. Nijhuis - van der Sanden \\ Department of Pediatric Physical Therapy, \\ University Children's Hospital, \\ UMC St Radboud Nijmegen.
}

Chapter 1 


\section{Introduction}

Most of us take our ability to move around for granted. We move all day long to survive, to do the things we want to do, to communicate and to express to others who and what we are. Although it may appear to be a simple thing, this movement co-ordination process actually is very complicated. At birth, basic motor skills are available, but development and learning during lifetime is necessary. A major dilemma is to define what "normal" or adequate motor skills look like. The variety of motor responses in a given situation is immensely large and a particular reaction results from the interaction of individual, environmental and task characteristics (Shumway-Cook \& Woollecott, 2001). The complexity of motor skills becomes especially apparent when we consider the diversity in presentation of movement disorders.

Pediatric physical therapists have been referred to as "experts in motor functioning" and they specifically focus on the influence of learning and development of motor skills, from birth until adolescence, in children with movement disorders (Nijhuis - van der Sanden, Van Goor-Dijkstra, Engelbert \& Heerkens, 2001). The rate at which a child acquires certain skills, and the performance level he can attain are limited by constraints of e.g. musculature, nervous system, developmental stage and overall learning capacity. The presence of pathology defines systematically these constraints. Therefore, understanding the nature of movement control and insight in constraints in relation to pathology is necessary in order to design adequate therapeutic strategies. Questions a therapist has to answer are: Which internal (or external) constraints limit motor performance capacity? And is it possible to enlarge motor performance capacity by creating a therapeutically leaming environment dealing with the found constraints?

\section{Turner Syndrome}

Turner Syndrome (TS) is a genetic disorder resulting from the loss of the entire or a part of the X-chromosome characterized by short stature, specific physical features, gonadal dysgenesis, and decreased secondary sexual development. TS is also characterized by specific cognitive problems and clumsiness. Many parents mention feeding problems in early 
childhood. Later, at school age and in adolescence, slowness, clumsiness, lack of insight in certain practical situations, problems at school (in particular with arithmetic) and problems with social relations are often mentioned.

The Turner Syndrome (TS) was probably described first by Giovanni Battista Morgagni (1682-1771) in 1761, in Letter 46 in his famous book 'De Sedibus et Causis Morborum'. Subsequently, a number of case reports were published, particularly in Germany. The paper by Ullrich in 1930 meant a breakthrough in the interest in this syndrome (in Germany it is still referred to as the Ullrich-Turner Syndrome). Henry H. Turner (1938) argued that the typical physical features were caused by a disorder of the pineal gland and introduced treatment with estrogens and growth hormones. Shaffer and Money noted the characteristic psychological profile in 1962 (see for a detailed historical overview: Kollmann, 1992).

Although TS has a relatively high incidence (one in 2000 to 5000 live born females; Rosenfeld, 1990) and parents and teachers frequently mention functional motor performance problems in girls with TS, to date little theory-driven research is available conceming these motor problems. Moreover, it is sometimes argued that these problems might be due to specific cognitive problems in TS, e.g. poor visuospatial perception (Ross, Zinn, \& Mc Cauley, 2000; Rovet, 1993). Although not always clear evidence is available, clinicians believe that early intervention can help maximizing functional development to prevent secondary psychosocial problems. However, before such an intervention can be established, it is necessary to detect the exact nature of the motor performance problems. Subsequently, the benefits of such an intervention and the implications for daily life activities can be evaluated. 


\section{Karin, a girl with Turner Syndrome}

At the age of seventeen, Karin, was referred to the psychologist and physical therapist by the pediatric endocrinologist. She had problems with her professional education. After she had finished high school, she went through schooling trajectories for three different professions. Each time the theoretical examination was no problem. However, during the practical phase the professional coaches complained about her slowness, clumsiness and lack of planning capacities. When Karin asked for advice, she was working as secretary in the practical stage of her fourth professional training. Her school counselor had advised this course, because of the clarity of the activities. Again, she failed for the test of the practical exam. She also indicated that she had had problems learning to drive a car. Her question for help was clear: she did not want to fail again.

Karin failed on a motor performance test battery. She scored below the 1st percentile on the Movement Assessment Battery for Children (Henderson and Sugden, 1992). In all skills she had major problems: manual dexterity, ball skills and static and dynamic balance. Movements were disfluent, slow, and not rhythmical and she had severe problems with adequate placing and timing. Muscle strength seemed to be adequate and her general condition was very good. No soft neurological signs were detected.

Full Scale Intelligence Score (FSIQ) on Wechsler Adult Intelligence Scale was 96 (within the normal range), while Verbal Intelligence Score (VIQ) was 107, and Performal Intelligence Score (PIQ) was 84. This low PIQ score was due to problems with visual-spatial tasks. Concentration was high, but the psychologist noted that she was very slow; reducing working time caused a decrease of results. Not surprisingly, Karin had a low self-esteem, and she told that she was afraid to ask for help from colleagues.

The physical therapist trained Karin on the job. Her colleagues and her supervisor were informed about her limitations and her aims. The motor skills she needed like folding letters and typing, were trained in a therapeutical setting to increase velocity. Special materials were used to support planning of daily activities, such as a checklist with daily activities. With much patience, from herself and her colleagues, and thanks to marvelous coaching from her supervisor, Karin managed to function adequately as secretary. She decided to stop learning to drive a car.

(Karin is not the real name). See also: Nijhuis - van der Sanden, Dijkstra - Hekkink, Thoonen \& Nabuurs, 1998). 


\section{Motor skills}

Skilled performance always involves an organized sequence of activities. The spectrum of skills is broad and includes both the sequential organization of actions and the organization of spatial and temporal factors of the movements. The proficiency of a motor skill is reflected in the accuracy, velocity, fluency and adaptability of the activity. When we study overt goal-directed motor behavior in children, we are always looking at the result of a long chain of processes, necessary to co-ordinate the observed movements. A clinician should observe accurately what a child is doing, how he is doing it and then try to understand why the child is doing it in this particular manner.

A number of theories on perceptual motor skills have been described in the literature (Jeannerod, Arbib, Rizzolatti, \& Sakata, 1995; Rosenbaum, Engelbrecht, Bushe, \& Loukopoulos, 1993; Schmidt, 1975; Wolpert, Ghahramani, \& Jordan, 1995). These theories share the assumption that motor performance can be modeled by a series of hierarchically organized processing levels, representing the transformation of information from intention to action. The group of Van Galen $(1990,1991,1992,1995)$ distinguishes in their information processing model, roughly speaking, five different stages. In the first, perceptual stage, stimuli from the environment are perceived, and the relevant features have to be encoded in order to recognize such stimuli. In the next stage, a decision has to be made which (motor) response should be selected. The last three stages, mentioned in that model, are motoric in nature: a motor programming, a parametrization and an initiation process. In the motor programming process, a motor program is selected from long-term memory for the chosen response. In the parametrization process, appropriate movement parameters, like force, duration and size are added to that abstract motor program. In the final initiation stage, the program is translated into motor unit recruitment commands. Such a process orientated, diagnostic model provides insight in the nature of observed motor problems, not only in research questions, but also in clinical questions. It is the overall goal of the present thesis to link up the above-mentioned hierarchical model of motor control with the motor problems in TS. 


\section{Aim and Outline of the Thesis}

The more specific aim of the present thesis is three-fold. The first aim is to examine whether and to what degree motor performance is a real problem in TS children. The second aim is to investigate whether motor performance problems are related to neuropsychological problems, which have been described frequently, such as visuospatial perception (Money, 1993; Ross et al., 2000; Temple \& Carney, 1995). And the third aim is to investigate the nature of motor control in TS within the above-mentioned theoretical framework. Taken together these targets are helpful to determine the strategies and potential benefits of physical therapy.

In chapter 2, the Tumer Syndrome is described and the state of the art of research on neuropsychological and motor functioning in TS is reviewed. In chapter 3 a study is presented, in which the degree of motor problems in TS is established using a norm-referenced motor performance test. Also, the possible relationship with cognitive functioning is discussed. In a study by Smits - Engelsman, Nijhuis - van der Sanden \& Duysens (in press) the results of the TS children and controls on a clinical motor performance test and a writing test are related to real-time kinematic data of a drawing task (one of the subtest from the clinical motor performance test). We explored variables such as accuracy, trajectory length, movement time, velocity, and pen pressure. The objective of this study was to identify possible kinematic variables that characterize the movement patterns of the TS group. These studies indicated that TS individuals in fact suffer from motor problems, to a certain extent independent of cognitive deficits. We then turned towards the main question: what is the essential nature of this motor problem.

Using the above-mentioned theoretical framework, the core of the thesis is presented in the next three chapters, which focus on the identification of the motor control problem in TS. In the study reported in chapter 4, we used an experimental procedure with which we attempted to evaluate the role of spatial-accuracy demands in different task conditions. The aim of this study was to discriminate between two features that in principle may both cause motor performance problems in TS: motor execution and motor programming. It appeared that in TS accuracy is not the main problem but velocity is consistently lower in TS. While in this study only simple motor tasks were used, in the next study (Chapter 5) we used more controlled 
experimental task-loading conditions addressing the three process levels (Van Galen, 1991), involved in motor execution: the muscle initiation process, the parametrization process and the motor programming process. In these experiments girls with TS showed specific problems in the tuming points of the movements, and it seemed that velocity in agonist-antagonist coordination was the problem. In chapter 6 the hypothesis is tested whether the velocity problems in girls with TS are related to increased variability of the nervous signal, transmitted from the brain to the muscle and/or in the motor unit recruitment processes. To this end we used an isometric force production paradigm. Finally, in Chapter 7 , the results and the conclusions of the preceding chapters are evaluated in the light of methodological and theoretical considerations. Specifically the significance of the thesis as a whole is summarized and some future directions for research are outlined. 


\section{Reference List}

Jeannerod, M , Arbıb, M A , Rizzolattı, G , \& Sakata, H (1995) Grasping objects The cortical mechanisms of visuomotor transformation Trends in Neuroscience, 18, 314320

Kollmann, F (1992) Die entdeckungsgeschichte de Ullnch-Turner-Syndroms In Weidmann, O (Ed ) Frankfurter Beitrage zur Geschichte, Theone und Ethuk der Medızın Hildesheım George Olms AG

Money, J (1993) Specific neuro-cognitive imparments associated with Turner's (45 XO) and Klınefelter (47 XXY) syndromes a review Social Bıology, 40, 147-151

Nıhuis - van der Sanden, M W G , Van Goor-D1jkstra B , Engelbert R , \& Heerkens Y (2001) Functieprofiel Kinderfysıotherapeut In order of KNGF and NVFK, Amersfoort Nıjhus - van der Sanden, M W G, Dijkstra-Hekkınk, J G B , Thoonen, G \& Nabuurs, L (1998) Het Turner Syndroom dagelıjkse problemen in kaart gebracht Fysiopraxis 7 , 13-18

Rosenbaum, D A , Engelbrecht, S E , Bushe, M M , \& Loukopoulos L D (1993) A model for reaching control Acta Psychologica, 82, 237-250

Rosenfeld RG (1990) 'Preface' In Rosenfeld R G Grumbach M M (des) Tumer Syndrome New York and Basel Marcel Dekker Inc

Ross, J L , Zınn, A \& Mc Cauley, E (2000) Neurodevelopmental and psychosocial aspects of Tumer Syndrome Mental Retardation and Developmental Disabilitıes Research Reviews, 6, 135-141

Rovet, J (1993) The psycho-educational characteristıcs of children with Tumer's Syndrome Joumal of Learning Disabilities, 26, 333-341

Schmidt, R A , \& Lee, T D (1999) Principles of simple movement In R A Schmidt \& T D Lee (Eds ), Motor control and learning A behavioral emphasis (pp 172-180) Illino1s, United States Human Kinetics

Shaffer, J W (1962) A specific cognitıve deficit observed in gonadal aplasia (Tumer's Syndrome) Journal for Clincal Psychology, 18, 403-406

Shumway-Cook, A , \& Woollacott, M H (Eds , 2001) Motor Control Theory and practıcal applications (pp 2-9) Baltımore, Unıted States Lippıncott Willıans \& Wilkıns

Smits - Engelsman, B C M , Nıjhuis - van der Sanden, M W G , \& Duysens, J (in press) An exploratory Study of the kınematıcs of girls with Tumer Syndrome in a visuo-motor task Infant and Child Development

Temple, C M , \& Camey, R A (1995) Patterns of spatial functioning in Tumer's Syndrome Cortex 31, 109-118 
Turner, H H (1938) A syndrome of infantılısm, congenıtal webbed neck, and cubıtus valgus Endocnnology,23, 566-574

Ullnch, O (1930) Uber typısche Kombınatıonsbilder multıpler Abartungen Zeıtung fur Linderheilkunde, 49, 271-276

Van Galen, G P (1991) Handwntıng Issues for a psychomotor theory Human Movement Science, 10, 165-191

Van Galen, G P , \& De Jong, W P (1995) Fitss'law as the outcome of a dynamic noise filtenng model of motor control Human Movement Science, 14, 539-572

Van Galen, G P , \& Schomaker, L R B (1992) Fitts' Law as a low-pass filter effect of muscle stıffness Human Movement Science, 11, 11-22

Van Galen, G P , Van Doom, R R A , \& Schomaker, L R B (1990) Effects of motor programming on the power spectral density function of finger and wrist movements Joumal of Expenmental Psychology Human Perception and Performance, 16, 755- 765

Van Galen, G P , \& Van Huygevoort, M (2000) Error, stress and the role of neuromotor noise in space onented behavior Biological Psychology, 51,151-171

Wolpert, D M , Ghahramanı, Z , \& Jordan, M I (1995) An internal model for sensorımotor integration Science, 269, 1880-1882 



\section{A review of neuropsychological and motor}

\section{studies in Turner Syndrome}

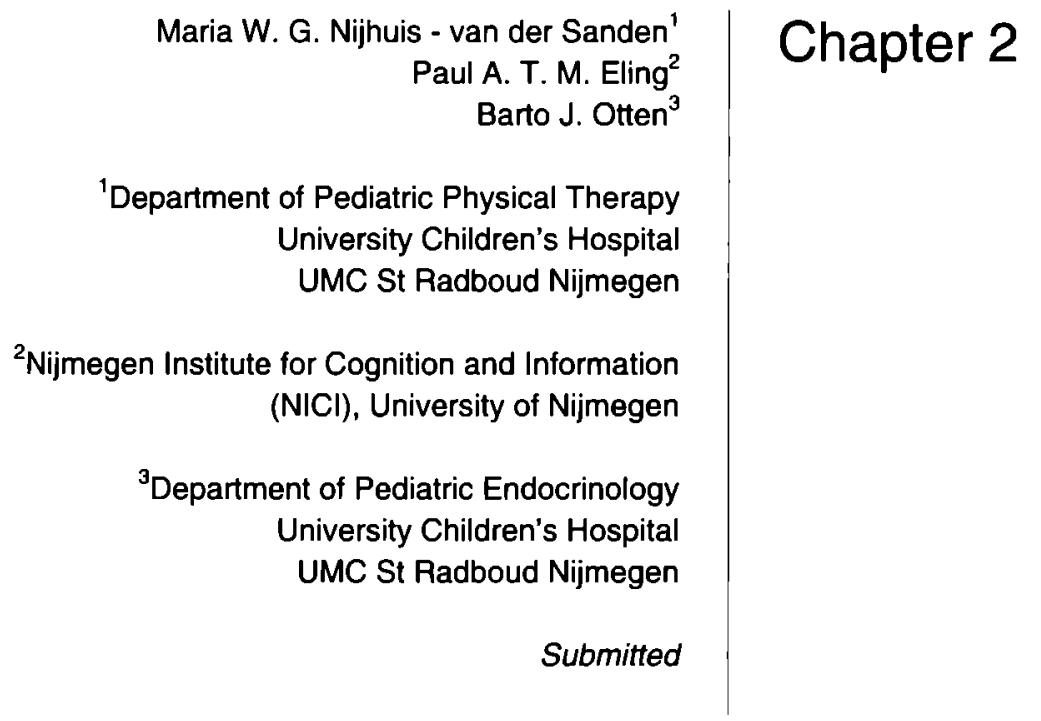




\section{Abstract}

We reviewed the literature on Turner Syndrome (TS) from 1962 until June 2002 with respect to the following questions: Is there a consistent pattern of cognitive and/or motor dysfunction in TS girls and if so, is there a relationship to the behavioral disturbance, also reported for this syndrome? Many studies indicate that girls with TS have a disharmonic IQ profile: a verbal IQ that seems to be at a (nearly) normal level and a decreased PIQ. This profile remains into adulthood. Visual-spatial problems are mentioned most frequently and there is some evidence for a relationship to particular neuro-anatomical structures, hormonal dysfunction, and genotype. Although much less research has been done on motor performance in TS, there is clear evidence that it is disturbed in TS. Many authors emphasize the interaction between somatic, psychological and social factors, but we did not find a clear theoretical framework explaining this relationship. We argue that there may be two independent problems: a visuospatial and a motor deficit and both have implications for functioning in daily life. 


\section{Introduction}

Tumer Syndrome (TS) is a genetic disorder resulting from the loss of the entire or a part of the X-chromosome. Apart from physical features such as short stature, sexual infantilism, webbed neck and cubitus valgus, also a number of functional problems in daily life are frequently reported in the clinical situation. Many parents mention feeding problems in early childhood. Later, at school age and in adolescence, slowness, clumsiness, lack of insight in certain practical situations, problems at school (in particular with arithmetic) and problems with social relations are often mentioned. When the TS-girls become older and prepare for a professional career, they may experience problems both in their training, in their occupation and in the organization of domestic tasks. For these kinds of problems the medical specialist often refers the girls to a psychologist and/or a physical therapist.

Many publications support the above-mentioned clinical impression and describe these psychosocial problems. The most frequently mentioned problems are a low self-esteem, social interaction problems and less friendship relations in school age, hyperactivity, attention deficit, and emotional infantilism [1-15]. Adult women with TS are less likely to leave the parental home than their healthy peers $[16,17]$ and they have a lower occupational status than would be expected from their level of education [16].

Such psychosocial problems may be, at least partly, the result of other more basic deficiencies, such as cognitive and motor problems. In order to improve our understanding of the functional motor problems in TS, we started a research project into these underlying factors. We first reviewed the literature with respect to the following question: Is there a consistent pattern of cognitive and/or motor dysfunction in girls with TS and if so, is there an explanation for the disturbance? We started with a broad search (medline and psych-lit) of the literature between the years 1962-2002. In total 368 publications were found. Studies were included based on the following criteria: conclusions relevant to our research question, use of norm-referenced tests or use of a control group, clear presentation of data and statistical analysis. Group size was not a decisive criterion. Thus, 89 articles were selected and studied; the results are discussed in this review. 
Firstly, the findings concerning general and specific cognitive functioning are discussed. We will then evaluate the literature on general and specific motor problems. Subsequently, we will focus on studies examining the issue of localization, the potential influence of deficiency and suppletion of hormones, and finally the influence of chromosomal variation in TS.

\section{General Cognitive Functioning}

In general, cognitive functioning can be measured using a Full Scale Intelligence Quotient (FSIQ). In children the Wechsler Intelligence Scale for Children (WISC, $[18,19]$ is frequently used for this purpose and in adults the Wechsler Adult Intelligence Scale (WAIS, $[19,20]$ is the most widely used test. In these tests two different proficiencies are distinguished: a verbal IQ (VIQ), related to verbal skills, and a performance IQ (PIQ), related to more practical skills. Particularly these latter skills are of special interest, because these skills could be related to the functional motor problems experienced by TS-girls in daily life.

Shaffer [21] first reported a specific cognitive intelligence profile in TS, using the WISC. In a group of twenty girls with TS (mean age $15.11 \mathrm{yrs)}$ he found slightly but significantly higher scores for VIQ, but $P I Q$ was significantly lowered. In accordance with these results, Rovet [7] found in a group of 67 girls with TS, that PIQ was one standard deviation below the level of age-matched controls, whereas VIQ was normal or slightly above normal, and Full Scale IQ (FSIQ) did not deviate from normal peers. Shucard, Shucard, Clopper, and Schachter [22] found a remarkably weak performance on specific subtests like 'Block Design' and 'Object Assembly' in a group of 8 girls with TS, while the intellectual capacities were normal. In contrast to these four studies, many other studies $[1,16$, 23-35] reported a significantly lower FSIQ, caused by a decreased $P I Q$, mainly resulting from low scores on subtests assessing visual-spatial processing. Apparently in the majority of studies higher VIQ scores do not compensate the underperformance in PIQ.

Only Pennington et al., [29] found that VIQ was also subnormal. Rovet [36] found some evidence for mild verbal problems too. In her study, the combined results of 13 studies, representing 226 girls with TS and 142 
peers indicated that mild verbal and conceptual problems are occasionally present in TS, but problems with spatial and perceptual skills are more widespread.

Taken together, it can be concluded that girls with TS have a disharmonic IQ profile, with a verbal IQ that seems to be at a (nearly) normal level and a decreased PIQ. This specific profile persists in adulthood [e.g. 37, 38].

\section{Specific Aspects of Neuropsychological Profile}

As described above, it can be concluded that a lower PIQ score has been demonstrated in girls with TS. However, TS girls seem to perform poorer in some, but not all of the subtests of the Performance IQ scale [e.g. 28-32, $34,39]$. In more recent studies various neuropsychological tests and experimental procedures have been used to examine in more detail the nature of underlying cognitive problem.

The literature has been clear and consistent regarding the deficiencies in visual-spatial functions in TS girls $(3,5,6,31,33,36,39-45]$. Other deficits, that have been reported, include problems with visual memory [40, 47], deficits in visual constructional skills [40,48], and deficits in visualspatial working memory [49].

Buchanan et al. [49] remarked that many tasks that have been used (e.g., mental rotation, part-whole en left -right decisions), do not distinguish between processing components in visual-spatial tasks. They associated the observed visual-spatial problems to abnormalities in the parietal and occipital brain structures, and visual memory and attention deficits to abnormalities in hippocampus and caudate, found in studies using a variety of methods [e.g. 30, 40]. They used a neurocognitive model, describing two components of visual processing: locating an object in space (where?, parietal) and determining the identity of an object (what?, temporal). Buchanan et al., [49] could not distinguish between TS and controls in either object or spatial processing per se: TS girls reacted similarly as the controls on task manipulations, but reaction time and number of errors were greater in TS. They concluded that the problems are mainly based on a core deficit in visual-spatial working memory. Although this study was a first attempt, clearly more investigations are needed, using models that are well 
grounded in neuroscience, and that are effective in isolating a defective processing component, especially one that may coincide with the neuroanatomical and/or neuropsychological abnormalities, already described in the TS population.

Besides these visual spatial problems, a few other problems have been mentioned, such as deficits in arithmetic [7, 8, 10, 21, 25, 40, 47, 49-53]. Also 'word fluency' problems [2, 35, 41], problems with short-term memory [3, 21, 54], problems in long-term memory [29] and facial expression recognition $[3,49]$ have been described. Temple [55] studied oral fluency and narrative production in TS, and confirmed fluency problems in TS, and she suggested that these problems could be attributed to executive language retrieval processes or to an impairment in episodic memory. Some authors (e.g. 1, 3, 7, 48, 51, 52] suggest that deficits in arithmetic and visual constructional skills, as well as in facial expression recognition are related to, or based on the visual-spatial problems.

Taken together, decreased PIQ is the result of poor performance on subtests of the Performance IQ scale. Visual-spatial problems are mentioned most frequently, but the exact nature of the deficit and the relationship to other deficits are not yet clear.

\section{General Motor Functioning}

Although parents frequently report problems concerning motor development [12], only a few studies examined motor function in girls with TS. Salbenblatt, Meyers, Bender, Linden, and Robinson [56] investigated gross and fine motor functions, using the Bruininks Oseretsky Test of Motor Proficiency (BOTMP): In 14 of 21 TS girls BOTMP composite scores were below the 10th percentile. Additional problems were deficient sensory-motor integration, hypotonia, associated with diminished strength, poor joint stability and gait abnormalities. Moreover, based on retrospective data, it was argued that the age at which each infant reached the developmental milestone of independent walking was delayed in $11(52 \%)$ of the TS girls (Denver Developmental Screening Test criteria). Significant motor performance deficits were also established in the study of Nijhuis van der Sanden, Smits - Engelsman, and Eling [57], using the Movement 
Assessment Battery for Children (MABC) [58, 59]. In TS girls ( $n=15$, ages 5.8-12.5 years) mean MABC percentile score was 2.93 (range 1 to 8). None of the girls with TS scored above the $15^{\text {th }}$ percentile, 5 girls scored between the $15^{\text {th }}$ and 5 th percentile, and 10 girls scored below the $5^{\text {th }}$ percentile. However, no specific profile of motor impairment, and no significant correlation with intelligence scores were found.

\section{Specific Motor Functioning}

A study on oral-motor skills in ten babies with TS revealed an oral-motor dysfunction at a very early age [60]. This is in agreement with clinical impressions and parental complaints about feeding problems in anamnestic interviews. Van Borsel et al. [53], using questionnaires, found in their study of $128 \mathrm{TS}$ girls (aged 2.4 to 58.8 years) that many girls received treatment for stuttering, articulation problems and/or delayed language development ( $24 \%$ ); only in $5 \%$ of the girls motor problems were mentioned.

Waber [35] observed that TS-girls also perform poorly in the area of visuomotor coordination and motor learning. Recently, Smits - Engelsman, Nijhuis - van der Sanden, and Duysens [61], using an XYZ-digitizer, studied in more detail motor performance with such a visuomotor coordination task: the flower trail, one of the sub-tests of the MABC [58]. TS girls did not make more errors than controls in drawing a line between two narrow boundaries. However, kinematic analysis revealed that trajectory length was more than $10 \%$ longer in TS girls compared to controls. Moreover, they made more pen lifts and more changes in velocity. These findings suggest that controlling the execution of the movement seems an especially important factor and these findings support Waber's [35] view, that low scores on certain spatial tasks may be secondary to poor motor coordination.

Clark et al. [62] found significantly decreased grip strength compared to controls in older TS women, but in the study of McGlone [63] no difference in grip strength between young TS girls and controls was found. In a recent study by Nijhuis - van der Sanden, Van Asseldonk, Eling, and Van Galen [64] it was found that Maximal Voluntary Contraction (MVC) in an isometric finger contraction is much higher in young TS girls $(n=15)$ 
than in controls $(n=15)$, while at the same time no difference in accuracy of force initiation was found. However, all TS girls participated at that time also in a nation-wide study in the Netherlands on the effect of growthhormone treatment in combination with or without oxandrolon. It is possible that this hormonal treatment has positively affected the muscle mass and therefore the muscle force of the TS girls. Taken together, it is not yet clear whether general strength problems are common in TS (as suggested by the data of Salbenblatt et al., [56], and Clark et al., [62] or are related to other factors such as growth hormone treatment. More experimental research is needed.

With respect to motor speed, Clark et al. [62] did not find group differences in finger-tapping tasks, in contrast to Bender et al. [24] and McGlone [63]. The latter authors suggest that in TS, not only visual-spatial defects are present, but also impaired motor control. In contrast to this view, Ross, Kushner, and Roeltgen [65] found that TS girls $(n=78)$ performed worse than controls $(n=145)$ particularly on motor tasks with high visual-spatial demands and not on simple motor tasks. In contrast, the group of Nijhuis van der Sanden et al.[61, 64,66,67] concluded that a problem in motor execution is present, independent of visual spatial perception problems. These conclusions are based on experiments, demonstrating that TS girls move with the same accuracy as their normal peers. Moreover, speed was always decreased in TS girls, independent of task manipulations such as using a discrete or serial movement condition and/ or increasing spatial accuracy demands. Manipulating complexity of figure patterns had no additional effects on accuracy and velocity: accuracy remained as high as in controls while velocity remained consistently lower. At the same time it was found that differences in velocity and variability between TS girls and controls were not present in goal-directed isometric tasks, and therefore it was concluded that fast turnings in movement direction (related to agonistantagonist coordination) might be the main problem in movement execution.

Although studies in motor function are limited in number and group sizes are small, there is clear evidence that motor performance is disturbed in TSgirls. Some authors suggest that the problems in visual-motor coordination are caused by visual-spatial perception problems. However, it appears that the motor execution component plays an important role too. 


\section{Cerebral Localization}

Many studies have attempted to identify the actual brain area responsible for the typical cognitive deficits seen in TS. The issue of hemispheric specialization has received much attention in the seventies and eighties of the last century [68] and it has also been considered with respect to TS. The view of a right hemispheric dysfunction in girls with TS was mainly based on the findings that these girls tend to have intact verbal skills (left hemisphere) and difficulties with visual-spatial tasks (right hemisphere). In the early studies, a number of authors ascribed these findings, often without direct empirical evidence, to such a right-hemispheric dysfunction $[8,22$, $26,29,32,69-73]$. Until now, only little direct evidence has been obtained through the use of computed tomography scans, electroencephalography or other imaging techniques to support the notion of abnormal lateralization [8, 74]. Shucard et al. [22] found visual-spatial problems related to electrophysiological evidence, indicating a right-hemispheric abnormality. Their results suggest that the deficit may be related to poor memory or reduced ability to visualize the location of an object in space. Other studies (using MRI and autopsy) revealed anatomical differences in the right posterior (temporal, parietal, and occipital) regions $[30,39,75,76]$ between TS adults and normal controls. Clark, Klonoff, \& Hayden [62] reported a significantly reduced glucose uptake in the occipital and parietal cortex in the TS group. The reduction in glucose uptake was particularly notable in the primary and secondary visual cortex, and these authors argued that the reduction in the parietal cortex might reflect a lack of innervation from the occipital cortex, related to the observed lower scores on visual tests.

Some authors [36,77-79] stated that TS girls suffer from a lack of development of normal hemispheric lateralization, due to a shortage of estrogens. As a consequence, some verbal functions might be localized in the right hemisphere leading to interference with the normal visual spatial functions of the right hemisphere. This is referred to as the "crowding effect'.

The deficits in motor planning and performance have also been interpreted as due to insufficient development of hemispheric lateralization, specific for TS [24, 26, 70]. In tapping tasks, pegboard tasks [24] and in cutting 
tasks [26] TS girls had similar scores for both hands, while in controls the dominant hand was faster. However, Dellantonio et al. [70] found in TS girls an exceptionally low score for the non-dominant hand.

In contrast to a more localized dysfunction hypothesis, other studies suggest TS girls suffer from a more diffuse or global disorder, which is not restricted to the right hemisphere $[2,35,80]$. An early advocate of this view is Waber [35], who advocated a process-oriented approach. She demonstrated that girls with TS do not perform badly on all visuospatial tasks. She found in TS-girls disorders in attention, visual memory and motor coordination too, and she argued that performance in visual-spatial tasks is to some extent determined by these processes. In this context, she referred to the findings of Silbert et al. [73], indicating that TS girls have problems with figure-ground discrimination, both visually and auditory. Some authors, who found a marked deficit in drawing, support this view [48, 77, 80]. Reiss, Freund, Plotnick, Baumgardner, Green, Sozer, et al. [81] performed a MRI study in a set of monozygotic, prepuberal twin girls, one girl with TS and one normal girl. The TS girl demonstrated normal verbal abilities with relatively decreased visuoperceptual and visuomotor abilities and prolonged reaction times compared to her twin sister, combined with a larger total brain volume and an enlarged right sided ventricle. Also, the fourth ventricle and the cisterna magna appeared larger. The volume of the grey matter was reduced in the left parietal and right prefrontal areas. The volumes of cerebellar vermis, pons and medulla were smaller. The authors argued that this latter finding might be due to involvement of the brain stem and cerebellum in arousal, attention, cognitive processing and modulation of motor processes.

Johnson, Rohrbaugh and Ross [82] suggested both may be true: decreased maturation of hemispheric lateralization and a global dysfunction. They found that event related potentials (ERP's) in older TS girls resembled more those of younger TS girls than those of age-matched controls, and these authors argue that this points to an age-dependent deficit, caused by an altered maturation of the brain lateralization in girls with TS. However, in the same study reaction times were longer in TS girls than in controls in all conditions, while error percentage was the same and these results were interpreted as an age-independent more global congenital defect. Reiss et al. [81] ascribed the motor problems to abnormalities in the brain stem and 
cerebellum, because aspects like arousal, sensory integration and motor modulation seemed to play a role as well.

In summary, it can be concluded that there is some evidence for localized problems in the posterior part of the right hemisphere $[21,72,75]$, related to PIQ problems and functions localized in the parietal and occipital lobes, associated to visual perception problems [e.g. 29, 38, 48]. At the same time, motor execution problems appear to be related to problems in subcortical structures, cerebellum, pons, and thalamus $[39,81]$.

\section{Influences of Hormones}

TS is characterized by premature ovarian failure and neurocognitive deficits may arise from a lack of estrogen during the first year of life, when there is normally a period of increased ovarian estrogen production [49]. This view refers to the finding that visual-spatial processes and working memory are influenced by sex hormones during early development [54].

Other deficits have been ascribed to lack of estrogen during early puberty, prior to receiving estrogen replacement therapy. Romans et al. [42] investigated changes in motor skills during the transition from adolescence to young adulthood. In their study, females with TS in early adulthood performed at levels comparable to normal female controls during simple motor tasks, in contrast to the performance in the younger age group, and they related this to an estrogen effect. Ross et al. [44] found a positive estrogen-effect on nonverbal processing speed and motor speed in young TS girls. However, marked estrogen effects on simple motor tasks were absent in contrast to the spatially mediated tasks, and therefore Ross et al. [45] argued that estrogen particularly influences visual-spatial processing. In their view, the impaired performance in visual-spatial tasks is caused by persisting visuospatial difficulties, independent of motor components.

However Ross et al. [37] found no estrogen replacement effect on cognitive deficits in adult females with TS. They suggest that these results reflect the specific influence of hormonal factors on brain maturation during puberty.

In the last ten years, treatment with synthetic growth hormones has been introduced, to improve body growth during childhood in order to diminish the practical and psychological problems of extremely short stature. We 
could find only one study, examining growth hormone replacement effects on cognitive functioning [83]. In this study no effect on cognitive functioning was found. Nijhuis - van der Sanden et. al [64] reported an increased Maximum Voluntary Contraction in isometric force tasks in TS, but this might be ascribed to the addition of oxandrolon to the treatment of growth hormone. The authors suggested that the observed increased MVC could possible be the effect of hormonal therapy.

In summary, important work has been done by the group of Ross et al. [6, $37,42-46,65,76,82,83]$, but the literature with respect to the effects of hormones on cognitive and motor function is still difficult to interpret. Essentially, no study has looked in detail at the working mechanism of estrogen on the nervous system, and only indirect evidence is available.

\section{Influences of Karyotype}

The notion that the nature of the genetic abnormality might influence the results, measured in cognitive and behavioral tasks, was introduced in the literature in the early sixties [21]. Approximately $60 \%$ of all affected TS patients have a classic TS karyotype, in which there is only a single Xchromosome (45 XO), while individuals with mosaicism have two or more cell lines $(45 \mathrm{XO} / 46 \mathrm{XX})$. In $10 \%$ of the cases a structural deformation of the X-chromosome (e.g., absence of the short arm) is present [84].

Although some studies did not find differences between girls with classic karyotype and mosaics $[7,72,85]$, it has been generally assumed that TS girls with classic karyotype perform worse than mosaics in cognitive and motor tasks [e.g. 34, 56]. Temple and Carney [56] noted that a disharmonic intelligence profile is present in the subgroup of TS girls with a $45 \mathrm{XO}$ karyotype, while mosaic girls show a more harmonic profile [see also: 9 , $24,49,86]$. Salbenblatt, Meyers, Bender, Linden, \& Robinson [56] noted that 12 of $1545 \mathrm{XO}$ TS girls scored below the 1st percentile norm, while only 2 of the 6 mosaic girls scored below 10th percentile. It must be noted that the distinction between $45 \mathrm{XO}$ karyotype and mosaics is disappearing gradually since techniques have been developed for establishing the extent of the genetic abnormality. Chu [87] argued that all live born patients must be mosaic for a critical cell line. The very high intrauterine loss, coupled with the observation that there is a higher ratio of mosaic karyotypes to 
monosomy $\mathrm{X}$ in live-boms compared with aborted fetuses, has led to this speculation. Moreover, recent molecular genetics studies [88] indicate there may be as many as five genes located in different regions of the $\mathrm{X}$ chromosome, contributing to the physical and hormonal abnormalities found in TS. This would imply that distinguishing between $45 \mathrm{XO}$ karyotype and mosaics is probably a matter of diagnostic bias. Rather, the different combinations of these genes are thought to be associated with variations in the TS physical stigmata. Specific aspects of the neurocognitive phenotype of TS may be related to the number of copies of relevant genes, referred to as dosage effect (dosage 1 for $45 \mathrm{XO}$ karyotype, dosage 2 for 46XX karyotype and mosaics somewhere between 1 and 2 , while in abnormal X-chromosome arms the dosage is dependent of the length of the abnormal arm). Murphy et al. [30,31, 39] provided evidence for "X chromosome dosage" effects in the intelligence profile in TS girls. They argued that in human beings this X-chromosome plays an important role in the development of grey matter in the striatum, diencephalon and the associative areas in the neocortex in both hemispheres. This argument is based on the differences in MRI-measured volumes of hippocampus, nucleï, and parieto-occipital brain matter found between controls and TS girls [30], and the increased glucose metabolism in the left temporal and parietal region in the $45 \mathrm{XO}$ girls compared to mosaics and controls [31].

More recently, different specific disabilities have also been attributed to a phenomenon known as genetic imprinting, referring to the parental origin of the single X-chromosome [89-91]. Imprinting is the process whereby expression of the gene depends on whether this gene is maternal of paternal of origin. Because only one of both is expressed, the other one is suppressed. This imprinting presumably also plays a role in TS. TS girls with a paternally derived $\mathrm{X}$ are significantly better in verbal and higherorder executive function skills, and have less social interaction problems, but they have disproportional memory problems in copying a figure [8991]. TS girls with a maternally derived X-chromosome, on the other hand, suffer from enhanced verbal forgetting $[89,91]$. However, Kuntschi et al., [92] could not confirm these imprinting effects in their study.

Taken together, it is not clear which genes on the $\mathrm{X}$-chromosome are responsible for specific neurocognitive (dys)functions, but there is some evidence that the neurocognitive phenotype in TS is caused by absence or dislocation of specific genes on the $\mathrm{X}$-chromosome. 


\section{General Conclusion}

Methodological differences (e.g. theoretical framework, selection of the study sample, group size, differentiation for karyotype, age range, nature of the control group, and choice of test procedures) prevent a solid evaluation of the results $[46,93]$. Studies have used a wide range of theoretical perspectives, resulting in large differences in selection of instruments to examine behavior and they are often restricted to a description of potential or existing problems using clinical test batteries [49]. Although these measurements are useful for detecting clinically important global impairments in individuals, they are not effective in isolating potentially defective processing components. Only a few studies [e.g. 49, 51, 66] used a process-oriented model to detect the exact nature of the functional problems and more research along these lines is necessary.

Nevertheless, there is rather convincing evidence that PIQ is lowered in TS [e.g. 7-9, 25, 28-34, 39, 43-46]. Moreover, it appears that visual-spatial processing is the main cognitive problem. Yet, the precise nature of this problem is not clear; for instance some claim it is a visual-spatial perception problem while others argue that visual spatial working memory is affected [37, 44, 45, 49,65, 83]. Sometimes other problems such as deficits in arithmetic, in visual constructional skills, and facial expression recognition are observed and the suggestion that these are related to, or based on the visual-spatial problems [e.g. 3, 8, 49, 51-53] does not have a solid empirical basis. The majority of tasks assessing these functions seem to assess a mixture of processing components; therefore, apart from visualspatial problems, many other factors can be responsible for the observed results.

Surprisingly few empirical studies have been performed, directed at motor functioning, given that many parents complaint about motor performance problems and oral-motor dysfunctions $[12,45,60]$. These complaints seem to be in line with the findings of Ross et al. [6], showing that TS girls suffer from a decreased perceived sense of athletic ability and physical selfimage. However, the available evidence clearly indicates that motor performance is defective in TS $[35,56,57,63]$. Moreover, differences in average performance scores between TS girls and controls are rather large, and almost all TS girls performed below the fifth percentile on clinical tests and this indicates that motor performance is a real problem in this 
population. Symptoms such as hypotonia, reduced strength, poor joint stability, decreased speed, gait abnormalities and difficulties with balance and diadochokinesis [56] suggest that the cause of these motor problems might be very fundamental in nature and affect all movements. These elementary execution problems have been established in the studies of Nijhuis - van der Sanden et al.[66, 67].

There are some data concerning the brain area that might be relevant for these cognitive and motor problems. Not surprisingly, there is some support for a right hemisphere problem, probably localized in the posterior part [22, $72,75]$. Structures in the parietal and occipital lobe, related to visual perception, seem to be affected [30, 39, 49, 62, 76]. Abnormalities in frontal structures have seldom been observed, with the exception of a case study of twins discordant for TS [81]. Some studies report also involvement of subcortical structures [39] more bilateral or deep structures such as cerebellum and pons, [81], hippocampus, lenticular nucleus, and thalamus [39]. These last regions could offer a neurological explanation for motor execution problems. However, obviously, much more work is needed, using controlled tasks, to examine such a causal relationship.

Turning to the hormonal influence, it is suggested that visual-spatial processes and working memory are influenced by estrogen deficits during early development [49, 54]. Ross et al. [37] suggested that estrogen influences brain maturation during puberty. They found a positive effect of estrogen suppletion therapy during early puberty $[42,44,45]$ on nonverbal processing speed and motor function, verbal and nonverbal memory, but this effect was not present in adults [37]. Another hormone issue concerns the treatment with synthetic growth hormones to improve body growth during childhood in order to diminish the practical and psychological problems of extremely short stature. No hormone replacement effects on cognitive functioning [83] have been found, but we only found one study looking into this issue. Taken together, especially the group of Ross has studied questions regarding the influence of hormones on cognitive and motor function, but many questions remain to be answered. For instance, no study has looked in detail at the working mechanism of estrogen on neurological functioning, and only indirect evidence for a relationship is available. 
Techniques for establishing the extent of the genetic abnormality have improved over the years, and consequently views have changed with respect to the relationship between karyotype and physical and psychological features in TS. Early studies indicated that in mosaics less problems are apparent than in classic TS [e.g. 21, 34, 56]. This dichotomy has now been replaced by the $\mathrm{X}$-chromosome dosage effect. Some authors found evidence for dosage effects on global IQ and visual memory [34, 39, 49]. The group of Murphy [30, 31, 39] argued that in humans development of grey matter in the striatum, diencephalon and the associative areas in the neocortex is related to such X-chromosome dosage effects. More recently, different neuropsychological profiles have been attributed to genetic imprinting, depending on whether the X-chromosome is parental or maternal in origin [89-91]. However, Kuntschi et al. [92] did not find such an effect of origin of the $\mathrm{X}$-chromosome. The influence of genes on neuropsychological and physical profile seems plausible, but no clear conclusions can yet be formulated about the identity and critical location of the relevant genes on the $\mathrm{X}$-chromosome.

In summary, this review clearly shows that psychosocial complaints are more common in TS girls than in controls [e.g. 3, 4, 7-9,12, 51, 65], and there is clear evidence that TS is characterized by a typical neurocognitive and motor profile $[39,45,49,57]$. Many authors noted that the variability of the genetic make-up, physical features and psychological characteristics is large in TS [e.g. 46, 93, 94], and they emphasize the interaction between somatic, psychological and social factors in the expression of many of the facets of TS (e.g. 93, 94]. No clear theoretical framework integrating these factors is available yet. Therefore no clear conclusion can be formulated with respect to the question how daily life problems are related directly to the genotype of TS. Nor can we determine whether they have to be considered as secondary to the typical physical features, to the specific neuropsychological and/or motor dysfunction.

\section{Acknowledgements}

The authors would like to thank Judith Dijkstra-Hekkink, Agnes BrugmanBoezeman, Geert Thoonen and Wil Renier for their contribution to the process of collecting and discussing relevant literature. We are also indebted to Gerard van Galen and Rob Sengers, for their comments on an earlier version of this paper. 


\section{Reference List}

1. Mazzocco MMM, Baumgardner T, Freund LS, Reiss AL. Social Functioning among girls with Fragile X or Tumer Syndrome and their sisters. J Autism Dev Dis 1998;28:509-17.

2. McCauley E, Ito J, Kay T. Psychosocial functioning in girls with TS and short stature: Social skills, behavior problems and self concept. J Am Acad Child Adolesc Psy 1986;25:105-12.

3. McCauley E, Kay T, Ito J, Treder, R. The Tumer Syndrome: Cognitive deficits affective discrimination and behavior problems. Child Dev 1987;58:464-73.

4. McCauley E, Ross JL, Kushner H, Cutler jr. G. Self-esteem and behavior in girls with Tumer Syndrome. J Dev Behav Pediatr 1995;16:82-8.

5. Money J, Mittenthal BA. Lack of personality pathology in Tumer's Syndrome: relation to cytogenetics, hormones and physıque. Behav Genet 1970;1:43-56.

6. Ross JL, McCauley E, Roeltgen D, Long L, Kushner H, Feuillan P, Cutler G. Selfconcept and behavior in adolescent girls with Turner Syndrome: potential estrogen effects. J Clin Endocr Metab 1996;81:926-31.

7. Rovet JF. The psychoeducational characteristics of children with Tumer's Syndrome J Leam Disabil 1993;26:333-41.

8. Rovet, J. Behavioral manifestations of Tumer Syndrome in children: a unique fenotype? In: Albertsson-Wikland K, Ranke MB, editors. Tumer syndrome in a life span perspective: research and clinical aspects. Amsterdam: Elsevier Science, 1995. p.28596.

9. Rovet J, Ireland L. Behavioral phenotype in children with Tumer syndrome. J Pediatr Psychol 1991;19:779-90.

10. Siegel PT, Clopper R, Stabler B. The psychological consequences of Turner Syndrome and review of the National Cooperative Growth Study Psychological Substudy. Pediatrics 1998;102:488-91.

11. Skuse D, Percy EL, Stevenson J. Psychosocial functioning in the Tumer Syndrome: a national survey. In: Stabler B, Underwood L, editors. Growth, stature and adaptation. Hillsdale, NJ: Laurence Erlbaum, 1994. p.151-64.

12. Slijper FME, Van Teunenbroek A, De Muinck Keızer-Schrama SMPF, Sas ThCJ. (). Een dochter met het Syndroom van Tumer: de betekenis voor de ouders. Ned Tijdschr Geneesk 1998;142:2150-54.

13. Swillen A, Fryns JP, Kleczkowska A, Massa G, Vanderschueren-Lodeweyckx M, Van den Berghe $\mathrm{H}$. Intelligence, behaviour and psychosocial development in Turner 
Syndrome A cross-sectional study of 50 pre-adolescent and adolescent girls (4-20 years) Gen Couns 1993,4 7-18

14 Willıams JK Behavioral characteristics of children with Tumer Syndrome and children with learning disabilities Westem J Nurs Res 1994,16 26-39

15 Williams J, Richman L, Yarbrough D A companson of memory and attention in Tumer Syndrome and learnung disability J Pediatr Psychol 1991,16 585-93

16 Downey J, Ehrhardt AA, Gruen R, Bell JJ, Monshıma A Psychopathology and social functioning in women with Tumer's Syndrome J Nerv Ment Dis 1989,177 191-201

17 Pavlidis K, McCauley E, Sybert V Psychosocial and sexual functioning in women with Turner Syndrome Clin Genet 1995,47 85-9

18 Wechsler D Manual for the Wechsler Intellıgence Scale for Chıldren-Revised New York Psychological Corp 1974

19 Wechsler D Intelligence definition, theory and the IQ In Cancro R editor Intellıgence New York, Grune \& Stratton 1971 p 50-5

20 Wechsler D Wechsler Adult Intelligence Scale- Revised Manual New York Psychological Corp 1992

21 Shaffer JW A specific cognitive deficit observed in gonadal aplasia (Turner's Syndrome) J Clin Psychol 1962,18 403-6

22 Shucard DW, Shucard JL, Clopper RR, Schachter M Electrophysiological and neuropsychological indices of cognitive processing deficits in Turner's Syndrome Dev Neuropsychol 1992,8 299-323

23 Bekker FJ, Van Gemund JJ Mental retardation and cognitıve defects in XO-Tumer Syndrome Maandschr v Kindergeneesk 1968,36 148-156

24 Bender BG, Linden MG, Robınson A Neuropsychologıcal ımpaırment in 42 adolescents with Sex Chromosome abnormalities Am J Med Genet 1993,48 169-73

25 Garron DC Intelligence among persons with Turner's Syndrome J Behav Genet 1977,7 105-27

26 Gordon HW, Galatzer A Cerebral organization in patients with gonadal dysgenesis Psychoneuroendocnno 1980,5 235-44

27 Money J Turner's Syndrome and panetal lobe functions Cortex 1973,9 385-93

28 Pennıngton BF, Bender B, Puck M, Salbenblatt J, Robınson A Leamıng disabılitıes in children with sex chromosome anomalies Child Dev 1982,53 1182-92

29 Pennington BF, Heaton RK, Karzmark P, Pendleton MG, Lehman R, Shucard DW The neuropsychological phenotype in Turner's Syndrome Cortex 1985,21 391-404

30 Murphy DGM, Allen G, Haxby JV, Largay KA, Daly E, White BJ, Powell MC, Shapiro MB The effects of sex steroids and the X-chromosome, on female brain function $A$ study of the neuropsychology of adult Turner's Syndrome Neuropsychology $1994,321309-23$ 
31. Murphy DGM, Mentis MJ, Pietrini PP, Grady C, Daly E, Haxby JV, De La Granja M, Allen G, Largay KA, White BJ, Powell MC, Horwitz B, Ropoport SI, Shapiro MB. A PET study of Turner's Syndrome: Effects of sex steroids and the X-chromosome on brain. Biol Psychiat 1997;41:285-98.

32. Rovet J, Netley C. Processing deficits in Tumer's Syndrome. Dev Psychol 1982;18:7794.

33. Rovet JF, Szekely C. Hockenberry M. Specific arithmetic calculation deficits in children with Tumer's Syndrome. J Clin Exp Neuropsychol 1994;16:820-39.

34. Temple CM, Camey RA. A comparison of behavioral phenotypes. Dev Med Child Neurol 1993 ;35:691-8.

35. Waber DP. Neuropsychological aspects of Tumer's Syndrome. Dev Med Child Neurol 1979;21:58-70.

36. Rovet JF. The cognitive and neuropschological characteristics of females with Tumer Syndrome. In: Berch DB, Bender BG. editors. Sex chromosome abnormalities and human behavior. Boulder: Westview Press, 1990. p. 38-77.

37. Ross JL, Stefanotos GA, Kushner H, Zinn A, Bondy C, Roeltgen D. Persistent cognitive deficits in adult women with Tumer Syndrome. Neurology 2002;58:218-25.

38. McCauley E, Sybert V, Ehrhardt A. Psychosocial adjustment of adult women with Tumer Syndrome. Clin Genet 1986;29:284-90.

39. Murphy DGM, DeCarli C, Daly E, Haxby JV, Allen G, White BJ, McIntosh AR, Powell CM, Horwitz B, Ropoport SI, Shapiro, MB. X-Chromosome effects on female brain: a magnetic resonance imaging study of Turner's Syndrome. Lancet 1993;342:1197-1200.

40. Downey J, Elkin EJ, Ehrhardt AA, Meyer-Bahlburg HFL, Bell JJ, Morishima A. Cognitive ability and every day functioning in woman with Turner Syndrome. $J$ Learn Disabil 1991;24:32-9.

41. Money J. Specific neuro-cognitive impairments associated with Turner's (45 XO) and Klinefelter (47 XXY) syndromes: a review. Sociobiology, 1993;40:147-51.

42. Romans SM, Stefanatos G, Roeltgen DP, Kushner H, Ross JL. Transition to young adulthood in Ullrich-Tumer Syndrome: Neurodevelopmental changes. Am J Med Genet 1998;79:140-7.

43. Ross JL, Reiss AL, Freund L, Roeltgen D, Cutler GB. Neurocognitive functioning and brain imaging in Tumer Syndrome - preliminary results. Horm Res 1993;39:65-9.

44. Ross J, Roeltgen D, Feuillan P, Kushner H, Cutler GB. Effects of estrogen on nonverbal processing speed and motor function in girls with Turner's Syndrome. J Clin Endocr Metab 1998;83:3198-3204.

45. Ross Л, Roeltgen D, Feuillan P, Kushner H, Cutler GB. Use of estrogen in young girls with Tumer Syndrome. Neurology 2000;54:154-70. 
46 Ross Л, Zinn A, Mc Cauley E Neurodevelopmental and psychosocial aspects of Tuner Syndrome Ment Retard Dev D R R 2000,6 135-41

47 Alexander D, Money J Turner's and Gerstmann's syndrome Neurophysıologic companson's Neuropsychology 1966,4 265-73

48 Temple CM, Carney RA Pattems of spatial functioning in Tumer's Syndrome Cortex 1995,31 109-18

49 Buchanan L, Pavlovic J, Rovet J A Reexamination of the visuo-spatial deficit in Turner Syndrome Contrbutions of workıng memory Dev Neuropsychol 1998,14 ,341-67

50 Hier DB, Atkıns L, Perlo VP Leaming disorders and sex chromosome aberrations $J$ Med Gen 1980,14 46-50

51 Mazzocco MMM A process approach to descnbing Mathematics difficulties in girls with Tumer Syndrome Pediatncs 1998,102 492-96

52 Mazzocco MMM Math learnıng disability and math LD subtypes Evidence from studies of Tumer Syndrome, Fragıle X Syndrome, and Neurofibromatosıs Type $1 \mathrm{~J}$ Leam Disabil 2001,34 520-33

53 Van Borsel J, Dhooge I, Verhoye K, Derde C Communcation problems in Tumer syndrome A sample survey J Commun Dis 1999,32 435-46

54 Willams CL, Meck WH The organizational effects of gonadal hormones on sexually dimorphic spatıal abılıty Psychoneuroendocrino 1991,16 155-76

55 Temple CM Oral fluency and narratıve productıon in chıldren with Turner's syndrome Neuropsychology 2002,40 1419-27

56 Salbenblatt JA, Meyers DC, Bender BG, Lınden MG, Robınson A Gross and fine motor development in 45,X and 47,XXX girls Pediatncs 1989,84 678-82

57 Nıjhuıs - van der Sanden MWG, Smıts - Engelsman BCM, Elıng PATM Motor Performance in girls with Turner's Syndrome Dev Med Child Neurol 2000,42 685-90

58 Henderson SE, Sugden DA Movement Assessment Battery for Chıldren Manual London Psychological Corporatıon, 1992

59 Smits - Engelsman BCM Movement ABC, Nederlandse Handleıdıng [Dutch manual Movement ABC] Lisse Swets en Zeitlinger, 1998

60 Mathısen B, Reılly S, Skuse D Oral motor dysfunctıon and feedıng disorders of infants with Turner's Syndrome Dev Med Chıld Neurol 1992, 34 141-9

61 Smits - Engelsman BCM, Nıhuus -Van der Sanden MWG, Duysens J An exploratory study of the kınematıcs of girls with Tumer Syndrome in a visuo-motor Task Inf Chıld Dev, in press

62 Clark C, Klonoff H, Hayden M Regıonal cerebral glucose metabolısm in Turner Syndrome Can J Neurol Scı 1990,17 140-4

63 McGlone J Can spatial deficits in Tumer's syndrome be explained by focal CNS dysfunction or a typical speech lateralızatıon? J Clın Exp Neuropsychol 1985,7 375-94 
64 Nijhuıs - Van der Sanden MWG, Van Asseldonk EHF, Elıng PATM, Van Galen, GP Slow motor performance in girls with Tumer Syndrome is not related to increased neuromotor noise, Motor Control, in press

65 Ross JL, Kushner H, Roeltgen D Developmental changes in motor function in girls with Tumer Syndrome Pediatr Neurol 1996,15 317-22

66 Nıhuss - Van der Sanden MWG, Smits - Engelsman BCM, Elıng PATM, Nıjhuss BJG, Van Galen GP Low elementary movement Speed is associated with poor motor skill in Tumer Syndrome Dev Neuropsychol 2003, 22(3), 643-70

67 Nijhuis -Van der Sanden MWG, Elıng PATM, Van Asseldonk EHF, Van Galen GP Decreased movement speed in girls with Tumer Syndrome a problem in motor plannıng or muscle initiation? , submitted

68 Efron $R$ The declıne and fall of hemisphenc specialızation Hıllsdale, New Jersey, USA Lawrence Erlbaum Associates, Inc , 1990

69 Alexander D, Walker HT, Money J Studies in durectional sense Archs Gen Psychiat $1964,10337-9$

70 Dellantio A, Lis A, Saviolo N, Rigon F, Tenconı R Spatial performance and hemisphenc specialization in the Tumer Syndrom Acta Med Auxol 1984,16 193-203

71 Garron DC, Molander L, Cronholm B, Lindsten J An explanation of the apparently increased incidence of moderate mental retardation in Tumer's Syndrome J Behav Genet 1973,3 37-43

72 Kolb JE, Heaton RK Lateralızed Neurologic deficits and psychopathology in a Tumer's Syndrome patient Arch Gen Psychıt 1975,4 265-73

73 Silbert A, Wolff PH, Lilienthal J Spatial and temporal processing in patients with Tumer's Syndrome Behav Genet 1977,7 11-21

74 Powell MP, Schulte T Tumer Syndrome In Goldsteın S, Reynolds CR editors Handbook of neurodevelopmental and genetic disorders in children New York The Gulford Press, 1999 p 277-97

75 Reske-Nielson E, Christensen A, Nielsen J A neuropathological and neuropsychological study of Tumer's syndrome Cortex 1982,18 181-90

76 Reiss AL, Mazzocco MM, Greenlaw R, Freund LS, Ross Л Neurodevelopmental effects of X-monosomy A volumetric imaging study Ann Neurol 1995,36 731-8

77 Hepworth SL, Rovet JF Visual Integration difficulties in a 9-year-old girl with Tumer Syndrome Parallel Verbal disabilities? Child Neuropsychol 2000,6 262-73

78 Levy J Possible basis for the evolution of lateral specialızation of the human brain Nature 1969,224 614-5

79 Netley C, Rovet J Atypical hemisphenc lateralization in Turner syndrome subjects Cortex 1982,18 377-84 
80. Alexander D, Ehrhardt AA, Money J. Defective figure drawing, geometric and human, in Tumer's Syndrome. J nerv ment dis 1966;142:161-7.

81. Reiss AL, Freund L, Plotnick L, Baumgardner MA, Green K, Sozer AC, Reader M, Boehm C, Denckla MB. The effect of X monosomy on brain development: monozygotic twins discordant for Tumer's Syndrome. Ann Neurol 1993;34:95-107.

82. Johnson R, Rohrbaugh JW, Ross JL. Altered brain development in Tumer's Syndrome. Neurology 1993;43:801-8.

83. Ross JL, Feuillan P, Kushner H, Roeltgen D, Cutler Jr. GB. Absence of growth hormone effects on cognitive function in girls with tumer syndrome. J Clin Endocr Metab 1997;82:1814-17.

84. Schorderet DF. Tumer phenotype and X-chromosome abnormalities. In: Turner Syndrome in a Life Span Perspective: research and clinical aspects. Proceedings of the 4th International Symposium on Turner Syndrome, May 1995.

85. Kessler E, Moos RH. Behavioral aspects of chromosomal disorders. Annu Rev Med 1973;24:89-102.

86. El Abd S, Turk J, Hill P. Annotation: Psychological characteristics of Turner Syndrome. J Child Psychiat 1995;36:1 109-25.

87. Chu C. Y-chromosome mosaicism in girls with Tumer's syndrome. Clin Endocr 1999;50:17-18.

88. Page DC. Mapping and targeting Tumer genes. In: Albertson-Wikland KA, Ranke MB. editors. Turner Syndrome in life span perspective: Research and clinical aspects. Amsterdam: Elsevier, 1995. p.11.

89. Bishop DVM, Canning E, Elgar K, Morris E, Jacobs PA, Skuse DH. Distinctive patterns of memory function in subgroups of females with Turner Syndrome: Evidence for imprinting loci on the $\mathrm{X}$-chromosome affecting neurodevelopment. Neuropsychology 2000;38:712-21.

90. Jacobs P, Dalton P, James R, Mosse K, Powe, M, Robinson D, Skuse D. Turner Syndrome: A cytogenitic and molecular study. J Am Hum Genet 1997;471-83.

91. Skuse DH, James RS, Bishop DVM, Copin B, Dalton P, Aamodt-Leeper G, BacareseHamilton M, Cresswell C, McGurk R, Jacops P. Evidence from Tumer syndrome of an imprinted X-linked locus affecting cognitive function. Nature 1997;378:705-8.

92. Kuntschi J, Skuse D, Elgar K, Morris E, Tumer C. Ring-X chromosomes: their cognitive and behavioural phenotype. Annu Hum Genet 2000;64:295-305.

93. Boman UW, Möller A, Albertsson-Wikland K. Psychological aspects of Turner Syndrome. J Psychosom Obst Gyn 1998;19:1-18.

94. Huisman J, Slijper FME. Psychologische kenmerken van meisjes met het Syndroom van Tumer. Ned Tijdschr v Kindergeneesk 2002;70:111-5. 


\section{Motor performance in girls with Turner Syndrome}

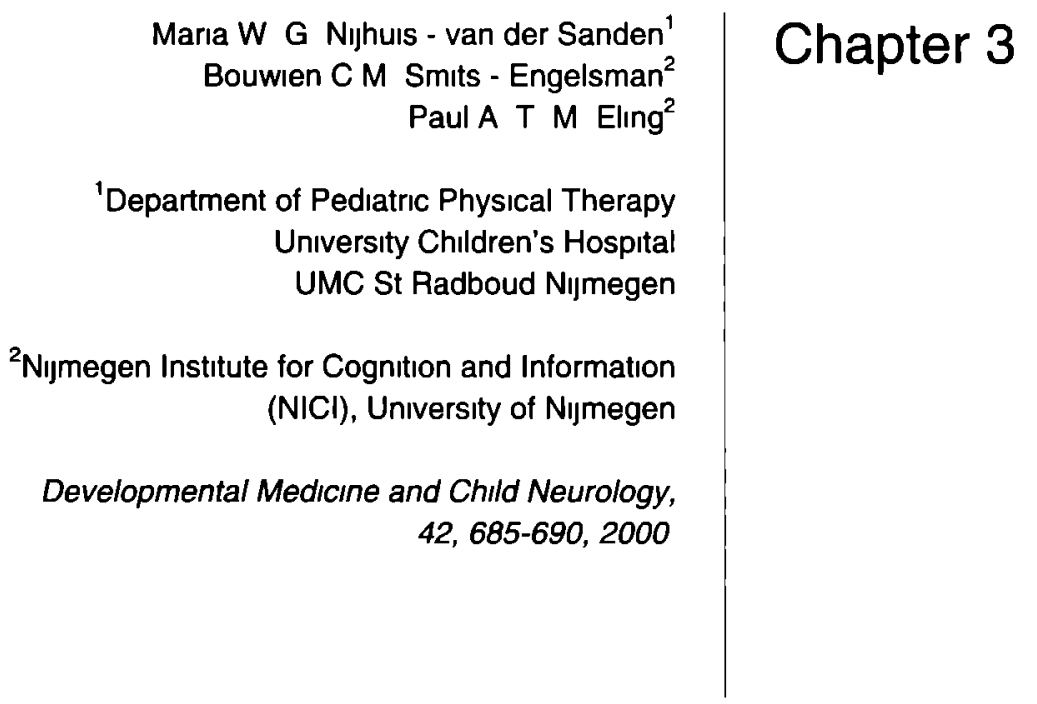




\section{Abstract}

In order to validate the movement problems in daily life for girls with Tumer syndrome (TS), as reported by teachers, parents and the girls themselves, we examined whether these girls have impaired motor ability and a specific pattern of motor impairment. As TS phenotypes are characterized by a particular profile of normal Verbal IQ (VIQ) and lowered Performance IQ (PIQ), we investigated whether there is a significant correlation between intelligence scores and motor performance scores. Fifteen girls with TS (age range 5.8-12.5 years) of whom nine had 45 XO karyotype and six girls mosaic karyotype, were individually tested on the Movement Assessment Battery for Children (MABC; Henderson and Sugden 1992, Smits - Engelsman 1998) and the Wechsler Intelligence Scale-Revised (WISC-RN; Vander Steene et al. 1986). Mean percentile score on the Movement ABC was 2.93 (range 1 to 8). Based on the total score of the MABC, none of the girls with TS fell into the 'normal' range; 5 patients were classified as 'at risk' and 10 as 'impaired'. Girls with TS made more errors and needed more time across all items tested; no specific profile of impairment was observed and no significant correlation between intelligence scores and motor performance scores was found. The results clearly demonstrate that girls with TS indeed experience a significant general motor impairment. The motor problems apparently cannot be attributed to cognitive problems. 


\section{Introduction}

Turner syndrome (TS) is a sex-chromosomal disorder characterized by short stature, gonadal dysgenesis, and decreased secondary sexual development. TS is also characterized by a number of variable changes in external appearance (webbing of the neck and a wide angle of arm i.e. cubitus valgus) and abnormalities of internal organs. TS has an incidence of 1 in 2000 to 5000 live-born females (Rosenfeld 1990; Rovet 1993). The most common karyotype is monosomy $\mathrm{X}$, characterized by the presence of only one X-chromosome, the other sex chromosome can be missing (45 $\mathrm{XO}$ ) or can be abnormal. Also a variant has been described that has mosaic chromosome constitutions ( $45 \mathrm{XO} / 46 \mathrm{XX}$ or $45 \mathrm{XO} / 46 \mathrm{XY}$ ).

Nijhuis - van der Sanden et al. (1998) reviewed the literature from 1962 until 1995 looking for a consistent pattem of neuropsychological and motor dysfunction in girls with Turner syndrome. Despite the fact that the theoretical framework, used to assess and describe psychological functions, had changed fundamentally during this period and in spite of methodological differences in the studies, it was concluded that neuropsychological dysfunction is a characteristic feature for girls with TS. Regarding the intelligence profile as measured by the Wechsler Intelligence Scale-Revised (WISC-R; Wechsler 1974) most studies report a Performance IQ (PIQ), which is lower than the Verbal IQ (VIQ). VIQ seems to be in the normal range. (Money 1973, Garron 1977, Waber 1979, Pennington et al. 1985, Downey et al. 1989, Bender et al. 1993, Temple and Carney 1993, Rovet et al. 1994). Most authors report especially decreased visuo-spatial and/or visuo-perceptual abilities, difficulty with tasks involving memory and attention, and decreased arithmetic skills (Money 1973, Garron 1977, Waber 1979, Pennington al. 1985, Downey et al. 1989, Bender et al. 1993, Temple and Carney 1993, Rovet et al. 1994, Ross et al. 1996). It might be expected that these impaired visuo-spatial and visuo-perceptual abilities would influence motor behavior. These abilities play a role in the mental representation of task features and in the determination of the spatial and temporal demands on control goal-directed movements. Problems can occur in planning, executing, or in evaluating the motor action. The opposite effect is also feasible. Problems in the execution of movements may influence subtest scores constituting the WISC-PIQ score. If VIQ scores are normal, but PIQ scores and motor function-scores 
are lower than in control patients, this might imply that the low PIQ scores do not reflect a deficit in cognitive functions, but could be due to visuomotor problems.

Although much attention has been devoted to intelligence and neuropsychological features, studies of motor function in girls with TS are limited in number. Except for a short section in Lewin (1926), the seminal paper by Hartgenbusch (1927) and the passage on reflexes in Koffka (1935), motor behavior in patients with TS was not made a topic of investigation until recently. Ross et al. (1996) investigated motor function in non-oestrogen- treated girls with TS, aged 7 to 9 years and 10 to 12 years $(n=78)$ and age-matched female controls $(n=145)$. Girls with TS performed less well than the control children, especially during motor tasks with the greatest spatial demands; this deficit was most evident in the older age group. Girls with TS also showed a decrease in their perceived sense of athletic ability and physical self-image. Clark et al. (1990) found that women with TS had a significantly lower manual strength then the control group as measured by a dynamometer. However, they did not find differences between the two groups in a finger-tapping test. In contrast, Bender et al. (1993) reported a significantly decreased speed on this task for women with TS. Mathisen et al. (1992) reported that babies with TS have considerable and persistent early feeding problems, which are associated with oral-motor dysfunction. To our knowledge, only one study has examined gross and fine motor performance in girls with TS by administering a norm-referenced test: the Bruininks-Ozeretsky test of Motor Proficiency (BOTMP; Salbenblatt et al. 1989). In this study, 12 of the 15 girls with TS exhibited both gross and fine motor dysfunction (defined as scores below $10^{\text {th }}$ centile). The scores of the patients with a sex chromosomal mosaic karyotype were more similar to those of the control girls. Additional problems were hypotonia, associated with diminished strength, poor joint stability, and gait abnormalities. At least 7 out of 10 patients experienced difficulty with balance, diadochokinesis, motor planning, and bilateral co-ordination.

The results of the studies mentioned above indicate that girls with TS have difficulties in motor functioning. To date no clear view on the profile of motor performance is available. During motor performance assessment in our clinic we observed that girls with TS need more time in functional motor tasks and have problems with planning complex actions. Parents, 
teachers, and the girls themselves report that these problems become most explicit at the time they start to practice their profession after the theoretical study and when they begin independent lives.

To validate the movement problems in daily life, reported by parents, teachers, and by the girls themselves, the purpose of this study was to examine whether girls with TS differ from their normally developing peers in motor performance. Secondly the current study aimed to investigate whether there is a specific pattern of motor impairment in girls with TS. The Movement Assessment Battery for Children (MABC; Henderson and Sugden 1992, Smits - Engelsman 1998), an instrument designed to identify children with impaired motor ability in daily life, was administered. This study also intended to determine if poor performance is domain specific (e.g. manual dexterity, ball skills, and balance) as tested by the MABC, or whether movement deficits may be characterized by a generally low level of motor performance. Finally, the study aimed to determine whether there is a possible relation between motor skills, as tested by the MABC, and cognitive abilities, as tested by WISC-RN (Dutch revised version; Vander Steene et al. 1986): Full-Scale IQ, FSIQ; VIQ; and in particular PIQ.

\section{Method}

\section{Patients}

Patients were recruited from the patients with TS treated in the paediatric endocrine clinic of the University Medical Centre St Radboud in Nijmegen, the Netherlands. The TS-karyotype was diagnosed by cytogenetic studies on cultured peripheral lymphocytes according to routine procedures. From each patient at least 30 GTG-banded metaphases were studied to rule out any low-grade mosaicism. None of the girls were treated with oestrogen; all girls had been treated with non-biological growth hormones. All 28 girls, born between 1983 and 1990, were selected to enrol in the study. Six girls from 28 girls were excluded because of a past medical history that could affect motor performance, and one girl was excluded due to an extremely low IQ (FSIQ < 80). Two girls moved out of the study region. The parents of 4 girls with TS refused participation. Parents and children confirmed that they would participate in the study. 
The final sample consisted of 15 patients with TS; age range 5.8 to 12.5 (mean 9.9) years. The karyotype was verified in 9 patients as $45 \mathrm{XO}$ and in 5 patients as mosaic ( 3 patients $45 \mathrm{XO} / 46 \mathrm{XX}$, one $45 \mathrm{XO} / 46 \mathrm{XY}$, one 45XO/46XX/47XXX). One girl showed a $46 \mathrm{XisoXq}$ karyotype (Table V). Fourteen girls were right-handed and one was left-handed. A control group was not considered necessary, as the norm scores for both the Motor and the IQ test used in this study have been validated for the Dutch population (Vander Steene et al. 1986, Smits - Engelsman 1998).

\section{Procedure}

The patients each visited the University Hospital for 1 day. Testing involved an assessment of cognitive functions in a session of approximately 2 hours, followed by an interval of at least 1 hour. Subsequently, motor functions were assessed in a session lasting between 1 and 1.5 hours.

\section{Materials}

\section{Motor function assessment}

To determine motor performance the MABC, an age-appropriate standardized test, was administered. The MABC was first published in 1972 by Stott, Moyes and Henderson as the Test of Motor Impairment (TOMI). It was revised in 1984 (Stott et al.) and again in 1992 (Henderson and Sugden 1992). Normative data have been collected in the US and UK. The MABC indicates motor functioning in daily life, and the manual provides normative data for children aged 4 to $\geq 12$ years, which is divided into four age bands. Each band is designed to be suitable for a restricted age group of children: age band I for 4-6 years, age band II for 7-8 years, age band III for 9-10 years, and age band IV for $\geq 11-12$ years. Each age band is identical in structure and contains eight items, divided into three sections: manual dexterity, ball skills, and static and dynamic Balance (Table 1). 
Table 1: Items on the Movement-ABC.

\section{Manual Dexterity}

1 Speed task for both hands separately

2 Bi-manual coordination

3 Eye-hand coordination with preferred hand (drawing with preferred hand)

\section{Ball Skills}

4 Catching moving object

5 Aiming at goal

\section{Balance}

6 Static balance (stance)

7 Dynamic balance while moving fast (jumping and hopping)

8 Dynamic balance while moving slowly (walking)

There are two sorts of tasks at each item level: time-related (scored in seconds) and error-related (scored by number of 'good' attempts). The aim of the test was to assess children's motor competence, the tester ascertained that the child understood the task before commencing. The raw score of the best attempt on each item is converted into a scaled score. (Fig. 1). The way this is done varies from task to task, but is well described in the test manual. Scaled interval scores for each item are provided: $0=$ good and $5=$ very poor (Table 2). Some items are performed by both the preferred and non-preferred hand or foot; the child's scores for both hands or feet were calculated and then divided. 
Figure 1: Example of scoring for manual dexterity pegboard test (patient number 15 , age band 2), measured in seconds.

(a) Raw data scores: preferred hand and non-preferred hand;

(b) Best raw scores converted into scaled scores for preferred and non-preferred hands;

(c) Itemscore: scaled score for preferred hand added to scaled score for non-preferred hand and divided by two.

\begin{tabular}{|ll|}
\hline Preferred hand \\
\hline Trial 1 & 30 \\
Trial 2 & 28 \\
\hline
\end{tabular}

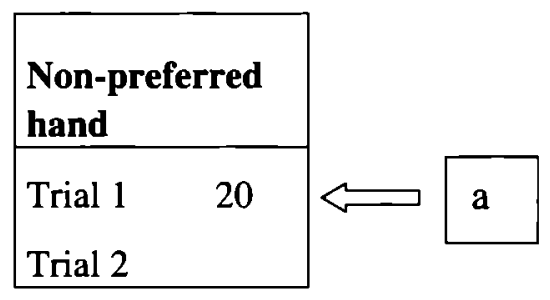

\begin{tabular}{|l|l|}
\hline age 7 & age 8 \\
\hline $0-23$ & $0-21$ \\
\hline $25-27$ & $22-23$ \\
\hline $28-29$ & 24 \\
\hline $30-33$ & $25-27$ \\
\hline $34-39$ & $28-29$ \\
\hline $40+$ & $30+$ \\
\hline
\end{tabular}

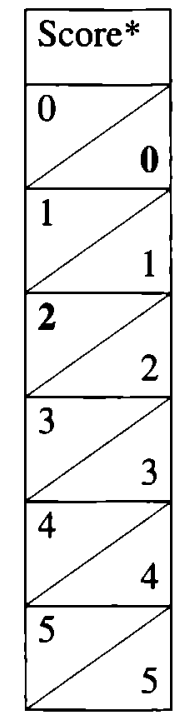

\begin{tabular}{|l|l|}
\hline age 7 & age 8 \\
\hline $0-29$ & $0-25$ \\
\hline $30-31$ & $26-28$ \\
\hline 32 & $26-28$ \\
\hline $33-37$ & $31-32$ \\
\hline $38-47$ & $33-34$ \\
\hline $48+$ & $35+$ \\
\hline
\end{tabular}
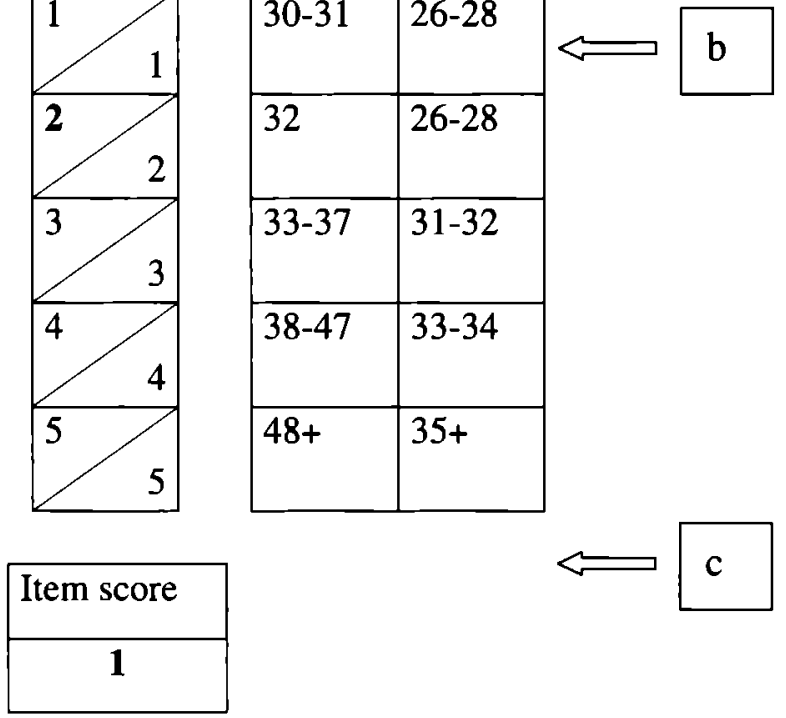
Table 2: Description of the 6-point scale used for scoring individual test items: normal distribution.

\section{Impairment score \% of sample in interval Cumulative \%}

\begin{tabular}{lcc}
\hline 0 & 75 & 100 \\
1 & 10 & 25 \\
2 & 5 & 15 \\
3 & 5 & 10 \\
4 & 3 & 5 \\
5 & 2 & 2 \\
\hline
\end{tabular}

A profile of the child's performance was produced by simply summing the item scores for the three sections of the test. The section score for Manual Dexterity will vary from 0 to 15 , the section score for Ball Skills from 0 to 10 , and for Static and Dynamic Balance from 0-15. These three section scores are then summed again to produce a Total Motor Impairment Score, ranging between $0-40$. The three section scores and the Total Impairment Score can then be interpreted using the percentile normative data tables. High scores on the MABC represent poor performance. The test has acceptable validity and reliability (Henderson and Hall 1982, Henderson and Sugden 1992, Lam and Henderson 1987, Smits - Engelsman 1998): inter-rater reliability ranges from 0.70 to 0.89 , while test-retest reliability is 0.75 . Research has shown that the test is very useful in identifying children with general motor difficulties (Henderson and Hall 1982, Laszlo and Bairstow 1985, Henderson et al. 1989, Smits - Engelsman, 1998).

\section{Cognitive Assessment}

Patients were administered the age-appropriate Wechsler Intelligence Scale for Children (WISC/RN, 1986, Revised Dutch version). This test of intellectual abilities yields three scores: FSIQ, VIQ and PIQ. It is used in nearly all of the studies in TS and is validated for the Dutch population (Van der Steene et al. 1986). 


\section{Data Analysis}

Motor performance was classified using the centiles from the MABC, first for the total score and subsequently for each of the section scores. The range between 100th and 16th centile is regarded as 'normal and good performance', 15th to 6th centile as 'at risk', and 5th centile and below was classified as 'impaired' performance. Data were analyzed by means of a $\chi^{2}$ test for differences in proportions of girls with TS below the 'at risk' and 'impaired' cut-off score in comparison to the percentage expected.

FSIQ, VIQ and PIQ scores were classified as follows: IQ-scores from 85 upwards were regarded as 'normal', between 84 and 70 as 'at risk', and IQscores of 69 and below were classified as 'impaired'; proportions were compared with the distribution for normally-developing children on the WISC-RN (Vander Steene et al. 1986).

Pearson correlation coefficients were calculated to examine the relation between IQ scores (FSIQ, VIQ, and PIQ) and motor performance scores (total impairment, manual dexterity, ball skills, and balance). The statistics were performed using SPSS software (version 9.0).

\section{Results}

\section{General Motor Performance}

The scores of the girls with TS on the MABC differ remarkably from the normative scores. Mean centile score of the Total Motor Impairment Score on the MABC was 2.93 (range 1-8). The proportions of patients with 'at risk' and 'impaired' scores were significantly different from those expected $(p<0.001)$. Overall means and standard deviations are shown in Table 3.

Examining the classification on the basis of the centile scores in more detail, it can been seen that none of the girls with TS scored in the 'normal' range; six patients were classified as 'at risk' and nine as 'impaired' (Table 4). Girls with TS made more errors and needed more time compared to their non-affected peers in all skills measured. 
Table 3: Mean and SD of Scaled Scores on the Movement-ABC for girls with TS $(n=15)$.

Scaled scores mean (SD)

\begin{tabular}{lc}
\hline Manual Dexterity* & $8.07(4.25)$ \\
Ball Skills** & $6.07(2.91)$ \\
Balance Skills*** & $7.00(3.20)$ \\
Total Impairment Movement ABC\# & $20.93(7.92)$
\end{tabular}

*Manual dexterity: 5 th centıle $=6.5 ; 15$ th centile $=5.0$

**Ball Skills: 5 th centile $=5.0 ; 15$ th centile $=2.5$

$* * *$ Balance Skills: 5 th centile $=7.5 ; 15$ th centile $=5.0$

\#Total Impairment score MABC: 5 th centule $=13.5$; 15 th centile $=10.0$

\section{Motor Profiles}

Manual Dexterity scores showed four patients who were classified as 'normal' and 11 as 'impaired'. A similar picture was obtained for the classification of Ball Skills. On these items one girl scored in the 'normal' range, three in the 'at risk' range and 11 in the 'impaired' range.

Performance on the Balance Skills was slightly better. On these items, five patients were classified as 'normal', three as 'at risk' and seven patients as 'impaired' (see Table 4).

Table 4: Girls with TS ( $n=15)$, scoring "impaired", " at risk" and “ normal" on the Movement- $\mathrm{ABC}$.

\begin{tabular}{lccc}
\hline & Normal* $^{*}$ & At Risk** & Impaired*** \\
\hline Manual Dexterity & 4 & 0 & 11 \\
Ball Skills & 1 & 3 & 11 \\
Balance Skills & 5 & 3 & 7 \\
Total Impairment Score & 0 & 6 & 9 \\
\hline
\end{tabular}

*Normal: score 100th-16th centile ** At Risk: 15th-6th centile

*** Impaired: 5th and below centile 
Table 5: Age, karyotype, scores per patient with TS.

\begin{tabular}{|c|c|c|c|c|c|c|c|c|c|}
\hline $\begin{array}{c}\text { Subject } \\
\text { no }\end{array}$ & Age & Karyotype & $\begin{array}{l}\text { MABC } \\
\text { Centule }\end{array}$ & $\begin{array}{c}\text { Manual } \\
\text { Dextenty* }\end{array}$ & $\begin{array}{c}\text { Ball } \\
\text { skills* }\end{array}$ & Balance* & FSIQ\# & VIQ\# & PIQ\# \\
\hline 1 & 10,1 & $45 \times 0$ & 1 & 2 & 2 & 2 & 91 & 85 & 101 \\
\hline 2 & 10,1 & $45 \times 0$ & 1 & 2 & 2 & 2 & 78 & 95 & 65 \\
\hline 3 & 10,4 & $46 X_{1 s o X q}$ & 6 & 0 & 2 & 0 & 109 & 101 & 114 \\
\hline 4 & 6,8 & $45 \times 0$ & 6 & 0 & 2 & 0 & 93 & 87 & 102 \\
\hline 5 & 9,1 & $45 \times 0$ & 1 & 2 & 1 & 2 & 90 & 89 & 93 \\
\hline 6 & 10,1 & $45 \times 0$ & 8 & 0 & 2 & 0 & 94 & 103 & 86 \\
\hline 7 & 12,6 & $\begin{array}{c}45 \mathrm{XO} / 46 \mathrm{X} \\
\text { nng } \mathrm{X} \quad 19-13\end{array}$ & 1 & 2 & 1 & 1 & 110 & 91 & 130 \\
\hline 8 & 9,2 & $45 \times 0$ & 1 & 2 & 2 & 2 & 94 & 91 & 100 \\
\hline 9 & 10,8 & $45 \times 0$ & 2 & 2 & 1 & 0 & 100 & 97 & 104 \\
\hline 10 & 10,8 & $45 \times 0$ & 1 & 2 & 2 & 2 & 99 & 101 & 97 \\
\hline 11 & 10,6 & $\begin{array}{l}45 \mathrm{XO} / 46 \mathrm{XX} \\
\text { delq23 22-10 }\end{array}$ & 6 & 2 & 0 & 1 & 93 & 96 & 90 \\
\hline 12 & 10,6 & $45 \times 0$ & 1 & 2 & 2 & 2 & 87 & 98 & 77 \\
\hline 13 & 12,3 & $\begin{array}{c}45 \times 0 / 46 \mathrm{XX} / \\
47 \mathrm{XXX}\end{array}$ & 1 & 2 & 2 & 2 & 98 & 105 & 91 \\
\hline 14 & 5,8 & $\begin{array}{c}45 \mathrm{XO} / \\
46 \mathrm{X} \text { iso } \mathrm{Xq}\end{array}$ & 1 & 2 & 2 & 1 & 104 & 97 & 111 \\
\hline 15 & 7,2 & $\begin{array}{c}45 \mathrm{XO} / \\
46 \mathrm{Xdıc}(\mathrm{y})\end{array}$ & 7 & 0 & 2 & 0 & 84 & 83 & 88 \\
\hline
\end{tabular}

* Classification: score 0: 100th-16th score 1: 15th-6th score 2 :5th and below \# Abbreviations: FSIQ= Full Scale IQ VIQ= Verbal IQ PIQ= Performance IQ 
These results clearly show that girls with TS not only performed poorly on one specific section, but that differences are evident across all items tested. Nine children showed a profile of overall decreased motor performance and scored below the 15th centile on all three sections (total impairment score for all these girls lies at the 1st centile). Two girls scored below the 15th centile on two of the three sections (total impairment score 2nd and 6th centile), four patients scored below the 15th centile on the ball skills section but nevertheless total impairment scores for these four were respectively on the 6th, 7th, and 8th centile (Table 5). At item level the patients scored significantly lower on the speed task for both hands separately and on the static balance task. The difference between left- and right-hand performance on the pegboard did not deviate from the differences in the normative scores.

\section{Relation between Motor Performance and Intelligence}

The mean FSIQ in the TS group was 94.93 (SD 8.77). Of the total group ( $n$ $=15$ ), two children had IQ ratings below 85 , a number that is expected in a normal distribution $(p=0.28)$. However, no child scored above 115 (see Tables 5 and 6).

Table 6: WISC-RN: Mean and Standard Deviation IQ- scores girls with TS $(n=15)$.

\section{IQ score mean/SD}

Verbal IQ

Performance IQ

Full Scale IQ
$94.60(6.70)$

$96.60(15.58)$

$94.93(8.77)$

The mean VIQ score was 94.60 (SD 6.70). Two children had ratings $\leq 85$, no child scored above the 115. The mean PIQ score was 96.60 (SD 15.58) (see Tables 5 and 6). One child scored below 85 and one above 115 . Nine children showed less than 1 standard deviation difference between VIQ and PIQ, and six patients showed more than 1 standard deviation difference between VIQ and PIQ. Of these discrepant profiles, three patients showed a 
higher VIQ, and in three cases the opposite discrepancy was found, namely a higher PIQ.

None of the Pearson correlation coefficients between MABC and WISCRN scores were significant. Moreover, no significant differences on FSIQ, VIQ, and PIQ were found between the girls classified by the MABC as 'at risk' and those classified as 'impaired'.

\section{Discussion}

In spite of the fact that the literature reveals heterogeneous motor performance in girls with TS (Waber 1977, Meyers et al. 1989, Clark et al. 1990, Salbenblatt et al. 1992, Bender et al. 1993, Reiss et al. 1993, Ross et al. 1996, Nijhuis - van der Sanden et al. 1998), this study reveals an overall poor motor performance. Although it is a small sample, the studied group must be considered as a representative selection in one of the largest treatment centers in the Netherlands. The group under investigation has a higher rate of motor-performance impairment than expected, based upon the literature. The children are characterized by substantially lower performance in fine motor skills, ball skills as well as in balance. Moreover, they made more errors and were slower in all motor skills measured. Taken together, these results should be considered as indicative of a general motor problem (Henderson and Sugden 1992).

Salbenblatt et al. (1989) administered the BOTMP, which is also an assessment containing items which test simultaneous and complex interlimb timing. Their study found impaired motor performance in girls with 45XO (BOTMP result 1st centile), but children with mosaic TS or partial deletion of $\mathrm{X}$ chromosome showed no significant difference in overall BOTMP-score. In our study the karyotype was verified in nine patients as $45 \mathrm{XO}$ and in five times as mosaic, comparison of these groups could not confirm any differences in motor performance based on karyotype. Beside differences in the domain of the test items, the findings in our study may be considered as a result of the fact that the children in this study are younger and, therefore, less influenced by motor learning factors. If girls with $45 \mathrm{XO}$ karyotype have more problems in learning new motor skills the difference could increase with age. As sample size of this study as well as of studies from the literature are small, the results should 
be interpreted with caution. Moreover, it is not clear whether the karyotype groups can be compared across studies as the possibilities for cytogenic investigations for determining the karyotypes of the Turner syndrome have changed over the years. Therefore, in the past the percentage of missed mosaics was greater because a smaller number of cells was examined.

Ross et al. (1996, 1998) suggest that oestrogen deficiency might explain the motor deficiency in girls with TS. The patients examined in this study were not yet treated with oestrogen so this aspect cannot be taken into account. Positive effects of oestrogen treatment have been reported on non-verbal processing speed and accelerated motor performance in 12-year old girls with TS (Ross et al. 1998). That motor performance would be slower in oestrogen-deficient females with TS is consistent with previous studies of influence of oestrogen on motor function. Future research must answer the question if oestrogen-replacement therapy diminishes the risk of motor impairment.

Looking at the item level of the MABC-scores, it can be observed that one item of manual dexterity, the pegboard task, showed the poorest performance for girls with TS. This item was scored for both the dominant and non-dominant hand, however, differences between hands did not deviate from control children. This result is in agreement with Ross et al. (1996, 1998), who found that there was no difference in performance of the dominant and non-dominant hands between the TS and control group. These findings are confirmed by our results and appear to hold for hand and leg preference. Ross et al. $(1996,1998)$ also found that patients with TS performed very poorly on pegboard tasks, and argued that this can be ascribed to the fact that these tasks required the greatest spatial demands. Observation of the girls during task performance revealed that the children misalign pegs with holes, use excessive force when inserting pegs, and do not use a supporting hand to stabilize the board. These observations in our study suggest there is not just a visuo-spatial problem involved, but there are also problems with other processes. It has not yet been investigated whether the functional motor problems are based on visuo-spatial problems, problems in planning, or execution of the motor activity itself.

In accordance with the literature on TS, the cognitive performance, as measured by WISC-RN, lies in the low-to-normal range and was confirmed for this group of girls with TS. The IQ results of the group under 
investigation (mean FSIQ 94.9) are very similar to those found in a review of 226 girls with TS (mean FSIQ 94.6) by Rovet J (1993); in only three patients was asymmetry found in cognitive ability, i.e. a normal VIQ and a decreased PIQ. This picture deviates from that frequently reported in the literature (Money 1973, Garron 1977, Waber 1979, Pennington et al. 1985, Downey et al. 1989, Bender al. 1993, Temple and Carney 1993, Rovet et al. 1994, Ross et al. 1996). Three patients with a significantly higher PIQ score also emerged; a characteristic intelligence profile for girls with TS associated with a selective impairment in PIQ is not found in this study. However, Pennington et al. (1985) also reported a considerable degree of heterogeneous IQ scores and also discovered several cases with a reversed asymmetry (PIQ > VIQ).

In this study, even in those instances where the mean PIQ score is higher than the VIQ score, the total motor performance scores clearly point to impairment. It appears that motor problems in girls with TS are not directly related to PIQ. As no significant correlation was found in this study between motor and cognitive performance, it is unlikely that the impaired motor performance can be ascribed to an underlying cognitive cause. Based on the present study it can be argued that girls with TS experience general motor problems, sometimes combined with cognitive or social problems. In general it seems that girls with TS have problems learning complex motor tasks: the manual dexterity item, on which girls with TS scored lowest in our study, is a goal-directed motor task, with both spatial and speed demands. Although this study indicates that the overall low motor performance in girls with TS does not result from problems in the cognitive domain, decreased visuo-spatial and/or visuo-perceptual abilities may add to motor problems. In teaching girls with TS movement skills it is important to have insight into both movement processes and the prerequisites for optimal motor planning and executing.

\section{Acknowledgements}

Thanks to the children who participated in this study and their parents, as well as to Dr B. Otten, endocrinologist, Mrs L. Nabuurs, and Drs. A. Brugman-Boezeman, psychologists, for their help with data collection. We also would like to thank the two anonymous referees for their comments and Joanne Postma for correcting the English. 


\section{Reference List}

Bender BG, Linden MG, Robinson A. (1993). Neuropsychological impaiment in 42 adolescents with Sex Chromosome abnormalities. American Journal of Medical Genetics (Neuropsychiatric Genetics) 48, 169-173.

Clark C, Klonoff H, Hayden M. (1990). Regional cerebral glucose metabolism in Tumer Syndrome. Canadian Journal of Neurological Sciences 17, 140-144.

Downey J, Ehrhardt AA, Gruen R, Bell JJ, Morishima A. (1989). Psychopathology and social functioning in women with Tumer's Syndrome. Joumal of Nervous Mental Disease 77 (4), 91-201.

Garron DC, Molander L, Cronholm B, Lindsten J. (1973). An explanation of the apparently increased incidence of moderate mental retardation in Tumer's Syndrome. Journal of Behavior Genetics 3, 37-43.

Garron DC. (1977). Intelligence among persons with Tumer's Syndrome. Journal of Behavior Genetics 7, 105-127.

Hartgenbusch HG. (1927a) Über die Messung von Wahmehmungsbildern. Psychologische Forschung 7, 28-74.

Hartgenbusch HG. (1927b). Beobachtungen und Bemerkungen zur Psychologie des Sports. Psychologische Forschung 7, 386-397.

Henderson SE, Hall D. (1982). Concomitants of clumsiness in young children.

Developmental Medicine and Child Neurology 24, 448-460.

Henderson SE, May DS, Umney M. (1989). An exploratory study of goal-setting behaviour, self-concept and locus of control in children with movement difficulties. European Journal of Special Needs Education 4(1), 1-14.

Henderson SE, Sugden DA. (1992). Movement Assessment Battery for Children: Manual London: Psychological Corporation.

Koffka K. (1935). Principles of Gestalt psychology. New York: Harcourt Brace.

Lam J, Henderson SE. (1987). Some applications of the Henderson revision of the Test of Motor Impaiment. British Journal of Educational Psychology 57, 389-400.

Laszlo JI, Bairstow PJ. (1985). Perceptual-motor behaviour. Developmental assessment and therapy. New York: Praeger Publishers.

Lewin K. (1926a). Untersuchungen zur Handlungs- und Affekt-Psychologie deel I:

Vorbemerkungen über die psychische Kräfte und Energien und über die Struktur der Seele. Psychologische Forschung 6, 294-329.

Lewin K. (1926b). Untersuchungen zur Handlungs- und Affekt-Psychologie deel II:

Vorsats, Wille und Bedurfnis. Psychologische Forschung 6, 330-385. 
Mathisen B, Reilly S, Skuse D. (1992). Oral motor dysfunction and feeding disorders of infants with Tumer's Syndrome. Developmental Medıcine and Child Neurology 34, 141-149.

McCauley E, Kay T, Ito J, Treder R. (1987). The Turner Syndrome: Cognitive Deficits, Affective Discrimination, and Behavior Problems. Child Development 58, 464-473.

Money J. (1973). Turner's Syndrome and parietal lobe functions. Cortex 9, 385-393.

Money J. (1993). Specific neuro-cognitive impairments associated with Tumer's (45 XO) and Klinefelter (47 XXY) syndromes: a review. Social Bıology 40, 147-151.

Murphy DGM, DeCarli C, Daly E, Haxby JV, Allen G, White BJ, McIntosh AR, Powell CM, Horwitz B, Ropoport SI, Shapiro MB. (1993). X-Chromosome Effects on female brain: a magnetic resonance imaging study of Tumer's Syndrome. Lancet 342, $1197-$ 1200.

Netley C, Rovet J. (1982). Atypical hemıspheric lateralisation in Turner syndrome subjects. Cortex 18(3), 377-384.

Nijhuis - van der Sanden MWG, Dijkstra-Hekkınk JGB, Brugman-Boezeman ATM, Eling PATM, Thoonen G, Otten B, Renier W. (1998). Het Turner Syndroom: Een literatuurstudie naar het belang van neuropsychologisch en motorisch onderzoek.

Tijdschrift voor Orthopedagogiek Kinderpsychologie en Kinderpsychiatrie 23, 11-18. Pennington BF, Heaton RK, Karzmark P, Pendleton MG, Lehman R, Shucard DW. (1985). The neuropsychological phenotype in Turner's Syndrome. Cortex 21, 391-404.

Reiss AL, Freund L, Plotnick L, Baumgardner MA, Green K, Sozer AC, Reader M, Boehm C., Denckla MB. (1993). The effect of X monosomy on brain development: monozygotic twins discordant for Turner's Syndrome. Annual Neurology 34 (1), 95 107.

Rosenfeld RG. (1990). 'Preface '. In: Rosenfeld RG, Gumbach MM. (Eds.). Turner Syndrome. New York and Basel: Marcel Dekker Inc.

Ross JL, Feuillan P, Kushner H, Cutler GB Jr. (1998). Effects of Estrogen on Nonverbal Processing Speed and Motor Function in Girls with Turner's Syndrome. Journal of clinical endocrinology and metabolism 82(6), 1814-1817.

Ross JL, Kushner H, Roeltgen DP. (1996). Developmental changes in motor function in girls with Tumer Syndrome. Pedriatric Neurology 15, 317-322.

Rovet J. (1993). The psychoeducational characteristics of children with Turner's Syndrome. Journal of Learning Disabilities 26, 333-341.

Rovet J, Szekely C, Hockenberry MN. (1994). Specific arithmetic calculation deficits in children with Tumer's Syndrome. Joumal of Clinical and Experimental Neuropsychology 16 (6), 820-839.

Salbenblatt JA, Meyers DC, Bender BG, Linden MG, Robinson A. (1989). Gross and fine motor development in $45 \mathrm{X}$ and $47 \mathrm{XXX}$ girls. Pediatrics 84(4), 678-682. 
Stott DH, Moyes FA, Henderson SE. (1972). The test of Motor Impatrment. San Antonio TX: The Psychological Corporation.

Stott DH, Moyes FA, Henderson SE. (1984). The test of Motor Impairment Henderson revision. Guelph Ontario: Book Educational Publishıng Ltd.

Smits - Engelsman BCM. (1998) Movement ABC; Nederlandse Handleiding [Dutch manual Movement ABC]. Swets en Zeitlinger Lisse.

Smits - Engelsman BCM, Henderson SE, Michels CGJ. (1998). The assessment of children with Developmental Coordination Disorder in the Netherlands: relationship between Movement Assessment Battery for Children and the Korperkoordinations Test fur Kinder. Movement Science 17: 699-709.

Temple CM, Camey RA. (1993). Intellectual Functioning of Children with Tumer Syndrome: A comparison of behavioural phenotypes. Developmental Medicine and Child Neurology 35: 691-698.

Vander Steene G, Van Haasen PP, De Bruyn EEJ, Coetsier P, Pijl YJ, Poortinga YH, Spelberg HC, Stinissen J. (1986): WISC-RN: Wechsler Intelligence Scale for ChildrenRevised, Nederlandstalige uitgave. Lisse, the Netherlands: Swets \& Zeitlinger.

Waber, DP. (1977). Biological substrates of field dependence: Implications of the sex difference. Pychological Bulletin, 84,1076-1087.

Waber DP. (1979). Neuropsychological aspects of Turner's Syndrome. Developmental Medicine and Child Neurology 21, 58-70.

Wechsler D. (1974). The Wechsler Intelligence Scale for Children-Revised. San Antonıo TX: Psychological Corporation. 

Low elementary movement speed is associated

with poor motor skill in Turner's Syndrome

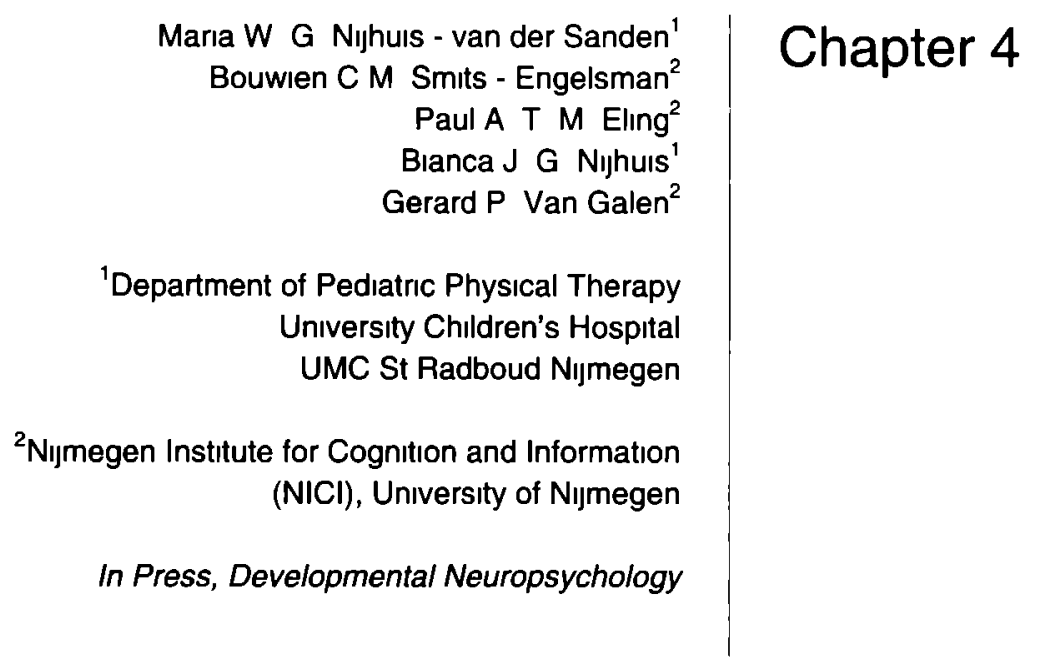




\section{Abstract}

The article aims at discriminating between 2 features that in principle both may be characteristic of the frequently observed poor motor performance in girls with Turner's syndrome (TS). On the one hand, a reduced movement speed that is independent of variations in spatial accuracy demands and therefore suggestive of a problem in motor execution, on the other hand a disproportional slowing down of movement speed under spatial-accuracy demands, indicating a more central problem in motor programming. To assess their motor performance problems 15 girls with TS (age 9.6-13.0 years) and 14 female controls (age 9.1-13.0 years) were tested using the Movement Assessment Battery for Children (MABC). In additionally, an experimental procedure using a variant of Fitts' graphical aiming task was used to try and disentangle the role of spatial-accuracy demands in different motor task conditions. The results of the MABC reestablish that overall motor performance in girls with TS is poor. The data from the Fitts' task reveal that TS girls move with the same accuracy as their normal peers but show a significantly lower speed independent of task difficulty. We conclude that a problem in motor execution is the main factor determining performance differences between girls with TS and controls. 


\section{Introduction}

Tumer's syndrome (TS) is a chromosome disorder characterized by short stature, gonadal dysgenesis and decreased secondary sexual development. The most common karyotype is $45 \mathrm{X0}$; females with this form of TS have only one $\mathrm{X}$-chromosome. The second most common form of TS is mosaicism with some cells containing a normal set and other cells a slightly different set of chromosomal material (45XO/46XX). Other types of abnormalities occur less frequently and include a partial deletion of one arm of the $\mathrm{X}$ chromosome with the loss of the other arm. TS is also characterized by a number of variable physical abnormalities. Furthermore, severe medical problems such as hearing problems, heart defects and kidney malformations can be found. TS has an incidence of 1 in 2,000 to 5,000 live born females (Rosenfeld \& Grumbach, 1990; Rovet, 1993). Nijhuis - van der Sanden, Smits - Engelsman, and Eling (2000) found that girls with TS have slight but statistically significant motor performance problems. Nijhuis - van der Sanden et al. (1998) found only few other authors reporting such motor performance problems (Bender, Linden \& Robinson, 1993; Clark, Klonoff \& Hayden, 1990; Mathisen, Reilly \& Skuse, 1992; Salbenblatt, Meyers, Bender, Linden \& Robinson, 1989).

Most studies find Verbal IQ (VIQ) to be in the normal range (Bender, Linden \& Robinson, 1993; Downey, Ehrhardt, Gruen, Bell \& Morishima, 1989; Garron, 1977; Money, 1973; Pennington, Heaton, Karzmark, Pendleton \& Shucard, 1985; Rovet, Szekely \& Hockenberry, 1994; Temple \& Carney, 1993; Waber, 1979). However, performance IQ (PIQ) scores tend to be lower than VIQ scores, and this may result in lower full-scale IQ (FSIQ) scores (Rovet, 1993). Most authors attribute the low Performal IQ scores to decreased visuospatial processing abilities (Downey, Elkin, Ehrhardt, Meyer-Bahlburg, Bell \& Morishima, 1991; Money, 1993; Romans, Stefanatos, Roeltgen, Kushner \& Ross, 1998; Ross, Feuillan, Kushner \& Cutler, 1998; Rovet, 1993; Temple \& Carney, 1995). The impoverished cognitive functioning appears to continue to exist throughout the patients' lifespan (Downey et al., 1991; Garron, 1977). Also, for the topic of poor motor performance, it might be suggested that poor visuospatial processing abilities are among the causal factors for less than optimal motor behavior because they play a role in controlling and planning 
goal-directed movements. In contrast to this view, Nijhuis - van der Sanden, Smits - Engelsman, \& Eling (2000) found no relationship between the FSIQ, VIQ, and PIQ scores on the WISC-RN in a representative sample of TS children (Vander Steene, Haasen, Bruyn, Coetsier, Pijl, Poortinga, Spelberg, \& Stinissen, 1986) and the motor performance scores on the Movement Assessment Battery for Children (MABC; Henderson \& Sugden, 1992; Smits - Engelsman, 1998; Stott, Moyes \& Henderson, 1972). A preliminary conclusion might be that motor problems in TS have a different etiology from the cognitive deficits found earlier. The motor problems in TS girls resemble those of children with Developmental Coordination Disorders (DCD's; DSM-IV; American Psychiatric Association, 1994). Several studies looking at motor performance in DCD children found that DCD children move as accurately as controls but need more movement time (Van Dellen \& Kalverboer, 1986; Van der Meulen, Denier van der Gon, Gielen, Gooskens \& Willemse, 1991a, 1991b). Missiuna (1994) found that this difference in movement time did not decrease after training in DCD children. Variability in timing and force production is higher in DCD children compared to controls (Geuze \& Kalverboer, 1987; Geuze \& Kalverboer, 1994; Henderson, Rose \& Henderson, 1992; Lundy-Ekman, Ivry, Keele \& Woolacott, 1991; Williams, Woollacott \& Ivry, 1992). Children with DCD show more disfluency in their movement execution and pause more frequently between the movement segments (Missiuna, 1994; Schoemaker, Hijlkema, \& Kalverboer, 1994; Geuze \& Van Dellen, 1990). Geuze and Kalverboer (1987;1994), Lundy-Ekman et al. (1991), and Williams et al. (1992) suggested that neuromotor noise might be the underlying cause for the increased variability, whereas Missiuna (1994), Schoemaker et al. (1994), and Geuze and Van Dellen (1990) suggest that problems in the perceptuomotor feedback system or that a lower neuronal conduction velocity are main factors. In a meta-analysis, Wilson and McKenzie (1998) found that visuospatial performance was investigated most frequently and appeared to discriminate best between groups; for several categories of motor programming and motor control tasks, there were too few studies to analyze group differences. The authors concluded that children with DCD generally performed worse than control children on measures of information processing. These authors suggest that DCD children suffer from a generalized visuospatial deficit, but they also concluded that a causal relationship between visuospatial and motor problems cannot be 
established; "just because two impairments are associated does not imply that they signal a unitary impairment".

\section{Studies of motor performance in girls with TS}

Only two studies (Nijhuis - van der Sanden, Smits - Engelsman, \& Eling, 2000; Salbenblatt et al., 1989) explored general motor performance in girls with TS by administering a norm-referenced test for motor performance. Salbenblatt, Meyers, Bender, Linden, and Robinson (1989), using the Bruininks-Ozeretsky test of Motor Proficiency, found that 12 out of 15 girls with TS exhibited both gross and fine motor dysfunction (defined as scores below the $10^{\text {th }}$ centile). Additional problems were hypotonia associated with diminished grip force, poor joint stability, gait abnormalities and difficulty with balance, diadochokinesis and problems with motor planning and bilateral coordination. These results are in line with the findings by Nijhuis - van der Sanden, Smits - Engelsman, and Eling (2000). Based on the Total Impairment Score of the MABC, these authors found that all girls with TS in their sample $(n=15)$ scored in the "subnormal" range $(\leq 15$ th percentile); five subjects were classified as "at risk"(5th to15th percentile) and ten as "impaired" ( $\leq 5$ th percentile). Both studies demonstrate that girls with TS indeed suffer from a general motor impairment, but also, both studies do not offer any views as to the underlying processing deficit.

Several other authors have investigated the performance of girls with TS on specific motor tasks. For example, Clark, Klonoff, and Hayden (1990) found that women with TS had a significantly lower manual strength, as measured by a dynamometer, than the control group. When performing a finger-tapping test, however, these authors did not find any differences between the two groups, this in contrast to Bender, Linden, and Robinson (1993), who reported significantly decreased velocity for women with TS.

Further, Ross, Kushner, and Roeltgen (1996), studying non-spatial repetitive motor tasks and spatially mediated motor tasks, reported that girls with TS ( $n=78$, age 7-9 and 10-12 years) performed less well than control children ( $n=145$ ) on the motor tasks with spatial demands only, particularly in the older age group (10-12.9 years). These findings suggest that especially spatial demands in a task play an important role in 
performance problems and, when girls with TS become older, deficiencies increase compared to healthy peers.

Ross and colleagues (1998) suggest that an estrogen deficit may play a role in processing speed. They found a positive estrogen treatment effect on non-verbal processing speed and motor action speed in 12-year-old girls with TS. Romans, Stefanotos, Roeltgen, Kushner, and Ross (1998) described changes in motor skills that occur in transition from adolescence to young adulthood. In the latter study, 99 females with TS and 89 normal female controls (two age groups 13.0 to 16.9 years and 17.0 to 21.9 years) were compared on simple motor tasks and motor tasks with visuospatial demands. In this study the women with TS performed at comparable levels to those of the controls on the simple motor tasks, especially in the older age group. The measurements of motor skills with an emphasis on visuospatial demands, however, revealed significant differences between females with TS and controls in both age groups. Based on the results of this study, Ross, Zinn, and Mc Cauley (2000) argued that the impaired performance is caused by persisting visuospatial difficulties, independent of motor components. It should be noted again, however, that the conclusion of deficient visuospatial processing is based only on indirect evidence. None of the above-mentioned authors have varied visuospatial demands or motor control demands in a direct manner.

There is hardly any other experimental research to be found in the literature concerning motor performance in girls with TS. From the previous literature review it is evident that the exact nature of the motor performance problems in girls with TS and the relationship to visuospatial task demands is not yet clear.

Current theories concerning perceptual motor skills, distinguish a cognitive stage in which information from the environment is encoded and related to internal information, resulting in the planning of an action (Schmidt, 1975; Jeannerod, Arbib, Rizzolatti \& Sakata, 1995; Wolpert, Ghahramani \& Jordan, 1995; Rosenbaum, Engelbrecht, Bushe \& Loukopoulos, 1993). Motor control processes embody subsequent operations that are responsible for selecting and programming an appropriate motor response on the basis of the environmental input and internal constraints. Most theories assume preprogrammed action schemas; they also assume that during movement execution the position of the limb is compared with the predicted position, 
whereas the actual sensory outcome is simultaneously compared with the predicted outcome, and when necessary error correction will occur. This process occurs to a large extent unconsciously.

However, before relying on a more complex theory about a possible cognitive or visuospatial deficit in TS, we thought it relevant to test whether more elementary motor functions such as movement speed and movement accuracy can be regarded as the principle factor for the poorer performance in everyday motor skills.

The aim of the present study, therefore, is to try to provide a deeper insight into the nature of the differences between TS girls and controls in movement execution through the use of well-controlled overlearned aiming tasks that involve little or no cognitive planning. As such, Fitts' aiming paradigm (Fitts, 1954) allows for the quantitative variation of motor-task difficulty, while holding relatively constant the overall sensory, cognitive and motivational contributions to task performance. In essence Fitts' task requires the subject to alternately aim at two target areas as quickly as possible with a minimum number of errors. Fitts found that the relationship between the amplitude (A) of a movement, the target width (W) and the resulting average movement time (MT) could be expressed by the following equation: $\mathrm{MT}=\mathrm{a}+\mathrm{b}\left[{ }^{2} \log (2 \mathrm{~A} / \mathrm{W})\right]$.

The equation represents a linear function with the constant $a$ being the intercept with the $y$-axis (on which usually MT is plotted) and the constant $b$ determining the slope of the linear function. The value of ${ }^{2} \log (2 \mathrm{~A} / \mathrm{W})$ reflects how "difficult" a particular combination of $\mathrm{A}$ and $\mathrm{W}$ is in a given task, and may be regarded as an index of difficulty (ID). In its simplest form the law says that the rate of information processing in repetitive motor tasks is constant, or differently stated, when the index of difficulty in a task grows linearly, the average execution time for each movement also increases linearly. The constant $a$ (the intercept) is the value of MT when the ID is zero. A movement with "zero difficulty" is one with a spatial layout of $2 \mathrm{~A} / \mathrm{W}=1.0$ (because ${ }^{2} \log 1=0$ ). Therefore, the intercept refers to the situation in which the amplitude is half the target width, which results in targets that are overlapping, so that the participants' task actually involves tapping up and down as quickly as possible. Thus, we can consider the intercept $a$ to represent elementary movement speed. The constant $b$ is the slope of the function and refers to the added MT by 
increasing the ID. The slope can thus be seen to represent the sensitivity of the motor control system to changes in the value of ID.

The Fitts' aiming paradigm (Fitts, 1954; Fitts \& Posner, 1967) has a long history in experimental psychology (Schmidt \& Lee, 1999). Since the first publication of Fitts' Law, many investigators have studied the law in a variety of contexts, revealing that the principle shows remarkable generality. Hay (1981) and Schellekens, Kalverboer, and Scholten (1984) found that Fitts' Law holds well for children.

In the present study, a variant of Fitts' task is used, namely a graphic aiming task. To explore whether the impaired motor performance in girls with TS can be ascribed to either a deviating elementary movement speed (intercept $a$ ) or to poorer information processing (slope $b$ ), task difficulty (ID) is manipulated by using three different target circles, while target distance is held constant in all conditions.

We used two variants of the task, namely an externally paced (discrete) task and a self-paced (serial) task. In the discrete task, consecutive aiming movements are performed separately since the subject can only initiate a new movement after the presentation of a machine-controlled signal. In the serial-task condition, consecutive aiming movements are performed continuously without any interruption. From the literature (Schmidt, 1999) it is well known that Fitts' Law is applicable in discrete as well as in cyclical movements. In a discrete condition, each time an individual has to initiate a new movement, and this enlarges total MT compared to serial movements. Therefore, we expect a shorter MT and a smaller slope in the serial condition. Further, to analyze the influence of different effector systems in both the discrete and the serial task, we used two separate conditions involving either finger or wrist movements. Langolf, Chaffin, and Foulke (1976) found that movement speed in wrist movements is higher than in finger movements, and also more sensitive to changes of the ID.

Manipulating the ID in these four experimental conditions, we analyzed differences in motor performance between girls with TS and controls: The lowered elementary movement speed hypothesis predicts that girls with TS have a longer movement time in all experimental conditions, while they react in the same manner as the controls to the different task conditions; 
differences between groups would be differences in intercept $a$. The alternative hypothesis that impaired motor control processes are the main discriminating factor would predict a larger increment in movement time with increasing index of difficulty in girls with TS, so slope $b$ will be greater for girls with TS than for controls. The discrete task condition and wrist movement condition will be more sensitive to changes in ID for both groups.

\section{Method}

\section{Participants}

Twenty girls with TS in the ages between 9 and 12 years were approached within the context of a national inquiry initiated by the University Medical Center St Radboud, forming part of a national information program for TS patients. Four girls and their parents refused participation. One girl with TS was excluded from the study because of diplegia spastica; none of the other girls had any physical abnormalities that could influence motor performance. Subsequently, 15 girls with TS participated in the study. None of the girls had participated in an earlier study (Nijhuis - van der Sanden et al., 2000). The TS-karyotype was diagnosed by cytogenetic studies on cultured peripheral lymphocytes according to routine procedures. From each patient at least 30 GTG-banded metaphases were studied to rule out any low-grade mosaicism. The karyotype of the included girls with TS was verified 4 times as $45 \mathrm{XO}$ and 11 times as mosaic. The mean age of the TS group was 11.8 years (range $=9.6$ years -13.0 years). Two participants in this group were left-handed. Four girls with TS were treated with estrogen and a further 12 girls with TS were treated with non-biological growth hormones. All TS girls attended regular elementary or secondary schools.

Fourteen female control subjects were recruited from an elementary and a secondary school, matched on age and school level. The mean age of the control subjects was 11.8 years (range $=9.1$ years -13.0 years). Three subjects in the control group were left-handed. Informed consent was obtained from all children and their parents. All parents filled in two 
questionnaires, one concerning the socio-economic status and another concerning general health and school performance.

No significant differences in the socio-economic status and general health between the families of the control and the TS groups were found. All girls received their education at regular schools. For the girls with TS more problems with concentration and mathematics were reported compared to the controls. Six girls with TS, but none of the controls, had experienced hearing problems in the past. None of the TS girls or controls reported any problems with vision.

\section{Procedures}

Three qualified pediatric physical therapists and two trained investigators tested all the participants with TS on the same day and the controls on another day. Testing involved assessment of general motor function by means of the MABC and motor execution by using graphic variants of Fitts' aiming task.

\section{General motor performance}

To determine general motor performance, an age-appropriate standardized test, that is, the MABC (Henderson \& Sudgen, 1992; Smits - Engelsman, 1998) was administered. This instrument is designed to identify children with impaired motor ability in daily life and determines poor performance in three domains of motor skills: manual dexterity, ball skills, and balance skills. The test has sufficient validity and reliability (Henderson \& Hall, 1982; Henderson, May, \& Umney, 1989; Henderson \& Sudgen, 1992; Lam \& Henderson, 1987; Laszlo \& Bairstow, 1985; Smits - Engelsman, 1998; Stott, Moyes \& Henderson, 1972): inter-rater reliability ranges from .70 to .89 , while test-retest reliability is .75. Smits - Engelsman (1998) translated the test into Dutch and no significant differences in norm scores were found (Smits - Engelsman, 1998), so the percentile scores of the original test are used. The MABC provides an indication of a child's everyday motor functioning and distinguishes four age ranges. The tests for each age range are identical in structure and each test contains 8 items, divided into 3 sections: Manual Dexterity, Ball Skills, and Static and Dynamic Balance. 
Motor Performance is scored either in terms of accuracy or speed. Per item scaled scores are provided ranging from 0 (good) to 5 (very poor).

Summing the item scores for each section produces a profile of the child's performance: Manual Dexterity (0-15), Ball Skills (0-10), and Static and Dynamic Balance (0-15). These three section scores are then summed again to produce a Total Motor Impairment Score ranging from 0 to 40 . The three section scores and the Total Impairment Score can be interpreted using norm tables. High scores on the MABC represent poor performance.

\section{Graphic aiming tasks}

To examine elementary movement speed and motor control processing, a Fitts' graphical aiming task was used (Fitts, 1954; Fitts \& Posner, 1967). Participants were seated in their usual writing posture at a desk of normal height holding a pen with their habitual pen grip. The tasks were executed on normal paper (A4 format, landscape orientation) that was placed on a WACOM 1218 RE digitizer. For either the finger or the wrist movements on each sheet diagonally opposed target circles with a distance of $2.5 \mathrm{~cm}$ were depicted (see Figure 1a and 1b).

Figure 1: The patterns used for the finger (1a) and wrist movement conditions (1b). Target size varies between $0.22 \mathrm{~cm}, 0.44 \mathrm{~cm}$ and $0.88 \mathrm{~cm}$.

$1 \mathbf{a}$

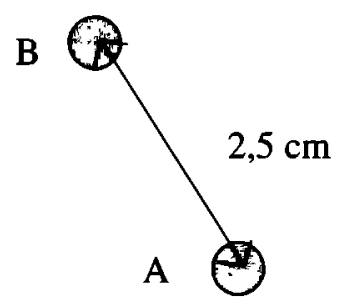

1b

A

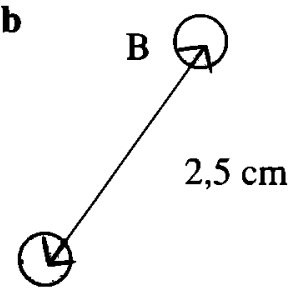

Participants were required to draw a straight line from the starting area into the target circle as fast and as accurately as possible. Prior to each task, subjects were allowed to place the sheet of paper in a position they felt most comfortable. An inkless, electronic pen of normal size was used to prevent participants from tracing over the previous pen strokes and to 
guarantee that targets remained visible during the entire task. The participants were instructed to place their lower arm in a comfortable position on the writing tablet, so that during each experimental condition they could produce wrist and finger movements easily without making forearm movements. The tasks were demonstrated and explained orally. Subsequently, participants were allowed to practice a few trials in each task condition to assure they understood the task. To determine whether the participants had actually performed the required wrist and finger movements, video recordings were made throughout the entire procedure.

Two tasks were executed: an auditory, externally paced discrete task and a self-paced serial task. In the discrete task, participants were asked to position the pen in the lower circle and, after the presentation of the auditory start signal, to move as quickly as possible toward and into the target circle, and to return to the lower target upon presentation of the next auditory signal. The auditory start signals were presented at random intervals (varying from $0.5-2 \mathrm{sec}$ ). In each trial a subject made eight up and eight down strokes between two targets (16 segments).

In the serial task, subjects had to move their pen in a continuous, repetitive, up and down movement back and forth between the targets as fast as possible during a period of $20 \mathrm{sec}$, a measurement period starting and ending with an auditory signal. Both tasks were performed in three accuracy conditions. In each condition, a different target width was presented: diameters of $0.22 \mathrm{~cm}, 0.44 \mathrm{~cm}$ and $0.88 \mathrm{~cm}$, respectively. The distance between the centers of the targets ( $A$ and $B$ ) remained constant at $2.5 \mathrm{~cm}$. To manipulate the joint involved in the movement, both tasks were performed using:

- Finger movements (see Figure 1a); aiming movements were produced from circle $A$ to circle $B$ and vice versa by successive flexion and extension of the fingers. The left-handed girls used the pattern depicted in Figure $1 \mathrm{~b}$ for this condition.

- Wrist movements (see Figure 1b); aiming movements were produced from circle $A$ to circle $B$ and vice versa by successive abductions and adductions of the wrist. The left-handed girls used the pattern depicted in Figure 1a for this condition. 
After the practice trials, uneven numbered subjects started with the discrete task condition, even numbered subjects with the serial task condition to counterbalance order effects. Each subject of the TS group was matched with one control; each matched pair was exposed to the same order of experimental conditions. Within both the discrete and the serial task, six experimental conditions, derived from the combination of Target Width (three levels) and Joint Movement (two levels) were presented in a random order to the participants.

\section{Analysis}

\section{General motor performance}

Mean scores for the MABC Item Scores, Section Scores and the Total Impairment Score were calculated for each group. The Mann-Whitney Test was used to examine differences between groups. A chi-square test for differences in proportions was used to compare the distribution of the Total Impairment Score of the TS group and the control group with that of the norm population.

\section{Graphic aiming tasks}

Kinematic variables were measured using a WACOM 1218 RE digitizer, an electronic pen, a PC, and OASIS software (De Jong, Hulstijn, Kosterman, \& Smits - Engelsman, 1996). During the sampling period, the pen movements were recorded at a rate of $206 \mathrm{~Hz}$ with a spatial accuracy of 0.1 $\mathrm{mm}$. For each trial the data record consisted of three variables as a function of time, that is, the $X$-coordinate, the $Y$-coordinate of the pen position and the $Z$-coordinate representing the axial pressure of the pen.

A semiautomatic computer program divided all recorded movements in separate up- or down segments. The beginning of a segment was defined as the point where velocity was higher than $0.5 \mathrm{~cm} / \mathrm{sec}$; the end of a segment was defined as the point where velocity was lower than $0.3 \mathrm{~cm} / \mathrm{sec}$ nearest the target. In the discrete task condition participants did not always actually come to a halt. Secondary movements were sometimes made either to correct an error and enter the target area before starting the next movement 
segment or to move further to the center of the target area while waiting for the next starting signal. The sampled data points between the defined end and starting points of the segments were regarded as between-segment movements and were not used in the analysis for the kinematic variables. None of the subjects stopped at the target between consecutive movements in the serial task condition. All segments were checked by means of a manual-visual inspection to verify that begin and endpoints of the segments were positioned at the right place. Segments were not included in the analysis if participants had made a faulty trajectory or when the segmentation was apparently wrong. Less than $5 \%$ of the segments were removed; no systematic relation was apparent between these segments and task conditions.

For each condition the first two segments and the last segment of a trial were not entered into the data analyses in order to control for variance due to start-up tuning and anticipation of the end of the trial. From the remaining data, three dependent variables were derived for each condition. First, the trajectory length was analyzed. To analyze accuracy, Hit Rate (HR) was calculated defined as the percentage of hits relative to the total number of aiming movements. We opted for the percentile Hit Rate as a measurement of accuracy because in the serial task condition the total count of the aiming movements differed between individuals. Finally, as a measure for movement speed, for each segment the Movement Time (MT; that is, time elapsing between the start point and the endpoint of a segment) was calculated and averaged over a trial. The statistical analysis selected for comparisons between and within groups was a $2 \times 3 \times 2 \times 2$ (Group $\times$ Target Width $x$ Task $x$ Joint Movement) factorial ANOVA with Repeated Measures on the latter three factors.

Using linear regression curve estimation, intercept $a$ and slope $b$ were calculated for MT as a function of ID in all experimental conditions. Because in this experiment we used graphical two-dimensional aiming tasks, the subject had to position a pencil over a distance $(A)$ into a region of tolerance $(W)$, that is, the surface of a circle. Therefore a slightly modified equation was used to compute the intercept $a$ and slope $b$ : MT = $\mathrm{a}+\mathrm{b}\left[{ }^{2} \log (A / W+1)\right]$ (MacKenzie, 1992). $A$ is the distance between the center of the circles $(2.5 \mathrm{~cm})$ and $W$ is the surface of the target circle $\left(\Pi \mathrm{R}^{2)}\right.$. This equation results in a better fit and corresponds more closely to the information theorem. A significance level of $\alpha=.05$ was used for all 
statistical tests. The statistics were performed using SPSS software (version 10.0).

\section{Results}

\section{General motor performance}

The results of the Movement $\mathrm{ABC}$ revealed an overall poor motor performance in the girls with TS. Mean section scores for Manual Dexterity, Ball Skills, Balance Skills and the Total Impairment Scores were all higher for the girls with TS than for the controls, indicating a poorer motor skill performance for the girls with TS (see Table 1). Manual Dexterity, $U=42.0, p=0.005$, and Total Impairment Score, $U=43.0, p=$ 0.006 , differed significantly between the groups. Mean percentile score for the TS group was $15.20(S D=22.24$, range $=1-79)$ and for the controls mean percentile score was $40.17(S D=27.98$, range $=1-89)$. At item level, the girls with TS performed significantly more slowly than controls on the Manual Dexterity $1, U=34.0, p=.001$, and Manual Dexterity 2, $U$ $=58.5, p=.041$ (see Table 1). In both tasks motor performance was scored in terms of speed. A significant difference was also found for Balance Skills $1, U=38.5, p=.003$.

Finally, the distribution of the Total Impairment Score of the TS group differed significantly from the expected distribution, based on the norm population, $\chi^{2}(2, n=15)=77.59, p=.000$. For the control group no significant differences were found, $\chi^{2}(2, n=14)=.454, p=.797$. The results clearly demonstrated that overall motor performance in the girls with TS was very poor. 
Table 1: Mann-Whitney Test Results on the Movement ABC: Means and Standard Deviations (in Brackets) of Item and Section Scores and Mean Ranking Scores for Turner's Syndrome Girls ( $T ; n=15$ ) and Controls $(C ; n=14)$.

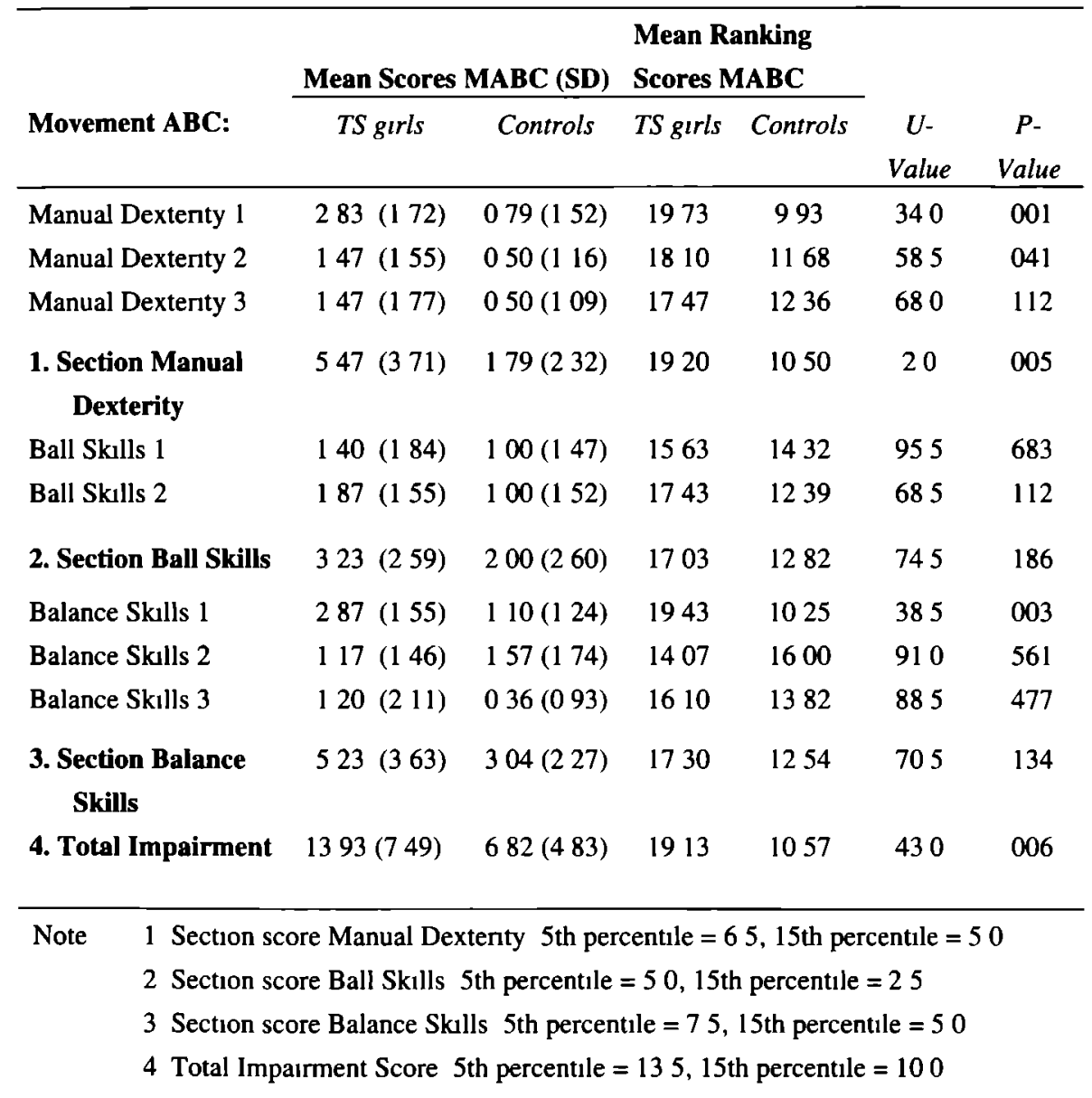




\section{Graphic aiming tasks}

\section{Trajectory length.}

Trajectory length of the strokes was analyzed first to enable further analyses according to Fitts' paradigm (see Tables 2 and 3; Figure 2). Main effects were found for Target Width, $F(2,26)=5.76, p=.008$, est $\eta^{2}=$ .307 , Task, $F(1,27)=17.21, p=.000$, est $\eta^{2}=.389$ and Joint Movement, $F(1,27)=6.15, p=.020$, est $\eta^{2}=.185$. Trajectory length was longer when Target Width was smaller $(0.22 \mathrm{~cm}: M=2.60 \mathrm{~cm}, S E=.02 ; 0.44 \mathrm{~cm}: M=$ $2.56 \mathrm{~cm}, S E=.03 ; 0.88 \mathrm{~cm}: M=2.47 \mathrm{~cm}, S E=.05)$. Also, trajectory length was longer in the discrete task $(M=2.67 \mathrm{~cm}, S E=.02)$ than in the serial task $(M=2.42 \mathrm{~cm}, S E=.06)$ and when the task was performed with finger movements in contrast to wrist movements $(M=2.58 \mathrm{~cm}, S E=.03$ vs. $M=2.51 \mathrm{~cm}, S E=.04)$. The interaction between Target Width and Task was significant too, $F(2,26)=9.50, p=.001$, est $\eta^{2}=.422$; in the discrete task trajectory length was nearly equal in all target-width conditions $(0.22 \mathrm{~cm}: M=2.65 \mathrm{~cm}, S E=.02 ; 0.44 \mathrm{~cm}: M=2.68 \mathrm{~cm}, S E=$ $.03 ; 0.88 \mathrm{~cm}: M=2.67 \mathrm{~cm}, S E=.03)$, whereas in the serial condition trajectory length decreased when target width was larger $(0.22 \mathrm{~cm}: M=$ $2.55 \mathrm{~cm}, S E=.03 ; 0.44 \mathrm{~cm}: M=2.44 \mathrm{~cm}, S E=.06 ; 0.88 \mathrm{~cm}: M=2.28 \mathrm{~cm}$, $S E=.09)$. No significant main effect was found for Group, $F(1,27)=$ $2.21, p=.149$, est $\eta^{2}=.076$.

We can conclude that, overall, both groups reacted similarly in the experimental conditions; in the discrete condition trajectory length was longer for both groups because they reached the center of the targets more frequently and with less variability than in the serial condition. In the serial task all subjects used the degrees of freedom associated with the perimeters of the targets: when target width was larger, trajectory length was shorter and variability greater, and in both conditions the trajectory length of the finger movements was somewhat longer than that of the wrist movements. 
Figure 2: Mean Trajectory Length for Turner Syndrome girls and controls in all experimental conditions. Bars show means, error bars show $95 \% \mathrm{Cl}$. of mean.

discrete task wrist movements serial task wrist movements
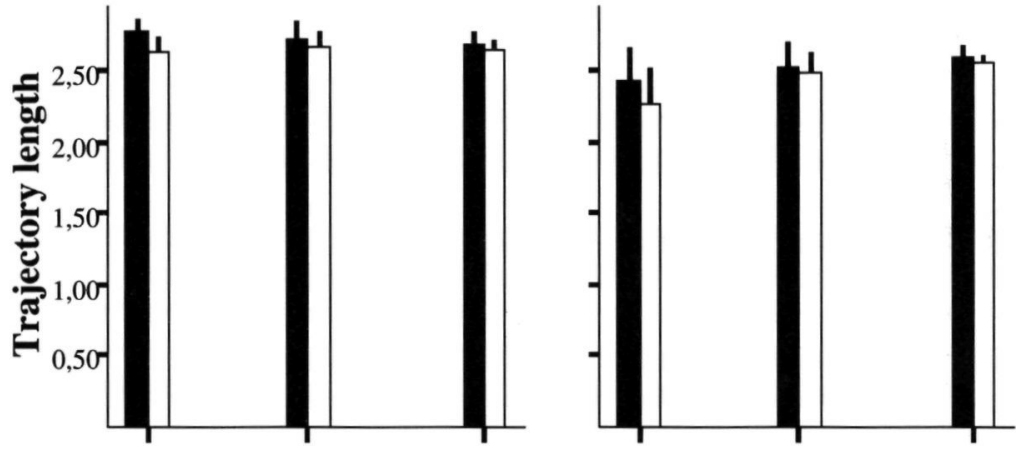

discrete task finger movements serial task finger movements
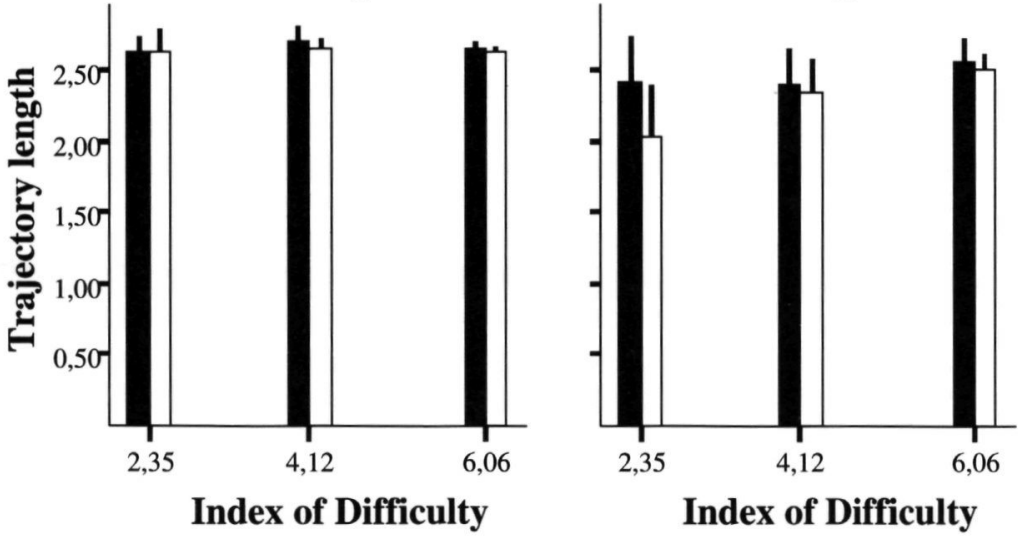

Group

girls with TS

$\square$ controls 


\section{Accuracy}

To ensure that Movement Time could be used for establishing differences between groups according to the logic of the Fitts' paradigm, we analyzed HR to ascertain that both groups had indeed performed the tasks with the same accuracy. The means and standard deviations for HR are presented in Table 2 and Figure 3. Results of the $2 \times 3 \times 2 \times 2$ (Group $\times$ Target Width $\times$ Task $x$ Joint Movement) factorial ANOVAs with Repeated Measures are presented in Table 3.

Table 2: Results of the Graphic Aiming Task: Means and Standard Deviations (in Brackets) of Trajectory Length, Hit Rate, and Movement Time (MT) in All Experimental Conditions for Turner's Syndrome Girls $(T ; n=15)$ and Controls $(C ; n=14)$.

\section{Discrete task}

$I D 6.06(0.22 \mathrm{~cm}) \quad I D 4.12(0.44 \mathrm{~cm}) \quad I D 2.35(0.88 \mathrm{~cm})$

\begin{tabular}{lccccccc}
\cline { 3 - 7 } Variable & Group & Finger & Wrist & Finger & Wrist & Finger & Wrist \\
\hline Trajectory & $\mathrm{T}$ & $2.68 \pm .14$ & $2.65 \pm .10$ & $2.71 \pm .22$ & $2.69 \pm .18$ & $2.77 \pm .18$ & $2.63 \pm .17$ \\
$\begin{array}{l}\text { Length } \\
\text { (cm) }\end{array}$ & $\mathrm{C}$ & $2.64 \pm .12$ & $2.62 \pm .06$ & $2.67 \pm .16$ & $2.65 \pm .12$ & $2.63 \pm .18$ & $2.63 \pm .25$ \\
Hit Rate & $\mathrm{T}$ & $79 \pm 15$ & $68 \pm 18$ & $91 \pm 12$ & $89 \pm 11$ & $98 \pm 2$ & $98 \pm 4$ \\
$(\%)$ & $\mathrm{C}$ & $64 \pm 27$ & $64 \pm 21$ & $88 \pm 18$ & $91 \pm 14$ & $97 \pm 4$ & $97 \pm 7$ \\
Movement & $\mathrm{T}$ & $0.76 \pm .28$ & $0.67 \pm .18$ & $0.70 \pm .31$ & $0.60 \pm .19$ & $0.56 \pm .18$ & $0.52 \pm .19$ \\
Time & $\mathrm{C}$ & $0.62 \pm .17$ & $0.55 \pm .17$ & $0.55 \pm .22$ & $0.48 \pm .15$ & $0.46 \pm .18$ & $0.39 \pm .15$ \\
(sec) & & & & & &
\end{tabular}

Serial task

\begin{tabular}{lccccccc}
\hline Trajectory & $\mathrm{T}$ & $2.60 \pm .16$ & $2.55 \pm .29$ & $2.52 \pm .33$ & $2.40 \pm .45$ & $2.43 \pm .41$ & $2.41 \pm .60$ \\
$\begin{array}{l}\text { Length } \\
\text { (cm) }\end{array}$ & $\mathrm{C}$ & $2.54 \pm .10$ & $2.49 \pm .21$ & $2.48 \pm .25$ & $2.34 \pm .42$ & $2.26 \pm .46$ & $2.01 \pm .60$ \\
Hit Rate & $\mathrm{T}$ & $59 \pm 19$ & $42 \pm 25$ & $79 \pm 17$ & $72 \pm 20$ & $92 \pm 10$ & $90 \pm 12$ \\
$(\%)$ & $\mathrm{C}$ & $59 \pm 20$ & $49 \pm 20$ & $80 \pm 14$ & $79 \pm 11$ & $96 \pm 5$ & $94 \pm 5$ \\
Movement & $\mathrm{T}$ & $0.60 \pm .21$ & $0.54 \pm .22$ & $0.43 \pm .18$ & $0.40 \pm .21$ & $0.30 \pm .17$ & $0.29 \pm .16$ \\
Time & $\mathrm{C}$ & $0.48 \pm .16$ & $0.45 \pm .16$ & $0.35 \pm .15$ & $0.31 \pm .14$ & $0.24 \pm .11$ & $0.20 \pm .10$ \\
\hline
\end{tabular}


Table 3: Results of ANOVA with Repeated Measures Design for the Three Dependent Variables: Trajectory Length, Hit Rate and Movement Time.

\begin{tabular}{|c|c|c|c|c|}
\hline Variables & Effect & Statistics & $\mathbf{p}$ & $\begin{array}{l}\text { Effect size } \\
\text { estimates } \eta^{2}\end{array}$ \\
\hline Trajectory & Group & $F(1,27)=2.21$ & .149 & .076 \\
\hline \multirow[t]{6}{*}{ Length } & Target width & $F(2,26)=5.76$ & $.008 * *$ & .307 \\
\hline & Task & $F(1,27)=17.22$ & $.000 * *$ & .389 \\
\hline & Joint movement & $F(1,27)=6.15$ & $.020^{*}$ & .185 \\
\hline & Group $x$ Target width & $F(2,26)=1.85$ & .177 & .125 \\
\hline & Group x Task & $F(1,27)=.43$ & .518 & .016 \\
\hline & Group x Joint movement & $F(1,27)=$ & .804 & .002 \\
\hline \multirow[t]{7}{*}{ Hit Rate } & Group & $F(1,27)=$ & .959 & .000 \\
\hline & Target width & $F(2,26)=98.68$ & $.000 * *$ & .884 \\
\hline & Task & $F(1,27)=50.18$ & $.000^{* *}$ & .649 \\
\hline & Joint movement & $F(1,27)=3.60$ & .068 & .118 \\
\hline & Group $x$ Target width & $F(2,26)=\quad .98$ & .389 & .070 \\
\hline & Group x Task & $F(1,27)=5.06$ & $.033 * *$ & .158 \\
\hline & Group x Joint movement & $F(1,27)=1.39$ & .249 & .049 \\
\hline Movement & Group & $F(1,27)=4.00$ & $.028 * * *$ & .129 \\
\hline \multirow[t]{6}{*}{ Time } & Target width & $F(2,26)=127.25$ & $.000 * *$ & .907 \\
\hline & Task & $F(1,27)=40.05$ & $.000 * *$ & .597 \\
\hline & Joint movement & $F(1,27)=10.80$ & $.003 *$ & .286 \\
\hline & Group x Target width & $\mathrm{F}(2,26)=$ & .722 & .025 \\
\hline & Group x Task & $\mathrm{F}(1,27)=$ & .502 & .017 \\
\hline & Group x Joint movement & $\mathrm{F}(1,27)=$ & .993 & .000 \\
\hline
\end{tabular}

Note: *significant difference at the $p<0.05$ level

** significant difference at the $\mathrm{p}<0.01$ level

***significant difference at the $\mathrm{p}<0.05$ level, one-tailed 
As expected a significant main effect of Target Width and Task was found. With increased target width HR increased $(0.22 \mathrm{~cm}: M=60 \%, S E=3 ; 0.44$ cm: $M=84 \%, S E=2 ; 0.88 \mathrm{~cm}: M=95 \%, S E=1), F(2,26)=98.68, p=$ .000 , est $\eta^{2}=.884$. In the discrete task, HR was higher than in the serial task $(M=85 \%, S E=1$ vs. $M=74 \%, S E=2), F(1,27)=50.02, p=.000$, est $\eta^{2}=.649$. The main effect of joint movement is nearly significant: HR was higher in finger movements $(M=82 \%, S E=1)$ than in wrist movements $(M=78 \%, S E=2), \mathrm{F}(1,27)=3.60, p=.068$, est $\eta^{2}=.118$.

No significant main effect for Group was found for HR (girls with TS vs. controls: $M=80 \%, S E=2$ vs. $M=80 \%, S E=2), F(1,27)=0.003, p=$ .959 , est $\eta^{2}=.000$, and differences were very small. A significant interaction effect was found for Group by Task: HR in TS girls was higher than for controls in the discrete condition $(M=87 \%, S E=2$ vs. $M=84 \%$, $S E=2$, respectively), $F(1,27)=5.06, p=.033$, est $\eta^{2}=.158$, whereas in serial task HR in TS girls is somewhat lower than for controls $(M=72 \%$, $S E=3$ vs. $M=76 \%, S E=3$ ).

In summary, both groups reacted in the same manner to the experimental conditions. All subjects used the possibility to reduce trajectory length when target width was larger without this having any negative effect on accuracy. Especially in the discrete task condition accuracy was high, whereas in the serial task and during wrist movements both groups tended to lose some accuracy when the Index of difficulty was high (target width = $0.22 \mathrm{~cm}$ ). We were thus able to conclude that there were no differences in accuracy between the two groups. 
Figure 3: Mean Hit Rate for Turner Syndrome girls and controls in all experimental conditions. Bars show means, error bars show 95 $\% \mathrm{Cl}$. of mean.
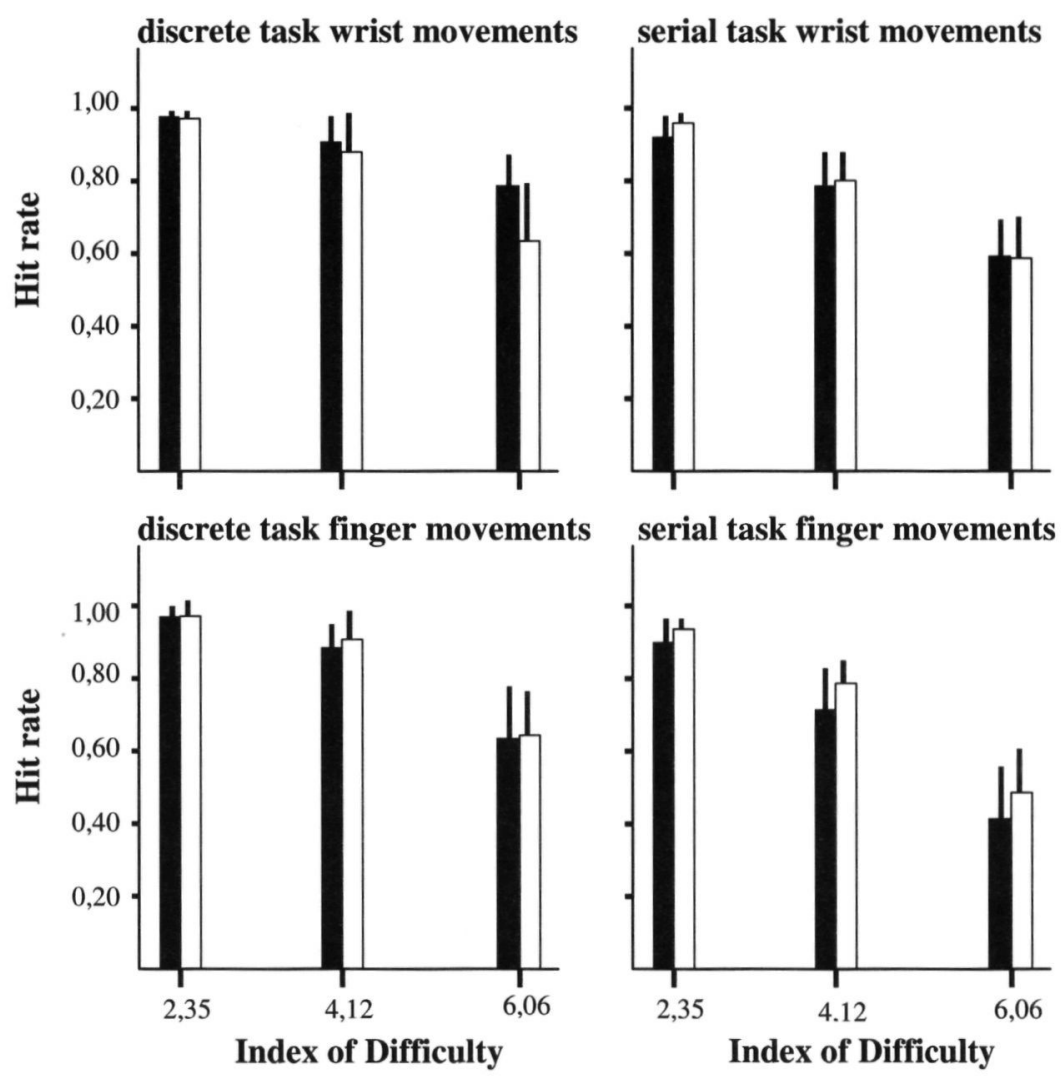

Group

girls with TS

$\square$ controls 


\section{Movement time}

Since no group differences in Trajectory Length and HR were found, we could analyze Movement Time to test our hypothesis that girls with TS would need longer Movement Time compared to the controls and examine whether any differences were due to a reduced elementary movement speed or impaired motor control processes. The means and standard deviations for Movement Time are presented in Table 2 and Figure 4. Results of the $2 \times 3$ x 2 × 2 (Group x Target Width x Task x Joint Movement) factorial ANOVAs with Repeated Measures are presented in Table 3. The results of the linear regression analysis are presented in Table 4.

Table 4: Intercept a and Slope $b$ for Turner's Syndrome Girls $(T ; n=15)$ and Controls $(C ; n=14)$ in the Discrete and Serial Task for Wrist and Finger Movements with ID $=2.35,4.12$, and 6.06, respectively. Movement Time $=a+b .{ }^{2} \log (A / W+1), W=\Pi r^{2}$.

\section{Group Intercept a $t$ - value $p$-value Slope b $t$-value $p$-value}

\section{Discrete Task}

\begin{tabular}{llllllll}
\hline Wrist & $\mathrm{T}$ & .44 & 3.870 & .000 & .05 & 2.135 & .040 \\
Finger & $\mathrm{C}$ & .36 & 4.226 & .000 & .04 & 2.288 & .030 \\
& $\mathrm{~T}$ & .43 & 5.273 & .000 & .04 & 2.143 & .040 \\
& $\mathrm{C}$ & .30 & 4.248 & .000 & .04 & 2.625 & .012 \\
\hline \multirow{2}{*}{ Wrist } & $\mathrm{T}$ & .10 & 1.268 & .212 & .08 & 4.333 & .000 \\
& $\mathrm{C}$ & .09 & 1.441 & .157 & .06 & 4.528 & .000 \\
\multirow{2}{*}{ Finger } & $\mathrm{T}$ & .13 & 1.542 & .130 & .07 & 3.461 & .001 \\
& $\mathrm{C}$ & .03 & .536 & .595 & .07 & 4.934 & .000 \\
\hline
\end{tabular}


As expected, a significant main effect of Target Width, Task and Joint Movement was found for MT (see Table 2). MT decreased when target width increased $(0.22 \mathrm{~cm}: M=0.58 \mathrm{sec}, S E=.03 ; 0.44 \mathrm{~cm}: M=0.48 \mathrm{sec}$, $S E=.03 ; 0.88 \mathrm{~cm}: M=0.37 \mathrm{sec}, S E=.03), F(2,26)=127.25, p=.000$, est $\eta^{2}=.907$. MT was longer in the discrete than in the serial task $(M=0.57$ sec, $S E=.03$ vs. $M=0.38 \mathrm{sec}, S E=.03), F(1,27)=40.05, p=.000$, est $\eta^{2}=.597$, and MT for the wrist movements $(M=0.45 \mathrm{sec}, S E=.03)$ was shorter compared to MT for the finger movements $(M=0.50 \mathrm{sec}, S E=.03)$, $F(1,27)=10.80, p=.003$, est $\eta^{2}=.286$. A significant interaction effect for Target Width by Task, $F(2,26)=5.85, p=.008$, est $\eta^{2}=.310$, was found: When target width was larger, MT decreased less in the discrete task $(0.22 \mathrm{~cm}: M=0.65 \mathrm{sec}, S E=.04 ; 0.44 \mathrm{~cm}: M=0.58 \mathrm{sec}, S E=.04 ; 0.88$ $\mathrm{cm}: M=0.48 \mathrm{sec}, S E=.03)$ than in the serial task $(0.22 \mathrm{~cm}: M=0.51 \mathrm{sec}$, $S E=.03 ; 0.44 \mathrm{~cm}: M=0.37 \mathrm{sec}, S E=.03 ; 0.88 \mathrm{~cm}: M=0.26 \mathrm{sec}, S E=$ $.03)$. Another interaction effect was found for Task by Joint Movement for MT, $F(1,27)=7.50, p=.011$, est $\eta^{2}=.217$ : Differences in MT between wrist and finger movements were greater in the discrete task (wrist $M=$ $0.61 \mathrm{sec}, S E=.04$ vs. finger $M=0.53 \mathrm{sec}, S E=.03$ ) compared to the serial task (wrist $M=0.40 \mathrm{sec}, S E=.03$ vs. finger $M=0.37 \mathrm{sec}, S E=.03$ ).

Taken together, these main effects indicate that the experimental conditions were well chosen and the overall effects on MT were as predicted. The interaction effects of Target Width by Task and Task by Joint Movement show that in repetitive fast movements variability of movement execution indeed followed the laws of kinematics and less corrective actions were needed, resulting in a reduced load on information processes necessary to optimize movement speed and accuracy (Latash \& Anson, 1996).

\section{Group Effects}

Tested one-sided, a significant main effect of Group was found for MT (TS girls $M=0.53 \mathrm{sec}, S E=.04$ vs. controls $M=0.42 \mathrm{sec}, S E=.04, F(1,27)=$ $4.00, p=.028$, est $\eta^{2}=.129$. No interaction effects for Group $\times$ Target Width, $F(2,26)=0.33, p=.722$, est $\eta^{2}=.025$, Group $\times$ Task, $\mathrm{F}(1,27)=$ $.463, p=.502$, est $\eta^{2}=.017$, or Group x Joint Movement, $F(1,27)=.000$, $p=.993$, est $\eta^{2}=.000$ were found. Therefore, we conclude that the data 
provides strong evidence that girls with TS need more Movement Time than controls but that they react in the same manner to experimental manipulations of target width and of executor limb. In particular the absence of any interaction effects with Group together with a strong main effect of Group suggests that differences are due to a reduced movement speed and not to a more central problem in motor control.

An alternative way to illustrate how the results can be related to Fitts' Law, is calculating the intercept and slope of the linear relationship between MT and ID. Because of the limited number of trials per subject, data points were pooled over subjects within groups and within conditions (see Figure 4). Using Mackenzie's equation $\mathrm{MT}=a+b\left(\log _{2}[A / W+1]\right)$ intercepts and slopes were calculated using linear regression curve estimation (see Table 4). Visual inspection of Figure 4 makes clear that in all four task conditions intercept, $a$, is consistently greater for the girls with TS, whereas slope, $b$, is nearly the same for both groups, confirming once again the conclusion that reduced movement speed is the main discriminating factor. In the discrete task condition, intercept $a$ differed mostly during finger movements (.43 for TS girls vs. .30 for controls, respectively), whereas slope $b$ is the same (.04 for both). The values of intercept $a$ for wrist movements were .44 (TS) versus .36 (controls) and the values of slope $b$ were .05 (TS) versus .04 (controls). In the serial task condition, intercept $a$ again differs more for finger movements (.13 vs. .03) and there is no difference in slope $b(.07)$. The smallest difference in intercept $a$ between the TS girls and controls was found for wrist movements: .10 (TS) versus .09 (controls) and only in this condition was slope $b$ found to be slightly different (.08 for TS vs. .06 for controls). The values for intercept $a$ en slope $b$ clearly confirm the ANOVA results: The longer Movement Time in the girls with TS is based on a greater intercept $a$, whereas differences between groups in slope $b$ are negligible. 
Figure 4: Mean Movement Time and intercept $a$ and slope $b$ for Turner Syndrome girls and controls in all experimental conditions, ID = $2.35,4.12$ and 6.06 .

discrete task wrist movements
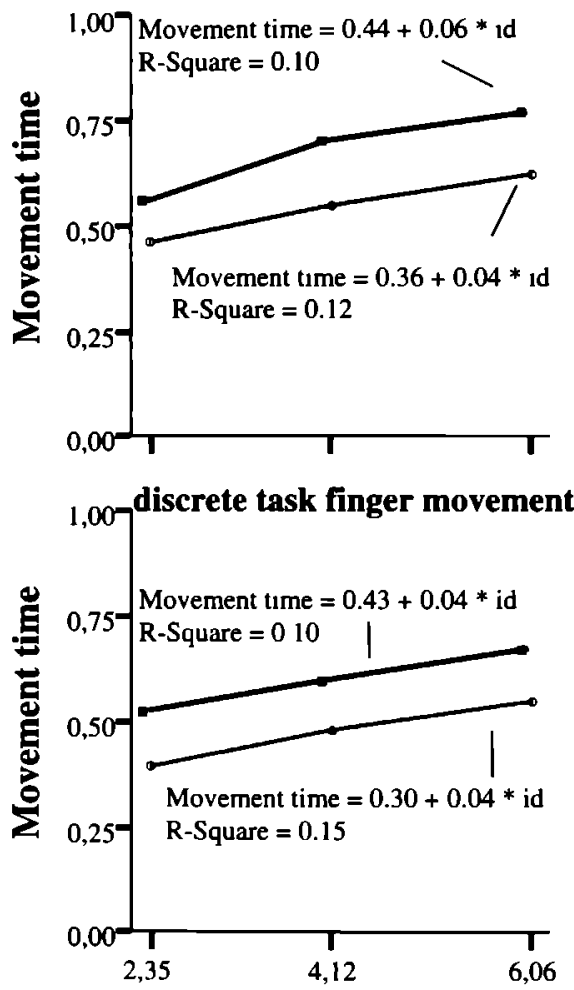

Index of Difficulty
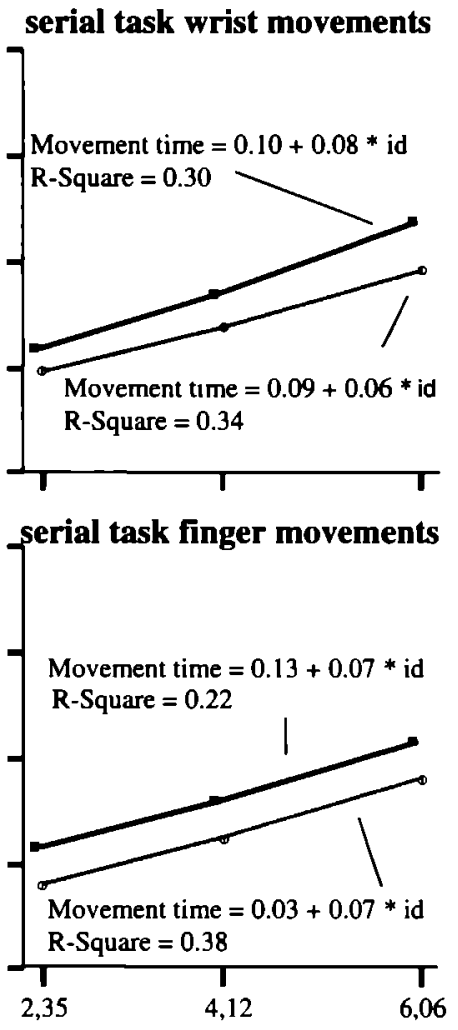

Index of Difficulty

Group

$\rightarrow$ girls with TS

$\vartheta$ controls 


\section{Discussion}

In line with earlier studies (Nijhuis - van der Sanden, Smits - Engelsman \& Eling, 2000; Salbenblatt et al., 1989) the results of the MABC revealed an overall poor motor performance in the girls with TS. Especially the Manual Dexterity and Total Impairment scores differed significantly between groups. However, the main goal of the present study was to try and provide a deeper insight into the nature of this poor motor performance. Using Fitts' graphic aiming tasks we attempted to discriminate between two possible explanations for the loss of motor performance: a reduced elementary movement speed or impaired motor programming processes. Significant main effects of Target Width, Task, and Joint Movement for Hit Rate and Movement Time (see Table 3) indicate that task manipulations were well chosen and were indeed sensitive to detect differences in information processing. At the same time, the absence of interaction effects with Group indicates that both groups responded similarly in all experimental conditions. Girls with TS executed the aiming movements with the same accuracy as their healthy peers but with a significantly longer Movement Time (MT). This absence of any interaction effects for movement time is underlined by the fact that we found differences in intercept $a$ in all conditions and no differences in slope $b$. Therefore, these results clearly support the hypothesis that elementary movement speed is the main discriminating factor between girls with TS and controls.

Several authors studied perceptuo-motor skills in DCD children and found analogous results: DCD children need more movement time (Geuze \& Kalverboer, 1987; Geuze \& Van Dellen, 1990; Van Dellen \& Kalverboer, 1986; Van der Meulen et al., 1991a; 1991b). However, these studies focused on visuomotor performance and cognitive motor planning by varying perceptual and cognitive task demands. Moreover, rather different outcome measures are used. In those studies perceptual and cognitive factors are very difficult to distinguish from motor execution factors. In this study, a simple Fitts' task is used, requiring relatively little perceptual and cognitive planning.

Maruff, Wilson, Trebilcock, and Currie (1999), and Wilson, Maruff, Ives, and Currie (2001) also used Fitts' tasks, like in the present study, and found that in normal control children there is a logarithmic relation between ID and MT in both imagined and real movements. This is in line with findings 
by Decety and Jeannerod (1996), who demonstrated that in purely mental actions speed-accuracy trade-off follows Fitts' law as well as in actually executed movements. Apparently, Fitts' law governs already the planning of movements. In the studies of Maruff, Wilson, Trebilcock, and Currie (1999) and Wilson, Maruff, Ives, and Currie (2001), the same results are found for DCD children as for TS girls; DCD children need a longer MT but react in the same manner on ID manipulation as controls in real movements. However, in imagined movements MT in DCD children is in all ID conditions the same. The authors suggest that DCD children are unable to predict imaginary MT from real movements, because in DCD children interruptions in the parietal lobe may result in impairment in the processing or generation of corollary discharge. It is unclear how this impairment would only affect planning problems in imagined and not in real movements.

In a meta-analysis of research findings in DCD children, Wilson and McKenzie (1998) found that most of the studies focused on visuomotor performance. They found for complex visuospatial tasks involving a motor component that the effect size in the meta-analysis was very high, whereas for visuoperceptual tasks without a motor component it was moderate to high. The authors proposed a generalized visuospatial deficit in DCD, not localized in the visual system but in the kinesthetic and cross-modal perceptual system. They also concluded that a causal relationship between visuospatial and motor problems could not be established. This suggests that there may be two kinds of problems, namely a visuo-perceptual and a motor problem. This conclusion may apply to girls with TS as well: there are indications that they have visuospatial problems (Bender et al., 1993; Money, 1993; Nijhuis - van der Sanden et al., 1998; Romans et al., 1998; Ross et al., 2000) and this study provides evidence for motor execution problems independent of visuospatial problems. Taken together it seems that elementary movement speed is a factor in DCD children too, as suggested already by Van Dellen \& Geuze (1988) and by the results of the real movement condition in the study of Maruff et al. (1999) and Wilson et al. (2001). It is plausible that motor execution problems influence the learning of motor skills (Geuze \& Van Dellen, 1990; Missiuna, 1994). Although there are some similarities between both groups, it should be noted that TS is a well-defined clinical syndrome whereas the DCD group may be very heterogeneous. 
In our view it could be argued that in TS girls the lowered elementary movement speed is due to internal biomechanical constraints. This can be illustrated by the "neuromotor noise model", which is based on neurocognitive and biomechanical properties of the motor system (Van Galen \& Schomaker, 1992; Van Gemmert \& Van Galen, 1997; 1998). The rationale of the latter model is that the speed of an aiming movement is the optimized outcome of a stochastic, oscillatory recruitment signal to the involved muscles. To assure acceptable end-point variability filtering of the neuromotor signal is necessary by either increasing movement speed (phasic filtering) or by an increment in limb stiffness (tonic filtering; Van Gemmert \& Van Galen, 1997; Van Galen \& Huygevoort, 2000). Increasing the stiffness of the limb by simultaneous contraction of agonist and antagonist muscles, results in a decrease in acceleration leading to increments of reaction time and movement time (Van Galen \& Schomaker, 1992; Van Gemmert \& Van Galen, 1997; 1998). The normal brain uses the gamma motor neuron system to modulate sensory information at its source in order to adapt to the requirements of movements. It can be argued, that deregulation of the gamma motor system plays a role in the motor problems in Turner syndrome and perhaps also in DCD. Especially, the independency of the motor delay from task difficulty and the consistency in deviation of the movement time of TS girls from that of controls points in the direction of an execution problem. Increased variability in timing in DCD children compared to controls (Geuze \& Kalverboer, 1987; Geuze \& Kalverboer, 1994; Henderson et al., 1992; Lundy-Ekman et al., 1991; Williams, Woollecott, \& Ivry, 1992) and increased disfluency (Geuze \& Van Dellen, 1990; Missiuna, 1994; Schoemaker et al., 1994) are compatible with this interpretation. Moreover, the latter authors suggested that a problem in proprioceptive feedback could be a causal factor and that the settings of the gamma motor system are a decisive factor.

The hypothesis that increased movement time in TS girls is the result of enhanced filtering in a noisy system also predicts differences between TS girls and controls in other motor tasks. In the MABC, TS girls needed significantly more MT than controls on an unimanual pegboard task and a bimanual task (see Table 1), both tasks requiring accuracy-speed trade-off. However, in the subtest "flower trail" (drawing test without speed requirements), no significant differences were found. Although girls with TS have a motor deficit, they are able to draw a line accurately between 
two narrow boundaries just as well as the control children when speed is not a critical factor and the task allows choosing their own strategy to optimize their performance. Van Galen and Schomaker (1992) suggested that controlling the amount of limb stiffness would give direct control over the endpoint variability of fast aiming tasks, and this is an important factor in the ball items in the MABC: When limb acceleration is too low, due to tonic filtering, precise timing in throwing and catching a ball is a serious problem. TS girls differed also significantly in the task where they had to balance as long as possible on the preferred and non- preferred leg: in such a task tonic limb stiffness regulation is an important constraint and again deregulation of the gamma motor system may be a causal factor. The additional problems in TS girls mentioned by Salbenblatt (1989) such as hypotonia, associated with diminished grip force, poor joint stability, gait abnormalities and difficulty with balance and diadochokinesis, may be explained too by problems in stiffness regulation.

Ross and colleagues (1996) found a significantly longer movement time in TS girls in pegboard tasks. However, they attributed the lower speed to differences in visuo-spatial information processing, and did not consider execution problems as a potential causal factor. Fitts and many other authors (see Schmidt, 1999) on the other hand, have shown that speed in such tasks follows Fitts' paradigm as well: MT is dependent on the movement amplitude and difference in diameter of pin and hole. In our opinion, visuo-spatial demands may be a factor in some pegboard tasks, but when the tasks are well known it is likely that elementary movement speed is perhaps a more decisive factor in these measurements.

Several authors concerning studies in TS used tapping tasks to test performance in simple motor tasks. According to Fitts' paradigm, repetitive tapping tasks are cyclical movements with an Index of Difficulty of zero, so movement time in such tasks equals intercept $a$. Only Bender et al. (1993) reported a significantly decreased tapping speed for women with TS. Other authors (Clark, Klonoff, \& Hayden, 1990; Romans et al., 1998; Ross, Feuillan et al., 1998; Ross, Kushner et al., 1996) found that speed of motor performance for the girls with TS and control groups was quite similar in various tapping tasks, seemingly in contradiction with our prediction. In tapping tasks, the cyclical and biomechanical nature of the movement allows for storage and rebound of movement energy (Smits - Engelsman, Van Galen, \& Duysens, 2002) and in such tasks fewer numbers of newly 
recruited motor units are needed to sustain the oscillation than in discrete tasks. It therefore seems plausible that in such tasks, rather than by the capacity to recruit muscle force, movement velocity is to a greater degree determined by the specific biomechanical set-up. We suggest that such tasks are not sensitive enough and that therefore differences between groups can hardly be found. We found support for our conclusion when looking more closely at the studies by Clark, Klonoff, and Hayden (1990), Romans and colleagues (1998), Ross and colleagues (1998), and Ross and colleagues (1996). It appeared that, analogous to our study, TS girls moved more slowly than their peers, but differences were too small to be significant.

An important factor in this discussion is that most of the tasks Ross and Romans et al. (1998) used in the studies in TS, have cognitive demands at the level of visuospatial perception and planning, whereas we tested movement execution while keeping visuospatial demands relatively constant. Based on the fact that was found that especially motor skills requiring visual processing were decreased, Ross $(1996 ; 1998 ; 2000)$ concluded that motor execution is not a determining factor. We do not agree with this conclusion, although we do not exclude the possibility that TS girls may also suffer from a visuospatial processing problem.

Ross, Kushner, and Roeltgen (1996) further suggested that estrogen plays a role in a decreased speed of performance. They found a lower speed in complex motor tasks for the TS group and observed that these differences increased in the older age group (age 7 to 9 vs. 10 to 12 years). Romans and colleagues (1998) described changes in motor skills occurring during the transition from adolescence to young adulthood. In their study, females with TS in early adulthood performed at comparable levels with normal female controls during the simple motor tasks, in contrast to the performance in the younger age group. Ross and colleagues (1998) suggested that these findings implied that the decreased speed capacity in girls with TS is temporary, manifesting itself in particular during puberty to disappear in young adulthood and that this phenomenon could be related to an estrogen effect. In line with this hypothesis Ross and colleagues (1998) found a positive estrogen treatment effect on non-verbal processing speed and speeded motor performance in 12-year-old girls with TS. They hypothesized that estrogen has a main effect on visual processing. We cannot support this suggestion because in our study, the TS girls were in 
the age range of 9 tol 2 years. Also, because only 4 of the 15 girls with TS we studied were treated with estrogen, we could not analyze whether there indeed was a relationship between treatment and MT, so we cannot rule out the possibility either. McEwen and Wooley (1994) suggested that estrogen functions transiently as a neuromodulator, permanently by altering synapse formation and structural/organizational remodeling or both. These process levels are relevant in both visuospatial processing and motor execution, and therefore estrogen could be a decisive factor, but in our view conclusions are preliminary and further investigation is needed.

Differences between groups in task experience could be another explanation for differences in intercept $a$. However, the aiming tasks we used were very simple and familiar for children at this age. We assume that the differences in movement time were not due to differences in learning. Moreover, the consistent nature of the prolonged movement times in divergent but simple motor tasks makes it very likely that the longer movement time is based on properties of the biological system specific for Turner's syndrome. Which neurological, neuromotor or perhaps even biophysical factors (e.g. limb viscosity) are involved is still unclear. Ross, Zinn, and Mc Cauley (2000) argued "that neurophysiological and neuroanatomical differences between Tumer females and controls are consistent with a sustained abnormality in the cerebral substrate, either as a primary factor and/or secondary to the endocrine and/or genetic influences" (pp.136). In our view the found lower elementary movement speed could be caused by such differences in the biological system. The exact location where such deviations affect motor performance needs further investigation; it is not unlikely that the gamma motor system plays a role. A possible hypothesis suggested by the more piecemeal production of movement trajectories in maze tasks by girls with TS (Smits - Engelsman, Nijhuis - van der Sanden \& Duysens, in press) is an impoverished motor and recruitment process due to a deteriorated signal-to-noise ratio in neuromotor initiation (Van Galen \& Schomaker, 1992). Current research with isometric force production tasks in our lab may provide further evidence for this hypothesis. 


\section{Conclusion}

The results of this study support the findings of previous studies that girls with TS have major problems in motor performance. We found that in graphic aiming tasks, compared to controls, girls with TS can move with the same accuracy but need a longer movement time for all task conditions. We conclude that this speed difference is based on an overall reduced elementary movement speed, due to problems in the movement execution rather than to problems in action planning.

\section{Acknowledgments}

The authors would like to thank both the children and their parents for their participation in this study. We are also grateful to Dr. B. Otten, endocrinologist, for contacting the children and Geert van den Bome, movement scientist, for her help with the data collection. We would also like to thank Joanne Postma and Hanneke Meulenbroek for their language corrections, Prof. R. Sengers for his comments and Peter de Jong for developing the OASIS software needed for this research and advising us in the OASIS software analysis. 


\section{Reference List}

American Psychiatric Association. (1994). Diagnostic and statistical manual of mental disorders (4th ed.). Washington, DC: Author.

Bender, B.G., Linden, M.G., \& Robinson, A. (1993). Neuropsychological impaiment in 42 adolescents with sex chromosome abnormalities. American Journal of Medicine and Genetics, 48, 169-173.

Clark, C., Klonoff, H., \& Hayden, M. (1990). Regional cerebral glucose metabolism in Turner Syndrome. Canadian Journal of Neurological Science, 17, 140-144.

Decety, J., \& Jeannerod, M. (1996). Fitss' law in mentally simulated movements.

Behavioral Brain Research, 72, 127-134.

De Jong, W.P., Hulstijn, W., Kosterman, B.J.M., \& Smits - Engelsman, B.C.M. (1996). OASIS Software and its application in experimental handwriting research. In: Simner, M.L., Leedham, C.G., \& Thomassen, A.J.W.M. (Eds). Handwriting and Drawing Research: Basic and Applied Issues (pp. 429-440). Amsterdam: IOS.

Downey, J., Ehrhardt, A.A., Gruen, R., Bell, J.J., \& Morishima, A. (1989). Psychopathology and social functioning in women with Turner's Syndrome. Journal of Nervous Mental Disease, 177, 91-201.

Downey, J., Elkin, E.J., Ehrhardt, A.A., Meyer-Bahlburg, H.F.L., Bell, J.J., \& Morishima A. (1991). Cognitive ability and everyday functioning in women with Tumer Syndrome. Journal of Learning Disabilities, 24, 32-39.

Fitts, P.M. (1954). The information capacity of the human motor system in controlling the amplitude of movement. Journal of Experimental Psychology, 47, 381-391.

Fitts, P.M., \& Posner M.I.(1967). Human Performance. Belmont, California: Brooks/Cole Publishing Company.

Garron, D.C. (1977). Intelligence among persons with Turner's Syndrome. Journal of Behavior Genetics, 7, 105-127.

Geuze, R.H., \& Kalverboer, A.F. (1987). Inconsistency and adaptation in timing of clumsy children. Joumal of Human Movement Studies, 13, 421-32.

Geuze, R.H., \& Kalverboer, A.F. (1994). Tapping a rhythm: A problem of timing for children who are clumsy and dyslexic. Adapted physical Activities Quarterly 11, 203213.

Geuze, R.H., \& Van Dellen, T. (1990). Auditory precue processing during a movement sequence in clumsy children. Journal of Human Movement Studies, 19, 11-24.

Hay, L. (1981). The effect of amplitudo and accuracy requirements on movement time in children. Journal of Motor Behavior, 13, 177-186. 
Henderson, S E , \& Hall, D (1982) Concomıtants of clumsıness in young chıldren

Developmental Medictne and Child Neurology, 24, 448-460

Henderson, S E , May, D S , \& Umney, M (1989) An exploratory study of goal-settıng

behaviour self-concept and locus of control in children with movement difficulties

European Journal of Special Needs Education, 4, 1-14

Henderson, L , Rose, P , \& Henderson S E (1992) Improving handwritıng through

kınaesthetic sensitıvity practice Australian Occupatıonal Therapy Journal 39, 23-27

Henderson, S E , \& Sudgen, D A (1992) Movement Assessment Battery for Children

Manual London Psychological Corporation

Jeannerod, M , Arbıb, M A , Rizzolattı, G , \& Sakata, H (1995) Grasping objects The

cortical mechanisms of visuomotor transformation Trends in Neuroscience, 18, 314320

Lam, J , \& Henderson S E (1987). Some applications of the Henderson revisıon of the Test of Motor Imparment. Britısh Joumal of Experimental Psychology, 57, 141-149

Langolf, G D , Chaffin, D B , \& Foulke, J A (1976) An investıgation of Fitts' law using a wide range of movements amplitudes Joumal of Motor Behavior, 8, 113-128

Laszlo, J I , \& Bairstow, P J (1985) Perceptual-motor Behavior Developmental Assessment and Therapy New York Praeger Publıshers

Latash, M L , \& Anson, J G (1996) What are "normal movements" in atypical populations? Behavioral and Brain Science, 19, 55-106

Lundy-Ekman, L , Ivry, R , Keele, S , \& Woolacott, M (1991) Tımıng and force control deficits in clumsy children Journal of cognitıve Neuroscience, 3, 367-376

MacKenzie, I S (1992) Fitts' Law as a research and design tool in human-computer interaction Human-Computer Interaction, 7, 91-139

Maruff, P , Wilson, P , Trebılcock, M \& \& Currie J (1999) Abnormalıties of imagined motor sequences in chıldren with developmental coordinatıon disorder Neuropsychologıa 37, 1317-1324

Mathısen, B , Reılly, S , \& Skuse, D (1992) Oral motor dysfunctıon and feedıng disorders of infants with Tumer's Syndrome Developmental Medicine and Child Neurology, 34, 141-149

McEwen, B S , \& Wooley, CS (1994) Estradıl and progesterone regulate neuronal structure and synaptıc connectıvity in adult as well as developing brain Experımental Gerontology, 29, 431-436

Missıuna, C (1994) Motor skıll acquisition in children with Developmental Coordination Disorder Adapted Physical Activities Quarterly 11, 214-235

Money, J (1973) Tumer's Syndrome and paretal lobe functions Cortex, 9, 385-393

Money, J (1993) Specific neuro-cognitıve impairments associated with Turner's (45 XO) and Klinefelter (47 XXY) Syndromes A review Socıal Bıology, 40, 147-151 
Nıjhuis - van der Sanden, M W G , Dijkstra-Hekkınk, J G B , Brugman-Boezeman, A T M , Eling, P A T M , Thoonen, G, Otten, B, et al (1998) Het Turner Syndroom Een literatuurstudie naar het belang van neuropsychologisch en motonsch onderzoek (The Tumer Syndrome A literature review of the importance of neuropsychological and motor studies) Tydschrift voor Orthopedagogiek, Kinderpsychologie en

Kınderpsychiatrie, 23, 11-18

Nijhuis - van der Sanden, M W G , Smits - Engelsman, B C M , \& Elıng, P A T M (2000) Motor performance in girls with Tumer Syndrome Developmental Medicine and Child Neurology, 42, 685-690

Pennington, B F , Heaton, R K , Karzmark, P , Pendleton, M G , Lehman, R , \& Shucard, D W (1985) The neuropsychological phenotype in Turner's Syndrome Cortex, 21 , 391-404

Romans, S M , Stefanatos, G , Roeltgen, D P , Kushner, H , \& Ross, J L (1998) Transition to young adulthood in Ullnch-Tumer Syndrome Neurodevelopmental changes American Journal of Medical Genetics, 79, 140-147

Rosenbaum, D A , Engelbrecht, S E , Bushe, M M , \& Loukopoulos L D (1993) A model for reaching control Acta Psychologica, 82, 237-250

Rosenfeld, R G, \& Grumbach, M M (1990) Turner Syndrome Basel Marcel Dekker Inc Ross, J L , Feuillan, P , Kushner, H , \& Cutler, G B , Jr (1998) Effects of estrogen on nonverbal processing speed and motor function in girls with Turner's Syndrome Journal of Clinical Endocrinology and Metabolism, 82, 1814-1817

Ross, J L , Kushner, H , \& Roeltgen, D P (1996) Developmental changes in motor function in girls with Tumer Syndrome Pediatric Neurology, 15, 317-322

Ross, J L , Zinn, A , \& Mc Cauley, E (2000) Neurodevelopmental and psychosocial aspects of Tumer Syndrome Mental Retardation and Developmental Disabilttes Research Reviews, 6, 135-141

Rovet, J (1993) The psycho-educational charactenstics of children with Turner's Syndrome Journal of Learning Disabilities, 26, 333-341

Rovet, J, Szekely, C , \& Hockenberry, M N (1994) Specific anthmetıc calculation deficits in children with Tumer's Syndrome Journal of Clinical and Experimental Neuropsychology, 16, 820-839

Salbenblatt, J A , Meyers, D C , Bender, B G , Linden, M G , \& Robinson, A (1989) Gross and fine motor development in 45,X and 47,XXX girls Pediatrics, 84, 678-682

Schellekens, J M , Kalverboer, A F , \& Scholten, C A (1984) The Micro-structure of tapping movements in children Joumal of Motor Behavıor, 16, 20-39

Schmidt, R A (1975) A schema theory of discrete motor skıll leaming Psychological Review, 82, 225-260 
Schmudt, R A , \& Lee, T D (1999) Prnciples of simple movement In R A Schmidt \& T D Lee (Eds), Motor control and learning A behavioral emphasts $\left(3^{\text {rd }}\right.$ ed, chap 7 , pp 172-180) Champargn IL Human Kunetics

Schoemaker, M M , Hilkema, M G J , \& Kalverboer, A F (1994) Physıotherapy for clumsy children an evaluation study Developmental Medicine and Child Neurology, $36,143-155$

Smits - Engelsman, B C M (1998) Movement ABC, Nederlandse Handlezding [Dutch manual Movement ABC] Lisse, The Netherlands Swets en Zeitlinger

Smuts - Engelsman, B C M , Nıhuıs - van der Sanden, M W G , \& Duysens, J (in press) An exploratory Study of the kinematics of girls with Turner Syndrome in a visuo-motor task Infant and Child Development

Smuts - Engelsman, B C M , Van Galen, G P , \& Duysens, J (2002) The breakdown of Fitts' law in rapid, reciprocal aiming movements Experimental Brain Research, 145, 222-230

Stott, D H , Moyes, F A , \& Henderson, S E (1972) The Test of Motor Impairment San Antonio TX The Psychological Corporation

Temple, C M \& \& Carney, R A (1993) Intellectual functioning of children with Tumer Syndrome A comparison of behavioral phenotypes Developmental Medicine and Child Neurology, 35, 691-698

Temple, C M , \& Camey, R A (1995) Patters of spatial functioning in Tumer's Syndrome Cortex, 31, 109-118

Van Dellen, T \& \& Kalverboer, A F (1986) De controle van doelgenchte handbewegingen by kınderen Een kınaematısche analyse [The Control of Goal-Directed Hand Movements in Chuldren A Kunematic Analysıs] Nederlands Tidschrift voor Psychologie, 41, 3-13

Van der Meulen, J H P , Denier van der Gon, J J , Gielen, C C A M , Gooskens, R H J , \& Willemse J (1991a) Visuomotor performance of normal and clumsy children I Fast goal directed arm movements with and without visual feedback Developmental Medicine and Child Neurology 33, 40-54

Van der Meulen, J H P , Denier van der Gon, J J , Gielen, C C A M , Gooskens, R H J , \& Willemse J (1991b) Visuomotor performance of normal and clumsy chıldren II Arm trackıng movements with and without visual feedback Developmental Medicine and Child Neurology 33, 118-129

Van der Steene, G, Haasen, P P van, Bruyn, E E J de, Coetsier, P, Pıll, Y J , Poortınga, Y H , Spelberg, H C , Sunıssen, J (1986) WISC-RN Wechsler Intelligence Scale for Children-Revised, Nederlandstalige utgave [Dutch Manual] Lisse, the Netherlands Swets \& Zeitlınger 
Van Galen, G.P., \& Schomaker, L.R.B. (1992). Fitts' Law as the outcome of a dynamic noise filtering model of motor control. Human Movement Science, 11, 11-22.

Van Galen, G.P., \& Van Huygevoort, M. (2000). Error, stress and the role of neuromotor noise in space oriented behavior. Biological Psychology, 51, 151-171.

Van Gemmert, A.W.A., \& Van Galen, G.P. (1997). Stress, neuromotor noise and human performance: A theoretical perspective. Journal of Experımental Psychology: Human Perception and Performance, 23, 1299-1313.

Van Gemmert, A.W.A., \& Van Galen, G.P. (1998). Auditory stress effects on preparation and execution of graphical aiming: A test of neuromotor noise concept. Acta Psychologica, 98, 81-101.

Waber, D.P. (1979). Neuropsychological aspects of Turner's Syndrome. Developmental Medicine and Child Neurology, 21, 58-70.

Williams, H.G., Woollacott, M.H. \& Ivry, R. (1992). Timing and motor control in clumsy children. Journal of Motor Behavior, 2, 165-172.

Wilson, P.H., Maruff, P., Ives, S., \& Currie J. (2001). Abnormalities of motor and praxis imagery in children with DCD. Human Movement Science 20, 135-159.

Wilson, P.H., \& McKenzie B.E. (1998) Information processing deficits associated with Developmental Coordination Disorder: A meta-analysis of research findings. Journal of Child Psychology and Psychiatry and Allied Health Disciplines, 39, 829-840

Wolpert, D.M., Ghahramani, Z., \& Jordan, M.I. (1995). An internal model for sensorimotor integration. Science, 269, 1880-1882. 


\section{Decreased movement speed in girls with Turner Syndrome: A problem in motor planning or muscle initiation?}

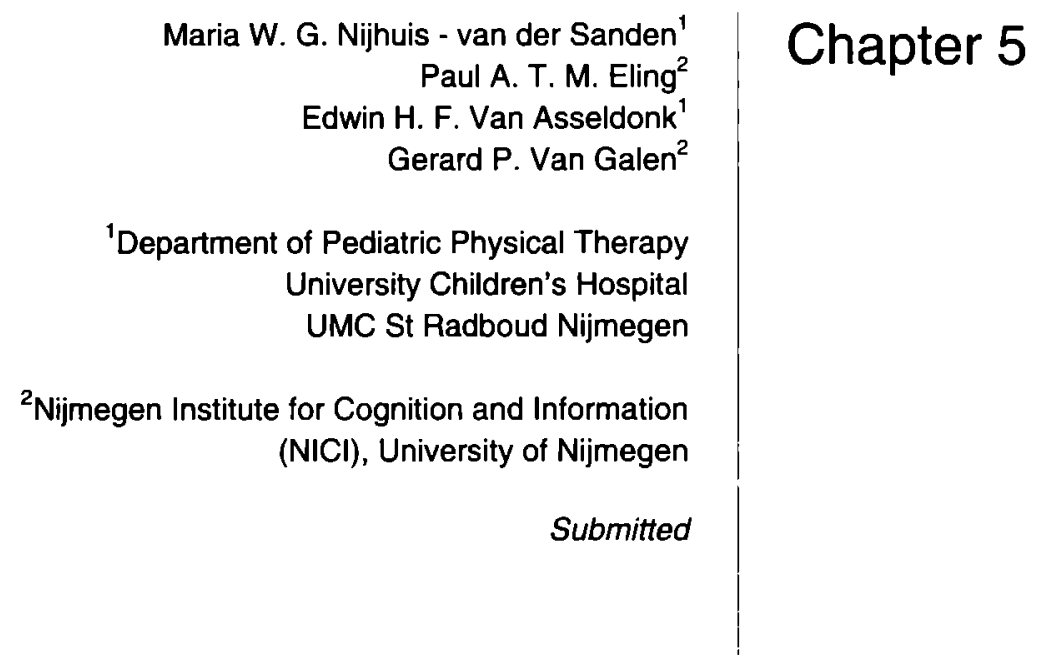




\section{Abstract}

In three experiments with electronically monitored graphical tasks we examined whether the decreased movement speed observed in girls with Tumer Syndrome (TS) is caused either by a diminished motor planning capacity or by more peripheral motor execution problems. Fourteen girls with TS (mean age 11.6 years) and 14 matched controls (mean age 11.6 years) participated in the experiments. In each of the experiments taskloading conditions addressed the three specific levels of the psychomotor model of Van Galen (1991): The muscle initiation level, the size control level and the motor programming level. Kinematic analyses confirmed that the girls with TS were as accurate as their normal peers but that overall movement speed was low. Especially in the first experiment, in which fast tuning of muscle initiation was the loading factor, girls with TS experienced velocity problems. Loading on size control and motor programming had no additional effects on velocity. Overall, girls with TS used more piecemeal movements and we conclude that the present results seem to confirm problems at the muscle initiation level, and in particular reflect difficulties in agonist-antagonist co-articulation. 


\section{Introduction}

Turner Syndrome (TS) is a genetic disorder resulting from the loss of the entire or a part of the second $\mathrm{X}$ chromosome. TS is characterized by short stature, gonadal dysgenesis and decreased secondary sexual development (Rosenfeld \& Grumbach, 1990; Rovet, 1993), and by a particular neurocognitive profile of normal verbal skills and impaired visuospatial and/or visuoperceptual abilities (Ross, Zinn, \& Mc Cauley, 2000). Moreover, girls with TS have difficulties in motor functioning (Salbenblatt, Meyers, Bender, Linden, \& Robinson, 1989; Nijhuis - Van der Sanden, Smits - Engelsman, \& Eling, 2000; Nijhuis - Van der Sanden, Smits Engelsman, Eling, Nijhuis, \& Van Galen, in press). Although poor visuospatial processing abilities (e.g. Ross et al., 2000) are amongst the causal factors for subnormal motor behavior, Nijhuis -Van der Sanden et al. (2000) found no significant correlation between intelligence scores and motor performance scores and thus concluded that motor problems in TS could have a different etiology.

Only a few studies examined motor problems in girls with TS, and little attention has been directed at the execution level of motor performance. Ross, Feuillan, Kushner, and Cutler (1998), Ross, Kushner, and Roeltgen (1996), Ross et al. (2000), and Romans, Stefanatos, Roeltgen, Kushner, and Ross (1998) emphasized the cognitive demands at the level of visuospatial perception and planning in motor tasks. Ross et al. (1996) found a decreased velocity in girls with TS in pegboard tasks. They attributed the lower speed to differences in visuospatial information processing. Using tapping tasks, only Bender, Linden, and Robinson (1993) reported a significantly decreased tapping speed for women with TS. However, Nijhuis - Van der Sanden et al. (in press) argued that in other studies (Clark, Klonoff, \& Hayden, 1990; Romans et al., 1998; Ross et al., 1998; Ross et al., 1996) girls with TS seem to have a decreased tapping speed as well. They proposed that such tapping tasks might not be sensitive enough to detect significant differences in movement time, because in such tasks, the cyclical and biomechanical nature of the movement allows for storage and rebound of movement energy (Smits - Engelsman, Van Galen, \& Duysens, in press) and therefore fewer numbers of newly recruited motor units are needed to sustain the oscillation. 
Using graphical aiming tasks, Nijhuis - Van der Sanden et al. (in press) demonstrated that girls with TS moved with the same accuracy as their normal peers but movement speed was significantly lower in both the discrete and serial movement condition, independent of visuospatial task demands and independent of joints used. While most studies on Turner Syndrome (for a review see Ross et al., 2000) focused on perceptuomotor processes and suggested that motor planning problems may be an important causal factor, Nijhuis - Van der Sanden et al. (in press) suggested that in girls with TS motor execution is the main problem, due to biophysical and/ or neurophysiological properties of their motor execution system.

A number of theories share the assumption that motor performance can be modeled with a series of hierarchically organized processing levels representing the transformation of information from intention to action (Schmidt, 1975; Jeannerod, Arbib, Rizzolatti, \& Sakata, 1995; Wolpert, Ghahramani, \& Jordan, 1995; Rosenbaum, Engelbrecht, Bushe, \& Loukopoulos, 1993). Van Galen (1991) described such a hierarchical architecture of processing modules for handwriting. This model can be used to analyze the production of simple line drawings. Focusing on the motor components of this model, Van Galen distinguishes three different modules: A module for the selection and programming of graphic forms, a module for size control, and finally a module for muscular initiation. Familiar graphic forms, such as lines, triangles, squares, circles or letters, are in this model represented as preprogrammed schemes or motor programs, stored in memory and responsible for the production of a pattern of action. Typically, the order of events, the temporal phasing, and the relative force are structured in such motor programs as the fixed invariant features (Bernstein, 1947; Bruce, 1994; Keele, Cohen, \& Ivry, 1990; Lashley, 1951; Schmidt \& Lee, 1999). The second module in Van Galen's model is responsible for size control, needed to produce letters or figures of a size adjusted to the environmental task constraints. At this level a limited number of parameters are applied to the chosen motor program: An overall duration parameter ( Pew 1974; Summers, 1975; Shapiro, 1977) and an overall force parameter (Pew, 1974; Van Galen, 1991). The muscular initiation module in Van Galen's model performs the function of activation of the most appropriate motor units. At this level co-activation of limb segments will have an effect on the stiffness of the limb, which in turn will change the mechanical responsiveness of the limb to its own driving forces 
and this will prolong the movement duration. The basic assumption in the model of Van Galen and De Jong (1995) and Van Galen and Schomaker (1992) is that in ballistic aiming, accuracy is not realized by iterative corrections towards a target, but stiffness regulation (e.g. a higher degree of muscular co-contraction) is used to reduce endpoint variability. Speedaccuracy trade-off is determined by the fine-tuning of the motor initiation process and thus by neurophysiological and biomechanical constraints.

As stated above, Nijhuis - Van der Sanden et al. (in press) suggested that girls with TS suffer from problems at the execution level. However, in this latter study only single line drawing tasks were used and therefore the load on the size control level and the motor programming level was rather low. To answer the question whether in girls with TS the deficit is localized on motor unit initiation level, or size control level or motor programming level (Van Galen, 1991), we used in the present study graphical tasks in which task loading conditions addressed these three levels.

In three experiments the participants were asked to draw prescribed figures as fast and as accurately as possible. Under such task demands the system must optimize the motor program and adapt movement speed to the required endpoint accuracy. To increase the likelihood that all movements would primarily be controlled by internal motor programming rather than by visual feedback, in all three experiments a non-inking pen was used: participants could not see their own drawing results during task execution.

In the first experiment task loading was specifically directed at the muscular initiation level. Participants had to draw an apex, consisting of only two line segments (see Figure 1). Accuracy was manipulated by varying target width. We assumed that variation in target width does require only optimized speed-accuracy trade-off through fine-tuning of motor initiation. Moreover, to examine group differences in preprogramming and ongoing control modes of the task, the girls executed the tasks in a discrete, externally paced condition and a self-paced, serial concatenation condition (Schmidt, 1999). Going back and forth, thus alternating finger- and wrist movements, the children had to draw the apex by passing through a target placed above and at the same distance from two targets at the baseline. In the discrete condition, each time a single apex was to be produced following an auditory signal, whereas in the self-paced condition the children continuously concatenated the same movement 
pattern back and forth. We assumed that the discrete condition would specifically elicit preprogramming of the complete figure and the presetting of an adequate overall stiffness regime. The self-paced serial condition, on the other hand, was thought to lend itself well for a distribution of programming and current control during the full trajectory. In this latter task condition the preprogrammed parameters function as reference value for the actual position of the limb and the actual sensory outcome (Schmidt, 1975; Jeannerod, et al., 1995; Wolpert, et al., 1995; Rosenbaum et al., 1993) and when error detection occurs, a corrective movement is initiated (Meyer, Smith, Kornblum, Abrams, \& Wright, 1990).

In the second experiment serial patterns of three apexes (see Figure 1) were presented. By varying the size of the apexes (three large vs. three small, or changing the size of the middle apex only), task load increased at the size control level. In this condition the children had to adjust the size of the figures to the horizontal reference lines by adapting the overall duration or force parameter (Pew, 1974a; Hollerbach, 1978; Van Galen, 1991).

In the third experiment shape was manipulated while size was held constant. We presented varying patterns each consisting of three figures: Three apexes, three arcs or a combination in which the middle figure deviated from the first and last element (see Figure 1). It was assumed that alternative motor programs have to be activated when graphic forms are changing and thus the motor programming stage would be challenged in particular in this experiment.

The three experimental blocks were presented randomly on the same day to each of the children. Each girl of the TS group was matched to one control subject, both receiving the same order of experimental conditions and tasks.

Based on the study of Nijhuis - Van der Sanden et al. (in press), we predicted that girls with TS would experience difficulties at the muscular initiation level. This means that movement time and dwell time were expected to be increased in all experimental conditions, but no interaction with size control or programming load was expected. If, on the other hand, size control is the crucial problem in TS, variation in size (experiment 2) should show greater disturbances in the accuracy and/or movement and dwell times of the girls with TS. Finally, if the motor problems are related to the programming stage, this will be expressed by more errors in figure 
reproduction and more variable velocity profiles as compared to the controls, especially in the third experiment in which task load on the programming level is highest (see Figure 1).

Figure 1: The copying patterns used in experiments 1,2 and 3 in all experimental conditions.

Experiment 1: Target width manipulation

\section{Discrete and \\ Serial}

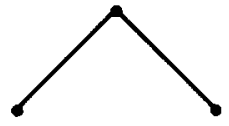

$0,22 \mathrm{~cm}$

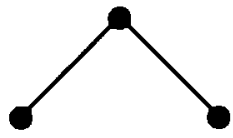

$0,44 \mathrm{~cm}$

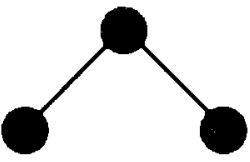

$0,88 \mathrm{~cm}$

Experiment 2

Experiment 3

Regular
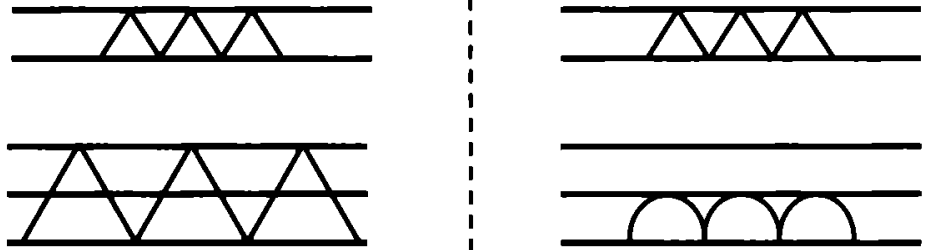

Irregular
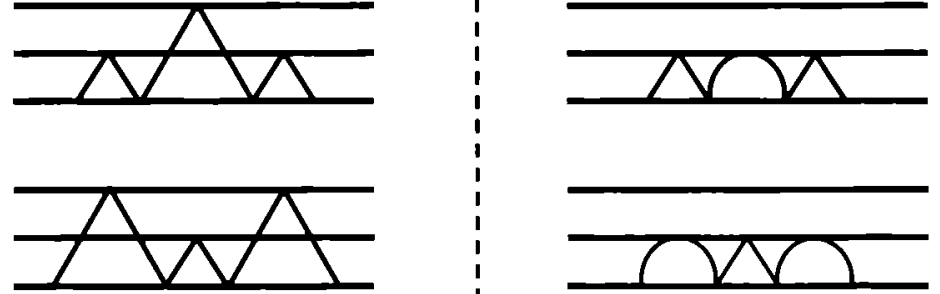


\section{Experiment 1: Copying one figure}

In this experiment an apex was used to test whether in girls with TS an increase in precision requirements would lead to a greater drop in average speed. We assumed that the two line segments in this experiment would be preprogrammed as a single action. As mentioned above, three different target widths were presented in an externally paced discrete and a selfpaced serial task condition, respectively.

\section{Method}

\section{Participants}

Twenty girls with TS (age 9 - 12 years) were approached through a national inquiry initiated by the University Medical Center St Radboud, Nijmegen, The Netherlands. Of a total of 20 respondents 4 girls and their parents refused participation. One girl with TS was excluded from the study because of diplegia spastica. None of the other girls had physical abnormalities that could influence motor performance and thus 15 girls with TS were enrolled in the study. Fifteen female control subjects were recruited from an elementary and a secondary school, matched individually to girls with TS on age, grade and school performance level as reported by teachers. All girls received their education at regular schools. Informed consent was obtained from all children and their parents. However, one of the controls withdrew her consent after data sampling and subsequently the data of the matching girl with TS were excluded from the analyses. Mean age of the 14 participating girls with TS was 11.6 years (range: 9.5 yrs $13.0 \mathrm{yrs}$ ); mean age of the control girls was 11.6 years (range $=9.1 \mathrm{yrs}$ $13.0 \mathrm{yrs}$ ). All parents filled in two questionnaires concerning their socioeconomic status and their daughter's general health. No significant differences in the socio-economic status and general health between groups were found. Only 3 girls with TS started estrogen therapy and 12 girls with TS used growth hormones. None of the girls with TS or controls reported any problems with vision. 


\section{Procedure}

Two trained investigators tested all girls with TS and controls. The children were seated in their usual writing posture at a desk of normal height, holding a pen with their habitual pen grip. The tasks were executed on normal paper (A4 format, landscape orientation) that was placed on a WACOM $1218 \mathrm{RE}$ digitizer. The girls were allowed to place the sheet of paper in a position they felt most comfortable with. On each sheet 3 target circles (A, B and C, see Figure 1) were depicted at the corners of a virtual triangle. Targets $\mathrm{A}$ and $\mathrm{C}$ were placed $2.5 \mathrm{~cm}$ from $\mathrm{B}$, the top of the triangle, forming a 90-degree angle. The children were instructed to draw an apex, starting at $\mathrm{A}$, and moving through $\mathrm{B}$ to $\mathrm{C}$. An inkless, electronic pen of normal size was used. The girls were instructed to place their lower arm in a comfortable position upon the writing tablet so that during each experimental condition they could produce wrist and finger movements easily without having to make forearm movements. The tasks were explained orally and then demonstrated. Subsequently, all children were allowed to practice the task until they indicated that they felt comfortable with it.

Two task modes were presented: An auditory paced discrete task and a selfpaced serial task. In the discrete task, the participants positioned the pen in the lower left circle (A in Figure 1) and after the presentation of an auditory start signal moved as quickly as possible towards and into the middle target circle (B), to proceed immediately towards and into the right lower circle (C). After the next auditory signal, they again had to draw two connecting lines but now in reverse order (C-B-A). The auditory signal was presented at random intervals, varying from $0.5-2 \mathrm{~s}$. In total 8 trials were presented in each condition. 
In the serial task, the children were instructed to move the pen in a continuous, repetitive forth and back movement between the targets (A-B$\mathrm{C}$ and $\mathrm{C}-\mathrm{B}-\mathrm{A}$ ) as fast as possible during a period of 30 seconds with each period starting and ending with an auditory signal.

Three target size conditions were presented with diameters of $0.22 \mathrm{~cm}$ $($ small $=\mathrm{S}), 0.44 \mathrm{~cm}$ (middle $=\mathrm{M}$ ) and $0.88 \mathrm{~cm}$ (large $=\mathrm{L})$, respectively, while the distance between the centers of the targets (A and B and C) remained constant at $2.5 \mathrm{~cm}$.

After practice trials, uneven numbered pairs of participants started with the discrete task condition, even numbered pairs with the serial task condition to counterbalance order effects. Within both the discrete and the serial task, the three experimental target width conditions were presented in a random order to the matched pairs.

\section{Data Analysis}

Kinematic variables were measured using a WACOM 1218 RE digitizer, an electronic pen, a PC, and OASIS software (De Jong, Hulstijn, Kosterman, \& Smits - Engelsman, 1996). During the sampling period, the pen movements were recorded at a rate of $170 \mathrm{~Hz}$ with a spatial accuracy of 0.1 $\mathrm{mm}$. For each trial the data record consisted of two variables as a function of time, i.e., the $\mathrm{X}$-coordinate and the $\mathrm{Y}$-coordinate of the pen position. The data were further processed in Matlab (The Mathworks, inc., Natick, United States of America). All recorded movement trajectories were subdivided into 4 segments (A-B, B-C, C-B and B-A, see Figure 1). The end of each segment was defined as the local extreme value in the $\mathrm{Y}$ direction. The start of the next segment was the moment at which the pen velocity exceeded $0.15 \mathrm{~cm} . \mathrm{s}^{-1}$. The segment of the movement pattern produced between the end of the first upgoing part of the apex and the start of the second, downgoing part of the apex is called the "between segment". Two trained observers monitored task execution and by visual inspection determined whether a subject made a faulty trajectory or lifted the pen from the paper during a pen stroke or "between segment"; such segments were subsequently excluded from analysis. Less than $0.5 \%$ of the segments were removed and no systematic relationship was apparent between the removed segments and task conditions or experimental groups. 
To analyze accuracy, Hit Rate $(H R)$, defined as the percentage of hits relative to the total number of aiming movements, was calculated. For each segment (A-B, B-C, C-B, B-A) mean pen velocity was calculated. Pen Velocity ( $P V$; covered distance divided by time elapsed between the start and end point of a segment) was calculated and averaged over the trial. Further, the deceleration fraction ( $D F$; duration of the deceleration phase divided by time elapsed between the start and end point of a segment) was calculated and averaged over each trial. Dwell Time (DT; duration of the between segment) was calculated and averaged per trial. DT was considered as the starting time of the oncoming segment.

The four segments were grouped as follows: The two upward strokes (from the starting point to the middle target; A-B forwards and C-B backwards) were regarded as the first part of the movement, while the two downward strokes (from the middle target to the end point; B-C forwards and B-A backwards) were taken as the second part of the movement. Of all previously described variables, averages were calculated for both the first and second part of the movement. Data were analyzed with a $2 \times 2 \times 3 \times 2$ (Group $\mathrm{x}$ Task $\mathrm{x}$ Target Width $\mathrm{x}$ First- Second segment) factorial ANOVA with Repeated Measures on all factors.

In all three experiments the factor Group is treated as a within factor because each TS girl was matched to one control, and a significance level of $\alpha=.05$ was used for all statistical tests. The statistics were performed using SPSS software (version 10.0). 


\section{Results}

\section{Accuracy: Hit Rate (HR)}

The means and standard deviations of all variables are presented in Table 1. Overall, HR is high in girls with TS $(M=76 \%, S E=2)$ as well as in controls $(M=74 \%, S E=2), F(1,13)=.26, p=.62$. As expected, HR increases with target width, $F(2,12)=307.30, p=.00$ (respectively S- M $\mathrm{L}: M=47 \%-84 \%-94 \%)$. Moreover, $\mathrm{HR}$ is higher in the discrete task condition $(M=79 \%, S E=1), F(1,13)=30.70, p=.00$ than in serial condition $(M=71 \%, S E=2)$. In the discrete condition HR on the end target is somewhat higher than on the middle target, in contrast to the serial condition where no differences in HR between targets were found (interaction effect Task by First-Second, $F(1,13)=6.02, p=.03$ ). These differences between the middle and end target get smaller with increasing target width (significant interaction effect Target Width by First-Second, $F(2,12)=9.35, p=.00$ ). Although, in general, the two groups do not differ in $\mathrm{HR}$, the results point to a significantly different strategy in girls with TS and controls (interaction effect Group by First-Last), $F(1,13)=10.43, p=$ .01 . In controls HR is lower in the middle target $(M=69 \%, S E=3)$, than in the end target $(M=79 \%, S E=2)$. Apparently, in controls the whole figure is preprogrammed in one action from the starting target through the middle target into the end target. In contrast, in girls with TS HR in the middle target $(M=77 \%, S E=3)$ is nearly the same as in the end target $(M=74 \%$, $S E=3$ ) pointing to a more piecemeal movement strategy in girls with TS. Apparently they first move into the middle and then into the end target. 
Table 1: Results of Experiment 1 in girls with TS (T) and Controls (C): Means and Standard Deviations of Hit Rate, Pen Velocity, Deceleration Fraction, and Dwell Time for the First and Second Movement Segments in All Experimental Conditions.

\begin{tabular}{|c|c|c|c|c|c|c|c|}
\hline \multirow[b]{3}{*}{ Variable } & & \multicolumn{6}{|c|}{ Discrete condition } \\
\hline & & \multicolumn{3}{|c|}{ First } & \multicolumn{3}{|c|}{ Second } \\
\hline & & $0.22 \mathrm{~cm}$ & $0.44 \mathrm{~cm}$ & $0.88 \mathrm{~cm}$ & $0.22 \mathrm{~cm}$ & $0.44 \mathrm{~cm}$ & $0.88 \mathrm{~cm}$ \\
\hline \multirow[t]{2}{*}{ Hit Rate } & $\mathrm{T}$ & $0.55 \pm 0.22$ & $0.84 \pm 0.17$ & $0.95 \pm 0.08$ & $0.60 \pm 0.20$ & $0.90 \pm 0.12$ & $0.95 \pm 0.07$ \\
\hline & $\mathrm{C}$ & $0.38 \pm 0.26$ & $0.81 \pm 0.21$ & $0.96 \pm 0.05$ & $0.61 \pm 0.17$ & $0.92 \pm 0.10$ & $0.99 \pm 0.03$ \\
\hline \multirow[t]{2}{*}{ Pen Velocity $(\mathrm{cm} / \mathrm{s})$} & $\mathrm{T}$ & $4.05 \pm 1.04$ & $4.81 \pm 1.11$ & $6.24 \pm 1.93$ & $3.95 \pm 0.75$ & $4.73 \pm 1.14$ & $5.95 \pm 1.50$ \\
\hline & $\mathrm{C}$ & $4.90 \pm 1.66$ & $6.11 \pm 1.68$ & $7.57 \pm 1.99$ & $4.21 \pm 1.23$ & $5.21 \pm 1.09$ & $6.26 \pm 1.57$ \\
\hline Deceleration & $\mathbf{T}$ & $0.54 \pm 0.03$ & $0.55 \pm 0.04$ & $0.54 \pm 0.04$ & $0.56 \pm 0.03$ & $0.58 \pm 0.03$ & $0.57 \pm 0.04$ \\
\hline Fraction (\%) & C & $0.54 \pm 0.04$ & $0.55 \pm 0.05$ & $0.53 \pm 0.05$ & $0.56 \pm 0.05$ & $0.59 \pm 0.04$ & $0.58 \pm 0.04$ \\
\hline \multirow[t]{3}{*}{ Dwell Time (s) } & $\mathrm{T}$ & & & & $0.25 \pm 0.15$ & $0.14 \pm 0.08$ & $0.12 \pm 0.12$ \\
\hline & $\mathrm{C}$ & & & & $0.16 \pm 0.10$ & $0.12 \pm 0.06$ & $0.07 \pm 0.04$ \\
\hline & & \multicolumn{6}{|c|}{ Serial Condition } \\
\hline \multirow[t]{2}{*}{ Hit Rate } & $\mathbf{T}$ & $0.49 \pm 0.19$ & $0.85 \pm 0.18$ & $0.93 \pm 0.07$ & $0.39 \pm 0.21$ & $0.77 \pm 0.25$ & $0.86 \pm 0.19$ \\
\hline & $\mathrm{C}$ & $0.27 \pm 0.28$ & $0.76 \pm 0.16$ & $0.96 \pm 0.05$ & $0.46 \pm 0.14$ & $0.83 \pm 0.16$ & $0.92 \pm 0.13$ \\
\hline \multirow[t]{2}{*}{ Pen Velocity $(\mathrm{cm} / \mathrm{s})$} & $\mathrm{T}$ & $5.09 \pm 1.16$ & $6.05 \pm 1.39$ & $8.63 \pm 2.52$ & $4.82 \pm 0.93$ & $5.73 \pm 1.27$ & $7.79 \pm 1.75$ \\
\hline & $\mathrm{C}$ & $5.95 \pm 1.26$ & $7.58 \pm 1.87$ & $9.69 \pm 2.94$ & $5.28 \pm 1.07$ & $6.31 \pm 1.28$ & $8.25 \pm 2.26$ \\
\hline Deceleration & $\mathrm{T}$ & $0.58 \pm 0.03$ & $0.58 \pm 0.03$ & $0.56 \pm 0.03$ & $0.58 \pm 0.04$ & $0.56 \pm 0.03$ & $0.55 \pm 0.06$ \\
\hline Fraction (\%) & $\mathrm{C}$ & $0.59 \pm 0.03$ & $0.58 \pm 0.05$ & $0.55 \pm 0.04$ & $0.57 \pm 0.04$ & $0.57 \pm 0.04$ & $0.54 \pm 0.02$ \\
\hline \multirow[t]{2}{*}{ Dwell Time (s) } & $\mathrm{T}$ & $0.17 \pm 0.15$ & $0.12 \pm 0.09$ & $0.09 \pm 0.08$ & $0.16 \pm 0.10$ & $0.12 \pm 0.09$ & $0.08 \pm 0.07$ \\
\hline & C & $0.10 \pm 0.05$ & $0.07 \pm 0.04$ & $0.07 \pm 0.07$ & $0.10 \pm 0.05$ & $0.07 \pm 0.06$ & $0.04 \pm 0.03$ \\
\hline
\end{tabular}


Figure 2: Mean Pen Velocity in the first and second segment of the movement patterns for all target widths in the discrete and serial conditions for both groups. Lines show means, error bars show $+/-1$ SE.
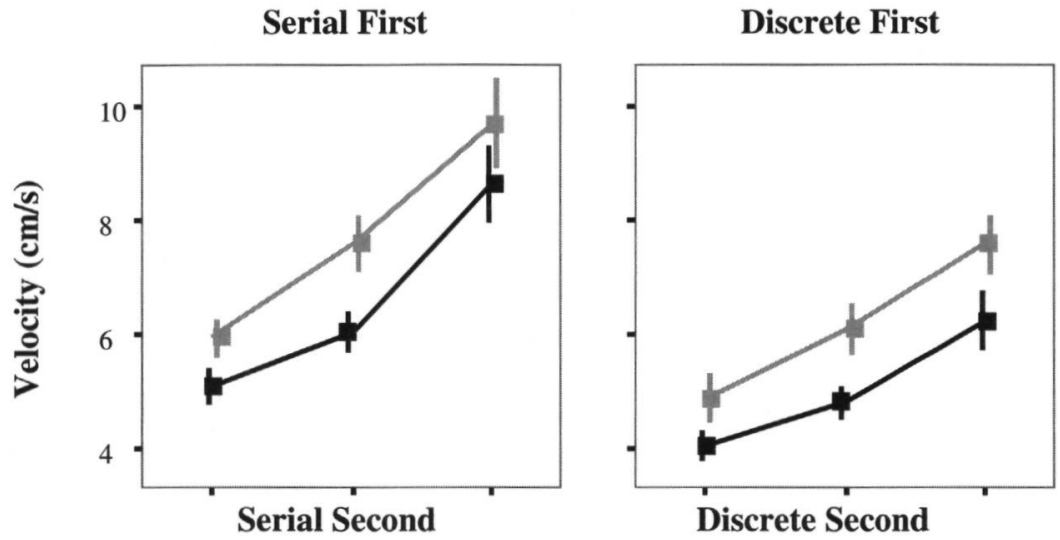

Discrete Second

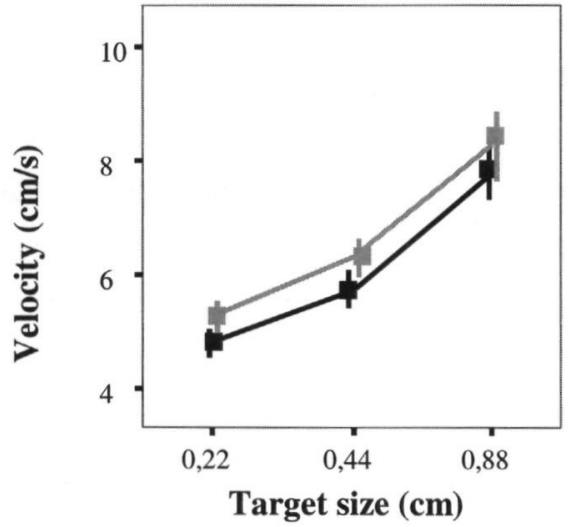

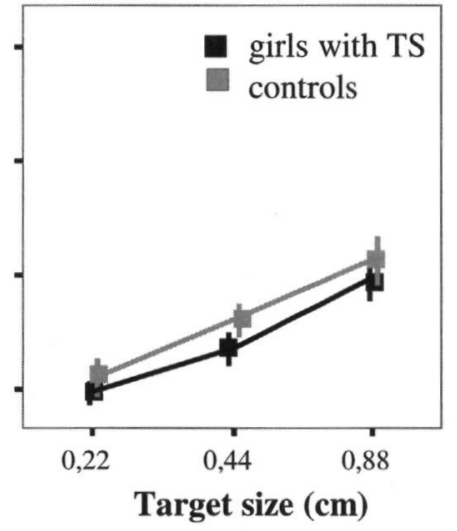

\section{Pen velocity (PV)}

As can be seen in Figure 2, PV is consistently lower in the girls with TS ( $M$ $=5.6 \mathrm{~cm} / \mathrm{s}, S E=.3)$, compared to the controls $(M=6.4 \mathrm{~cm} / \mathrm{s}, S E=.4)$, $F(1,13)=9.50, p=.01$ (see Table 1$)$. PV is lower in the discrete $(M=5.3$ $\mathrm{cm} / \mathrm{s}, S E=.3)$ than in the serial task $(M=6.8 \mathrm{~cm} / \mathrm{s}, S E=.4), F(1,13)=$ $33.23, p=.00$. PV in both the first and the second part of the movement is 
highly determined by target width in both the discrete and serial condition (as predicted by Fitts' law): increasing PV when target width increases, $F(2,12)=132.21, p=.00$, and PV is higher in the first part of the movement compared to the second part of the movement, $F(1,13)=36.61$, $p=.00$. The interaction effect of Group by First-Second, $F(1,13)=15.38$, $p=.00$, points out that the girls with TS do not speed up their PV in the first part of the movement (first $M=5.8 \mathrm{~cm} / \mathrm{s}, S E=.3$ vs. last $5.5 \mathrm{~cm} / \mathrm{s} \pm .3$ ) as much as the controls do (first $M=7.0 \mathrm{~cm} / \mathrm{s}, S E=.3$ vs. last $M=5.6$ $\mathrm{cm} / \mathrm{s}, S E=.3$ ). This again points to a more piecemeal execution. Moreover, it is obvious that greater target width allows more preprogramming, as can be seen by the greater increase in velocity in the first segment towards the larger targets (Target Width by First-Second, $F(2,12)=9.94, p=.00$ ) and a greater increase in PV in the discrete condition (Task by Target Width, $F(2,12)=5.65, p=.01)$. The absence of any other interaction effects with Group by Target Width or Task, points to the fact that the decreased velocity in the girls with TS is not related to the differential experimental manipulations.

\section{Deceleration fraction (DF)}

Temporal phasing proves to be a quite stable parameter in the velocity profiles: the acceleration phase is somewhat shorter than the deceleration phase. These data clearly demonstrate that groups do not differ in the form of their overall velocity profiles, $F(1,13)=0.00, p=.99$, although velocity in girls with TS is lower. These findings point to "stretched-out" velocity profiles in girls with TS (girls with TS: $M=56 \%, S E=6$ vs. controls: $M=$ $56 \%, S E=7$ ). A significant main effect of Task, $F(1,13)=5.28, p=.04$, indicates that the DF is somewhat longer in the serial task $(M=56 \%, S E=$ 6 vs. $M=57 \%, S E=4)$. Deceleration starts relatively later when target width is greater $F(2,12)=4.92, p=.01$, (S: $M=57 \%, S E=6$; M: $M=$ $57 \%, S E=5 ; \mathrm{L}: M=55 \%, S E=4)$. In the first part of the movement, deceleration starts relatively later than in the second part, $F(1,13)=4.91$, $p=.04$.

\section{Dwell time (DT)}

In the discrete task condition DT prior to the initiation of the first movement segment was determined by the experimental settings (subjects started after presentation of an auditory signal), and therefore DT was only 
analyzed before the start of the second movement segment with a $2 \times 2 \times 3$ (Group x Task x Target Width) factorial ANOVA with Repeated Measures on all factors. Means and standard deviations are presented in Table 1.

Girls with TS $(M=0.15 \mathrm{~s}, S E=.02)$ start more slowly than controls $(M=$ $0.09 \mathrm{~s}, S E=.01), F(1,13)=7.08, p=.02$. DT decreased with increasing target width, $F(2,12)=34.14, p=.00(\mathrm{~S}-\mathrm{M}-\mathrm{L}: M=0.17 \mathrm{~s}-0.11 \mathrm{~s}-0.08$ s) and in the discrete task condition mean DT of the second movement was longer than in the serial condition, $F(1,13)=9.91, p=.01(M=0.14 \mathrm{~s}, S E$ $=.01$ vs. $M=0.09 \mathrm{~s}, S E=.01$ ).

Only for the serial task did we analyze differences in DT before the start of the first and second movement segments with a $2 \times 3 \times 2$ (Group $\times$ Target Width $x$ First Second segment) factorial ANOVA with Repeated Measures on all factors. Again, this yielded a significant main effect of Group, $F(1$, $13)=5.89, p=.03$, i.e., the girls with TS $(M=0.12 \mathrm{~s}, S E=.02)$ start up more slowly than the controls $(M=0.07 \mathrm{~s}, S E=.01)$. DT decreases with increasing target width, $F(2,12)=21.97, p=.00$ (S - M - L: $M=0.13 \mathrm{~s}$ $0.09 \mathrm{~s}-0.07 \mathrm{~s}$ ). In both conditions girls with TS need more time to start up a movement, which is in accordance with the lower velocity used.

\section{Summary of Results}

Taken together, the main effects of Task condition and Target Width for the variables HR, PV, DF, and DT indicate that the experimental conditions were well chosen. In the discrete condition accuracy is higher, pen velocity lower, the deceleration phase shorter than in the serial condition. When target width gets smaller, accuracy reduces, velocity decreases, the deceleration phase becomes longer, and mean dwell time is prolonged.

No group differences in accuracy are found and although velocity is lower, velocity profiles are similar and temporal phasing is comparable.

Apparently, girls with TS are equally aware of the appropriate strategy needed to complete the task as their normal counterparts: they adapt their velocity to reduce endpoint variability. Another finding is that controls program and execute the entire figure in one movement action: higher velocity in the first part of the movement, combined with lower HR in the 
middle target, whereas in the end target HR is higher accompanied with lower velocity in the second segment. For the girls with TS, on the other hand, the HR and velocity are the same in both movement segments, which seems to suggest that they execute two identical movements. The prolonged dwell time in the girls with TS seems to be related to the decreased velocity and indicative of restarting problems when the movement direction needs to be reversed. We will return to this issue in the general discussion.

\section{Experiment 2: Size Manipulation}

In this experiment we presented the girls with a figure consisting of three consecutive apexes whose sizes were manipulated. In the regular condition size was kept constant (either large or small) and in the irregular condition the middle apex differed in size from the other two (see Figure 1). We restricted task load specifically to the size control level. Motor programs are constant and only force parameters need to be adapted (Pew, 1974).

\section{Methods}

\section{Participants}

The girls taking part in this experiment were the same girls that participated in experiment 1 .

\section{Procedure}

The test procedure and apparatus were the same as those used in experiment 1 . In this experiment the girls were presented with a sheet of paper (A4) with preprinted sequences of three horizontal reference lines (line width $0.1 \mathrm{~cm}$ ) with a spacing of $0.625 \mathrm{~cm}$. A separate sheet was presented showing an example of the apex pattern to be drawn between three such horizontal reference lines. The three lines indicated the target height of the apexes to be drawn; the width of the apexes was not imposed (see Figure 1). Size was manipulated by presenting four different apex patterns: small-small-small, small-large-small, large-large-large and large- 
small-large. The girls were instructed to copy the four different patterns as accurately and as fast as possible, going back and forth. They were required to perform each condition for a period of 30 seconds, starting and ending after an auditory signal. The four experimental conditions (small-regular, small-irregular, large-regular and large-irregular) were presented in random order to the matched pairs, whereas each matched pair was exposed to the same order of experimental conditions.

\section{Data Analysis}

The apparatus and the sampling and recording procedures were the same as in experiment 1 . The data were processed with Matlab (The Mathworks, inc., Natick, United States of America). All movement trajectories were subdivided into 12 segments (see Figure 3 ). The segments and "between segments" were defined using the same method as applied in experiment 1. Based on visual inspection, two observers determined whether a subject made a faulty trajectory or lifted the pen during a pen stroke or in a "between segment". These segments were subsequently excluded from analysis $(0.75 \%)$. Furthermore, errors in size were monitored. When small apexes were drawn as large ones (the endpoint of the ascending segment was closer to the upper reference line than to the middle target line) or vise versa the apex sequence was excluded from the analysis. Only 8 size errors were recorded (girls with TS: 3, controls: 5).

To analyze the endpoint variability of the segments in the $Y$-direction the accuracy variability in $Y$-direction was calculated ( $Y$-error). The $Y$-error was calculated for each condition in the following way:

$Y$-error $=\frac{\sum_{t=1}^{n}\left(\left|y_{t}-y_{p}\right|\right)}{n}$,

where $Y$-error is the variability of an end point of a defined segment (EP1-12, see Figure 2); $\mathrm{y}_{i}$, is the actual vertical segment end point; $\mathrm{y}_{p}$, is the vertical end point, specified by the prescribed horizontal line, and $n$, is the total number of replications of this segment. 
Figure 3: Segmentation method used in experiments 2 and 3 to compute dependent variables: $Y$-error, $\mathrm{AV}-\mathrm{x}, \mathrm{PV}, \mathrm{DF}$, and DT.
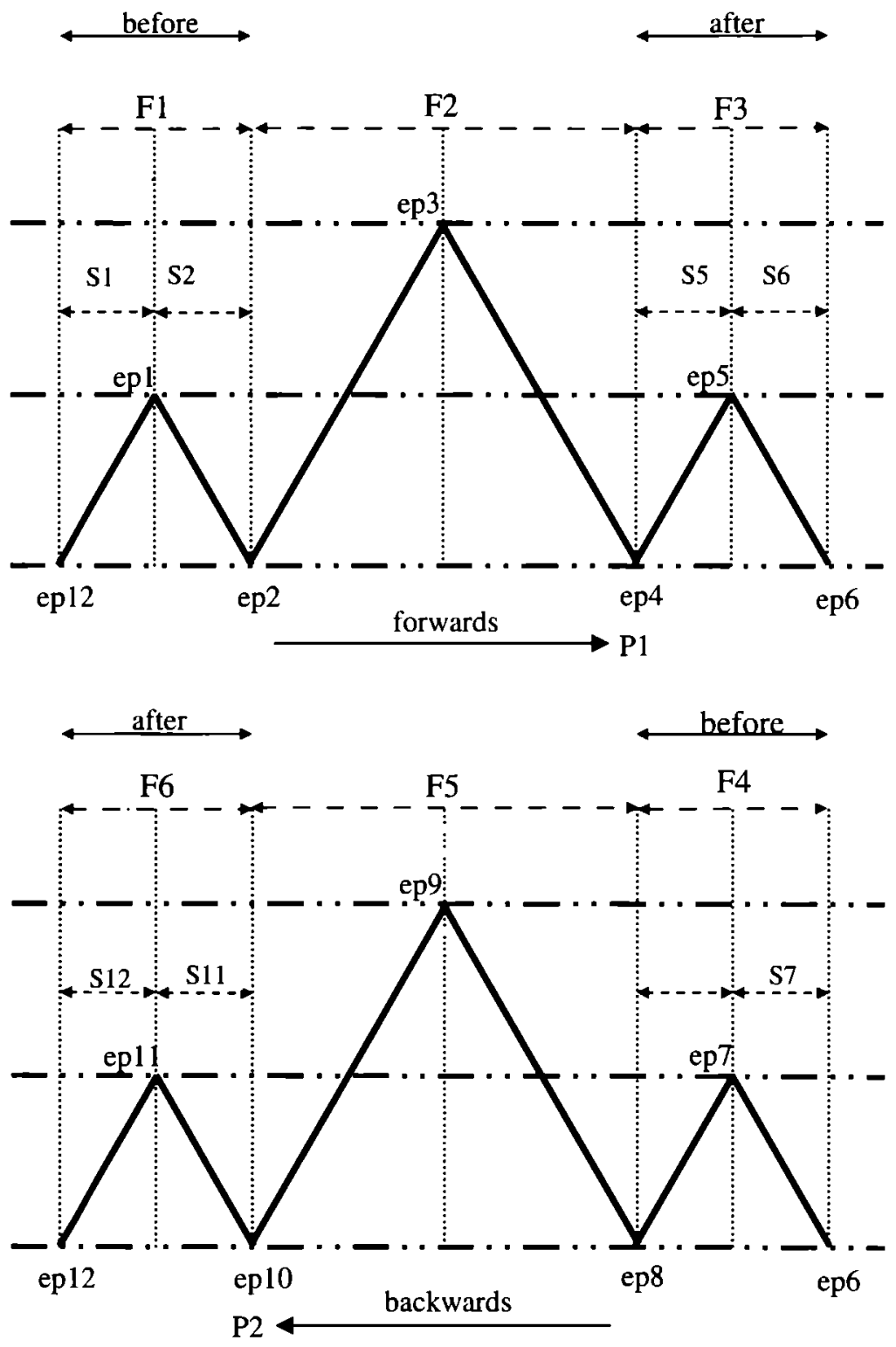
To analyze the endpoint variability of the segments in the X-direction the accuracy variability in $X$-direction was calculated (AV-x). The AV-x was calculated for each condition in the following way:

$\mathrm{AV}-\mathbf{x}=\frac{\sum_{i=1}^{n}\left(\left|x_{i}-x_{m}\right|\right)}{n}$,

where $A V-x$ is the variability of an endpoint of a defined segment (EP1-12, see Figure 2), $x_{1}$, is the actual horizontal segment endpoint; $x_{m}$ is the mean of the horizontal endpoints of all replications of this segment, and $n$ is the total number of replications of this segment. In addition, for each segment (S1-S12) mean Pen Velocity (PV), Deceleration Fraction (DF), and Dwell Time (DT) were defined and calculated using the same methods as applied in experiment 1.

The twelve segments (S) were grouped together in six different figures $(F)$ of two segments each (see Figure 3): In the forward movement direction F1 $=(\mathrm{S} 1+\mathrm{S} 2), \mathrm{F} 2=(\mathrm{S} 3+\mathrm{S} 4), \mathrm{F} 3=(\mathrm{S} 5+\mathrm{S} 6)$ and in the reversed direction $\mathrm{F} 4=$ $(\mathrm{S} 7+\mathrm{S} 8), \mathrm{F} 5=(\mathrm{S} 9+\mathrm{S} 10)$ and $\mathrm{F} 6=(\mathrm{S} 11+\mathrm{S} 12)$. This results in two identical movement patterns $(\mathrm{P})$ : One in a forward direction $\mathrm{P} 1(\mathrm{~F} 1+\mathrm{F} 2+\mathrm{F} 3)$ and one in a backward direction $\mathrm{P} 2(\mathrm{~F} 4+\mathrm{F} 5+\mathrm{F} 6)$. In the irregular condition the middle apex of the movement pattern was considered the distressing figure ( $F 2$ in the forward pattern and F5 in the backward pattern). Because we were interested in the influence of regularity on the execution of the figures before and after the interfering middle figure, only these first and last apexes of the movement pattern were compared.

The figures F1 (forward direction P1) and F4 (backward direction P2) were defined as the first figure in the movement pattern (P1 and $\mathrm{P} 2$, respectively), the figures F3 (forward direction P1) and F6 (backward direction $\mathrm{P} 2$ ) as the last figure in the movement pattern (P1 and P2, respectively).

Outcome values of Y-error, AV-x, PV, DF, and DT were averaged for first and last figures separately and for each experimental condition. The Y-error, AV-x, PV, DF, and DT were analyzed with a $2 \times 2 \times 2 \times 2$ (Group x First-Last x Regularity x Size) factorial ANOVA with Repeated Measures on all factors. 
Table 2: Results of Experiment 2 in girls with TS (T) and Controls (C): Means and Standard Deviations of Y-error, $\mathrm{X}$-var, Pen Velocity, Deceleration Fraction, and Dwell Time for the First and Last Figure of the Copying Patterns in all experimental conditions.

\begin{tabular}{lccccccccc}
\hline & & \multicolumn{9}{c}{ First } & \multicolumn{3}{c}{ Last } \\
\cline { 3 - 10 } Variable & & \multicolumn{2}{c}{ Regular } & \multicolumn{2}{c}{ irregular } & \multicolumn{2}{c}{ regular } & \multicolumn{2}{c}{ irregular } \\
\cline { 3 - 11 } & & small & large & small & large & small & large & small & large \\
\hline Y-error (mm) & $\mathrm{T}$ & $0.77 \pm 0.25$ & $1.12 \pm 0.36$ & $0.82 \pm 0.27$ & $1.25 \pm 0.41$ & $0.71 \pm 0.22$ & $1.01 \pm 0.38$ & $0.79 \pm 0.26$ & $1.20 \pm 0.46$ \\
& $\mathrm{C}$ & $0.92 \pm 0.34$ & $1.12 \pm 0.32$ & $0.79 \pm 0.27$ & $1.02 \pm 0.30$ & $0.88 \pm 0.22$ & $1.05 \pm 0.27$ & $0.71 \pm 0.14$ & $1.04 \pm 0.37$ \\
X-var (mm) & $\mathrm{T}$ & $1.56 \pm 1.34$ & $1.03 \pm 0.66$ & $1.29 \pm 1.26$ & $1.00 \pm 0.99$ & $1.55 \pm 1.24$ & $1.07 \pm 0.84$ & $1.28 \pm 1.25$ & $0.96 \pm 0.82$ \\
& $\mathrm{C}$ & $1.23 \pm 1.00$ & $0.95 \pm 0.64$ & $0.81 \pm 0.56$ & $0.79 \pm 0.59$ & $1.31 \pm 1.09$ & $1.04 \pm 0.75$ & $0.79 \pm 0.42$ & $0.84 \pm 0.53$ \\
Pen Velocity & $\mathrm{T}$ & $2.74 \pm 0.96$ & $3.49 \pm 1.36$ & $2.57 \pm 0.86$ & $3.51 \pm 1.28$ & $2.56 \pm 0.72$ & $3.39 \pm 1.04$ & $2.47 \pm 0.72$ & $3.44 \pm 1.10$ \\
(cm/s) & $\mathrm{C}$ & $3.24 \pm 1.22$ & $4.68 \pm 1.69$ & $3.04 \pm 0.95$ & $4.25 \pm 1.65$ & $2.82 \pm 0.80$ & $4.14 \pm 1.23$ & $2.77 \pm 0.77$ & $3.91 \pm 1.40$ \\
Deceleration & $\mathrm{T}$ & $0.57 \pm 0.04$ & $0.56 \pm 0.04$ & $0.57 \pm 0.04$ & $0.57 \pm 0.03$ & $0.57 \pm 0.03$ & $0.56 \pm 0.03$ & $0.57 \pm 0.03$ & $0.56 \pm 0.04$ \\
Fraction (\%) & $\mathrm{C}$ & $0.56 \pm 0.02$ & $0.55 \pm 0.03$ & $0.56 \pm 0.03$ & $0.55 \pm 0.03$ & $0.57 \pm 0.02$ & $0.57 \pm 0.03$ & $0.57 \pm 0.03$ & $0.56 \pm 0.04$ \\
Dwell & $\mathrm{T}$ & $0.16 \pm 0.12$ & $0.16 \pm 0.13$ & $0.15 \pm 0.10$ & $0.16 \pm 0.13$ & $0.13 \pm 0.09$ & $0.17 \pm 0.15$ & $0.19 \pm 0.13$ & $0.15 \pm 0.09$ \\
Time (s) & $\mathrm{C}$ & $0.08 \pm 0.06$ & $0.09 \pm 0.08$ & $0.08 \pm 0.05$ & $0.07 \pm 0.5$ & $0.09 \pm 0.05$ & $0.09 \pm 0.05$ & $0.10 \pm 0.05$ & $0.10 \pm 0.07$
\end{tabular}




\section{Results}

\section{Accuracy: Y-error and accuracy variability in X-direction (AV-x).}

The means and standard deviations of the accuracy measures are listed in Table 2. Although in this experiment complexity of the task was greater than in the first experiment, accuracy is high and no main effect of Group, $F(1,13)=.02, p=.88$, was found: Girls with TS: $M=0.96 \mathrm{~mm}, S E=.07$ vs. controls: $M=0.94 \mathrm{~mm}, S E=.05$. Absolute error in the Y-direction is very low and was as expected dependent of the apex size, $F(1,13)=57.63$, $p=.00$. (small: $M=0.80 \mathrm{~mm}, S E=.04$ vs. large: $M=1.10 \mathrm{~mm}, S E=.05$ ). Moreover, the girls with TS react as expected: more variable in the irregular condition (regular vs. irregular: $M=0.90 \mathrm{~mm}, S E=.07$ vs. $M=$ $1.01 \mathrm{~mm}, S E=.08$ ), in contrast to the controls (regular vs. irregular: $M=$ $0.99 \mathrm{~mm}, S E=.06$ vs. $M=0.89 \mathrm{~mm}, S E=.06$ ), who are more variable in the regular condition, $F(1,13)=12.30, p=.00$.

Variability in the $\mathrm{X}$-direction is also very low in both groups, $F(1,13)=$ $1.08, p=.32$. The large apex leads to lower variability $F(1,13)=6.47, p=$ .02 (large vs. small: $M=0.96 \mathrm{~mm}, S E=.15$ vs. $M=1.23 \mathrm{~mm}, S E=.18$ ). In contrast to what we expected, variability is greater in the regular condition, $F(1,13)=4.53, p=.05$ (regular vs. irregular: $M=1.22 \mathrm{~mm}, S E=.18$ vs. $M$ $=0.97 \mathrm{~mm}, S E=.16)$.

\section{Pen velocity (PV)}

As was observed in the first experiment the girls with TS $(M=3.0 \mathrm{~cm} / \mathrm{s}, S E$ $=.2)$ proved to move more slowly than the controls $(M=3.6 \mathrm{~cm} / \mathrm{s}, S E=.3)$ in all conditions, $F(1,13)=3.37, p=.04$ (one-sided; see Table 2 and Figure 4). $\mathrm{PV}$ is higher in the first figure, $F(1,13)=8.65, p=.01$, and also higher in the regular than in the irregular condition, $F(1,13)=9.04, p=$ .01 . As expected velocity is higher in the large apex, $F(1,13)=78.25, p=$ .00 . As can be seen in Figure 4 , the controls move faster in the first figure than in the last, $F(1,13)=8.49, p=.01$, whereas the girls with TS move with nearly the same velocity in both the first and the last figure. In contrast to girls with TS, the controls speed up in the first figure and profit from regularity in the movement pattern. 
Figure 4: Mean Pen Velocity in the first and second segment of the movement patterns in the regular and irregular conditions in experiment 2 (size manipulation) and experiment 3 (shape manipulation) for both groups. Bars show means, error bars show mean $+/-0.95 \mathrm{SE}$.

size manipulation small apex

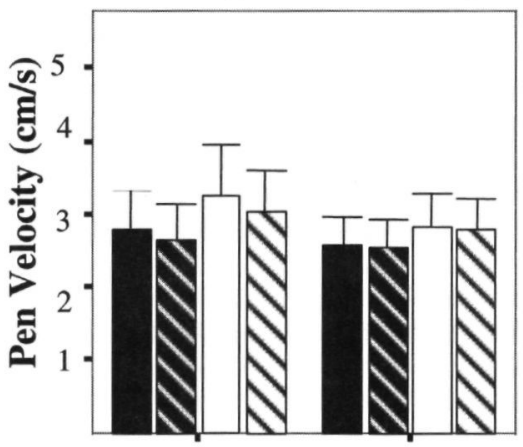

size manipulation large apex

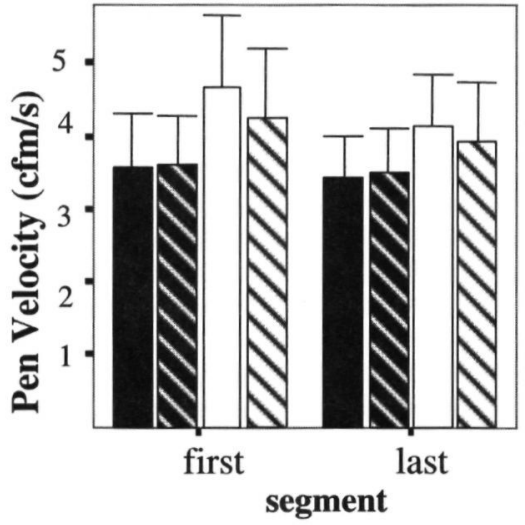

shape manipulation small apex

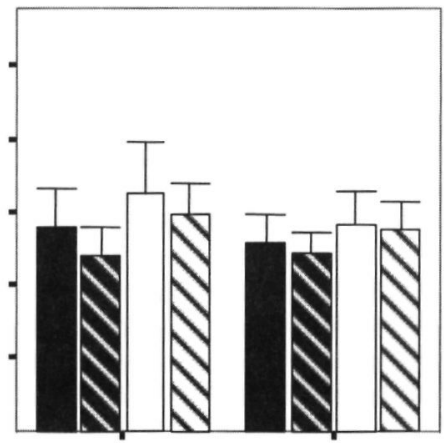

shape manipulation arc

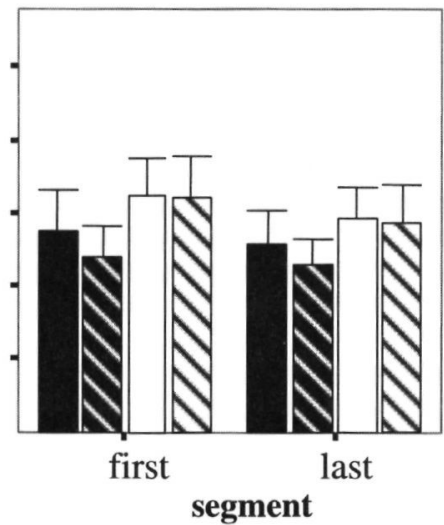

Control/ Regular Control/ Irregular 


\section{Deceleration fraction (DF)}

The DF data clearly show that the acceleration/deceleration profile is very robust and stable in all conditions (see Table 2 ). Size-dependent velocity changes do not influence these profiles, $F(1,13)=2.22, p=.16$, nor a main effect of First-Last, $F(1,13)=1.18, p=.30$, or of Regularity, $F(1,13)=$ $0.26, p=.62$. were found. Moreover, the deceleration phase is similar for both groups, $F(1,13)=0.31, p=.59$.

Figure 5: Mean Dwell Time in the first and second segment of the movement patterns in the regular and irregular conditions in experiment 2 (size manipulation) and experiment 3 (shape manipulation) for both groups. Bars show means, error bars show mean +/- 0.95 SE.

Size manipulation small apex

\section{Shape manipulation small apex}
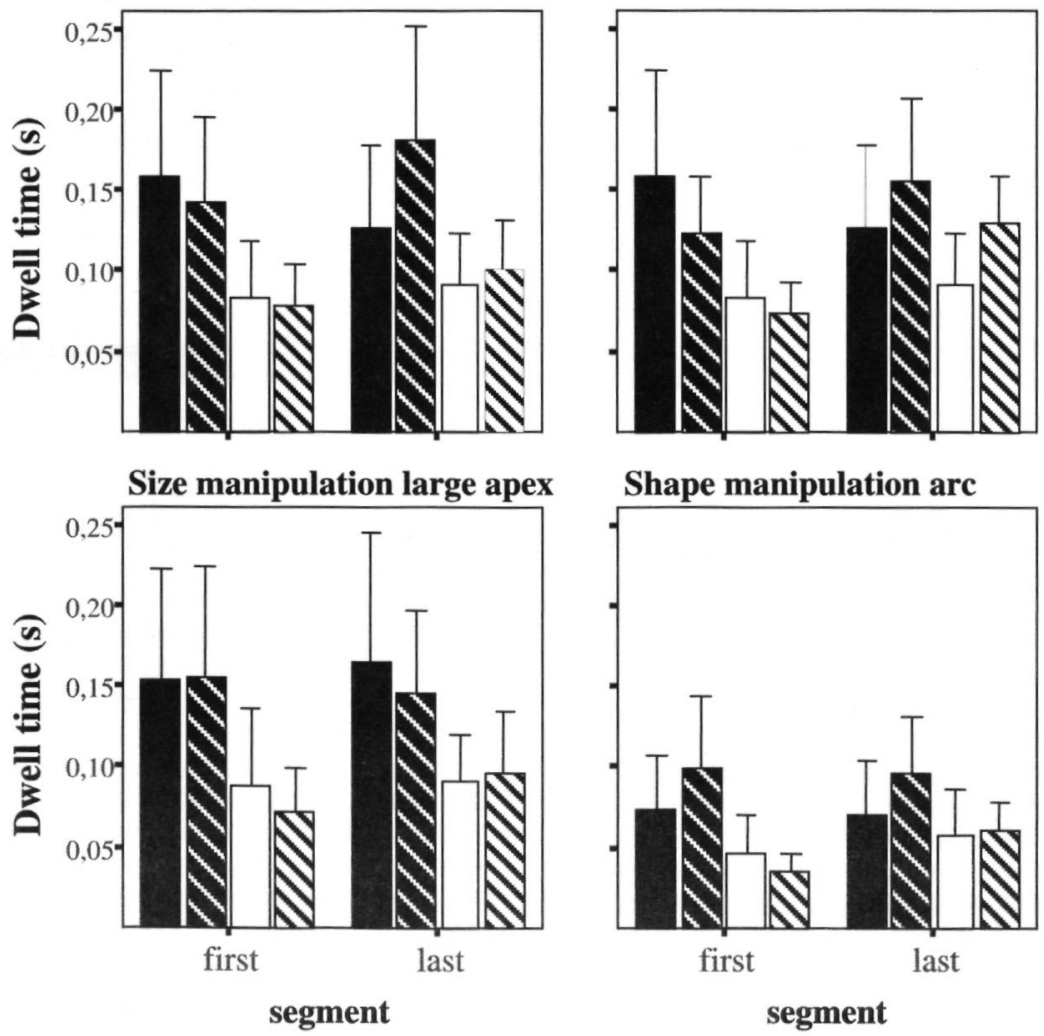

Turner/ Regular $\square$ Control/ Regular

$\mathbf{N}$ Turner/Irregular $\mathbf{N}$ Control/Irregular 


\section{Dwell time (DT)}

Dwell Time yielded a significant main effect of Group, $F(1,13)=11.80, p$ $=.00$ : The girls with TS pause longer than the controls $(M=0.16 \mathrm{~s}, S E=$ .03 vs. $M=0.09 \mathrm{~s}, S E=.01$; see also Table 2 and Figure 5) and variability in dwell time is higher in the girls with TS than in the controls. Dwell time is independent of manipulations for both groups: no further significant main effects or interaction effects were found.

\section{Summary of Results}

Although the pattern to be drawn in this experiment was more complex than the single apex used in experiment 1 , essentially the same results can be observed. Errors in figure production are negligible and for both groups accuracy is high. Velocity increases in both the large apexes and in the regular condition and velocity is also highest in the first figure. As in experiment 1 , velocity profiles are similar in both groups and another finding of experiment 1 is confirmed here: while controls move at a higher speed in the first figure, girls with TS move with the same velocity in both figures, indicating that girls with TS program the figures within the threefigure pattern as separate elements. The dwell times are longer in girls with TS independent of size manipulation.

\section{Experiment 3: Shape Manipulation}

In this experiment we presented the subjects with a pattern of three figures in which shape was varied, assuming that switches between motor programs are necessary under such conditions (Bruce, 1994; Bernstein, 1947; Keele et al., 1990). If decreased velocity in girls with TS is explained by programming problems, within this condition differences groups should be greatest. The pattern of the three small apexes from experiment 2 is used again as one of the sequences to be drawn in the regular condition. The second regular sequence consisted of three arcs. In the irregular condition an altemating concatenation of arcs and apexes were to be copied, while size was held constant (see Figure 1). 


\section{Methods}

\section{Participants}

The same girls, who had participated in experiments 1 and 2, took part in this experiment.

\section{Procedure}

The same test procedure, apparatus and test instructions were used as in the two previous experiments. The task was executed on an A4 sheet with three horizontal reference lines and examples of the patterns were presented to the subjects on separate sheets (see Figure 1). Four new pattems were compared: apex-apex-apex, apex-arc-apex, arc-arc-arc and arc-apex-arc. The subjects were instructed to copy the prescribed patterns as accurately and as fast as possible, going back and forth for a period of 30 seconds, the start and end of the period being indicated by an auditory signal.

\section{Data Analysis}

Data were analyzed in the same way as in experiment 2 . Segmentation into 12 segments (see Figure 3), definition of "between segments", and the method applied to score execution errors, with subsequent exclusion from the analysis, were also the same as in experiment $2(2.77 \%$ of the segments were excluded). Errors in shape were defined as apexes that had no sharp turning point or arcs that had a sharp turning point. The two segments of the apex or the arc in which a shape error occurred were excluded from further analysis. Only 23 shape errors were recorded (controls 13 and girls with TS 10) and no further analysis was performed on these errors.

As in experiment 2, the $\mathrm{Y}$-error, AV-X, PV, DF, and DT were defined and calculated for the 12 segments (S1-S12) and analyzed with a $2 \times 2 \times 2 \times 2$ (Group $x$ First-Last $x$ Regularity $x$ Shape) factorial ANOVA with Repeated Measures on all factors. 


\section{Results}

\section{Accuracy: Y-error and X-variability ( $A V x)$}

The means and standard deviations of the results of experiment 3 are presented in Table 3 . No group differences were found nor in $Y$-direction, $F(1,13)=0.27, p=.61$, nor in $\mathrm{X}$ direction, $F(1,13)=0.06, p=.80$. Yerror is smaller in the apex than in the $\operatorname{arc} F(1,13)=24.83, p=.00$. In the regular condition $\mathrm{Y}$-error is smaller as compared to the irregular condition, $F(1,13)=18.62, p=.00$, while in the same time $\mathrm{X}$ variability is higher in the regular condition, $F(1,13)=12.83, p=.00$. In the regular condition $\mathrm{Y}$ error is quite similar in both apex and arc, while in the irregular condition drawing the arc is less accurate, $F(1,13)=10.33, p=.01$.

\section{Pen velocity (PV)}

The findings of experiments 1 and 2 are confirmed: girls with TS move with a lower velocity than controls, $F(1,13)=6.08, p=.01$ (one-sided, see Table 3 and Figure 4) and do not speed up their velocity in the first figure in contrast to the controls, $F(1,13)=32.22, p=.00$. Moreover, $\mathrm{PV}$ is higher in the first figure as compared to the last, $\mathrm{F}(1,13)=8.98, p=.01$, lower in the irregular condition, $F(1,13)=13.03, p=.00$, but does not differ between apex and arc, $F(1,13)=0.08, p=.79$. 
Table 3: Results of Experiment 3 in TS Girls (T) and Controls (C): Means and SDs of Y-error, X-var, Pen Velocity, Deceleration Fraction, and Dwell Time for the First and Last Figure of the Copying Patterns in All Experimental Conditions.

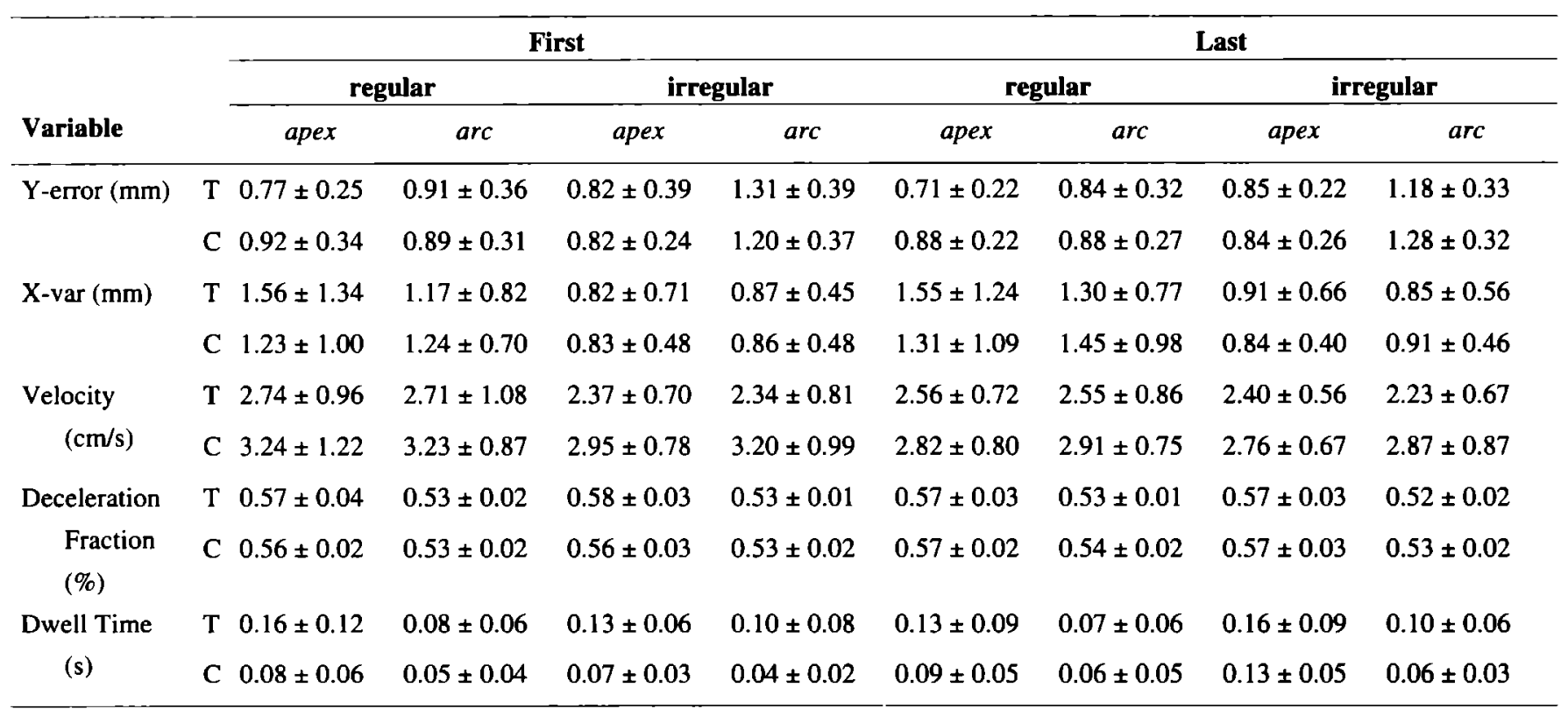




\section{Deceleration fraction (DF)}

Deceleration fraction is quiet stable in all conditions (see Table 3 ) and no main effect of Group was found, $F(1,13)=0.33, p=.57$. Although no influence of shape on velocity was found, it can be seen that the velocity profile changes: In arcs deceleration is set in later than in apexes, $F(1,13)=$ $177.74, p=.00$ (apex: $M=57 \%, S E=.00$ vs. arc: $M=53 \%, S E=.00$ ). This experiment shows that the acceleration/deceleration profile is part of a figure-specific motor program.

\section{Dwell time (DT)}

The girls with TS stop longer than the controls, $F(1,13)=15.67, p=.00$ (see Table 3 and Figure 5), and while in girls with TS, DT is similar in the first and last figure, in controls dwell time is longer in the last figure, $F(1$, 13) $=6.99, p=.02$. Notwithstanding the fact that shape manipulation did not affect velocity the change of shape did have an effect on DT.

Probably, in arcs more current control is applied during the ongoing movement and therefore DT is shorter in arcs than in apexes, $F(1,13)=$ $23.12, p=.00$.

\section{Summary of results}

In this experiment the girls with TS are somewhat less accurate in the last figure, and velocity is lower independent of the manipulations. Again girls with TS split up the figure into two movement parts.

\section{General Discussion}

To try and explain the observed speed problems in TS the main question in this study was: Do girls with TS show evidence of problems in either figure programming or size control, or, alternatively, are their problems restricted to the more peripheral, muscular initiation level? To examine this issue we manipulated task-loading conditions addressing each of these three different processing levels. 
There is evidence that both groups used preprogrammed motor programs. The number of errors in figure reproduction was negligible, accuracy levels were high and velocity was sensitive to target width, size and shape, whereas temporal phasing was stable throughout. These findings point to preprogrammed control processes and confirm that the experimental manipulations were valid to detect potential differences in the use of preprogrammed schemes when task demands change.

Returning to the differential effects of the task demands, it should be stressed that there were quite consistent analogies between groups over all experiments as well as differences. Both groups copied the figures with the same overall degree of accuracy.

Variability was somewhat higher in girls with TS when task load increased (irregular condition experiments 2 and 3); controls were more variable when task load decreased (regular condition). This is in line with the results of experiment 1: girls with TS were more accurate with the smallest target while controls had a higher hit rate with the larger target. This seems to be a strategy effect: Controls opt for a higher velocity, whereas girls with TS try to keep accuracy levels high by adapting velocity. The more piecemeal programming in girls with TS could be interpreted as a strategy effect too. Apparently this is the most efficient way to deal with task demands and internal constraints. We conclude that in both groups the motor control processes are intact but that girls with TS choose a different chunking strategy.

Velocity is consistent and stable lower in girls with TS, while already in the first experiment changes in velocity due to the experimental task demands were the same for both groups (see Figure 3). These results are in line with the results of Nijhuis - Van der Sanden et al. (in press) and in line with the findings in experiments 2 and 3 (see figure 4). Although velocity differed between groups, velocity profiles were similar but task-specific and especially sensitive to changes in accuracy demands and shape: A longer deceleration phase was observed for a smaller target, and for the arcs a shorter deceleration than for the apexes. These movement patterns with stable acceleration-deceleration phasing also confirm the intact usage of motor programs with fixed invariant features (Bernstein, 1947; Bruce, 1994; Keele et al., 1990). The lower velocity in TS can thus be interpreted 
as preprogrammed but "stretched-out" copies of the faster movements in controls ( Pew 1974; Summers, 1975; Shapiro, 1977).

Similar to the movement time, dwell time was longer in girls with TS in all three experiments and no interaction effects were found of task manipulations. From a theoretical perspective, more explanations are possible for this prolonged dwell time. For instance, it may reflect error detection through visual and/or somatosensory feedback. Alternatively, difficulties in motor planning may play a role, but also muscle initiation processes may be involved (Van Dellen \& Kalverboer, 1986). Turning to the hypothesis of error detection, basically two loops for error detection and correction are described: A long loop for intentional action (150 ms) and a much faster subcortical loop ( $80 \mathrm{~ms}$; Schmidt, 1999). Group differences in dwell time could be due to a difference in error detection strategy. This would mean that girls with TS used a more visual and intentional control (long loop), while in controls the somatosensory system deals with the demands on a lower level (subcortical loop). However, this would imply that correction of errors was a main factor and this was neither observed in this study nor in previous studies on TS (Nijhuis - Van der Sanden et al. 2000; Nijhuis - Van der Sanden et al., in press; Smits - Engelsman, Nijhuis -van der Sanden \& Duysens, in press). In our view, it is more likely that both groups prefer movement accuracy as the optimality criterion; the longer movement times, piecemeal production and the longer dwell times are necessary adaptation strategies in girls with TS. The second suggestion that the longer dwell time reflects difficulties in motor programming would imply that dwell time is more determined by task-specific information load in TS than in controls and this is not what we found. Therefore, it is most likely that the capacity in starting up new movement segments is related to a decreased ability in initiating motor units promptly, or to an increased stiffness regulation necessary to deal with constraints, specific for TS syndrome. This interpretation would fit in with a phenomenon we observed in all three experiments: girls with TS moved in a more piecemeal manner, whereas controls seemed to produce the figure pattern more in one go. These findings suggest that girls with TS use a different chunking strategy in motor programming than controls and this could be interpreted as an adaptation to difficulties in agonist-antagonist regulation.

We take the view that neurophysiological and/or biomechanical constraints in girls with TS influence the interaction with the environment when 
movements are executed. This can be illustrated by the "neuromotor noise model", which is based on neurocognitive, neurophysiological and biomechanical properties of the motor system (Van Galen \& Schomaker, 1992; Van Gemmert \& Van Galen, 1997; 1998). The rationale of the latter model is that motor behavior is a noisy process and the level of neuromotor noise is determined by both psychological and biophysical factors. To ensure acceptable end-point variability filtering of the neuromotor signal is necessary by either increasing movement speed (phasic filtering) or by an increment in limb stiffness (tonic filtering; Van Galen \& De Jong, 1995; Van Galen \& Huygevoort, 2000; Van Gemmert \& Van Galen, 1997). The kinematic parameters are the product of the stochastic nature of the force generation process and the filtering capacities of the limbs, which is not only a passive feature of the limb's tissues and bones but is also modified by the simultaneous contraction of agonist and antagonist muscles. This cocontraction results in a decrease in acceleration leading to increments of dwell time and movement time (Van Galen, \& Schomaker, 1992; Van Gemmert \& Van Galen, 1997; 1998). Variability in the stochastic, oscillatory recruitment signal to the involved muscles is likely to be multifactorial in origin (McAuley \& Marsden, 2000). Amongst these signals are the motor unit vector pool related to the intended output signal, physiological tremor, motor unit recruitment noise, servo control loops, and mechanical oscillations of the tendon and muscle tissues (Van Galen \& Van Huygenvoort, 2000). We suggest that in girls with TS neuromotor noise is increased, which induces them to use a higher tonic stiffness in the limb to attain the same accuracy. Some authors reported abnormalities in the brain stem and cerebellum in girls with TS and related these to problems in sensory integration and motor modulation (Murphy, DeCarli, Daly, Haxby, Allen, White, et al., 1993; Reiss, Mazzocco, Greenlaw, Freund \& Ross, 1995). In the CNS the settings of the gamma motor system are a decisive factor in the agonist- antagonist regulation of cocontraction and in the processing of proprioceptive feedback. It can be argued that deregulation of the gamma motor system plays a role in the motor problems in Turner Syndrome. And, in that perspective, it can be argued that the absence of interaction effects of Group on velocity and dwell time is caused by the tonic filtering of a noisy system to attain high accuracy. However, also the typical anatomical features of TS, in particular short stature, cubitus valgus and short metacarpals could be another influencing factor for differences in inertial properties of the movement. We cannot exclude the influence of 
cognitive strategies either, but in our opinion prolonged movement time and dwell time in girls with TS is partly due to increased stiffness.

A few other studies investigating motor performance in girls with TS yielded a decreased velocity (Bender et al, 1993: Clark et al., 1990; Romans et al., 1998; Ross et al., 1998; Ross et al., 1996). Ross et al. (1998) found a positive estrogen treatment effect on non-verbal processing speed and motor action speed in 12-year-old girls with TS. However, Romans et al. (1998) searched for (estrogen dependent) changes from childhood to adulthood and they found no velocity differences on the simple motor tasks, but motor skills with an emphasis on visuospatial demands revealed significant differences between girls with TS and controls. They hypothesized that estrogen has a main effect on visual processing. We can not support this suggestion because in our study, the TS girls were in the age range of 9-12 years and since only 3 of the 14 girls with TS we studied were treated with estrogen, we could not analyze whether there indeed was a relationship between treatment and MT, so we cannot rule out the possibility either. Although we do not exclude the possibility that girls with TS may suffer from a visuospatial processing deficit, we would like to argue that in these studies biological and biomechanical reality of movement production were hardly taken into account and that biomechanical problems may play a more prominent role than assumed. We maintain that, rather than potential visuospatial problems, in our experiments the differences in controlling the "effector" organ may have influenced the planning and execution of the movements in the girls with TS.

The motor problems in girls with TS seem to resemble those of children with Developmental Coordination Disorders (DCD; DSM-IV; American Psychiatric Association, 1994). Also DCD children move as accurately as controls but need more movement time (Geuze \& Kalverboer, 1987; 1994; Geuze \& Van Dellen, 1990; Henderson, Rose, \& Henderson, 1992a; 1992b; Van Dellen \& Kalverboer, 1986; Van der Meulen, Denier van der Gon, Gielen, Gooskens, and Willemse, 1991a; 1991b). Most of the investigators agree with the suggestion of Van der Meulen et al. (1991a; 1991b) that lower velocity is due to an impaired capacity for anticipatory control caused by a decreased response organization process (Rösblad \& Von Hosten, 1994; Williams et al., 1992). However, most of these authors do not exclude the possibility that deficits in the execution of movements are 
present as well (Van Dellen, 1987; Van Dellen \& Geuze, 1988; Van der Meulen et al., 1991b; Williams et al., 1992). In a meta-analysis of research findings in DCD children, Wilson and McKenzie (1998) suggested the kinesthetic and crossmodal perceptual system to play a role in motor control. This is in accordance with the findings reported by Geuze and Van Dellen (1990), Smyth and Glencross (1986), Van Dellen and Geuze (1988), and Williams, Woollacott, and Ivry (1992). They suggested a causal relationship between deficits in the sensory system and motor problems. Taken together, it can be concluded that there are several similarities in the results of the studies into DCD and the findings in the studies on TS. However, in most studies on DCD the motor planning factors are very difficult to distinguish from motor execution factors. Irrespective of the question whether a similar interpretation of the motor problems can be given for both DCD and girls with TS, it must be taken into account that TS is a well-defined clinical syndrome with clear diagnostic inclusion criteria whereas the DCD group may be very heterogeneous, because diagnostic criteria are variable. It is possible that for that reason a common interpretation is hard to detect.

In conclusion, this study suggests that girls with TS move as accurately as normal peers but slower and in a more piecemeal manner and this can be interpreted as an adequate adaptation to variability in movement execution, possible due to structural neurophysiological and/or biomechanical changes in their system. Ongoing research with isometric force production tasks in our lab may provide further insight into the relevant constraints in Turner Syndrome.

\section{Acknowledgements}

The authors would like to thank both the children and their parents for their participation in this study. We are also grateful to Dr. Barto Otten, endocrinologist, for contacting the children and their parents. We are indebted to Dr. Bouwien C. M. Smits - Engelsman for her advice on the study design, Geert van den Borne for her help with the data collection, and Bianca Nijhuis, movement scientist, for her help with the data collection and her critical comments on earlier versions of the manuscript. Finally, we would like to thank Hanneke Meulenbroek for her language corrections, and Peter de Jong for developing the OASIS software needed for this research. 


\section{Reference List}

Amencan Psychiatric Association (1994) Diagnostic and stattstical manual of mental disorders ( $4^{\text {th }}$ Edn ) Washıngton, DC Author

Bender, B G , Linden, M G , \& Robinson, A (1993) Neuropsychological impaimnent in 42 adolescents with sex chromosome abnormalities American Joumal of Medicine and Genetıcs (Neuropsychological Genetıcs), 48, 169-173

Bernstein, N A (1947) On the structure of movements Moscow State Medical Publishıng House

Bruce, D (1994) Lashley and the problem of the senal order American Psychologist, 49. 93-103

Clark, C , Klonoff, H , \& Hayden, M (1990) Regıonal cerebral glucose metabolısm in Turner Syndrome Canadian Journal of Neurological Science, 17, 140-144

Decety, J , \& Jeannerod, M (1996) Fitss' law in mentally simulated movements Behavioral Brain Research, 72, 127-134

Fitts, P M (1954) The information capacity of the human motor system in controlling the amplitude of movement Journal of Expertmental Psychology, 47, 381-391

Fitts, P M , \& Posner M I (1967) Human Performance Belmont, Calıfomıa Brooks/Cole Publıshing Company

Geuze, R H \& Kalverboer, A F (1987) Inconsistency and adaptation in tıming of clumsy children Joumal of Human Movement Studies, 13, 421-32

Geuze, R H \& Kalverboer, A F (1994) Tappıng a rhythm A problem of tıming for children who are clumsy and dyslexic Adapted physical Acttvities Quarterly 11, 203213

Geuze, R H \& Van Dellen, T (1990) Auditory precue processing dunng d movement sequence in clumsy children Journal of Human Movement Studies, 19, 11-24

Henderson, L, Rose, P , \& Henderson S E (1992a) Improving handwritıng through kınaesthetic sensitıvity practice Australian Occupatıonal Therapy Journal 39, 23-27

Henderson, L , Rose, P , \& Henderson S E (1992b) Reactıon tıme and movement tıme in children with a developmental coordination disorder Joumal of Child Psychology and Psychlatry, 33 (5), 895-905

Henderson, S E , \& Sudgen, D A (1992) Movement Assessment Battery for Children Manual London Psychological Corporation

Jeannerod, M , Arbıb, M A , Rızzolattı, G , \& Sakata, H (1995) Grasping objects The cortical mechanısms of visuomotor transformation Trends in Neuroscience, 18, 314320 
Jordan, M.I., \& Rosenbaum, D.A. (1990). Actıon. In Possner M.B. (Ed.) Foundations of Cognitive Science (pp.727-767). Cambridge, MA: MIT Press.

Keele, S.W., Cohen A., \& Ivry, R. (1990). Motor Programs: Concepts and Issues. In Jeannerod (Ed.), Atttention and performance XIII (pp.77-110). Hillsdale, NJ: Erlbaum.

Lashley, K.S. (1951). The problem of serial order in behavior. In L.A. Jeffress (Ed.), Cerebral mechanism in behavior: The Hixon symposium (pp.112-136). New York: Wiley.

Maruff, P., Wilson, P., Trebilcock, M., \& Currie J. (1999). Abnormalities of ımagined motor sequences in children with developmental coordination disorder. Neuropsychologia 37, 1317-1324.

McAuley, J.H., \& Marsden, C.D. (2000). Physiological and pathological tremors and rhythmic central motor control. Brain, 123, 1545-1567.

Meyer, D.E., Smith, J.E.K., Kornblum, S., Abrams, R.A., \& Wright, C.E. (1990): Speedaccuracy tradeoffs in aimed movements. Toward a theory of rapid voluntary action. In: M. Jeannerod (Ed.): Motor Control and representations, Attention and Performance XIII (pp.173-226). Erlbaum Publishers, Hillsdale.

Murphy, D.G.M., DeCarli, C., Daly, E., Haxby, J.V., Allen, G., White, B.J., McIntosh, A.R., Powell, C.M., Horwitz, B., Ropoport, S.I., Shapiro, MB. (1993). X-Chromosome effects on female brain: a magnetic resonance imaging study of Tumer's Syndrome. Lancet, 342, 1197-1200.

Nijhuis - Van der Sanden, M.W.G., Smits - Engelsman, B.C.M., \& Eling, P.A.T.M. (2000). Motor performance in girls with Turner's Syndrome. Developmental Medicine and Child Neurology, 42, 685-690.

Nijhuis - Van der Sanden, M.W.G., Smits - Engelsman, B.C.M., \& Eling, P.A.T.M., Nijhuis, B.J.G., Van Galen G.P. (in press). Low elementary movement Speed is associated with poor motor skill in Tumer Syndrome. Developmental Neuropsychology.

Pew, R.W. (1974). Human perceptual-motor performance. ln: B.H. Kantowitz (Ed.), Human information processing: Tutorials in performance and cognition (pp.1-39). Hilsdale, NJ: Erlbaum.

Reiss, A.L., Mazzocco, M.M., Greenlaw, R., Freund, L.S., Ross, J.L. (1995).

Neurodevelopmental effects of $\mathrm{X}$-monosomy: A volumetric imaging study. Annals of Neurology, 36, 731-738.

Romans, S.M., Stefanatos, G., Roeltgen, D.P., Kushner, H., \& Ross, J.L. (1998). Transition to young adulthood in Ullrich-Turner Syndrome: Neurodevelopmental changes. American Journal of Medical Genetics, 79, 140-147.

Rösblad, B., \& von Hosten, C. (1994). Repetitive goal-directed arm movements in children with developmental coordination disorders: Role of visual information. Adaptive Physical Activity Quarterly, 11, 190-202 
Rosenbaum, D A , Engelbrecht, S E , Bushe, M M , \& Loukopoulos L D (1993) A model for reaching control Acta Psychologıca, 82, 237-250

Rosenfeld, R G , \& Grumbach, M M (1990) Turner Syndrome Basel Marcel Dekker Inc Ross, J L , Feuillan, P , Kushner, H , \& Cutler, G B , Jr (1998) Effects of estrogen on nonverbal processing speed and motor function in girls with Tumer's Syndrome Journal of Clinical Endocrinology and Metabolısm, 82, 1814-1817

Ross, J L , Kushner, H , \& Roeltgen, D P (1996) Developmental changes in motor function in girls with Turner Syndrome Pediatric Neurology, 15, 317-322

Ross, J L , Zınn, A \& Mc Cauley, E (2000) Neurodevelopmental and psychosocial aspects of Tumer Syndrome Mental Retardation and Developmental Disabilittes Research Reviews, 6, 135-141

Rovet, J (1993) The psycho-educational charactenstics of children with Turner's Syndrome Journal of Learning Disabilities, 26, 333-341

Salbenblatt, J A , Meyers, D C , Bender, B G , Linden, M G , \& Robinson, A (1989) Gross and fine motor development in 45,X and 47,XXX girls Pediatrics 84, 678-682

Schmıdt, R A , \& Lee, T D (1999) Pnnciples of sımple movement In R A Schmıdt \& T D Lee (Eds ), Motor control and learning A behavioral emphasts (pp 172-180) Illınoıs, United States Human Kinetics

Smyth, T R , \& Glencross, D J (1986) Information processing deficits in clumsy children Journal of Psychology, 38, 13-22

Smits - Engelsman, B C M , Nijhuis - Van der Sanden, M W G , \& Duysens, J (in press) An exploratory study of the kinematics of girls with Tumer Syndrome in a visuo-motor Task Infant and Child Development

Smuts - Engelsman, B C M , Van Galen, G P , \& Duysens, J (2002) The breakdown of F1tts' law in oscillatory movement regimes Expenmental Brain Research, 145, 222230

Shapiro, D C (1977) A prelımınary attempt to determıne the duration of a motor program In D M Landers \& R W Chnstına (Eds), Psychology of motor behavior and sport1976 (pp 17-24) Champaign,IL Human kinetıcs

Summers, J J (1975) The role of tımıng in motor program representation Journal of Motor Behavior, 7, 229-241

Van Dellen, T , \& Kalverboer, A F (1986) De controle van doelgenchte handbewegıngen bıj kınderen Een kınaematısche analyse (The Control of Goal-Directed Hand Movements in Chıldren A Kınematic Analysıs ) Nederlands Tydschrift voor Psychologie, 41, 3-13

Van Galen, G P (1991) Handwnting Issues for a psychomotor theory Human Movement Sctence, 10, 165-191 
Van Galen, G P , \& De Jong, W P (1995) Fitss'law as the outcome of a dynamic noise filtenng model of motor control Human Movement Science, 14, 539-572

Van Galen, G P , \& Schomaker, L R B (1992) Fitts' Law as the outcome of a dynamic noise filtenng model of motor control Human Movement Science, 11, 11-22

Van Galen, G P , Van Doom, R R A , \& Schomaker, L R B (1990) Effects of motor programming on the power spectral density function of finger and wnst movements Journal of Experimental Psychology Human Perception and Performance, 16, 755 765

Van Galen, G P , \& Van Huygevoort, M (2000) Error, stress and the role of neuromotor noise in space onented behavior Btological Psychology, 51,151-171

Van Gemmert, A,W A , \& Van Galen, G P (1997) Stress, neuromotor noise and human performance A theoretical perspectıve Journal of Experımental Psychology Human Perception and Performance, 23, 1299-1313

Van Gemmert, A,W A , \& Van Galen, G P (1998) Auditory stress effects on preparation and execution of graphical alming A test of neuromotor noise concept Acta Psychologica, 98, 81-101

Van der Meulen, J H P , Denuer van der Gon, J J , Gielen, C C A M, Gooskens, R H J , \& Willemse J (1991a) Visuomotor performance of normal and clumsy children I Fast goal directed arm movements with and without visual feedback Developmental Medicıne and Child Neurology 33, 40-54

Van der Meulen, J H P , Denıer van der Gon, J J , Gielen, C C A M , Gooskens, R H J , \& Willemse J (1991b) Visuomotor performance of normal and clumsy children II Arm trackıng movements with and without visual feedback Developmental Medicine and Child Neurology 33, 118-129

Willıams, H G , Woollacott, M H \& Ivry, R (1992) Timing and motor control in clumsy children Journal of Motor Behavior, 2, 165-172

Wilson, P H , Maruff, P, Ives, S , \& Cume J (2001) Abnormalities of motor and praxis Imagery in chuldren with DCD Human Movement Science 20, 135-159

Wilson, P H , \& McKenzie B E (1998) Information Processing Deficits Associated with Developmental Coordination Disorder A meta-analysis of Research Findings Journal of Child Psychology and Psychiatry and Allied Health Disciplines, 39, 829-840 


\section{Slow motor performance in girls with Turner Syndrome is not related to increased neuromotor noise}

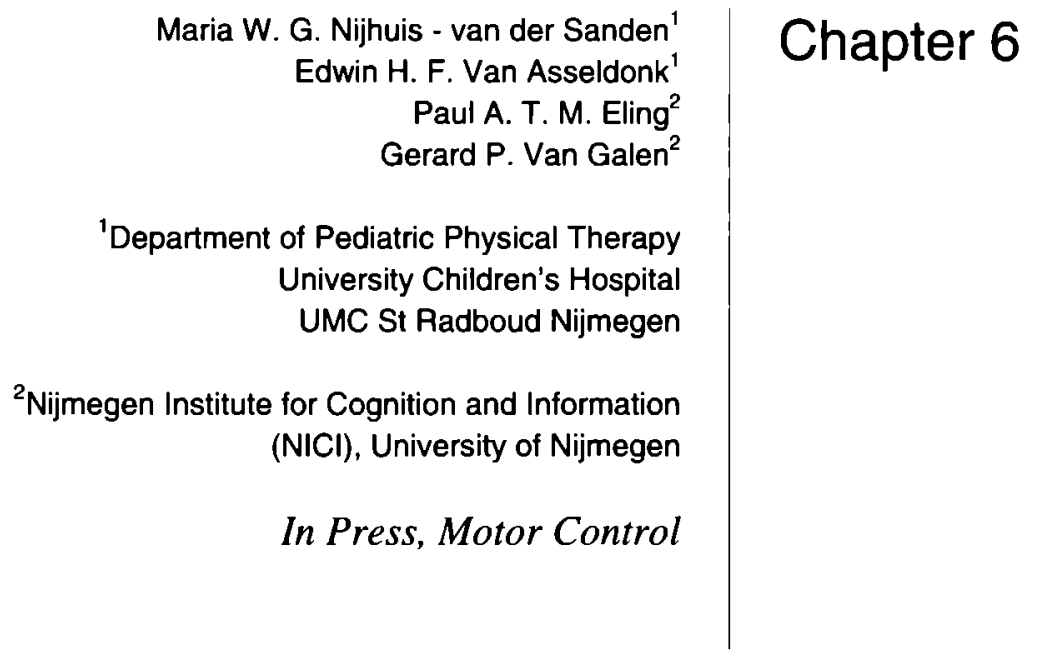




\section{Abstract}

This study examined the relationship between decreased speed-accuracy trade-off and increased neuromotor noise in girls with Turner Syndrome (TS). Fifteen girls with TS and 15 age-matched controls performed isometric force contractions with both index fingers separately at five force levels, based on their maximum voluntary contraction. The results revealed that (a) groups did not differ, neither in speed-accuracy trade-off, nor in neuromotor noise, (b) output-variability increased linearly with force level, (c) Signal-to-Noise Ratio changed according to an inverted U-shaped function, (d) broadening in the frequency profile is highest at the lower force levels, (e) with increasing force level the power peak in the $0-4 \mathrm{~Hz}$ domain dominates, (f) frequency profile broadens more in the dominant hand.

These findings suggest that in girls with TS motor performance is not diminished in an isometric force task, that motor recruitment is intact and that neuromotor noise is not increased. The findings are discussed with respect to motor control and neuromotor noise. 


\section{Introduction}

Turner Syndrome (TS) is a chromosomal disorder in which the second sex chromosome is missing (XO). The physical constitution in TS consists of short stature, streak gonads, short or webbed neck, cubiti valgi, and short metacarpals (Rosenfeld, 1990) and sometimes abnormalities in internal organs. Girls with TS have slight but significant motor performance problems, but little theory-driven research is available (Bender, Linden \& Robinson, 1993; Mathisen, Reilly \& Skuse, 1992; Nijhuis - Van der Sanden, Smits - Engelsman \& Eling, 2000; Salbenblatt, Meyers, Bender, Linden \& Robinson, 1989). Movement patterns in girls with TS differ only slightly from those seen in the general population and commonly are referred to as "clumsiness". Sometimes hypotonia, strength problems, poor joint stability, decreased speed, gait abnormalities and difficulties with balance and diadochokinesis are mentioned (Salbenblatt et al., 1989). There is clear evidence that visuo-spatial processing abilities in girls with TS are decreased (Downey, Elkin, Ehrhardt, Meyer-Bahlburg, Bell \& Morishima, 1991; Money 1993; Rovet 1993; Temple \& Carney 1995; Ross, Kushner \& Roeltgen, 1996), and many authors have suggested that motor performance problems are secondary to these visuo-spatial problems. However, the available evidence clearly indicates that motor performance problems may occur independent from visuo-spatial deficits and are a genuine problem too in this population (McGlone, 1985; Nijhuis - Van der Sanden et al., 2000; Salbenblatt et al., 1989), probably responsible for a number of difficulties in everyday life.

Some studies investigated clumsiness in TS (Nijhuis - Van der Sanden, Smits - Engelsman, Eling, Nijhuis \& Van Galen, in press; Nijhuis - Van der Sanden, Eling, Van Asseldonk \& Van Galen, 2003; Smits - Engelsman, Nijhuis - Van der Sanden \& Duysens, in press), and showed that spatial accuracy is not the main problem, but movement time is significantly longer than in controls, both in simple and in more complex goal-directed line drawing tasks. Given the consistent nature of these prolonged movement times it is very likely that the more tardy movement strategy has to be considered as optimal for the given state of their motor system (Latash \& Anson, 1996). Because prolonged movement time was independent of task complexity in various simple motor tasks, Nijhuis Van der Sanden, et al. (in press) suggested that prolonged movement time 
was specifically coupled to movement execution and possibly related to specific features of the biological system in TS-girls. They argued that girls with TS need more filtering of the noisier neuromotor signal by an increment in limb stiffness to attain acceptable end-point accuracy (Van Galen \& De Jong, 1995; Van Galen \& Huygevoort, 2000; Van Gemmert \& Van Galen, 1997). This modified active engagement of stiffness parameters of the limb by simultaneous contraction of agonist and antagonist muscles would consequently explain the decrease in acceleration leading to increased movement time (Van Galen \& Schomaker, 1992; Van Gemmert \& Van Galen, 1997; 1998). The notion, that movement speed, anatomical and other biomechanical settings are degrees of freedom in optimizing motor control, fits into the more general theoretical view of the regulation of degrees of freedom in dynamic motor behavior, as advocated by Bemstein (1967) and more recently by Latash \& Anson (1996).

In the motor studies by Nijhuis - van der Sanden et al., (in press, submitted) in girls with TS, mentioned above, only kinematic data from dynamic task conditions were analyzed to detect differences in motor planning and motor execution in girls with TS. In such tasks, large sets of elements (multiple joints and multiple muscles crossing the joints) are organized into task-specific synergies and errors introduced by an imprecise action of one element are corrected by changes in the activity of other elements (Latash \& Anson, 1996). Because we want to investigate the influence of neuromotor noise on basic principles of motor recruitment processes, we need to disentangle the role of such adaptive interactions, and therefore we decided to analyze aiming movements within an isometric force production paradigm. In such a task, the sets of elements are much smaller and better controlled. The muscle-tendon complex and limb position remain relatively stable, compared to dynamical tasks, and therefore redundancy is reduced (Bernstein, 1967). Moreover, there is evidence that isometric force applications reflect the instantaneous activity of muscles and neuromotor signals (De Jong \& Van Galen, 1999; Deutsch \& Newell, 2001; Slifkin \& Newell, 1999; Van Galen \& De Jong, 1995). Therefore, isometric force production tasks may be a useful and easily applicable method to analyze differences in neuromotor noise in children and clinical groups.

The first purpose of the present study is to investigate whether, in the kinematic domain, decreased speed-accuracy trade-off in girls with TS 
(longer movement time) is present in an isometric aiming task too. The second purpose of the study is to determine whether, in the force recruitment domain, force output signals provide more direct evidence of possible differences in force variability related to neuromotor noise, between (clumsy) girls with TS and controls.

\section{The kinematic domain: speed-accuracy trade-off}

Using a Fitts' aiming task Nijhuis - Van der Sanden et al. found in both discrete and serial movements a constantly prolonged movement time in all conditions, independent of index of difficulty, between girls with TS and controls. To clarify the role of internal constraints specific for TS and present in all task conditions, (e.g., increased neuromotor noise or reduced motor-unit recruitment capacity based on biophysiological changes in TS) and task specific constraints (e.g., orchestrating agonist-antagonist synergy) again a Fitts' aiming task was used. Billon, Bootsma, \& Mottet (2000) argued that speed-accuracy functions could be adequately tested in such an isometric aiming task. Conform Fitts' paradigm (Fitts, 1954), the adjustment time (time necessary to place the cursor into the target bar) could be considered to be a direct reflection of the capacity of the neuromotor system to generate an accurate recruitment signal in different task levels.

\section{The force recruitment domain: neuromotor noise and motor control}

Van Galen \& De Jong (1995) proposed a neuromotor noise model of motor control, based on neurocognitive, neurophysiological and biomechanical properties of the motor system (De Jong \& Van Galen, 1999; Van Galen \& Schomaker, 1992; Van Galen \& De Jong, 1995; Van Gemmert \& Van Galen, 1997; 1998). The rationale of this model is that motor performance is the optimized outcome of a stochastic, oscillatory recruitment signal to the involved muscles. Variability is related to the capacity of the system to deal with the noisiness in such a signal. Such noisiness is likely to be multifactorial in origin (McAuley \& Marsden, 2000). It is assumed that the total variance in the measured force signal is composed of the sum of variances from the original oscillation signals (Van Galen \& De Jong, 
1995). Amongst these signals are the motor unit vector pool related to the intended output signal, physiological tremor, motor unit recruitment noise, servo control loops, and mechanical oscillations of the tendon and muscle tissues (Van Galen \& Van Huygenvoort, 2000). A system with a high level of Gaussian noise would reveal low signal-to-noise ratios, related to high performance variability. In dynamic tasks, the motor control system optimizes accuracy by mechanisms that reduce the effects of intrinsic motor noise, such as stiffness control by agonist-antagonist co-contraction, viscosity, or friction due to surface contact (De Jong \& Van Galen, 1999; Van Galen \& De Jong, 1995; Van Galen \& Schomaker, 1992; Van Gemmert \& Van Galen, 1997; 1998).

Power Spectral Density Analysis (PSDA) has been used already in isometric force production tasks to investigate the relationship between variability in motor performance and the organizational properties of the recorded time-series signal in terms of its frequency content (De Jong \& Van Galen, 1999; Deutsch \& Newell, 2001; Slifkin \& Newell, 1999). The profile of such a power spectrum provides clues about the relative contribution of the various underlying oscillations to the recorded signal (De Jong \& Van Galen, 1999; Van Galen \& De Jong, 1995; Van Galen \& Huygevoort, 2000). For a highly rhythmic signal, the power in the spectrum will be confined to a small number of frequencies and will therefore be peaked. On the other hand, power will be equally distributed across all frequencies if a signal is completely random, and consequently the frequency profile will be a straight horizontal line. In the power spectra, derived from isometric force tasks in young adults, De Jong \& Van Galen (1999) found peaks predominantly around $2 \mathrm{~Hz}, 6 \mathrm{~Hz}$, and $11 \mathrm{~Hz}$. They suggested that the observed $2-\mathrm{Hz}$ peak might be associated with visual feedback processing, the $11-\mathrm{Hz}$ peak with motor unit recruitment oscillations, while the 6-Hz peak was proposed to be associated with physiological tremor related to servo-loops at the spinal, sub-cortical and cortical level of the neural system. In many studies force variability is found to increase exponentially with force level in isometric force tasks, whereas the signal-to-noise ratio (defined as the mean force divided by the standard deviation) as well as the noise measured by PSDA change according to an inverted U-shaped function and are not linearly related to the variability in force output (De Jong \& Van Galen, 1999; Deutsch \& Newell, 2001; Slifkin \& Newell, 1999; Van Galen \& De Jong, 1995). 
Deutsch and Newell (2001) presented isometric force tasks to children (610 years). They observed that, with increasing age, the force output signal was increasingly characterized by higher degrees of irregularity and the power spectrum took on a more broadband frequency profile, while at the same time performance improved, and signal-to-noise ratio rose. These age-related changes were only observed in the presence of visual feedback. These authors found that improvement of performance is associated with a broader power spectrum across frequency range and therefore they proposed that age-related enhancements in motor performance are primarily due to a more appropriate tuning of the neuromotor system to task constraints, rather than to changes in the system capacity and overall noisiness of the system itself. In contrast with the hypothesis from Van Galen and de Jong (1999), these results suggest that a more broadening frequency profile is not per se related to increased outcome variance. Deutsch and Newell (2001) also found that power spectrum profiles and motor performance outcome in the older children ( 10 years and older) are the same as in adulthood, indicating that performance level in such (simple) tasks increases not furthermore from the age of ten years.

Currently no data are available relating clumsiness in TS to properties of the neuromotor signal. In this study we combined an aiming task (to test speed-accuracy trade-off in the kinematic domain in an isometric task) with an isometric force task (to analyze instantaneous activity of muscles and neuromotor signals within the force recruitment domain). Participants had to move a square cursor as fast and as accurately as possible by pressing a load cell (i.e., a force transducer) towards and into a horizontal bar, presented on a monitor. Subsequently they had to keep the cursor as stationery as possible within the confines of the bar at five different force levels, based on an individually determined maximum voluntary contraction (MVC).

Since the absolute width of the target bar and cursor remained constant, task difficulty is manipulated by the height of the target bar, representing force level conditions. It was expected that girls with TS need longer adjustment times. The signal-to-noise ratio (SNR) provides an index of the system's capacity to reduce noisiness related to the signal and we expected girls with TS to exhibit a lower signal-to-noise ratio than controls. The profile of the power spectrum was analyzed to reveal possible differences in the relative contribution of different oscillators in the system to the 
signal. With this experiment we hoped to find TS-specific profiles in the outcome signals that would support the hypothesis that different forms of stiffness regulation in girls with TS is the result of adaptations within the system, to reduce the consequences of increased neuromotor noise.

\section{Methods}

\section{Participants}

The girls with Turner Syndrome (TS) were recruited from the pediatric endocrine clinic of the University Medical Center St Radboud in Nijmegen and the Catharina Hospital in Eindhoven, the Netherlands, both specialized in the treatment of TS. In total 24 girls, bom between 1989 and 1993, were selected to enroll in the study. The parents of 7 girls refused participation. One girl was excluded because of spastic diplegia and one girl was excluded because she was not able to meet the task demands. The final sample consisted of 15 girls with TS with an age range of 8.0 to 13.0 (mean 10.1) years. None of the girls had participated in earlier related studies by Nijhuis - van der Sanden et al. (2000; in press; submitted). All girls with TS attended mainstream elementary or secondary schools.

Fifteen age-matched female control subjects (age range 8.1 to 12.0 years, mean age 10.6 years) were recruited from an elementary school in Denekamp, the Netherlands.

Informed consent was obtained from all children and their parents. All parents filled in two questionnaires, one concerning the socio-economic status and another concerning their daughter's general health. No significant differences in the socio-economic status and general health between the families of the controls and the TS group were found. All girls with TS and controls had normal or corrected-to-normal vision. 


\section{Procedure}

The girls with TS carried out the experimental task at the hospital following a medical consultation. Performance of the isometric force task took approximately 45 minutes. The controls executed the task at school in a separate room. All girls were tested in the same manner and by the same investigator, experienced in the testing of children.

\section{Apparatus}

Force data were collected using a load cell force transducer (BC302, DS Europe s.r.l., Milan, Italy), with a $12 \mathrm{~mm}$ diameter, full scale range of $60 \mathrm{~N}$, sensitivity about $1.6 \mathrm{mV} / \mathrm{V}$ full scale. The output from the load cell was amplified (Burn Brown INA 125, Burr Brown, Tucson, USA) using a gain of 500 times, the excitation supply of $5 \mathrm{~V}$ was delivered by the instrumentation amplifier. The amplified signal was processed by means of a second-order $100 \mathrm{~Hz}$ Low-Pass filter. The output was sampled continuously at $512 \mathrm{~Hz}$ using a 16 bit analog-to-digital converter (DAQcard AI-16XE-50, National Instruments, Austin, USA) and saved to a Computer Pentium III Processor for off-line data analysis by MATLAB procedures. The load cells were calibrated in Newton $(\mathrm{N})$ using known weights. Force was measured in units of $0.0045 \mathrm{~N}(0.46 \mathrm{~g})$. A flat screen monitor (15 inch; $1024 \times 768$ pixels per screen) displayed the target force and the participant's force trajectory: Target force level was depicted as a 7-mm wide target bar and force trajectory by the displacement of a yellow cursor (quadrant of 5x5mm.). Once every $10 \mathrm{~ms}$ the exerted force was fed back to the computer display to update the position of the cursor and thus provided online performance information to the participant. 
Figure 1: A schematic drawing of the experimental set-up.

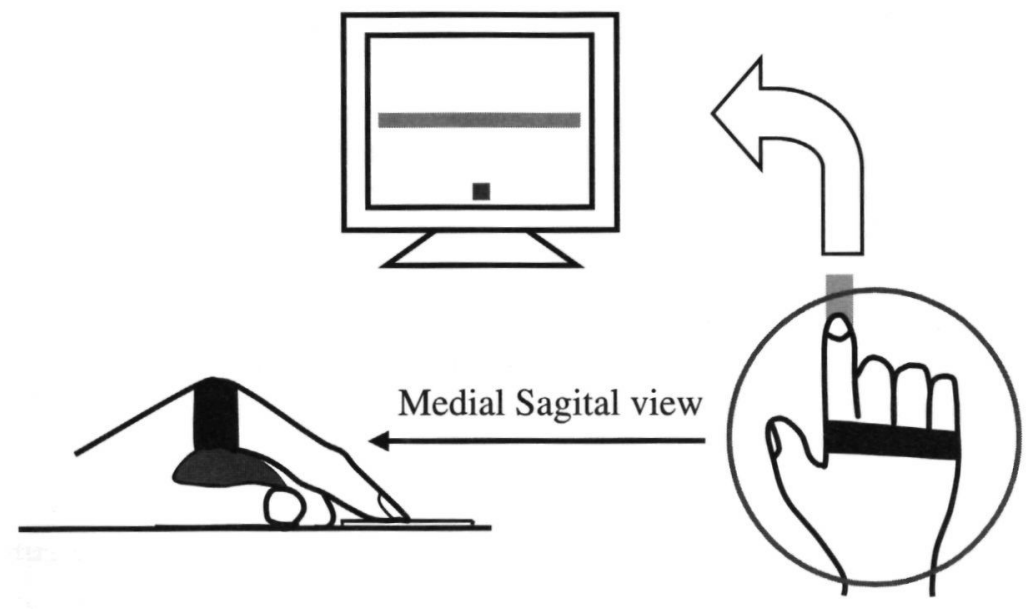

\section{Experimental protocol}

Participants were seated on a height-adjustable chair with their feet on a height-adjustable footstool (hips, knees and feet in a 90-degree flexion) at a desk of standard size in front of the computer display. The screen was placed at eye level and the horizontal viewing distance was approximately $100 \mathrm{~cm}$. The girls' forearms rested on the desk and both hands were oriented towards the computer display and strapped to a handgrip (see Figure 1.). This height-adjustable handgrip was placed under the metacarpophalangeal joints of the four fingers in such a way that these joints were forced into a 90-degree flexion. The thumb was left free. By attaching the hands to the handgrip the girls were prevented from using the weight of their forearms to apply a higher force and it guaranteed that finger position could not be changed during the trial. Mounted in front of these handgrips were two load cells of which the distance could be adjusted for each participant. By pressing these load cells with the top of their right or left index finger the girls could control the vertical position of a yellow, square cursor on the computer display. Force was produced by flexion of the index finger in the metacarpophalangeal and proximal interphalangeal joint, whereas the distal interphalangeal joint was maximally extended. The position of the cursor on the screen was directly proportional to the force applied on the load cells: The harder the cells were pressed, the higher the 
position of the cursor on the display. The participants were instructed to move the cursor towards and into a white horizontal bar as quickly and accurately as possible after they heard an auditory signal. Because the gain of the feedback on the position of the cursor was directly related to the girls' individual Maximum Voluntary Contraction (MVC), for each participant the position of the target bar on the computer screen was the same: $0 \%$ of MVC was near the bottom of the display and $50 \%$ was near the middle. Once they had reached the target bar, they were required to keep the cursor as stable as possible within the target bar until another auditory signal indicated the end of the trial. Time between the starting signal and the end signal was 8 seconds. When the child had completed the trial and indicated to be ready, the examiner started the next trial.

The instructions the girls received ran as follows: "As soon as you hear a beep, a white bar will appear on the screen. You don't know at what height the bar will appear, but you must try and put the cursor into the bar as quickly as you can. Then you need to try and keep the cursor in the bar as well as you can, until you hear another beep. Tell me when you are ready, then I will start the next task."

For each girl MVC was assessed immediately prior to the actual experiment using the task to be presented in the subsequent experimental trials. MVC was determined as follows: All the girls were presented with an initial trial in which the target force level was set at an estimated MVC of $30 \mathrm{~N}$. They were asked to press the load cells as hard as they could with both their index fingers, pressing only once in one go to prevent them from "pumping up" the force. The position of the target bar for the next trial was set at the MVC level obtained in this first trial and the girls were subsequently asked to try and move the cursor higher than the target bar and keep it there for some seconds. When they were able to comply with the task demand, each next trial the target force level increased by $1 \mathrm{~N}$. As soon as they could no longer meet the imposed force level, they were given one more go and if they failed again, MVC measurement was ended. The MVC for each finger was then set at the highest force level each girl had been able to obtain. Once the MVC had been determined, the girls performed two practice trials for each of the five target force levels (ranging from 10 to $50 \%$ of MVC). The experiment itself consisted of two blocks of trials, one for the dominant and one for the non-dominant hand. In each block, the five target force levels $(10 \%, 20 \%, 30 \%, 40 \%$ and $50 \%$ of MVC) were measured 5 
times in a randomized block design, resulting in a total of 50 trials per subject ( 25 trials for the dominant and 25 trials for the non-dominant hand).

\section{Data Analysis}

The signals from the load cells were sampled with a frequency of $512 \mathrm{~Hz}$ for a period of $8 \mathrm{~s}$, starting and ending with an auditory signal. Before starting each experiment a $0 \%$ condition was used to measure equipment noise. During this condition the subjects were not allowed to touch the load cells.

The Force records were analyzed and the following outcome data were computed:

\section{Kinematic domain}

\section{Adjustment Time}

Adjustment Time (AT) was defined as the time elapsed between the moment the rate of force production (derivative of the force) increased above $1 \mathrm{~N}^{-1}{ }^{-1}$ and the start of the stabilization phase. This interval was determined by means of a computer algorithm (the third crossing of the imposed force line). Additionally, two independent raters visually inspected all trials off-line. If necessary, they could correct the start or end point of this interval.

\section{Relative Force Distance}

To measure the efficiency of the force adjustment used to move the cursor into the target bar the Relative Force Distance (RFD) was calculated. The RFD was defined as the sum of the absolute differences in force between the consecutive force samples during the adjustment phase divided by the target force. A large value indicates a large deviation from the most efficient force adjustment path. In formula:

$\mathrm{RFD}=\frac{\sum_{R T}^{R T+A T}\left|F_{1}-F_{t-1}\right|}{F_{\mathrm{lmp}}}$, 
where RFD is the Relative Force Distance, $F_{1}$ the force in the $\mathrm{i}^{\text {th }}$ sample of the force adjustment and $F_{1 m p}$ the imposed force.

\section{Force recruitment domain}

\section{Mean force}

To measure spatial accuracy in the stabilization phase for each trial the Mean percentage of MVC $(\mathrm{MF}=\% \mathrm{MVC})$ was calculated.

\section{Standard Deviation of absolute force}

The spatial consistency in the stabilization phase was established by calculating the Standard Deviation (SD) of the absolute mean force in each trial.

\section{Signal-to-noise Ratio}

The Signal-to-Noise Ratio (SNR) was obtained by dividing the mean absolute force during the stabilization phase by the standard deviation for each trial.

Before the Power Spectral Density Analyzes (PSDA) was performed, the 4-s interval during the stabilization phase in which the standard deviation reached its smallest value was determined. This 4-s interval was used for the PSDA analyzing and for calculating Approximate Entropy. To remove high frequency quantization-noise, a low pass filter may be used. However, the choice of the filter characteristics directly influences the resulting power spectrum. An alternative approach is reducing the sample frequency, so that the frequency of the quantization-noise falls beyond the range of the power spectrum. In our study the data are down sampled with a factor 8 (resulting frequency $64 \mathrm{~Hz}$ ). This down sampling procedure prevents loss of information by forming different subsets of data (first subset consisting of $1^{\text {th }}, 9^{\text {th }}, 17^{\text {th }}$ etc. sample, second subset consisting of $2^{\text {nd }}, 10^{\text {th }}, 18^{\text {th }}$ etc. sample, and so on). The even subsets were mirrored and subsequently all subsets were placed after each other and detrended. With this method no information is lost. After this down sampling procedure, the derivative, or jerk signal, was computed as an estimate of signal noise, because it does not contain the otherwise very dominant spectral power of mean force. This 
jerk signal was entered into the PSDA routine of Matlab. The window size was chosen in such a way that the end of a subset always coincided with the end of a window. The resulting raw PSDFs consisted of 33 bins ranging from 0 to $32 \mathrm{~Hz}$. From these spectra the Maximal Peak Power (MPP) was determined.

\section{Proportional Maximal Peak Power}

To provide a measure of spread of power in the power spectrum, we divided the MPP by the total power in the spectrum. The PMPP provides a measure of the proportional contribution of the dominant frequency component to the power in the overall oscillations in force output. Decreasing PMPP reflects a broadening of the power spectrum (the contribution of the Peak Power to the total power spectrum decreases) and therefore increases in signal noisiness.

\section{Proportional Power in each frequency band at each Force level}

To get a more global index of the distribution of the Proportional Power (PP) over the frequency bins at each separate force level, frequency bins were grouped together in 6 frequency bands of 4 bins together $(0-4 \mathrm{~Hz}$ etc.). At each force level for each of the normalized PSDFs the percentage of power surface was calculated for six frequency bands of equal bandwidth: 0-4 Hz, 4-8 Hz, 8-12 Hz, $12-16 \mathrm{~Hz}, 16-20 \mathrm{~Hz}$ and $20-24 \mathrm{~Hz}$. The power between $24-32 \mathrm{~Hz}$ was (on average) only $1.5 \%$ of the total power and was therefore not analyzed further. The power in each frequency band represented the PP in the overall amplitude, attributable to the frequencies specified by that band. The measure enabled us to relate differences in noise profiles to underlying sensorimotor or neurophysiological processes. 


\section{Regularity in the time domain}

Approximate Entropy (ApEn; Pincus \& Goldberger, 1994) is assumed to capture the sequential structure of a neuromotor signal. This ApEn provides an index of the regularity and predictability of a measured signal in the future time based on past time-series events. The more random the signal output (more noise in the signal), the more information is required to specify future values, and the higher ApEn value will be. Further information about the algorithm used to calculate the approximate entropy can be found in Slifkin and Newell (1999), and Pincus and Goldberger (1994). To compare our results with the results of Newell et al., frequency was reduced to $102.4 \mathrm{~Hz}$ (by resampling at $1 / 5$ times the sampling frequency) after filtering with an eight-order Chebyshev type I low-pass filter with a cut-off frequency of $40.96 \mathrm{~Hz}$. The ApEn was calculated using a run length $m=2$ and a filter width $r=0.2$. Therefore, the value of the ApEn ranges from zero to 2 . Signals that are highly regular and predictable (i.e., sinus waves) yield an ApEn value close to 0 and conversely, an ApEn value close to 2 will be found when signals are highly irregular and unpredictable over time, such as would be expected for white Gaussian noise.

AT, RFD, MF, SD, SNR, PMPP, PP and ApEn were averaged for each force level and each finger set. Statistical analyses were performed on each of the above-mentioned dependent variables. AT, RFD, MF, SD, SNR, PMPP and ApEn were analyzed using a 2 x 2 x 5 (Group $x$ Dominance $x$ Force level) factorial ANOVA with Repeated Measures on the latter two factors. For each force level Proportional Power was analyzed using a 2 × 2 x 6 (Group x Dominance x Frequency Band) factorial ANOVA with Repeated Measures on the latter two factors. A significance level of $\alpha=.05$ was used for all statistical tests. The statistics were performed with SPSS software (version 10.0). 
Figure 2: Example of five force-time series for isometric force production at force levels of $10 \%, 20 \%, 30 \%, 40 \%$ and $50 \%$ of the Maximum Voluntary Contraction (MVC) of one of the girls with TS.

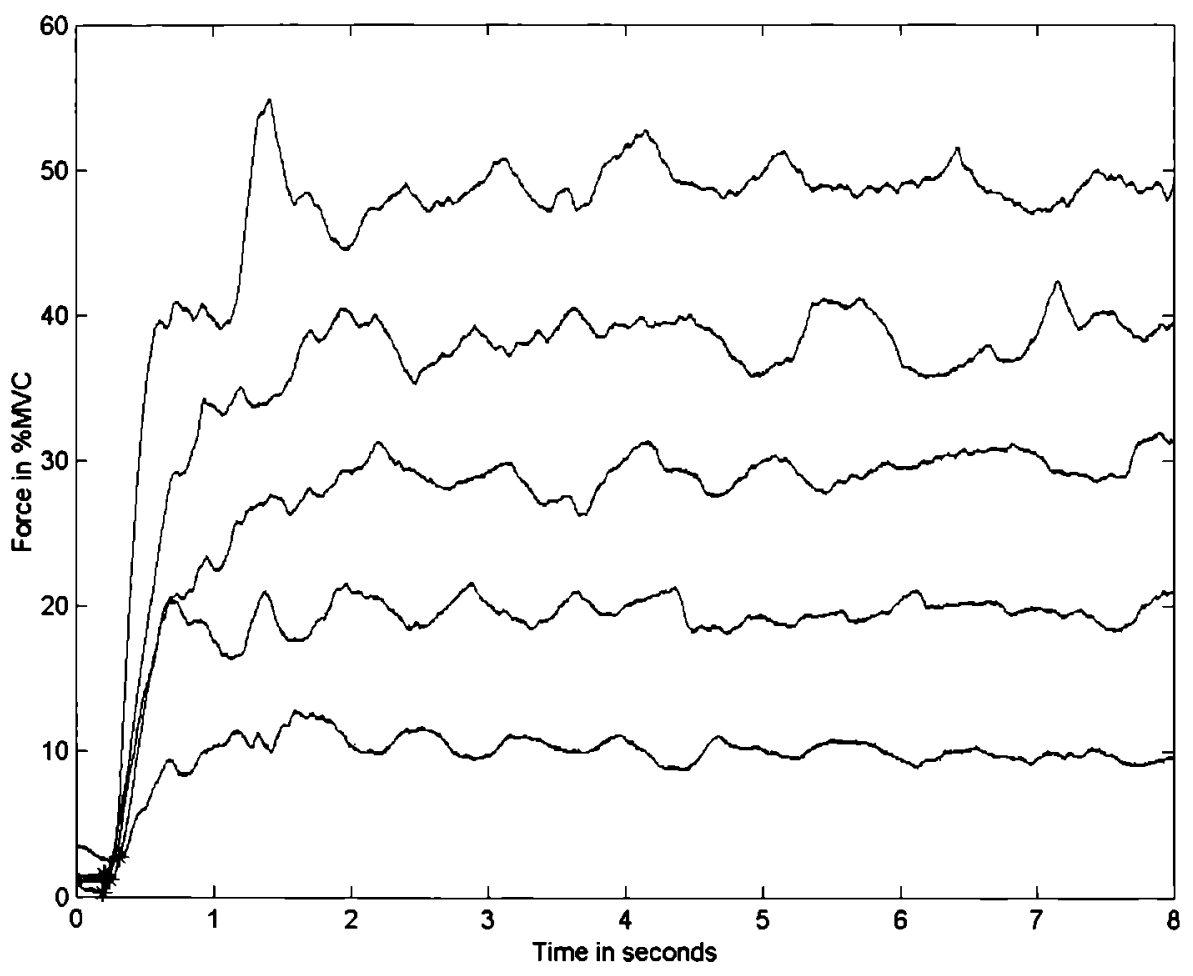




\section{Results}

All girls were able to perform the requested task. Figure 2 shows representative samples of five force-time series produced by one of the girls with TS at the $10 \%, 20 \%, 30 \%, 40 \%$ and $50 \%$ MVC levels. After the experiment we compared the neuromotor noise, as assessed through our analysis, with the amount of equipment noise and this showed that the latter was negligibly small: The averaged SD in the $0 \% \mathrm{MVC}$ trials over all conditions was only $0.008 \mathrm{~N}$, and therefore no signal corrections were made.

The mean number of trials used to measure the MVC did not differ significantly between girls with TS $(M=5.3)$ and controls $(M=5.4)$. Mean MVC in girls with TS $(M=11.6 \mathrm{~N}, S D=2.2$, range $8-15 \mathrm{~N})$ and in controls $(M=9.0 \mathrm{~N}, S D=1.2$, range $7-11 \mathrm{~N})$ differed significantly, $t=3.9$, $d f=28, p=.00$.

\section{Kinematic domain}

\section{Adjustment Time}

As expected, the mean AT depended significantly on force level, $F(4,112)$ $=9.81, p=.00, \eta^{2}=.26$ (see Table 1 ). AT is linearly related to force level conform Fitts' law, although somewhat prolonged at the $10 \%$ force level (respectively $10 \%: M=2.09 \mathrm{~s}, S E=.08 ; 20 \%: M=1.77, S E=.0730 \%: M$ $=1.87 \mathrm{~s}, S E=.09 ; 40 \%: M=2.06 \mathrm{~s}, S E=.06 ; 50 \%: M=2.30 \mathrm{~s}, S E=.10$ ). At the $10 \%$ level it seems to be difficult to adjust the muscle force to meet the imposed level. The AT in the dominant and non-dominant hand did not differ, $F(1,28)=0.25, p=.62$. As Table 1 shows, the girls with TS did not need a longer AT in this isometric task, $F(1,28)=0.30, p=.59$ (girls with TS: $M=2.05 \mathrm{~s}, S E=.08$; controls: $M=1.99 \mathrm{~s}, S E=.08$ ). Since no interaction effects were found, they obviously reacted in the same manner as their normal peers in this isometric task. These data do not suggest a decreased speed-accuracy trade-off in an isometric task for girls with TS. 
Table 1: Means and Standard Deviations of all dependent variables in onefinger isometric contraction for the girls with TS and the controls for the domınant and non-domınant hand

\begin{tabular}{|c|c|c|c|c|c|c|}
\hline & & & & Dominant Har & & \\
\hline Force Level MVC & & $10 \%$ & $20 \%$ & $30 \%$ & $40 \%$ & $50 \%$ \\
\hline Adjustment Time & C & $229 \pm 57$ & $183 \pm 54$ & $182 \pm 40$ & $186 \pm 36$ & $221 \pm 62$ \\
\hline (AT in seconds) & $\mathbf{T}$ & $209 \pm 61$ & $172 \pm 62$ & $187 \pm 50$ & $211 \pm 49$ & $221 \pm 51$ \\
\hline Relative Force & $\mathrm{C}$ & $1226 \pm 300$ & $595 \pm 237$ & $383 \pm 85$ & $308 \pm 77$ & $298 \pm 74$ \\
\hline Distance (RFD) & $\mathrm{T}$ & $885 \pm 331$ & $411 \pm 175$ & $305 \pm 86$ & $279 \pm 90$ & $257 \pm 69$ \\
\hline Mean Force & $\mathrm{C}$ & $1071 \pm 98$ & $2025 \pm 63$ & $2956 \pm 57$ & $3906 \pm 88$ & $4839 \pm 113$ \\
\hline (\% from MVC) & $\mathrm{T}$ & $1090 \pm 116$ & $2044 \pm 102$ & $2966 \pm 84$ & $3901 \pm 136$ & $4817 \pm 197$ \\
\hline Standard Deviation & $\mathrm{C}$ & $009 \pm 04$ & $012 \pm 05$ & $016 \pm 05$ & $019 \pm 08$ & $026 \pm 14$ \\
\hline$(\mathrm{SD}$ in $N)$ & $\mathbf{T}$ & $011 \pm 04$ & $016 \pm 08$ & $020 \pm 13$ & $023 \pm 13$ & $034 \pm 18$ \\
\hline Signal-to-noise & $\mathrm{C}$ & $1317 \pm 388$ & $1828 \pm 583$ & $2107 \pm 658$ & $2271 \pm 826$ & $2168 \pm 762$ \\
\hline Ratıo (SNR) & $\mathrm{T}$ & $1477 \pm 578$ & $2183 \pm 943$ & $2360 \pm 1002$ & $2653 \pm 1188$ & $2205 \pm 857$ \\
\hline Prop Max Peak & $\mathrm{C}$ & $014 \pm 02$ & $016 \pm 03$ & $017 \pm 03$ & $018 \pm 05$ & $020 \pm 06$ \\
\hline Power (PMPP) & $\mathbf{T}$ & $016 \pm 03$ & $017 \pm 03$ & $017 \pm 04$ & $020 \pm 05$ & $023 \pm 04$ \\
\hline Approximale & C & $042 \pm 10$ & $038 \pm 09$ & $036 \pm 10$ & $034 \pm 10$ & $031 \pm 10$ \\
\hline Entropy (ApEn) & $\mathbf{T}$ & $042 \pm 08$ & $037 \pm 08$ & $035 \pm 10$ & $034 \pm 08$ & $030 \pm 06$ \\
\hline & & & & Jon-dominant $\mathrm{H}$ & Hand & \\
\hline Adjustment Tıme & C & $203 \pm 68$ & $160 \pm 46$ & $192 \pm 103$ & $205 \pm 50$ & $226 \pm 61$ \\
\hline (AT in seconds) & $\mathbf{T}$ & $194 \pm 58$ & $193 \pm 40$ & $188 \pm 40$ & $224 \pm 43$ & $250 \pm 71$ \\
\hline Relatıve Force & $\mathrm{C}$ & $1148 \pm 370$ & $501 \pm 146$ & $437 \pm 226$ & $357 \pm 97$ & $332 \pm 93$ \\
\hline Distance (RFD) & $\mathbf{T}$ & $874 \pm 263$ & $502 \pm 183$ & $323 \pm 85$ & $316 \pm 103$ & $286 \pm 87$ \\
\hline Mean Force (\% & $\mathrm{C}$ & $1060 \pm 64$ & $1990 \pm 41$ & $2954 \pm 68$ & $3869 \pm 89$ & $4811 \pm 137$ \\
\hline from MVC) & $\mathbf{T}$ & $1065 \pm 101$ & $2011 \pm 81$ & $2985 \pm 69$ & $3884 \pm 83$ & $4815 \pm 149$ \\
\hline Signal-to-noise & $\mathbf{C}$ & $1176 \pm 351$ & $1655 \pm 540$ & $1912 \pm 584$ & $1995 \pm 692$ & $1874 \pm 652$ \\
\hline Ratıo (SNR) & $\mathbf{T}$ & $1627 \pm 781$ & $2062 \pm 871$ & $2417 \pm 1138$ & $2331 \pm 977$ & $2104 \pm 808$ \\
\hline Standard Deviation & & $010 \pm 03$ & $013 \pm 04$ & $017 \pm 09$ & $021 \pm 07$ & $029 \pm 16$ \\
\hline$(\mathrm{SD}$ in $\mathrm{N})$ & $\mathbf{T}$ & $010 \pm 05$ & $015 \pm 08$ & $019 \pm 10$ & $024 \pm 10$ & $032 \pm 14$ \\
\hline Prop Max Peak & $\mathrm{C}$ & $013 \pm 02$ & $017 \pm 03$ & $019 \pm 04$ & $021 \pm 04$ & $024 \pm 05$ \\
\hline Power (PMPP) & $\mathrm{T}$ & $014 \pm 02$ & $018 \pm 05$ & $018 \pm 04$ & $022 \pm 04$ & $025 \pm 05$ \\
\hline Approximate & $\mathbf{C}$ & $044 \pm 08$ & $039 \pm 09$ & $037 \pm 09$ & $032 \pm 07$ & $031 \pm 07$ \\
\hline Entropy (ApEn) & $\mathrm{T}$ & $045 \pm 14$ & $038 \pm 09$ & $035 \pm 09$ & $034 \pm 07$ & $031 \pm 07$ \\
\hline
\end{tabular}




\section{Relative Force Distance}

Looking at the RFD, we found a significant main effect of Force level, $F(4,12)=193.03, p=.00, \eta^{2}=.87$ : As the data in Table 1 show, RFD is highest at the $10 \%$ force level and decreases rapidly until the $30 \%$ level and then remains quite stable $(10 \%: M=10.33, S E=.47 ; 20 \%: M=5.02, S E$ $=.28 ; 30 \%: M=3.61, S E=.19 ; 40 \%: M=3.15, S E=.14 ; 50 \%: M=2.93$, $S E=.13$, respectively). The girls with TS are less variable than the controls when adjusting muscle force to the imposed level, $F(1,28)=1.90, p=$ $.005, \eta^{2}=.24$ (TS: $M=4.44$ vs. controls: $M=5.58$, both $S E=.27$ ). Moreover, the interaction effect of Group by Force Level was significant, $F(4,112)=1.93, p=.00, \eta^{2}=.18$. As can be seen in Table 1 , the differences in RFD between the groups are greatest at the $10 \%$ force level and become smaller with increasing force level. In the controls, the decrease in RFD in relation to the increasing Force level is greater than in the girls with TS. Apparently, in the lower force levels more over- and undershoots are used, especially in the controls.

\section{Force recruitment domain}

\section{Mean \% force}

Both groups were able to perform the task adequately with both the dominant and the non-dominant hand. Only the expected main effect of Force level was found, $F(4,112)=12915.53, p=.00, \eta^{2}=1.00$. No significant main effects of Group $F(1,28)=0.15, p=.70, \eta^{2}=.00$, or Dominance $F(1,28)=2.51, p=.12, \eta^{2}=.08$, were found. The deviation from the imposed force level was low in all conditions (respectively $10 \%$ MVC: $M=10,7 \%, S E=.16 ; 20 \%$ MVC: $M=20,2 \%, S E=.11 ; 30 \%$ MVC: $M=29,6 \%, S E=.11 ; 40 \%$ MVC: $M=38,9 \%, S E=.17 ; 50 \%$ MVC: $M=$ $48,2 \%, S E=.26$; see also Table 1 ).

\section{Standard Deviation}

The significant main effect of Force Level, $F(1,28)=63.77, p=.00, \eta^{2}=$ .70 , points out that SD increases gradually from the $10 \% \mathrm{MVC}$ condition to the $40 \%$ MVC condition, but from there to the $50 \%$ MVC level the increment is much steeper (see Table 1 and Figure 3). Differences between 
the groups $F(1,28)=1.22, p=.28, \eta^{2}=.04$ and the two fingers $F(1,28)=$ $0.50, p=.48, \eta^{2}=.02$, are small and not significant. The absence of a main effect of Group and of the interaction effect of Force Level by Group suggest, that the higher SD in girls with TS is related to their higher MVC; we return to this issue in the discussion section.

\section{Signal-to-noise Ratio}

A measure of special interest is the SNR, in which the SD is related to the Mean Force. Figure 3 shows the mean signal-to-noise ratio as a function of force level for both groups and both hands. There was a significant main effect of Force Level, $F(4,112)=32.01, p=.00$., $\eta^{2}=.533$. As expected, SNR changed according to an inverted $U$-shaped function over the range of force levels with an optimum at the $40 \%$ level for both groups. SNR is rather similar for both groups, $F(1,28)=1.66, p=.21, \eta^{2}=.06$ (see Table 1). The SNR was somewhat higher, $F(1,28)=3.99, p=.056, \eta^{2}=.13$, for the dominant hand $(M=20.56, S E=1.24)$ than for the non-dominant hand $(M=19.15, S E=1.28)$. These findings seem to indicate a slightly more effective force production in the dominant hand.

\section{Proportional Maximal Peak Power}

PMPP increases from the $10 \%$ MVC level to the 50\% MVC level, , $F(4$, 112 ) $=57.63, p=.00, \eta^{2}=.67$ (respectively 10\% MVC: $M=.141, S E=$ $.003 ; 20 \% \mathrm{MVC}: M=.171, S E=.005 ; 30 \% \mathrm{MVC}: M=.177, S E=.006$; $40 \%$ MVC: $M=.203, S E=.008 ; 50 \%$ MVC: $M=.232, S E=.008)$. This means that with increasing force level power is less evenly distributed and a dominant peak component is more pronounced. Moreover, PMPP in the dominant hand was significantly lower, $F(1,28)=8.14, p=.01, \eta^{2}=.23$, than in the non-dominant hand $(M=.179, S E=.006$ vs. $M=.190, S E=$ $.005)$. This means that in the dominant hand more broadening is present. The interaction Force Level by Dominance was also significant, $F(4,112)$ $=4.89, p=.00, \eta^{2}=.15$. In both, the dominant and non-dominant hand PMPP increases from the $10 \%$ MVC to the $50 \%$ MVC, but in the nondominant hand PMPP starts at a lower level at $10 \%$ MVC and increases much steeper to the $50 \% \mathrm{MVC}$ level, indicating that contribution to total power of the peak, is more present in the non-dominant hand especially at the higher force level. 
Figure 3: Mean Standard Deviation, and Signal-to-noise Ratio at each Force Level for the girls with TS and the controls for the dominant and non-dominant finger.

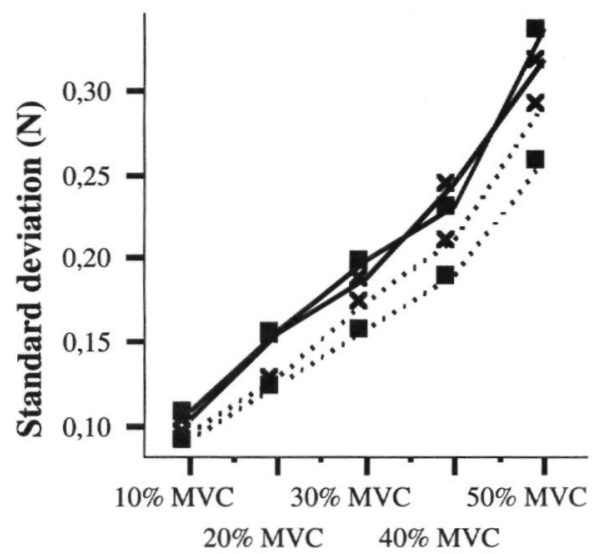

Force Level

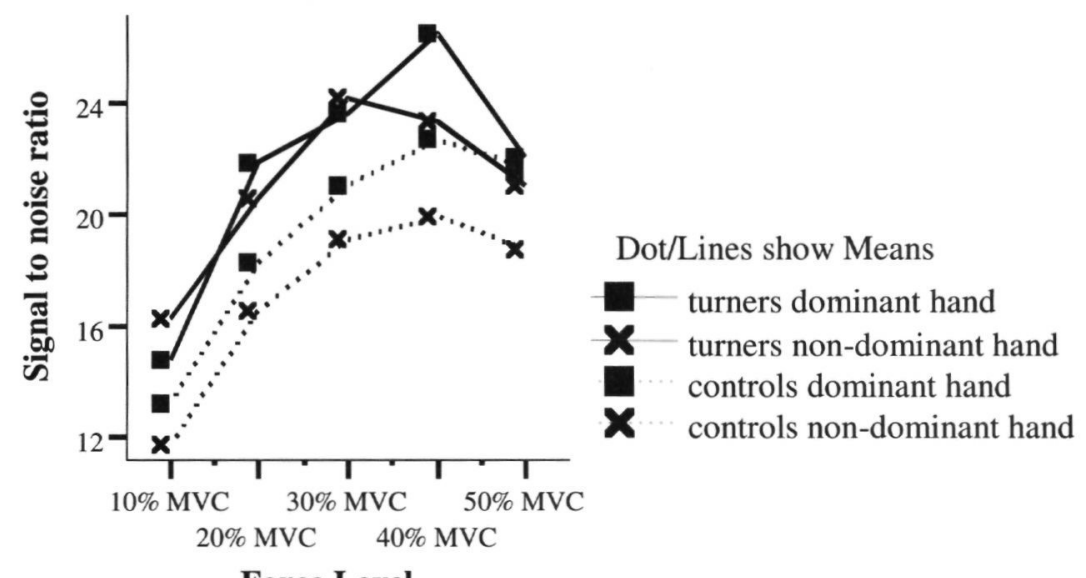

Force Level 
No significant main effect of Group, $F(1,28)=1.22, p=.28, \eta^{2}=.04$, was found. Taken together, in both groups contribution of peaked power to total power increases with increasing force level, especially in the nondominant hand. In the dominant hand more broadening is present, possibly due to the more frequent feedback contingent corrections in the less proficient non-dominant hand.

\section{Proportional Power in each frequency band at each Force level}

Figure 4 depicts the proportional power distribution per frequency band at each force level, and the outcome values for both groups in each condition are presented in Table 2. We found a main effect of Force Level, $F(4,112)$ $=82.98, p=.00, \eta^{2}=.75$ of Dominance, $F(1,28)=21.44, p=.00, \eta^{2}=$ .43 and of Frequency Band, $F(5,140)=292.56, p=.00, \eta^{2}=.91$. The interaction of Force Level by Dominance, $F(4,112)=18.81, p=.00, \eta^{2}=$ .40 , Force Level by Frequency Band, $F(20,560)=57.37, p=.00, \eta^{2}=.67$ and Dominance by Frequency Band, $F(5,140)=11.00, p=.00, \eta^{2}=.28$ were significant as well. The girls with TS and the controls used their system capacities in a comparable manner to deal with the requirements of the task, $F(1,28)=0.86, p=.361, \eta^{2}=.03$. Comparing the different force levels (see Figure 4), it can be observed that with increasing force level the PP profile shifts more and more from a nearly horizontal broadening profile $(10 \% \mathrm{MVC})$ to a profile with a concentrated peak in the lower frequency bands $(50 \%)$ and more and more concentrated in the $0-4 \mathrm{~Hz}$ domain, related to the visual controlling component. In the dominant finger more broadening is present and PMPP in the $0-4 \mathrm{~Hz}$ is lower compared to the non-dominant finger. Moreover, increasing visual control with increasing force levels is also higher in the non-dominant finger.

\section{Regularity in the time domain}

In the ApEn analysis only a significant main effect of Force level was found, $F(4,112)=32.02, p=.000, \eta^{2}=.53$ (see Table 1). The irregularity in the signal is highest at the $10 \% \mathrm{MVC}$ level and regularity increases to the $40 \%$ MVC level and remains stable in the 50\% MVC level (10-20-3040-50\% MVC: $M=.431, S E=.02 ; M=.383, S E=.02 ; M=.360, S E=.02$; $M=.339, S E=.01 ; M=.311, S E=.01 ; M=.311, S E=.01$, respectively). 
Again no group differences were found, $F(1,28)=0.18, p=.894, \eta^{2}=.00$. (girls with TS: $M=.363, S E=.02$; controls $M=.367, S E=.02$ ). As explained in the method section, values of the ApEn can vary between 0 (totally predictable) and 2 (not predictable). At all levels values are below 1 and they are, therefore, relatively predictable, with increasing predictability in the higher force levels. This increase in predictability is coupled to the increase in peaked power. Again, these data confirm that in $10 \% \mathrm{MVC}$ much noisiness is present and obviously at the $40 \%$ force level an optimum is reached.

Table 2: Proportional Power in each frequency band for the girls with TS and the controls for the dominant and non-dominant hand.

\begin{tabular}{|c|c|c|c|c|c|c|}
\hline \multirow{2}{*}{\multicolumn{2}{|c|}{$\begin{array}{l}\text { Proportional Power/ } \\
\text { frequency band }\end{array}$}} & \multicolumn{5}{|c|}{ Dominant Hand } \\
\hline & & $10 \% \mathrm{MVC}$ & $20 \%$ MVC & $30 \%$ MVC & $40 \% \mathrm{MVC}$ & $50 \% \mathrm{MVC}$ \\
\hline \multirow[t]{2}{*}{ Band 1: $0-4 \mathrm{~Hz}$} & $\mathrm{C}$ & $0.28 \pm .05$ & $0.35 \pm .09$ & $0.36 \pm .10$ & $0.42 \pm .10$ & $0.46 \pm .12$ \\
\hline & $\mathrm{T}$ & $0.30 \pm .08$ & $0.35 \pm .10$ & $0.39 \pm .11$ & $0.45 \pm .12$ & $0.51 \pm .08$ \\
\hline \multirow[t]{2}{*}{ Band 2: 4-8 Hz } & $\mathrm{C}$ & $0.21 \pm .05$ & $0.21 \pm .05$ & $0.23 \pm .05$ & $0.23 \pm .04$ & $0.24 \pm .06$ \\
\hline & $\mathrm{T}$ & $0.21 \pm .05$ & $0.18 \pm .03$ & $0.22 \pm .03$ & $0.20 \pm .04$ & $0.21 \pm .04$ \\
\hline \multirow[t]{2}{*}{ Band 3: $8-12 \mathrm{~Hz}$} & $\mathrm{C}$ & $0.13 \pm .04$ & $0.14 \pm .05$ & $0.15 \pm .05$ & $0.14 \pm .05$ & $0.12 \pm .05$ \\
\hline & $\mathrm{T}$ & $0.19 \pm .07$ & $0.18 \pm .07$ & $0.16 \pm .05$ & $0.15 \pm .07$ & $0.14 \pm .04$ \\
\hline \multirow[t]{2}{*}{ Band 4:12-16 Hz } & $\mathrm{C}$ & $0.14 \pm .03$ & $0.13 \pm .04$ & $0.12 \pm .05$ & $0.10=$ & $0.09 \pm .04$ \\
\hline & $\mathrm{T}$ & & .06 & & & .03 \\
\hline \multirow[t]{2}{*}{ Band 5: $16-20 \mathrm{~Hz}$} & $\mathrm{C}$ & & \pm .03 & & & \pm .01 \\
\hline & $\mathrm{T}$ & $0.05 \pm$ & $0.05 \pm .02$ & & .01 & $0.03 \pm .01$ \\
\hline \multirow[t]{3}{*}{ Band 6: $20-24 \mathrm{~Hz}$} & $\mathrm{C}$ & $0.14 \pm .05$ & $0.10 \pm .03$ & $0.08 \pm .04$ & $0.06 \pm$ & $0.05 \pm .03$ \\
\hline & $\mathrm{T}$ & & $0.08 \pm .04$ & $0.06 \pm .03$ & 0.05 & \\
\hline & & \multicolumn{5}{|c|}{ Non-dominant Hand } \\
\hline \multirow[t]{2}{*}{ Band 1: $0-4 \mathrm{~Hz}$} & $\mathrm{C}$ & $0.27 \pm .07$ & $0.38 \pm .06$ & & $0.48 \pm .11$ & $0.54 \pm .11$ \\
\hline & $\mathrm{T}$ & $0.27 \pm .08$ & $0.38 \pm .10$ & $0.41 \pm .12$ & 0.49 & $0.55 \pm .09$ \\
\hline \multirow[t]{2}{*}{ Band 2: 4-8 Hz } & $\mathrm{C}$ & & $0.23 \pm .05$ & .04 & 0.23 & 0.24 \\
\hline & $\mathrm{T}$ & $0.21 \pm .05$ & $0.21 \pm .05$ & \pm .05 & $0.21 \pm .04$ & $0.21 \pm .04$ \\
\hline \multirow[t]{2}{*}{ Band 3: 8-12 Hz } & $\mathrm{C}$ & $0.17 \pm .04$ & $0.15 \pm .04$ & $0.13 \pm .03$ & $0.13 \pm .04$ & $0.11 \pm .05$ \\
\hline & $\mathrm{T}$ & $0.18 \pm .05$ & $0.17 \pm .06$ & $0.16 \pm .06$ & $0.14 \pm .04$ & $0.13 \pm .06$ \\
\hline \multirow[t]{2}{*}{ Band 4:12-16 Hz } & C & $0.11 \pm .04$ & $0.08 \pm .03$ & $0.09 \pm .03$ & 0.07 & \pm .03 \\
\hline & $\mathrm{T}$ & & $0.10 \pm .03$ & $0.10 \pm .05$ & $0.08 \pm .03$ & $0.06 \pm .02$ \\
\hline \multirow[t]{2}{*}{ Band 5: $16-20 \mathrm{~Hz}$} & $\mathrm{C}$ & $0.09 \pm .03$ & $0.06 \pm .03$ & $0.05 \pm .02$ & $0.04 \pm .01$ & $0.03 \pm .01$ \\
\hline & $\mathrm{T}$ & $0.08 \pm .03$ & $0.05 \pm .02$ & $0.05 \pm .02$ & $0.03 \pm .01$ & $0.03 \pm .01$ \\
\hline \multirow[t]{2}{*}{ Band 6: $20-24 \mathrm{~Hz}$} & $\mathrm{C}$ & $0.11 \pm .04$ & $0.07 \pm .04$ & $0.06 \pm .03$ & $0.04 \pm .02$ & $0.02 \pm .01$ \\
\hline & $\mathrm{T}$ & $0.11 \pm .04$ & $0.07 \pm .03$ & $0.05 \pm .03$ & $0.03 \pm .02$ & $0.02 \pm .01$ \\
\hline
\end{tabular}


Figure 4: Mean Proportional Power per Frequency Band (0-4 Hz, 4-8HZ etc.) for each Force level for the girls with TS and the controls for the dominant and non-dominant finger.
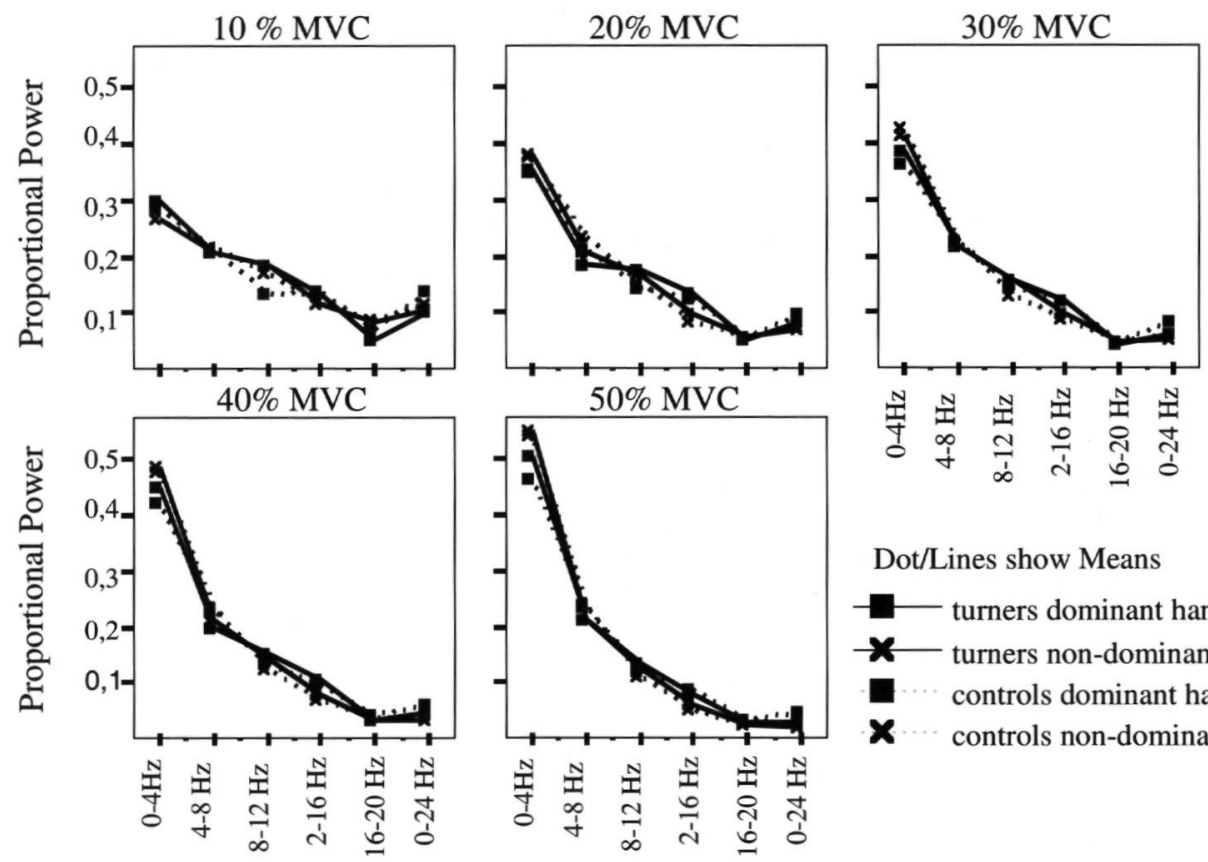

Dot/Lines show Means

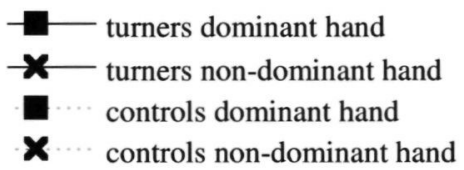

Frequency Domain

Frequency Domain 


\section{Discussion}

We used a one-finger isometric task to detect differences between (clumsy) girls with TS and controls in speed-accuracy trade-off, while at the same time we searched for possible differences in force variability related to neuromotor noise. The majority of outcome measurements failed to show significant group differences or interaction effects with group, neither in the kinematic domain, nor in the force recruitment domain. However, with respect to the more general aspects of force recruitment our study provided consistent data about the relationship between performance level (measured by SD and SNR) and specific power frequency profiles (measured by PSDA) and regularity in the power signal (measured by ApEn).

SD increased with increasing force level and SNR changed according to an inverted U-shaped function over the range of force levels, with an optimum at the 30\%-40\% level (optimal performance). At the same time, with increasing force level, total power was increasingly concentrated in a single power peak, localized in the frequency domain of $0-4 \mathrm{~Hz}$ (visual component), accompanied by increasing regularity of the overall spectrum. At $10 \%$ MVC, low performance (SD is high) was related to a broadened irregular spectrum over all frequency domains; at 40\% MVC: good performance, combined with increased, and relatively highly regular peaked power between $0-4 \mathrm{~Hz}$ was seen, whereas at $50 \%$ SNR was going down, more peak force was located between $0-4 \mathrm{~Hz}$ and the regularity measurement was becoming more stable. Performance in the non-dominant hand was lower, there was more peaked power in the $0-4 \mathrm{~Hz}$ band, which increased more strongly with increasing force level in comparison to the dominant hand.

Lack of difference between groups might have been caused by restricted statistical power due to group size or age-effects. The girls of the TS and the control group, however, were individually matched for age, and performance was comparable to that of adults. Defining force levels in terms of individual muscle force capacities results into normalized task demands. Moreover, the effects of force level manipulation and hand dominance are rather convincing and very consistent within this experiment and in agreement with literature. Therefore, it seems that the absence of a group difference is not an artifact. 


\section{Adjustment time}

The key question in the kinematic domain is: Why did not we find the expected longer adjustment time in this isometric aiming task? In previous studies, we found that girls with TS need more movement time in dynamical aiming tasks (Nijhuis - Van der Sanden et al., 2000, in press). Billon et al. (2000) measured in normal subjects the speed-accuracy tradeoff function as defined by Fitts (1954) in isometric aiming tasks. They found that in the case of pointing under isometric conditions (moving a cursor over a computer screen) increase of task difficulty resulted in a linear increase in movement time (as predicted by Fitts' law, 1954). In the present study, participants had to place a cursor in a bar as accurately and as quickly as possible. Cursor and width of the bar remained constant and therefore the distance to the target bar (representing the imposed force level) determined task difficulty. Indeed, adjustment time increased linearly with force level. Only at the $10 \% \mathrm{MVC}$ level adjustment time was higher in both groups (we retum to this issue later in the discussion section).

In contrast to our expectations, no decreased velocity was found in girls with TS in this isometric condition. Obviously, these girls were able to organize task-specific synergies (Latash \& Zatsiorsky, 1998). The sets of elements in such an isometric one-finger task is much smaller than in an isotonic condition (Bernstein, 1967). Unlike in an isotonic task, limb position remained relatively unchanged in this isometric task, and thus fewer changes may have occurred in the muscle-tendon complex, the biomechanical factors were reduced and there was no need to manage the inertial properties of the limbs. Only force-time adjustments were necessary and these did not require any adaptation of the joint angels to spatial demands. The force recruitment process as such is apparently not impoverished in $\mathrm{TS}$, and no evidence for a noisier force recruitment system was found. Taken together, this study again confirms that spatial-temporal patterning as a component of motor planning is not the main problem in girls with TS and that force regulation is not disturbed in a condition eliminating the confounding effects of biomechanical factors, resulting from actual limb displacement. 
Some authors found abnormalities in the brain stem and cerebellum in girls with TS and related these to problems in sensory integration and motor modulation (Murphy, DeCarli, Daly, Haxby, Allen, White, et al., 1993; Reiss, Mazzocco, Greenlaw, Freund \& Ross, 1995). Such abnormalities might be the reason for adaptive changes (Latash, 2001), leading to differences in orchestrated programming of agonist-antagonist groups and synergistic muscle recruitment (Van Galen et al., 1992, 2000; Wolpert, Garamani \& Jordan, 1995). Increased movement time in isotonic task conditions might therefore reflect the cost of a necessary adaptation strategy in dynamical tasks to constraints that are intrinsic to TS (Latash \& Anson, 1996; Latash, 2001).

\section{Relative force Distance}

The Relative Force Distance was significantly different between groups: in controls more over- and undershoots were present (especially at the $10 \%$ and 20\% MVC level), while girls with TS used a more step-by-step force adjustment strategy. However, looking at the data in more detail, it was obvious that variability in strategy was high between individuals, whereas at the same time choice of strategy seemed to be influenced by force level as well: with increasing force level overshoots disappeared gradually; at the $50 \%$ level the step-by-step adjustment strategy was most common in both groups. However, variation in strategy did not lead to overall differences in adjustment time or accuracy loss and various strategies were apparently effective. Scholz, Danion, Latash, and Schoner (2002) suggested that achieving successful task performance is not attained by selecting a single optimal solution, but by discovering an appropriate control law that selectively stabilizes specific combinations of degrees of freedom relevant to the task condition. The internal constraints are part of such a combination of degrees of freedom, and obviously girls with TS (as well as controls) choose the best-present solution within the task demands: accurate and fast. 


\section{Sources of variation in recruitment force}

Isometric contractions of hand muscles exhibit variability in force production that is proportional to the mean force exerted (Slifkin \& Newell, 1999). Invariant kinematics observed during goal-directed movements result from reducing the consequences of signal dependent noise on motor output (Harris \& Wolpert, 1998; Van Galen \& De Jong, 1995; Van Galen \& Huygevoort, 2000; Van Gemmert \& Van Galen, 1997) and task specific optimization occurs in the presence of such noise by using different strategies to minimize the final error. In a recent study Jones, Antonia, Hamilton, and Wolpert (2002) found that signal dependent noise (measured as force variability, SD) was linearly scaled with respect to the mean force level, but only in voluntary isometric contractions. In electrically stimulated contractions SD remained constant over the same range of mean forces. They found, that this linear scaling of $S D$ is a natural-by-product of orderly recruitment by twitch amplitude, which does not depend on noise in the motor command. However, the magnitude of the force variability at a given level of mean force output is determined by synaptic noise in the motor command and common drive. We also found that SD is predominantly related to force level in both groups. Neither linear scaling in SD, nor the magnitude of the SD differs between groups. This would mean that in both groups orderly recruitment by twitch amplitude and synchronization of motoneuron spiking were intact and occurred normally. The main findings of this study reestablished the findings of earlier studies: endpoint variability and motor control processes are intact in girls with TS compared to controls. And this study demonstrated that also motor recruitment processes are intact. Apparently, clumsiness in TS is not related to a lack of an effective optimization principle and obviously in the isometric task condition internal constraints are not redundant.

\section{Signal-to-noise Ratio}

The SD and SNR data are compatible with findings reported in the literature (De Jong \& Van Galen, 1999; Slifkin \& Newell, 1999, 2000; Van Galen \& De Jong, 1995). We found force variability (SD) to increase as a function of force level. In fact, even the size of standard deviation in the 10 to $50 \% \mathrm{MVC}$ domain was quite comparable with findings reported on 
adults (De Jong \& Van Galen, 1999; Slifkin \& Newell, 1999, 2000; Van Galen \& De Jong, 1995). Deutsch \& Newell (2001) also did not find major differences between 10-year-old children and adults. The SNR changed with increasing force levels according to an inverted $U$-shaped function with an optimum at the $40 \%$ MVC level (see also: Slifkin \& Newell, 2000). However, other studies reported different values: Slifkin and Newell, (1999) and Deutsch and Newell (2001) found the most optimal signal-to noise to lie at the $25 \%$ MVC level, while De Jong and Van Galen (1999) reported an optimum at $30 \%$ of MVC. This U-inverted relationship between SNR and force-level is the effect of steeper increasing SD at higher force levels. Jones et al. (2002) suggested that the \% MVC level, in which the last motor unit is recruited, differs in individual human muscles. Orderly recruitment occurs over the first 50\% MVC for hand muscles (Enoka \& Fuglevand, 2001) and over the first 85\% MVC in limb muscles. Linear scaling is present within the ranges, in which orderly recruitment occurs. Jones et al. suggest that as long as recruitment occurs over at least $30 \%$ MVC (m. extensor pollicis longus muscle) the scaling of SDN will tend to be linear. It must be noted that this statement is restricted to muscle acting in isolation; SD scaling in multiple synergies will differ. However, these findings concur with $U$-shaped SNR profiles with an optimum at around $25-40 \%$ MVC. It is assumable that the exact point of inversion depends on muscle properties and number of synergists, influenced by task conditions.

\section{Power spectrum profile}

Proportional peak power increased with increasing force level. This seems in contrast with Slifkin and Newell (1999; 2000), but this disparity can be explained by the fact that they calculated PSDA over the absolute power, whereas we calculated PSDA over the normalized jerk signal. In accordance with the findings of Slifkin and Newell $(1999 ; 2000)$, a very dominant peak is present in the frequency band of $0-4 \mathrm{~Hz}$ at all force levels. Slifkin, Vaillancourt, and Newell (2000) argued that a dominant oscillation in continuous force production at low frequencies, between 0,78 and 1.17 $\mathrm{Hz}$, are consonant with the hypothesis that expressions of closed loop sensorimotor information processes are restricted to a distinct, lowfrequency bandwidth of motor output (Freund \& Hefter, 1993). Moreover, in the study by Deutsch and Newell (2001) this relationship with visual feedback is confirmed: they found comparable profiles only in the visual 
feedback condition. For neither group could we confirm the findings of De Jong and Van Galen (1999), who found two other peaks band in young adults, namely in the $6-8 \mathrm{~Hz}$ and the $11-\mathrm{Hz}$ frequency. We did find a broader noisier profile (a relative horizontal line, see Figure 4) at the $10 \%$ MVC level, which is confirmed by the higher ApEn value. Variability at this force level seems to be more closely related to noisy, non-cognitive processes, like physiological tremor, motor unit recruitment and/or servomechanism. Enoka, Burnett, Graves, Kornatz \& Laidlaw (1999) demonstrated that isometric contractions in the first dorsal interossei are characterized by a Coefficient of Variation that is higher for lower forces. This phenomenon could be related to an increased variability in the discharges rates of motor neurons (Laidlaw, Bilodeau \& Enoka, 2000). The greater SD in the lower force levels is in accordance with the relatively longer adjustment time in the 10 and $20 \% \mathrm{MVC}$ level and the longer Relative Force Distance at the 10 and $20 \%$ MVC levels. Thus, the impact of physiological noise is relatively greater at the lower force levels, and visual feedback seems to be less adequate. The higher force levels, are characterized by a concentrated peak in the $0-4 \mathrm{~Hz}$ range, and a more regular and predictable signal. This means that visual steering increasingly becomes important at the higher force levels. The importance of visual steering is confirmed in the Deutsch and Newell study (2001), who found decreased SNR in the condition without feedback and with increasing force levels this SNR decreased.

\section{Relationship between motor performance and power profile}

Slifkin and Newell (1999) found the broadest spectrum at the 35\% MVC level (SNR is high) accompanied by a relative high irregularity level (higher ApEn value). We found a broader frequency profile in combination with a relatively high irregularity at the lower force levels (see Figure 4). However, higher SNR related to a wider spectrum in the dominant finger, whereas in the non-dominant finger more peak power occurred in the 0-4 $\mathrm{Hz}$ range (more visual steering). Looking at these results, we conclude that "broadening" or "noisiness" in the system is not related per se to variability in performance outcome (see also the results of Slifkin \& Newell, 1999 and Deutsch \& Newell, 2001) and, secondly, that in a sustained force control task visual feedback is an important factor controlling performance outcome. When variable performance outcome is combined with a broadened and irregular power profile (as is the case in the lower force 
levels), apparently the system is less able to adequately control such force output signals with feedback loops. On the other hand, a broadened profile combined with an optimal SNR is also found, and apparently less visual control is necessary in such a condition. Although our study was specifically designed to analyze noisiness in the neuromotor signal, we failed to confirm the hypothesis that greater noisiness is a critical factor in decreased motor performance in TS.

\section{Higher MVC in TS}

In contrast to what we had expected, we found a higher MVC in the TS group. This was somewhat surprising, since TS is associated with diminished growth: girls with TS are less tall than their healthy peers, and in the literature diminished grip force has been reported for TS (Clark, Klonoff \& Hayden, 1990; Salbenblatt et al., 1989). As regards the higher MVC, it needs to be mentioned that all girls with TS were at the time also participating in a nation-wide blind randomized study into the effect of growth-hormone treatment in combination with or without oxandrolon. It is possible that this hormonal treatment has positively affected the muscle mass and therefore the muscle force of the girls with TS. Unfortunately, no data were available on the treatments given to each of our subjects.

Although it appears that there are no differences in motor-unit recruitment processes, it is necessary to test possible effects of hormonal treatment on such processes in future investigations. 


\section{Conclusion}

Although we failed to find major differences between girls with TS and controls as the earlier dynamic aiming studies did, this study provides an insight into the motor control processes in isometric force production tasks for both girls with TS and controls. The data support the view that individuals optimize motor control related to specific task conditions and specific constraints (Latash \& Anson, 1996; Van Galen et al., 1992; 2000; Wolpert, Garamani \& Jordan, 1995). Lower movement speed or more variability in motor outcome may be regarded as the costs of such an optimizing process. In clinical populations such as girls with TS, regulation of degrees of freedom follows the optimizing principle in the same way as in normal peers, however the constraints differ. Apparently, in an isometric condition the Turner specific constraints are of less influence compared to an isotonic condition and therefore performance does not differ. Especially the dynamical aspects in tasks and the characteristics of synergistic programming seem to be important. This study indicates that motor unit recruitment or increased neuromotor noise are not significant factors explaining motor problems in TS.

\section{Acknowledgements}

The authors would like to thank both the children and their parents for their participation in this study and the teachers in the Prins Willem Alexander School in Denekamp, for their co-operation and the use of their rooms to test the control children. We are also indebted to Dr. B.J. Otten and Dr. J. Waelkens, pediatric endocrinologists, for contacting the patients. Our thanks also go to Anne Gelevert for her help with the data collection, and Bianca Nijhuis, movement scientist, for her critical comments on earlier versions of the manuscript. We would also like to thank Hanneke Meulenbroek for her language corrections, and Hubert Voogd and Jos Wittebrood for developing the software and hardware needed for this research. We are grateful to Prof. Dr. J. M.M.H. Thijssen, M. Van Wijk and Peter de Jong for advising in Power Spectral Density Analysis and Frans Gremmen for advising in statistical analysis. Finally, we thank two anonymous reviewers for their detailed and helpful comments. 


\section{Reference List}

Bender, B G , Lınden, M G , \& Robınson, A (1993) Neuropsychological impairment in 42 adolescents with Sex Chromosome abnormalities American Journal of Medical Genetıcs (Neuropsychology and Genetıcs), 48, 169-173

Bernsteın, N A (1967) The co-ordination and regulation of movements Pergamon, Oxford Billon, M , Bootsma, R J , \& Mottet, D (2000) The dynamıcs of human isometric pointıng movements under varying accuracy requirements Neuroscience Letters, 286, 49-52

Clark, C , Klonoff, H , \& Hayden, M (1990) Regional cerebral glucose metabolısm in Tumer Syndrome Canadian Journal of Neurological Science, 17, 140-144

De Jong, W P , \& Van Galen, G P (1999) Muscles act as low-pass filters on neuromotor no1se In G Leedham, M Leung, V Sagar \& X Xuhong (Eds) IGS proceedings of the 9th biennial conference of the International Graphonomics Society June 28-30, 1999, Singapore (pp 25-29) Nijmegen IGS/Nanyang Technological University

Deutsch, K M , \& Newell, K M (2001) Age differences in noise and vanability of 1sometnc force production Journal of Experimental Child Psychology, 80, 392-408

Downey, J , Elkın, E J , Ehrhardt, A A , Meyer-Bahlburg, H F L , Bell, J J , \& Morıshıma, A (1991) Cognitive abılıty and every day functioning in woman with Tumer Syndrome Journal of Learning Disabilttes, 24, 32-39

Enoka, R M , Burnett, R A , Graves, A E , Kornatz, K W , \& Laidlaw, D H (1999) Taskand age-dependent vanations in steadıness Progressıve Brain Research, 123, 389-395

Enoka, R M , Fuglevand, A J (2001) Motor unit physiology some unresolved issues Muscle nerve 24, 4-17

Fitts, P M (1954) The information capacity of the human motor system in controlling the amplitude of movement Journal of Experimental Psychology, 47, 381-391

Freund, H J , \& Hefter, H (1993) The role of the basal ganglia in rhythmuc movement In Narabayahsı, H , Nagatsu, T , Yanagisawa, Y, \& Mizuno, Y (Eds) Advances in Neurology (vol 60, pp 88-92) New York Raven Press

Harns, C M , \& Wolpert D M (1998) Signal-dependent noise determines motor planning Nature, 394, 780-784

Jones, K E , Antonıa de, F , Hamiton, C \& Wolpert, D E (2002) Sources of sıgnaldependent noise during isometric force production Journal Neurophysiology 88, 15331544

Laıdlaw, D H , Bilodeau, M , \& Enoka, R M (2000) Steadiness is reduced and motor unit discharge is more vanable in old adults Muscle Nerve, 23, 600-612

Latash, M L , \& Anson, J G (1996) What are normal movements in atypical populations? Behavioral Brain Science 19, 55-106 
Mathısen, B , Reılly, S , \& Skuse, D (1992) Oral motor dysfunction and feedıng disorders of infants with Tumer's Syndrome Developmental Medicine and Child Neurology, 34, 141-149

McAuley, J H , \& Marsden, C D (2000) Physiological and pathological tremors and rhythmic central motor control Brain, 123, 1545-1567

McGlone, J (1985) Can spatial deficits in Turner's syndrome be explanned by focal CNS dysfunction or a typical speech lateralızation? Journal of Clinical and Experimental Neuropsychology, 7, 375-394

Money, J (1993) Specific neuro-cognitive impairments associated with Tumer's (45 XO) and Klınefelter (47 XXY) syndromes a review Socıal Bıology, 40,_147-151

Murphy, D G M , DeCarlı, C , Daly, E, Haxby, J V , Allen, G, White B J , McIntosh, A R, Powell, C M , Horwitz, B , Ropoport, S I \& \& Shapiro, M B (1993) X-Chromosome Effects on female bran a magnetic resonance imaging study of Turner's Syndrome Lancet, 342, 1197-1200

Newell, K M \& \& Carlton, L G (1988) Force vanability in isometnc responses Journal of Experimental Psychology Human Perception and Performance, 14, 37-44

Nıjhuıs - van der Sanden M W G , Smits - Engelsman B C M , Elıng, P A T M (2000) Motor Performance in girls with Tumer's Syndrome Developmental Medicine and Child Neurology 42 685-690

Nıjhus -van der Sanden, M W G , Smits - Engelsman, B C M , Eling, P A T M , Nıjhuıs, B J G \& Van Galen G P (2003) Low elementary movement Speed is associated with poor motor skall in Tumer Syndrome Developmental Neuropsychology. 22 643-670 Nıjhuıs - van der Sanden, M W G, Elıng, P A T M , Van Asseldonk, E H F, Van Galen G P (2003) Decreased Movement Speed in girls with Turner Syndrome A Problem in Motor Planning or Muscle Initiation? Manuscnpt submitted for publıcation

Pincus, S M , \& Goldberger A L (1994) Physiologıcal tıme-senes analysıs what does regulanty quantify? American Journal of Physiology (Heart Circulatory Physiology), 266, H1643-H1656

Reiss, A L , Mazzocco, M M , Greenlaw, R, Freund, L S , Ross, J L (1995)

Neurodevelopmental effects of X-monosomy A volumetnc imaging study Annals of Neurology, 36, 731-738

Rosenfeld RG 1990 'Preface' In Rosenfeld, R G and Grumbach, M M (des) Turner Syndrome New York and Basel Marcel Dekker Inc

Ross, J L , Kushner, H , \& Roeltgen, D (1996) Developmental changes in motor function in girls with Turner Syndrome Pediatric Neurology 15, 317-322

Rovet, J F (1993) The psychoeducational charactenstics of children with Turner's

Syndrome Journal of Learning Disabllites, 26, 333-341 
Sdlbenblatt, J A , Meyers, D C, Bender, B G , Linden, M G , \& Robınson, A (1989) Gross and fine motor development in 45,X and 47,XXX girls Pediatrıcs, 84, 678-682

Schol7, J P , Danıon, F , Latash, M L , \& Schoner, G (2002) Understandıng finger coordination through analysıs of the structure of force varıabılıty Btological Cybernetics 86, 29-39

Slıfkın, A B , \& Newell, K M (1999) Noıse, information transmıssion, and force vanability Joumal of Expermental Psichologv Human Percepton and Performance, $25,837-85$ ]

Slıfkın, A B , \& Newell, K M (2000) Variabılity and noıse in contınuous torce production Joumal of Motor Behavior, 32, 141-150

Slifkın, A B , Vaillancourt, D E , \& Newell, K M (2000) Intermittency in the control of contınuous force production Journal of Neurophysiology, 7, 1708-1718

Smits - Engelsman, B C M , Nıhuis - van der Sanden, M W G , \& Duysens, J (in press) An exploratory Study of the kınematics of girls with Turner Syndrome in a visuo-motor task Infant and Child Development

Temple, C M , \& Camey, R A (1995) Patterns of spatial functıonıng in Turner's Syndrome Cortex 31, 109-118

Van Galen, G P , \& De Jong, W P (1995) Fitts' law as the outcome of a dynamıc noise filtering model of motor control Human Movement Science, 14, 539-572

Van Galen, G P , \& Schomaker, L R B (1992) Fitts' Law as a low-pass filter effect of muscle stıffness Human Movement Scıence, 11, 11-22

Van Galen, G P , \& Van Huygevoort, M (2000) Error, stress and the role of neuromotor noise in space onented behaviour Biological Psychology, 51, 151-171

Van Gemmert, A W A , \& Van Galen, G P (1997) Stress, neuromotor norse, and human performance A theoretical perspective Joumal of Experimental Psychology Human Perception and Performance, 23, 1299-1313

Van Gemmert, A W A , \& Van Galen, G P (1998) Auditory stress effects on preparation and execution of graphical aiming $A$ test of the neuromotor noise concept Acta Psychologıca, 98, 81-101

Wolpert, D M , Gharamanı, Z , \& Jordan, M I (1995) An internal model for sensorımotor integration Science, 269, 1880-1882 



\title{
General Discussion and Conclusion
}

\author{
Maria W. G. Nijhuis - van der Sanden \\ Department of Pediatric Physical Therapy, \\ University Children's Hospital, \\ UMC St Radboud Nijmegen.
}

Chapter 7 


\section{General Discussion}

The aim of this thesis was three-fold: Firstly, to examine whether and to what degree motor performance is a real problem in girls with Turner syndrome (TS). Secondly, to investigate whether motor performance problems are related to neuropsychological problems, especially visuospatial problems (Money, 1993; Ross, Zinn \& McCauley, 2000; Temple \& Carney, 1995), and thirdly, to analyze the specific nature of motor control in TS. Answers to these questions might be helpful in the future to determine potential benefits and strategies of physical therapy.

The information-processing model developed by Van Galen and his group $(1990,1991,1992,1995,2000)$ was taken as theoretical starting point for this thesis. This model distinguishes five hierarchically organized processing levels: 1) perception and encoding of information, 2) planning of action, 3) motor programming, 4) parametrization and 5) muscle initiation. We hypothesized that "clumsiness" in TS could be due to cognitive deficits (especially visual-spatial deficits; level 1 and 2) and/or to motor execution problems, based on neurophysiological deficits (level 3, 4, and 5). We first tried to disentangle the influence of cognitive and action planning factors on motor performance in TS. To this end, the existing literature was reviewed, searching for evidence for the presence of motor performance problems and their possible explanations (chapter 2). We then collected empirical data on motor performance in $\mathrm{TS}$, moving from a rather global descriptive level by using clinical tests (chapter 3 ) and kinematic data (Smits - Engelsman, Nijhuis - van der Sanden, \& Duysens, in press) to more controlled experiments, using experimental conditions addressing the three process levels involved in motor control (chapters 4, 5 and 6): motor planning, parametrization and muscle initiation.

In the literature as well as in our data we found clear evidence that TS is characterized by a typical motor and neurocognitive profile (Buchanan, Pavlovic \& Rovet, 1998; Murphy, DeCarli, Daly, Haxby, Allen, White, et al., 1993; Ross, Zinn, \& Mc Cauley, 2000; Salbenblatt, Meyers, Bender, Linden \& Robinson, 1989). Our results obtained with the MABC, revealed an overall poor motor performance in the girls with TS, in line with the study of Salbenblatt et al. (1989) (see chapter 3). In both the literature concerning Turner Syndrome (e.g. Ross, Kushner \& Roeltgen, 1996) and 
the literature on Developmental Coordination Disorder (Wilson \& McKenzie, 1998) the role of visuospatial perception in motor performance has been emphasized. However, we have found a motor execution problem in TS, which is independent from a visual-spatial dysfunction. For example, Performance Intelligence Scores (PIQ) did not correlate with motor performance scores (chapter 3). More explicit evidence that visualspatial perception was not the major factor causing the motor problems was found in the results of real-time kinematic data (Smits - Engelsman, Nijhuis - van der Sanden, \& Duysens, in press), which revealed that girls with TS in fact were as accurate as their normal peers, but they needed a longer trajectory length and used a more piecemeal movement strategy. All other studies (chapter 3, 4, 5 and 6) confirmed that visual-spatial perception is not the main problem and that girls with TS can move with normal accuracy.

This finding, namely that accuracy was intact despite a consistently prolonged movement time, was a new observation concerning motor performance in TS and a tuming point in our search for the nature of the movement execution problems. Analyzing the role of the different processing levels in the observed execution problems, we found indications that motor programming was intact as well as the parametrization process (chapter 4 and 5). These results were congruent with earlier studies. We argued that girls with TS preprogram their movements in a similar fashion as controls do. At the same time, we assumed that the lower velocity is an adequate adaptation strategy to improve accuracy. It was further hypothesized that increased neuromotor noise in girls with TS may induce such adaptation strategies. However, this hypothesis has not been confirmed as yet. In chapter 6 , using an isometric force production paradigm, it appeared that in a condition of sustained isometric force production (in contrast to the dynamic displacement task), speed-accuracy trade-off was unaffected and motor programming and motor unit recruitment processes were intact. The data in this thesis support the view that, although motor performance in girls with TS is subnormal as to executorial speed, it can be considered as the result of a strategy of optimizing motor control (Latash \& Anson, 1996; Van Galen et al., 1992, 2000; Wolpert, Garamani \& Jordan, 1995). This strategy is, in essence, not different from that of controls. 
Movement emerges from the interaction of three factors: the individual, the task, and the environment. From a clinical point of view, many authors focus on individual constraints and emphasize the possible influence of genetic, somatic, and psychological factors on various behavioral aspects of the Turner syndrome (e.g. Boman, Möller \& Albertsson-Wikland, 1998; Huisman \& Slijper, 2002; Ross et al., 2000). Van Galen and De Jong (1995) on the other hand emphasize that motor control is based on neurocognitive, neurophysiological and biomechanical properties of the motor system (De Jong \& Van Galen, 1999; Van Galen \& Schomaker, 1992; Van Galen \& De Jong, 1995; Van Gemmert \& Van Galen, 1997; 1998). If we now want to understand the nature of the motor execution problems in TS, we obviously need to consider a wide range of potential factors. This thesis focuses on task factors that were manipulated to detect the exact nature of the performance problem in girls with TS. The next step would be to search for internal constraints related to Tumer syndrome, which could provide an explanation for the typical motor performance profile in TS. The motor problems can be described quite clearly, namely a decreased velocity, particularly in dynamic tasks. Apparently the dynamic character of a task interacts with internal constraints, specific for the Turner Syndrome. We did not find any significant differences in motor unit recruitment, neuromotor noise, visual- spatial perception, motor programming or parametrization in simple motor tasks when girls with TS were compared to controls. It appeared however that changing limb position and/or managing the inertial properties of the limbs as is requested in real-time displacement tasks are crucial factors in the evocation of lower movement velocity. These problems are most likely related to genetic, neurological and/or anatomical differences between girls with TS and controls. We will discuss each of these possible etiologies in the next paragraphs.

The influence of genes on neuropsychological and physical characteristics seems plausible. Recent molecular genetics studies (Page, 1995) indicate there may be as many as five genes, located in different regions of the $\mathrm{X}$ chromosome, contributing to the physical and hormonal abnormalities in TS. The different combinations of these genes are thought to be associated with variations in physical and psychological stigmata in TS. Specific aspects of the TS phenotype may be related to the number of copies of relevant genes, referred to as dosage effect. They can also be attributed to a 
phenomenon known as genetic imprinting (Bishop, Canning, Elgar, Morris, Jacobs \& Skuse, 2000; Jacobs, Dalton, James, Mosse, Powe, Robinson \& Skuse, 1997; Skuse, James, Bishop, Copin, Dalton, Aamodt-Leeper, et al., 1997). Genetic imprinting is the process whereby expression of the gene depends on whether this gene is maternal of paternal of origin. Because only one of both is expressed, the other one is suppressed. Murphy et al. (1993) argued that in human beings the X-chromosome plays an important role in the development of grey matter in the striatum, diencephalon and the associative areas in the neocortex in both hemispheres. This argument is based on the differences in MRI-measured volumes of cerebral structures between controls and TS girls (Murphy, Allen, Haxby, Largay, Daly, White, et al., 1994), and differences in glucose metabolism brain regions (Murphy, Mentis, Pietrini, Grady, Daly, Haxby, et al., 1997). Moreover, these authors found evidence for " $\mathrm{X}$ chromosome dosage effects". They argued that the differences between girls with TS and controls in brain morphometry and cognitive performance could be due to genetic factors only, or could be related to endocrine factors as the result of genetic differences or the result of a combination of these factors. A role for the $\mathrm{X}$ chromosome in cerebral development is suggested by neuropsychological studies of other sex chromosome aneuploidies. For example, $47 \mathrm{XXY}$ Kleinfelter Syndrome males have verbal deficits, and girls who are 47 XXX have delayed language and cognitive development (Murphy et al., 1994). Thus, the absence or inactivity of specific genes on the $X$ chromosome may be responsible for the development of specific cerebral structures and therefore related to typical cognitive deficits and/ or motor deficits. Moreover, as the result of the genotype subjects with TS have gonadal dysgenesis. Sex steroids play a significant role in the development of the brain and therefore it could be argued that the influence of gonadal steroids play a role too in anatomical development of cerebrum and have relevance for understanding the abnormalities in cognition and in motor development. Currently, no data are available conceming such a relationship between genotype, brain structure and motor performance, but it is assumable that the reasoning concerning the relationship between genotype and cognition is also valid for motor performance deficits.

Looking at a possible relationship between TS and structures and functions of the CNS, it is obvious that movement control is achieved through the cooperative effort of many different brain structures, organized both 
hierarchically and in parallel. Some authors reported decreased volumes in different structures in the brain stem and cerebellum in TS girls and related these to problems in sensory integration and motor modulation (Murphy et al., 1993; Reiss, Mazzocco, Greenlaw, Freund \& Ross, 1995). The cerebral hemispheres and basal ganglia (Kandel, 1991) are involved in the planning of motor strategies or action planning and our experiments focused on the motor programming level and motor execution level. Therefore, it is important to perform complementary studies in the future, analyzing how the observed motor execution problems might influence motor strategies and choices in action planning. For instance, we found some evidence that girls with TS move in a more piecemeal fashion and we suggested that this was the result of a difficulty in quickly changing the direction of the movement at the turning point. It is likely that in more complex actions the choice of motor strategies is constrained by such concatenation problems leading to an alternative movement strategy. The observed daily life problems and problems with, for instance, driving a car indeed point to the direction of such motor adaptation strategy.

Some authors suggest a potential dysfunction of the cerebellum in girls with TS, resulting in problems in sensory integration and motor modulation (Murphy et al., 1993; Reiss, Mazzocco, Greenlaw, Freund \& Ross, 1995). The cerebellum has a special function in adjusting motor responses by comparing the intended output with sensory signals and to update movement commands if they deviate from the intended path (ShumwayCook \& Woollacott, 2000, p. 83). Perhaps this can explain the prolonged dwell time at the turning points of movements. For instance, this dwell time may reflect correction movements based on error detection through visual and/or somatosensory feedback. Basically two loops for error detection and correction have been described: A long loop for intentional action $(150 \mathrm{~ms})$ and a much faster subcortical loop (80 ms; Schmidt, 1999). Group differences in dwell time can be due to a difference in error detection strategy. This would mean that girls with TS, because of a cerebellar dysfunction, use more extensively the visual and intentional control (long loop), while in controls the somatosensory system deals with the same demands, but on a lower level (subcortical loop). This hypothesis would imply a longer loop and therefore a slower correction mechanism not only at the turning points of the movements. But this was not observed: accuracy level was high and in both discrete ballistic movements and serial current 
controlled movements velocity profiles were similar to those of the controls and no differences in velocity peaks were found. Moreover, also in the isometric force output signals we did not find evidence for differential effects of visual and somatosensory control loops between groups. The cerebellum is also involved in modulating force and movement range. We did not find any confirmation for the idea that girls with TS produce more adjustments of motor responses; the velocity profiles do not differ from those in controls, and neither force nor movement range modulation appear to be problematic. This suggests that a dysfunction of the cerebellum cannot explain our findings.

Another issue, that seems to involve both neurological and anatomical aspects, is the following. We proposed that the decreased movement velocity in girls with TS is possibly the result of an increment in limb stiffness (tonic filtering; Van Gemmert \& Van Galen, 1997; Van Galen \& Huygevoort, 2000), necessary to attain acceptable spatial accuracy. The normal brain uses the gamma motor neuron system to modulate sensory information at its source in order to adapt to the requirements of movements (Shumway-Cook \& Woollacott, 2000). It can be argued, that deregulation of the gamma motor system plays a role in the motor problems in Turner syndrome. Especially the independence of the motor delay from task difficulty and the consistency in deviation of the movement time of girls with TS from that of controls, point into this direction. The muscle spindles and Golgi tendon organs together regulate muscle stiffness (Gordon and Ghez, 1991), whereas muscle stiffness is defined as the force per unit length of a muscle. It is possible that the settings of the gamma motor system differ in Turner syndrome and therefore stiffness regulation itself works out differently. This means that changed stiffness regulation is not the result of an adaptation strategy, but stiffness regulation itself is an intrinsic factor that influences movement speed.

The typical anatomical features of TS, in particular short stature, cubitus valgus and short metacarpals could be another influencing factor for differences in inertial properties of the movement. This is in accordance with reported symptoms in TS, such as hypotonia, strength problems, poor joint stability, gait abnormalities and difficulties with balance and diadochokinesis (Salbenblatt et al., 1989). Another important point is the fact that we used in our research rather simple motor tasks. The number of degrees of freedom (Bernstein, 1967) in such tasks is relatively low. 
Moreover, we found no problems in the isometric task, studied in chapter 6 , but more problems in dynamic, isotonic tasks. Apparently, when the motor system needs to program more anatomical elements (for instance, when more joints are involved) more outspoken differences between TS and controls can be observed. Future experiments manipulating the complexity of motor tasks by increasing the type and the number of elements should provide insight into this matter. We hypothesize that the coordination of especially multi-joint movements could possibly lead to increased differences between the groups. More research is necessary to investigate which abnormalities in the CNS are the driving force for such adaptive changes (Latash \& Anson, 1996), leading to differences in orchestrated programming of agonist-antagonist groups and synergistic muscle recruitment (Van Galen et al., 1992, 2000; Wolpert et al., 1995). Also, to investigate the exact nature of the coordination of the synergistic muscle groups, we need measurement procedures that provide a direct insight into these synergistic mechanisms, for instance EMG registrations.

Important work has been done by the group of Ross and her colleagues $(1996,1998,2000)$. They investigated the influence of estrogen on neurocognitive and motor functioning in TS. Ross et al. (2000) argued "that neurophysiological and neuroanatomical differences between females and controls with Turner syndrome are consistent with a sustained abnormality in the cerebral substrate, either as a primary factor and/or secondary to the endocrine and/or genetic influences" (pp.136). TS is characterized by premature ovarian failure and neurocognitive deficits may arise from a lack of estrogen during the first year of life, when there is normally a period of increased ovarian estrogen production (Buchanan et al., 1998). This view refers to the finding that sex hormone levels influence visual-spatial processes and working memory during early development (Williams \& Meck, 1991). Other deficits have been ascribed to a lack of estrogen during early puberty, prior to receiving estrogen replacement therapy. Romans, Stefanatos, Roeltgen, Kushner, and Ross (1998) and Ross, Roeltgen, Feuillan, Kushner, and Cutler (1998) found a positive estrogen effect on nonverbal processing speed and motor speed in young girls with TS. However no estrogen replacement effect was found on cognitive deficits in adult females with TS (Ross, Stefanotos, Kushner, Zinn, Bondy \& Roeltgen, 2002). Ross and her colleagues suggest that these results reflect the specific influence of hormonal factors on brain maturation during 
puberty. Most of the girls with TS in our studies were in the age range of 912 years and only a few were treated with estrogen. Therefore we could not analyze whether there was a relationship between treatment and velocity, but we cannot rule out the possibility either. McEwen and Wooley (1994) suggested that estrogen functions transiently as a neuromodulator, and permanently by altering synapse formation and structural/organizational remodeling or both. Such synaptic structures are relevant in both visuospatial processing and motor execution, and therefore estrogen could be a decisive factor. In our view, however, any conclusions are premature. Essentially no study has looked in detail at the working mechanism of estrogen on the nervous system, and only indirect evidence is available. It is important to detect the exact relationship between sex hormones and the working mechanism in the regulation of movement speed in the future.

In the last ten years, treatment with synthetic growth hormones has been introduced in TS to improve body growth during childhood in order to diminish the practical and psychological problems of an extremely short stature. Only Ross, Feuillan, Kushner, Roeltgen, and Cutler (1997) studied growth hormone replacement effects on cognitive functioning, and they did not find any positive effect. Moreover, no studies on motor performance were found. In this thesis we did not focus on growth hormone treatment effects. It is possible that treatment with growth hormone, with or without oxandrolon, influences some results in our study. All participating girls with TS were also participating in a nation-wide blind and randomized study into the effects of growth-hormone treatment with or without oxandrolon. In contrast to what we had expected, we found a higher MVC in the TS group and this was somewhat surprising, since TS is associated with diminished growth: TS girls are smaller than their healthy peers, and in the literature diminished grip force has been reported for TS (Clark, Klonoff \& Hayden, 1990; Salbenblatt et al., 1989). This means that in future studies it is important to test whether indeed this higher MVC is related to treatment effects. Another question is unanswered too: In the last study we did not find any differences in motor control and motor recruitment processes, although we expected this on the base of other studies. We assumed that differences in task constraints are explanatory factors although we did not test in this group of 15 girls with TS velocity in dynamical tasks. Theoretically it is possible that treatment with growth 
hormones in combination with oxandrolon does have effects on movement velocity in dynamical tasks too. This needs future research also.

It might be argued that girls with TS are less proficient in motor tasks, since they are less inclined to engage in motor activities, for instance in sports. Although this would be a valid argument for the alleged poorer sport skills, the consistent nature of the prolonged movement times in divergent but simple motor tasks makes it very likely that the lower movement speed is not related to differences in experience. This is the more so because the tasks we used were very simple for children at this age and also because we did not find motor planning differences and differences in the velocity profiles.

That motor performance appears to be decreased will probably not surprise females and girls with TS themselves. Many of them report that they move relatively slowly. Moreover, complex motor tasks seem to be particularly difficult for girls with TS, especially if a high velocity is required. It is reasonable to assume that functional motor performance problems have consequences for daily life activities and social functioning. Most of the girls have a low self-esteem in school age and do not like sport activities. It is likely that in complex motor tasks in which velocity is a critical factor, accuracy is decreased too, for instance when catching a fast coming ball. In general velocity increases somewhat as the result of training (only few people function at their own champion level), but this would have only an effect on the untrained skills. In future investigations it is important to evaluate whether training daily life motor skills can improve movement velocity and to evaluate in which manner longer movement time in simple movements is related to the capacities to perform more complex movements. Moreover it is important in relation to the education of girls with TS to adapt requirements by the social environment to their capacities and to accept that velocity is a problem.

We observed that most of the studies in motor performance in Tumer Syndrome used clinical tests to detect differences between patients and normal controls. Motor tasks in such tests are often rather complex and differences in performance scores could be due to psychological and somatic factors. Experimental manipulation of likely constraints (speed, accuracy, parallel processing) can be a fruitful way to make progress towards theory-driven motor studies in different diagnostic groups. Turning 
to the studies in TS: based on clinical studies, it has always been assumed that motor performance problems were mainly determined by visual-spatial problems. However, most of the studies used clinical tests and did not disentangle the role of different processing levels in task performance. Most of the conclusions were based on descriptive data. Systematic manipulation of task constraints revealed that the execution of movements was a problem already in simple motor tasks, while motor planning seems to be intact. Of course this thesis is only a start and more studies are necessary to test if action planning is a decisive factor too in more complex tasks, and to test in which way the movement execution problems interact with action planning. Based on the results in this thesis, we concluded that such experimental studies could be used in clinical populations to get more insight in the nature of movement control and movement execution.

\section{Conclusions}

The following conclusions can be drawn from this thesis:

1. Motor performance is a real problem in girls with TS.

2. This "clumsiness" is not an accuracy problem but a velocity problem: girls with TS are as accurate as normal peers, however in both clinical and experimental tests they are consistently slower.

3. Although visual-spatial problems are present and relevant for motor action planning, it seems that motor execution problems are independent of visual-spatial problems.

4. TS girls can optimize their motor performance as adequately as normal controls. However, especially in dynamic tasks girls with TS have more problems than controls in particular at the turning points of movements.

5. Using a well-based theoretical framework and systematically designed experimental studies is a sensible strategy to detect the exact nature of motor performance problems in clinical populations. 


\section{Reference List}

Bernstein, N A (1967) The co-ordination and regulation of movements Oxford Pergamon Bıshop, D V M , Cannıng, E , Elgar, K , Moms, E , Jacobs, P A , \& Skuse D H (2000)

Distınctive patterns of memory function in subgroups of females with Turner Syndrome

Evidence for imprintıng loci on the $\mathrm{X}$-chromosome affectıng neurodevelopment

Neuropsychology, 38, 712-721

Boman, U W , Moller, A , \& Albertsson-Wikland, K (1998) Psychological aspects of

Tumer Syndrome Journal of Psychosomatic Obstetrics and Gynecology, 19, 1-18

Buchanan, L , Pavlovic, J , \& Rovet, J (1998) A Reexamınation of the visuo-spatial deficit

in Tumer Syndrome Contributıons of workıng memory Developmental

Neuropsychology, 14, 341-367

Clark, C, Klonoff, H , \& Hayden, M (1990) Regıonal cerebral glucose metabolism in

Tumer Syndrome Canadian Journal of Neurologıcal Sciences, 17, 140-144

Gordon, J , \& Ghez, C (1991) Muscle receptors and spinal reflexes the stretch reflex In

Kandel, E , Schwartz, J H , \& Jessell, T M (Eds) Princıples of neuroscience $\left(3^{\text {rd }} \mathrm{ed}\right.$, pp 564-580) New York Elsevier

Huisman, J, \& Slıjper, F M E (2002) Psychologısche kenmerken van meisjes met het

Syndroom van Tumer Nederlands Tydschrift voor Kindergeneeskunde, 70, 111-115

Jacobs P , Dalton P , James R , Mosse K , Power, M , Robınson D , \& Skuse D (1997)

Tumer Syndrome A cytogenitic and molecular study Journal of American Human

Genettcs, 6I, 471-483

Jeannerod, M , Arbıb, M A , Rızzolattı, G , \& Sakata, H (1995) Graspıng objects The cortical mechanısms of visuomotor transformation Trends in Neuroscience, 18, 314 320

Kandel, E Brain and Behavior In Kandel, E, Schwartz, J H , \& Jessell, T M (Eds )

Principles of neuroscience ( $3^{\text {rd }}$ ed, pp 5-17) New York Elsevier

Latash, M L , \& Anson, J G (1996) What are normal movements in atypical populations?

Behavioral Brain Science 19, 55-106

McEwen, B S , \& Wooley, CS (1994) Estradiol and progesterone regulate neuronal

structure and synaptic connectivity in adult as well as developing brain Experimental

Gerontology, 29, 431-436

Money, J (1993) Specific neuro-cognitive impauments associated with Turner's (45 XO)

and Klinefelter (47 XXY) syndromes a review Socıal Bıology, 40, 147-151

Murphy, D G M , Allen, G , Haxby, J V , Largay, K A, Daly, E, White, B J , Powell, M C,

\& Shapiro, M B (1994) The effects of sex steroids and the X-chromosome, on female 
brain function A study of the neuropsychology of adult Tumer's Syndrome Neuropsychology, 32,1309-1323

Murphy, D G M , DeCarlı, C , Daly, E , Haxby, J V , Allen, G, White, B J , McIntosh, A R , Powell, C M , Horwitz, B , Ropoport, S I, Shapiro, MB (1993) X-Chromosome effects on female brain a magnetic resonance imaging study of Turner's Syndrome Lancet, 342, 1197-1200

Murphy, D G M , Mentıs, M J , Pietrını, P P , Grady, C , Daly, E , Haxby, J V , De La Granja, M , Allen, G , Largay, K A , White B J , Powell, M C , Horwitz, B , Ropoport, S I , \& Shapıro, M B (1997) A PET study of Turner's Syndrome Effects of sex steroids and the X-chromosome on brain Biological Psychiatry, 41, 285-298

Page D C (1995) Mapping and targetıng Tumer genes In Albertson-Wıkland K A, Ranke M B (Eds) Turner Syndrome in life span perspective Research and clinical aspects (Vol 1, p 11) Amsterdam Elsevier

Reıss, A L , Mazzocco, M M , Greenlaw, R , Freund, L S , \& Ross, J L (1995)

Neurodevelopmental effects of X-monosomy A volumetric imaging study Annals of Neurology, 36, 731-738

Romans, S M , Stefanatos, G, Roeltgen, D P , Kushner, H , \& Ross, J L (1998) Transition to young adulthood in Ullnch-Tumer Syndrome Neurodevelopmental changes American Joumal of Medical Genettcs, 79, 140-147

Ross, J L , Feullan, P, Kushner, H , Roeltgen, D , Cutler Jr G B (1997) Absence of growth hormone effects on cognitive function in girls with Tumer Syndrome Journal of Clinical Endocrinology and Metabolism, 82, 1814-1817

Ross, J L , Kushner, H , \& Roeltgen, D (1996) Developmental changes in motor function in girls with Turner Syndrome Pediatric Neurology, 15, 317-322

Ross, J L , Roeltgen, D , Feullan, P , Kushner, H , \& Cutler, G B (1998) Effects of estrogen on nonverbal processing speed and motor function in girls with Turner's Syndrome Joumal of Clinical Endocrinology and Metabolism, 83, 3198-3204

Ross, J L , Stefanotos, G A , Kushner, H , Zınn, A , Bondy, C , \& Roeltgen, D (2002)

Persistent cognitive deficits in adult women with Turner Syndrome Neurology, 58, 218225

Ross, J L , Zinn, A \& Mc Cauley, E (2000) Neurodevelopmental and psychosocial aspects of Turner Syndrome Mental Retardatıon and Developmental Disabilities Research Reviews, 6, 135-141

Rovet, J (1993) The psycho-educational characteristics of chıldren with Turner's Syndrome Journal of Learning Disabilittes, 26, 333-341

Salbenblatt, J A , Meyers, D C , Bender, B G , Linden, M G \& Robınson, A (1989) Gross and fine motor development in 45,X and 47,XXX girls Pediatrics, 84, 678-682 
Skuse, D.H., James, R.S., B1shop, D.V.M., Copin, B., Dalton, P., Aamodt-Leeper, G., Bacarese-Hamilton, M., Cresswell, C., McGurk, R., \& Jacobs P. (1997). Evidence from Tumer syndrome of an imprinted $\mathrm{X}$-linked locus affecting cognitive function. Nature, 378, 705-708.

Schmidt, R.A., \& Lee, T. D. (1999). Principles of simple movement. In R.A. Schmidt \& T.D.Lee (Eds.), Motor control and learning: A behavioral emphasis (pp.172-180). Illinois, United States: Human Kinetics.

Shumway-Cook, A., \& Woollecott, M.H. (2000). Motor control: theory and practical applications. ( $2^{\text {nd }}$. ed., pp. 50-90). Baltimore: Lippincott Williams \& Wilkins.

Smits - Engelsman, B.C.M., Nijhuis - van der Sanden, M.W.G., \& Duysens, J. (in press). An exploratory Study of the kinematics of girls with Turner Syndrome in a visuo-motor task. Infant and Child Development.

Temple, C.M., \& Carney, R.A. (1995). Patterns of spatial functioning in Tumer's Syndrome. Cortex 3l, 109-118.

Van Galen, G.P. (1991). Handwriting: Issues for a psychomotor theory. Human Movement Science, 10, 165-191.

Van Galen, G.P., \& De Jong, W.P. (1995). Fitss'law as the outcome of a dynamic noise filtering model of motor control. Human Movement Science, 14, 539-572.

Van Galen, G.P., \& Schomaker, L.R.B. (1992). Fitts' Law as a low-pass filter effect of muscle stiffness. Human Movement Science, 11, 11-22.

Van Galen, G.P., Van Doorn, R.R.A., \& Schomaker, L.R.B. (1990). Effects of motor programming on the power spectral density function of finger and wrist movements. Journal of Experimental Psychology: Human Perception and Performance, 16, 755 765.

Van Galen, G.P., \& Van Huygevoort, M. (2000). Error, stress and the role of neuromotor noise in space oriented behavior. Biological Psychology, 51,151-171.

Williams, C.,L, \& Meck, W.H. (1991). The organizational effects of gonadal hormones on sexually dimorphic spatial ability. Psychoneuroendocrinology,16,155-176.

Wilson, P.H., \& McKenzie B.E. (1998). Information processing deficits associated with Developmental Coordination Disorder: A meta-analysis of research findings. Journal of Child Psychology and Psychiatry and Allied Health Disciplines, 39, 829-840.

Wolpert, D.M., Ghahramani, Z., \& Jordan, M.I. (1995). An internal model for sensorimotor integration. Science, 269, 1880-1882. 


\title{
Summary
}

\author{
Maria W. G. Nijhuis - van der Sanden \\ Department of Pediatric Physical Therapy, \\ University Children's Hospital, \\ UMC St Radboud Nijmegen.
}

\section{Summary}




\section{Summary}

This thesis is concerned with the psychological and behavioral implications of the Tumer Syndrome (TS) in girls at school age. In chapter 1 the more general biological and psychological characteristics of the Turner Syndrome (TS) are briefly introduced. Besides the potential consequences for daily life are described. The general aim of the thesis focuses on the analysis of the motor performance problems in TS and their possible etiological fundament. It is argued that these problems need to be studied within a scientifically well-based theoretical view on the nature of motor control.

In chapter 2 the existing literature on Turner Syndrome is explored to investigate whether a specific dysfunction in cognitive and/or motor processing is present in girls with TS, and to what extent these two aspects are related. Published studies clearly indicated that the intelligence profile is disharmonic and especially performance on visual spatial tasks is decreased. This profile remains stable into adulthood and there is some evidence suggesting a link with deviations in particular neuro-anatomical structures, hormonal regulation, and genotype. Although we found only a few studies examining motor performance in TS, we concluded that it is disturbed too. Moreover, there are indications that the poorer performance in motor and cognitive tasks, are in essence independent.

To validate the movement problems in daily life in girls with TS, we tested fifteen girls with TS on the Movement Assessment Battery for Children (MABC) and the Wechsler Intelligence Scale-Revised for the Netherlands (WISC-RN), as described in chapter 3. These clinical tests revealed impairment in all motor domains (manual dexterity, ball skills and static and dynamic balance) in girls with TS, whereas no correlation was found with the achievements on the Intelligence test. Girls with TS scored lowest compared to controls on the pegboard task: a goal-directed motor task, with both accuracy and speed demands. Moreover, no differences in scores between girls with TS and controls were found on the flower trail (another subtest in the MABC). They were able to draw a line between two narrow boundaries just as accurate as the control children: accuracy seemed to be no problem when velocity demands are absent.

The aim of the study described in chapter 4 was to discriminate between two features, that in principle both may be characteristic of the poor motor 
performance in girls with TS: a) a reduced movement speed, independent of spatial accuracy demands and therefore suggestive of a problem in motor execution or b) a decreasing movement speed as the result of increasing spatial-accuracy demands, indicating a more central problem in motor programming. A new group of fifteen girls with TS and 14 female controls were first tested using the MABC. The results replicated the findings of chapter 3, namely that overall motor performance in girls with TS is poor. Additionally, a Fitts' graphical aiming task was used. Participants were required to draw a straight line between two target circles $(2.5 \mathrm{~cm}$ apart) as fast and as accurately as possible, in both finger and wrist movement conditions, as well as in a discrete (a number of independent movements) and a serial task condition (continuous movements for a specified period of time). The data re-established that girls with TS move with the same accuracy as their normal peers, but they move with a significantly lower speed. This difference in velocity between groups was constant and did not depend on changing target sizes, joints or movement conditions. We concluded, therefore, that a problem in motor execution is the main factor determining performance differences between girls with TS and controls.

In chapter 5, three experiments with fourteen girls with TS and fourteen matched controls are described. In these experiments task-loading conditions addressed three specific levels of the psychomotor model of Van Galen (1991): the muscle initiation level, the size control level and the motor programming level. In all three experiments the participants were asked to draw prescribed figures as fast and as accurately as possible. In the first experiment task loading was specifically directed at the muscular initiation level. Participants had to repeatedly draw an apex, consisting of only two line segments, while accuracy was manipulated by varying target width in both a discrete and a serial movement condition. In the second experiment serial patterns of three apexes were presented. By varying the size of the apexes, task load increased at the size control level. In the third experiment we presented varying patterns each consisting of three figures. Now shape was manipulated while size was held constant. Kinematic analyses confirmed that the girls with TS were as accurate as their normal peers, but that overall movement speed was lower, while manipulating the size control and motor programming level had no additional effects on velocity. It appeared that especially fast tuning of muscle initiation was the critical factor. It was concluded that decreased velocity probably is the result of problems at the muscle initiation level. It was suggested that girls 
with TS have a higher level of neuromotor noise to which they adapt by increasing stiffness. This leads to changes in agonist-antagonist synergy and loss of velocity.

In chapter 6 the notion of increased neuromotor noise in girls with Turner syndrome (TS) and its relationship to decreased speed-accuracy trade-off was studied with the help of an isometric force production task. Fifteen TS girls and fifteen age-matched controls performed isometric force contractions with each index finger at five force levels based on a girl's individual maximum voluntary contraction. The results revealed that in such an isometric task condition, girls with TS did not differ from their normal peers, neither in speed or accuracy, nor in the quantity and quality of neuromotor noise. Moreover, the motor unit recruitment process seems to be intact. Moreover, it was concluded that such force output signals provide insight in the way individuals program their movements and in the contributions of diverse neuromuscular systems. It is concluded that such procedures can enrich our diagnostic possibilities, also for other clinical populations.

In chapter 7 , the main findings from the preceding chapters are discussed in relation to genetic, neurological and anatomical features of TS.

The following conclusions can be drawn from this thesis:

1. Motor performance is a real problem in girls with TS.

2. This "clumsiness" is not an accuracy problem but a velocity problem: girls with TS are as accurate as normal peers, however in both clinical and experimental tests they are consistently slower.

3. Although visual-spatial problems are present and relevant for motor action planning, it seems that motor execution problems are independent of visual-spatial problems.

4. TS girls can optimize their motor performance as adequately as normal controls. However, especially in dynamic tasks girls with TS have more problems than controls in particular at the turning points of movements.

5. Using a well-based theoretical framework and systematically designed experimental studies is a sensible strategy to detect the exact nature of motor performance problems in clinical populations. 


\section{Nederlandse Samenvatting}

Maria W. G. Nijhuis - van der Sanden

Department of Pediatric Physical Therapy, University Children's Hospital, UMC St Radboud Nijmegen.

\section{Samenvatting}




\section{Nederlandse Samenvatting}

Deze dissertatie heeft betrekking op de psychologische en gedragsmatige implicaties van het Turner Syndroom (TS). We hebben ons met name gericht op het motorisch functioneren van meisjes met TS in de schoolleeftijd. In hoofdstuk 1 worden de algemene biologische en psychologische karakteristieken van het Turner Syndroom kort geïntroduceerd. Bovendien worden de potentiële consequenties voor het dagelijks functioneren beschreven. De algemene doelstelling van deze dissertatie is het analyseren van de motorische problemen bij het Turner Syndroom en de mogelijke etiologische fundamenten. Daarnaast wordt beargumenteerd dat deze problemen bestudeerd moeten worden met behulp van een wetenschappelijk gefundeerd theoretisch kader, dat inzicht geeft in de aard van de motorische controle.

In hoofdstuk 2 wordt een literatuurstudie uitgevoerd om te onderzoeken of er sprake is van specifieke disfuncties in cognitieve en/of motorische processen, specifiek voor het Turner Syndroom. Daarnaast is gekeken in welke mate deze twee aspecten aan elkaar gerelateerd zijn. Uit de publicaties bleek duidelijk dat er sprake is van een disharmonisch intelligentieprofiel: met name de prestaties op visuo-spatiële taken zijn lager. Dit disharmonisch profiel is ook op volwassen leeftijd nog steeds aanwezig en er zijn aanwijzingen gevonden dat de neuropsychologische functiestoornissen een relatie hebben met afwijkingen in bepaalde neuronanatomische structuren, hormonale regulatie en genotype. Ondanks het feit dat er maar een paar studies zijn uitgevoerd op het domein van het motorisch functioneren bij TS, concludeerden wij dat het Turner Syndroom samengaat met meer motorische problemen. Bovendien vonden we aanwijzingen dat de lagere prestaties op motorische en cognitieve taken in wezen onafhankelijk van elkaar bestaan.

Om de omvang van de motorische problemen in het dagelijks leven te objectiveren bij meisjes met het Syndroom van Turner, zijn 15 meisjes getest met de Movement Assessment Battery for Children (MABC) en de Wechsler Intelligence Scale-Revised (WISC-RN). Dit onderzoek staat beschreven in hoofdstuk 3. Deze klinische testen wezen uit dat er sprake was van motorische problemen op alle domeinen (handvaardigheid, balvaardigheid, statische en dynamische balans), terwijl er tegelijkertijd geen correlatie werd gevonden met de prestaties op de Intelligentie test. In 
vergelijking tot de controles scoorden de meisjes met het Syndroom van Turner het laagst op de pinnetjestaak: een doelgerichte motorische taak met zowel nauwkeurigheidseisen als snelheidseisen. Bovendien werden er geen verschillen gevonden tussen de meisjes met het Syndroom van Tumer en de controles bij het bloemspoor (een andere subtest van de MABC). Zij waren even goed in staat als de controles om nauwkeurig een lijn te trekken tussen twee nauwe grenzen: nauwkeurigheid leek geen probleem als de snelheidseis verviel.

Het doel van het onderzoek in hoofdstuk 4 was om onderscheid te maken tussen twee eigenschappen, die in principe kenmerkend zouden kunnen zijn voor de zwakkere motorische prestaties bij meisjes met het Syndroom van Turner: a) een lagere bewegingssnelheid, onafhankelijk van de spatiële nauwkeurigheidseisen en derhalve wijzend op een probleem in de motorische uitvoering óf $b$ ) een verminderde bewegingssnelheid, die gekoppeld is aan toenemende spatiële nauwkeurigheidseisen en daarom meer wijzend op een centraal probleem in de motorische planning. Een nieuwe groep van 15 meisjes met het Syndroom van Tumer en 14 controlemeisjes werden eerst getest met de MABC. De resultaten bevestigden de bevindingen in de studie uit hoofdstuk 3 , namelijk dat er sprake is van verminderd functioneren op alle motorische domeinen.

Vervolgens werd een doelgerichte grafische taak gebruikt (een zogenaamde Fitts taak). De kinderen moesten zo snel en nauwkeurig mogelijk een recht lijntje trekken tussen twee doelcirkels over een afstand van $2,5 \mathrm{~cm}$. Deze taak werd aangeboden in twee condities: één waarin alleen vingerbewegingen en één waarin polsbewegingen gemaakt moesten worden. Bovendien moesten de bewegingen op twee manieren worden gemaakt: een discrete (een vast aantal op zichzelf staande bewegingen) en een seriële conditie (herhaalde bewegingen zonder stoppen gedurende een vaste periode). Deze data bevestigden opnieuw dat de meisjes met het Syndroom van Turner even nauwkeurig bewegen als de controles maar dat de bewegingssnelheid significant lager is. Deze lagere snelheid werd niet beïnvloed door veranderingen in de nauwkeurigheidseisen, of de gebruikte gewrichten of de bewegingsconditie. Daarom concludeerden we dat het probleem met name in de uitvoering van de bewegingen zit en dat dit de belangrijkste onderscheidende factor is tussen meisjes met het Syndroom van Tumer en controles. 
In hoofdstuk 5 worden drie experimenten beschreven, waaraan 14 meisjes met het Syndroom van Tumer en 14 controle meisjes van dezelfde leeftijd en hetzelfde schoolniveau meededen. In deze drie experimenten zijn taakcondities gebruikt die een specifiek beroep deden op de drie procesniveaus, benoemd in het model van Van Galen (1991): het spier initiatie niveau, het niveau dat de grootte van een grafisch patroon regelt en het niveau dat de vorm programmering regelt. In alle drie de experimenten werd de meisjes gevraagd de gepresenteerde grafische patronen zo snel en nauwkeurig mogelijk na te maken. In het eerste experiment werd met name een beroep gedaan op het spier initiatie niveau. De deelnemers moesten een dakje tekenen dat bestond uit slechts twee lijnsegmenten. De mate van nauwkeurigheid werd gemanipuleerd door de doelgrootte te variëren, en er werden opnieuw twee bewegingscondities gebruikt: een discrete en een seriële taak. In het tweede experiment werd een patroon van drie dakjes gepresenteerd. Door de grootte van de dakjes te variëren werd een beroep gedaan op het procesniveau dat verantwoordelijk is voor het programmeren van de juiste afmeting. In het derde experiment werden drie grafische patronen gepresenteerd die verschilden in vorm: dakjes en boogjes van dezelfde afmeting. Kinematische analyses bevestigden dat de meisjes met het Syndroom van Tumer deze taken even nauwkeurig konden uitvoeren als de controlemeisjes, maar met een lagere bewegingssnelheid, terwijl de grootte- en vorm manipulaties geen additioneel effect hadden op het verschil in snelheid. Met name het snel afstemmen bij de spierinitiatie leek het hoofdprobleem. Daarom concludeerden wij dat het verlies aan snelheid te wijten was aan problemen op het spierinitiatie niveau. Wij veronderstelden dat er sprake is van een hogere neuromotorische ruis bij meisjes met het Syndroom van Turner. Om hieraan te adapteren verhogen zij de stijfheid en dit leidt tot veranderingen in de agonist - antagonist synergie en een verlies van snelheid.

In hoofdstuk 6 is het idee van een verhoogde neuromotorische ruis bij meisjes met het Syndroom van Turner bestudeerd in relatie tot de langere bewegingstijd die bij hen noodzakelijk lijkt om het gewenste nauwkeurigheidsniveau te handhaven. Vijftien meisjes met het Syndroom van Turner en 15 controlemeisjes voerden isometrische spierkrachttaken uit met beide wijsvingers afzonderlijk. Er werden vijf spierkrachtniveaus gepresenteerd, die gebaseerd waren op de individuele maximale vrijwillige spiercontractie. Het bleek dat geen verschillen gevonden werden in tussen de turnergroep en de controlegroep bij deze isometrische taak, noch in 
snelheid en nauwkeurigheid, noch in kwantiteit of kwaliteit van de neuromotorische ruis en bovendien was het rekruteren van motor units intact. Het analyseren van spierkrachtsignalen was bruikbaar om inzicht te krijgen in de wijze waarop individuen hun bewegingen programmeren. Bovendien kunnen de bijdragen van de verschillende neuromusculaire subsystemen aan het outputsignaal gedetecteerd worden. Dit soort analyses zijn dus ook toepasbaar bij andere klinische populaties om een bijdrage leveren aan de diagnostische mogelijkheden.

In hoofdstuk 7 worden de bevindingen uit de vorige hoofdstukken kritisch besproken in relatie tot de genetische, neurologische en anatomische eigenschappen kenmerkend voor het Syndroom van Tumer.

Samengevat ondersteunen de studies in dit proefschrift de volgende algemene conclusies:

1. Motorisch functioneren is daadwerkelijk een probleem bij meisjes met het Syndroom van Turner.

2. De onhandigheid wordt niet gekenmerkt door een nauwkeurigheidsprobleem maar door een snelheidsprobleem: de meisjes met het Syndroom van Turner zijn even accuraat als de controles maar zowel bij de klinische als experimentele tests zijn ze consistent trager.

3. Hoewel er visuo-spatiële problemen aangetoond zijn en deze ook relevant zijn voor het plannen van handelingen, lijkt het dat de motorische uitvoeringsproblemen bij meisjes met het Syndroom van Turner onafhankelijk zijn van visuo-spatiële problemen.

4. Meisjes met het Syndroom van Turner optimaliseren hun bewegingsuitvoering even adequaat als controles; echter met name in dynamische taken hebben zij meer specifieke problemen dan controles op de omkeerpunten van de beweging.

5. Het gebruik maken van een wetenschappelijk gefundeerd theoretisch model en systematisch ontworpen experimenten is een verstandige strategie om de exacte aard van motorische problemen bij klinische populaties te detecteren. 



\section{Dankwoord}

Geen enkele prestatie kan iemand op zijn eentje leveren en dus ook niet het schrijven van een proefschrift. Dit was mij dan ook niet gelukt zonder de stimulans, betrokkenheid en directe hulp van velen, niet alleen de laatste jaren in Nijmegen maar ook tijdens de jaren in Almelo. Ik zou dan ook eigenlijk iedereen persoonlijk willen bedanken voor zijn of haar rol in het groeiproces dat uiteindelijk heeft geleid tot dit proefschrift, maar het is onmogelijk dit persoonlijk te doen en iedereen bij naam te noemen.

Voordat ik toch een aantal personen/instellingen bij name wil noemen, wil ik vanaf deze plek iedereen bedanken, die mij stimuleerde mijn grenzen te zoeken, die mij prikkelde om door te gaan, die mij leerde mijn verstand en mijn gevoel te gebruiken en die mij zelfvertrouwen gaf.

Mijn eerste dankwoord gaat uit naar Barto Otten; lieve Barto, nooit was dit proefschrift tot stand gekomen als je niet al die jaren dat we elkaar troffen als vrienden, ver uit elkaar wonend, bleef praten over dat schitterend Radboud van je. Ook in Almelo had ik al Turner meiskes en daar groeide de fascinatie. Toen je het voor elkaar had en ik naar Nijmegen kwam, namen jij, Cees Noordam, Agnes Brugman-Boezeman, Lida Nabuurs en Wil Renier me meteen op in hun team en kreeg ik alle ruimte en steun mijn eigen paden te ontdekken, jij was altijd bereid hindernissen weg te kappen. En op deze plaats ook mijn dank aan Judith Dijkstra-Hekkink: je kwam als beginnend onderzoekster op een afdeling die begon met onderzoek: maar je stond je vrouwtje en ik wil je dan ook hartelijk danken voor je loyale inzet. Ook Geert Thoonen was in de begintijd nog in de late uurtjes aanwezig en ondanks het feit dat hij met eigen deadlines worstelde, was hij altijd bereid te helpen bij de data ontcijfering, de eerste analyses en het worstelen met de computer.

Dan een woord van dank aan de Turnervrouwen die mij oprecht hun levensverhaal vertelden, die voor mij formuleerden waar ze tegenaan liepen: verhalen met een lach en een traan. Dank je wel aan al die meisjes en hun ouders die mee werkten aan het onderzoek en vol enthousiasme steeds weer bereid waren de experimenten ontelbare malen te herhalen, sommigen van jullie moesten een heel programma afwerken, maar nooit makten jullie er een probleem van. Velen hebben me geholpen een goede onderzoeksomgeving te creëren en de planning van de experimenten zo 
goed mogelijk te regelen. Bedankt Saskia de Vries, nooit een aarzeling altijd direct bereid oplossingen te zoeken, door het hele land heen!! Ook Benno Wiggers, voorzitter van de Turner patiëntenvereniging, stond altijd klaar om een goede data verzameling te ondersteunen: je was expert Benno als vader en als psycholoog, bedankt voor je praktische steun maar ook voor het ijzeren vertrouwen dat je had in een goede afloop. Ook dank aan de methylschool "De Trappenberg" in Huizen voor het beschikbaar stellen van ruimten. Dank aan Dr. J. Waelkens, die spontaan zijn medewerking bood bij het verzamelen van de data in de omgeving van Eindhoven. Dank ook aan de kinderen, de ouders en de schoolleiding en leerkrachten van al die controle kinderen: jullie deden mee, vulden lijsten in en regelden de planning en de ruimtes: basisschool "De Hazensprong" in Nijmegen, Het "Kandinsky college" in Nijmegen, de Prins Willem Alexander School in Denekamp, en de vriendinnetjes en klasgenootjes van Maaike van Alphen van basisschool "De Grote Lier" in Molenhoek: bedankt.

Voor de totstandkoming van het proefschrift zelf zijn een paar mensen van groot belang geweest en die wil ik dan ook speciaal bedanken. Op de eerste plaats Paul Eling; lieve Paul, zonder jou was er geen proefschrift geweest en ik weet niet of je wist waar je aan begon. Jij bent degene geweest die onvermoeibaar me de kneepjes van het wetenschappelijk werk bijbracht en met eindeloos geduld, maar ook met een kritische houding, structuur in mijn schrijfsels aanbracht, sorry, foutje, zorgde dat ik structuur in mijn schrijfsels aanbracht! Ik ben er trots op dat de krabbels in de kantlijn toch wel wat minder werden de laatste tijd! Wat je niet deed was me de ruimte ontnemen om mijn eigen ideeën vorm te geven. Je was een "bovenmeester" uit duizenden, en hebt me ontelbare boeken en meterslange leesstof aangereikt om me niet alleen de trucjes te leren maar om me ook inzicht in de wetenschapsfilosofie bij te brengen: de idolen van de psycholoog hebben een ereplaats op de boekenplank. Ik realiseer me dat je af en toe gek geworden moet zijn van mijn tempo, dat zo anders was dan het jouwe: bedankt en.. je bent nog niet van me af: er liggen nog wat data!!

Op de tweede plaats wil ik Gerard van Galen bedanken: Beste Gerard, onvoorwaardelijk zei je ja, toen ik in 1999 bij je kwam vragen samen met Bouwien of je mijn promotor wilde zijn. Ik had een plannetje op papier gezet en twee artikeltjes geschreven. Je ging met me in zee: maar je gevleugelde woorden van de laatste maanden zal ik niet vergeten: wat heb je een hoop geleerd, zei je steeds weer bij ieder artikel dat volgde: en ja 
inhoudelijk heb ik een hoop geleerd van je. Samen zaten we dan gebogen over de resultaten en voerden inhoudelijk diepgaande discussies met zijn tweeën: je legde vaak feilloos de vinger op de zwakke plek in de redenering en als ik bij je wegging kon ik weer vooruit. Dank voor het aanbrengen van nuances als ik weer eens te stellig was.

Bouwien, je bent me voorgegaan en was mijn voorbeeld. Jij bracht mij de eerste beginselen bij hoe een onderzoek van de grond te krijgen en benadrukte keer op keer de noodzaak van de wetenschappelijke onderbouwing van de kinderfysiotherapie. Je bracht mij zover om een stap te zetten en hebt Gerard overtuigd van mijn mogelijkheden. Samen hebben we de eerste opzet van het onderzoek uitgewerkt, en ik kan je zeggen dat ik geen spijt gehad heb van deze stap: onderzoek doen is me een waar genoegen.

Als tweede promotor wil ik Rob Sengers bedanken: jij was meteen bereid als promotor op te treden toen Barto Otten en ik onze plannen ontvouwden. Je kende me als hoofd van de afdeling, als klinisch therapeut maar niet als wetenschapper, ondanks dat gaf je me vanaf het begin je vertrouwen en kon ik dank zij de lieve medewerking van Sandra Eichelsheim altijd bij je binnenlopen. Jij was degene die het traject goed bewaakte, waar ik een klankbord vond als er problemen waren. Met raad en daad stond je me bij: Als ik bij je vandaan kwam wist ik dat het in orde kwam, en dat kwam het dan ook! Bedankt!

Lieve collega's: Marlou, Anjo, Gera, Anke, Perijn, Ineke, Jasper, Trees en Jetty: ik heb alles te danken aan het feit dat jullie me door dik en dun steunden en zo flexibel waren de problemen op te lossen, als ik er weer eens niet was. Vanaf het begin waren jullie solidair en is het een gezamenlijk project geweest: ik heb optimaal kunnen profiteren van de diversiteit aan talenten die ons team zo kleurrijk maken. Bedankt daarvoor en ook jullie kunnen met recht trots zijn. Het is moeilijk te beschrijven voor anderen wat wij met elkaar hebben, maar ik dank jullie voor de saamhorigheid, de integriteit, het kritisch vertrouwen, de tranen van boosheid, van ontroering en van het lachen, het rennen door de gangen maar ook de mijmeringen bij de koffie, de discussies in vergaderingen, de kritiek in de kantlijn maar ook de onvoorwaardelijke inzet als we samen een klus moeten klaren: ze zullen nog meer van ons horen. 
Bij een proefschrift als dit, is het niet klaar als de experimenten bedacht zijn. Het bouwen van de apparatuur en het ontwerpen van software vraagt specifieke kennis en de inzet van velen. De eerste experimenten kwamen van jou, Peter de Jong, en de tijdstippen waarop wij onze discussies voerden zijn in een normale agenda niet vast te leggen, maar je was altijd bereid de "bugs" zoals jij ze noemde de wereld uit te helpen. En daarna kwamen Hubert Voogd, Jos Wittebrood en Michel Verbruggen in beeld: jongens ik heb een onpeilbare bewondering voor de snelheid en effectiviteit waarop jullie onze vragen en wensen omzetten in goed functionerende onderzoeksopstellingen, ik hoop nog eens terug te mogen komen. Ook de jongens van het systeembeheer, Rien Cuypers, Herwig Goddaer en Hans Smit waren er voor me op mogelijke en onmogelijke tijden, leverden de noodzakelijke ondersteunende software programma's aan, zorgden dat de onderzoeksopstellingen functioneerden en losten de acute problemen met verbindingen, kabeltjes en netwerken snel en effectief op, nooit vroeg ik tevergeefs.

Data verzamelen is één, maar ze analyseren is twee en ik heb dan ook grote bewondering voor hen die even vlot een programma in matlab-taal schrijven. Ik hoefde alleen mijn wensen kenbaar te maken, en het programma verscheen en dat was het begin van de samenwerking met Edwin van Asseldonk. Lieve Edwin, ik denk dat onze samenwerking uniek was, ik bedacht wat ik wilde en jij wist me op mijn wenken te bedienen, vertaalde het in ingewikkelde analyse programma's en kreeg het ook nog voor elkaar om me te laten snappen wat er gebeurde, we hebben heel wat uren achter het schermpje gezeten en onze armen begonnen als muizen te piepen, maar het resultaat mag er dan ook zijn en is ook in de toekomst bruikbaar. Onze beider dank gaat uit naar Martin van Wijk en Prof. H. Thijssen die ons met raad en daad bij stonden, in de ook voor hen onbekende vraagstukken op het moment dat de spectraal analysen in beeld kwamen.

Aangezien ik nu eenmaal geen aangeboren taaltalent ben, zijn de complimenten van de reviewers, betreffende taal en stijl voor een deel ook te danken aan Joanne Postma en Hanneke Meulenbroek, die beiden kritisch de stukken hebben doorgelezen en fouten in het engels hebben opgespoord en gecorrigeerd. 
Ook Frans Gremmen wil ik hartelijk danken voor zijn wijze lessen in de statistiek, en vooral voor zijn steun bij het juist formuleren van de verdediging voor de gekozen analyses, statistiek leren is een kunst maar toepassen is een vak apart.

Verder wil ik Prof. Jacques Duysens van de Maartenskliniek hartelijk bedanken voor zijn gastvrije ontvangst in het laboratorium aldaar en Vivian Weerdesteyn en Bart Nienhuis voor het spontaan aanpassen van de software aan onze wensen en eisen tussen hun eigen onderzoek door.

Gedurende dit onderzoek hebben een groot aantal studenten hun medewerking verleend aan de dataverzameling en de organisatie: lang nog niet alles is geanalyseerd, maar dat komt nog hoor! Bianca Nijhuis, Geert van den Borne, Mirjam Verstegen, Lonneke Neilen, Bettine Fleerkotte en Anne Gelevert, bedankt! Ik vond het leuk met jullie te werken en jullie hebben heel wat werk verzet! ik bedank jullie voor de altijd enthousiaste en nauwgezette uitwerking van jullie stages en wat mij betreft was het nog gezellig ook!!

Last but not least wil ik mijn thuisfront bedanken. Allerliefste Louis, ik bedank je niet voor je ondersteuning in het huishouden en de maaltijden die je kookte omdat ik er nog niet was, daar wil je niet voor bedankt worden en dat hoeft ook niet: samen uit, samen thuis is altijd ons devies geweest!! Waar ik je wel voor wil bedanken is het feit dat ik altijd op je kon rekenen als maatje door dik en dun, als vader voor onze kinderen, als klankbord, als vriendje, als remmer maar ook als duwer, ik wil je bedanken voor je humor, je eeuwige verrassingen, je charmante reclameboodschappen en je mooie en verleidelijke (franse) dromen: je gave om me met de benen ook eens van de grond te laten komen!! Ik zal niet beloven dat het nu allemaal beter wordt en er zeeën van tijd overblijven na dit proefschrift, we weten beiden wel beter! We gaan gewoon door met samen gelukkig zijn!

Lieve Bianca, ook jou ben ik veel dank verschuldigd en je had al op vele plekjes in dit dankwoord thuis gehoord. Waar andere moeders winkelen met hun dochter, zaten wij geboeid gebogen over jouw dictaten van de colleges bewegingswetenschappen, was ik gefascineerd door jouw groeiende theoretische kennis van zaken. De eerste experimenten leidden tot felle discussies niet alleen over de opzet en organisatie. Jij werd volwassen en wij werden meer en meer partner en ontwikkelden ons 
allebei. Je leende zelfs je vriendje Edwin even aan me uit! Ik ben je dankbaar dat we moeder en dochter, maar ook collega's kunnen zijn, trots op elkaar. Ik ben je dankbaar voor je grote kennis van zaken, je ongelooflijke inzet, de vele mails en de lieve kaartjes; je werkte en leefde daadwerkelijk mee. Ik ben je dankbaar dat je een paar jaar terug de stap naar Amerika hebt genomen en ik weet zeker dat er binnenkort een moment komt dat je niet de "dochter van" bent, maar dat ik de "moeder van" wordt.

Lieve Mark, ook jij werd volwassen deze periode en hebt weliswaar niet direct aan het proefschrift bijgedragen, maar me wel veel geleerd. Ik ben je dankbaar voor de briefjes die je schreef, waarin je zo goed in staat was een spiegel voor te houden en aan te geven wat je bezig hield. Tot op de dag van vandaag hou je in de boekhandel bij of mijn boek Kinderfysiotherapie wel op de goede verkooptafel ligt en anders regel je dat wel!! Ik ben je dankbaar voor je gezellige huisje samen met Maaike, waar we altijd welkom zijn.

Lieve Frouke, jij bent de medische wereld ingestapt, maar ook jij zocht al meteen de combinatie met de psychologie. Ik voel me trots iedere keer als ik hoor dat je op me lijkt, maar weet ook dat het soms worstelen met jezelf is. Ik ben je dankbaar om je altijd vrolijke en gelijkmatige karakter en je relativeringsvermogen, je betrokkenheid, de zelfstandigheid die je al vroeg ten toon spreidde en ik ben je dankbaar voor de mooie dagen in Maastricht, de vorige zomer. Je komt er wel lieve meid zelfs nu al wereldwijd!

Lieve Maarten, dagelijks confronteer je me met je kritische scherpe opmerkingen, raak en recht voor zijn raap (niet alleen virtueel overigens, want je bent en blijft een knuffelworstelaar): jij zou het anders doen, gelukkig maar. Ik leer er wel van hoor, maar kan dat natuurlijk niet zomaar meteen toegeven, dát moet je zelf herkennen. Het klinkt een beetje raar in je oren denk ik maar dank zij jou bleven de werktijden nog enigszins binnen de perken. Ik zal het komend jaar je eindeloos ge-emmer over hoe die computer beter kan en je voortdurende correcties van mijn engelse uitspraak missen! 


\section{Curriculum Vitae}

(Ma)Ria W.G. van der Sanden werd op 28 april 1952 te Eindhoven. Na het behalen van het Gymnasium- $\beta$ diploma aan het Gymnasium 'Mater Deï' te Nijmegen in 1970, volgde zij de opleiding Fysiotherapie in de St.

Maartenskliniek te Nijmegen, waarna zij het Bewijs van Bevoegdheid van Fysiotherapeut ontving in 1974. In de jaren tussen 1976 en 1989 volgde zij diverse na- en bijscholingscursussen op het gebied van de Fysiotherapie en de Kinderfysiotherapie en in 1989 werd zij geregistreerd als Kinderfysiotherapeut. In 1989 startte zij een studie Sociale Wetenschappen aan de Open Universiteit, waarbij een groot aantal modulen, onder andere statistiek en methoden en technieken van onderzoek, met goed gevolg werden voltooid. In 1997 behaalde zij de Voortgezette Management Opleiding voor de non-profit sector aan de Hogeschool van Arnhem en Nijmegen.

$\mathrm{Na}$ haar afstuderen als fysiotherapeut was zij van 1974 tot 1976 werkzaam in een particuliere praktijk in Cuijk. In 1976 nam zij samen met haar man een praktijk voor Fysiotherapie over in Almelo. Vanuit deze praktijk was zij werkzaam op het Medisch Kinder-Dagverblijf "de Reggeberg" in Hellendoorn (tot 1981) en verbonden aan de "De Wissel", een school voor In-Ontwikkeling-Bedreigde-Kleuters- te Almelo. Daamaast was zij van 1978-1986 voorzitter van de Regionale Vereniging voor Fysiotherapie in de regio Almelo. Sinds 1993 is zij hoofd van de afdeling Kinderfysiotherapie in het Academisch Kinderziekenhuis St. Radboud te Nijmegen. Op deze afdeling werd vanaf 1998 het onderzoek, waarvan dit proefschrift het resultaat is, in samenwerking met de afdeling Kindergeneeskunde en het Nijmeegs Instituut voor Cognitie en Informatie (NICI) uitgevoerd. Sinds 1995 is Ria als docent en modulecoördinator verbonden aan de Modulaire Opleiding voor kinderfysiotherapie te Breda. Sinds 1999 is zij Secretaris van de Landelijke Neonatale Follow-up werkgroep van de Nederlandse Vereniging voor Kindergeneeskunde. 


\section{List of Publications}

\section{References of chapters}

Nıرhus -Van der Sanden, M W G , Elıng, P A T M , \& Otten, B J (submitted) A Review of Neuropsychological and Motor Studies in Turner Syndrome (Chapter 2)

Nijhuis - Van der Sanden, M W G, Smits - Engelsman, B C M , \& Elıng, P A T M (2000) Motor Performance in girls with Tumer's Syndrome Developmental Medicine and Child Neurology, 42,685-690 (Chapter 3)

Nıjhuss - Van der Sanden, M W G , Smuts - Engelsman, B C M , Elıng, P A T M , Nijhuıs, B J G , \& Van Galen, G P (2003) Low elementary movement Speed is associated with poor motor skıll in Tumer Syndrome Developmental Neuropsychology 22(3), 643-670 (Chapter 4)

Nijhuis - Van der Sanden, M W G , Elıng, P A T M , Van Asseldonk, E H F , \& Van Galen, G P (submitted) Decreased movement speed in girls with Turner Syndrome a problem in motor planning or muscle initiation? (Chapter 5)

Nıjhuls - Van der Sanden, M W G , Van Asseldonk, E H F , Eling, P A T M , \& Van Galen, G P (in press) Slow motor performance in gurls with Turner Syndrome is not related to increased neuromotor noise Motor Control (Chapter 6)

\section{Other Publications}

De Groot, L , Nijhuis - van der Sanden, M W G , \& Samson J (2000) De neuromotore ontwıkkelıng van het prematuur geboren kınd diagnostıek en interventıe Tydschrıft voor Kindergeneeskunde, 68, 222-229

De Kleıne, M J K , Den Ouden, L Kollée, L A A , Nıjhuıs - van der Sanden, M W G, Sondaar, M , van Kessel-Feddema, B J M , Knu1t, S , van Baar, A , Ilsen, A , BreurPieterse, R Bnet, J M Brand, R \& Verloove-Vanhonck, S P (in press) Development and evaluation of a follow-up assessment of preterm infants at five years of age Archives of Disease in childhood

Nıhuıs - van der Sanden, M W G , Elıng P A T M , \& Brugman-Boezeman A T M (2002) Onhandigheid bıj het Syndroom van Tumer is plannen of uitvoeren van bewegingen een probleem? Tydschrift voor kındergeneeskunde, 70, 116-121

Nıjhuıs - van der Sanden, M W G , Dıjkstra-Hekkınk, J G B , Brugman-Boezeman, A T M , Elıng P A T M , Thoonen, G , Otten, B J , \& Rener, W (1998) Het Tumersyndroom 
Een literatuurstudie naar het belang van neuropsychologisch en motonsch onderzoek

Tijdschrift voor Orthopedagogiek Kinderpsychologie en Kinderpsychiatrie, 23, 11-18

Nıjhuıs - van der Sanden, M W G , Dıjkstra-Hekkınk, J G B , Thoonen, G , \& Nabuurs, L

(1998) Het Tumer Syndroom dagelıjkse problemen in kaart gebracht Fysıopraxis, 7 , 13-18

Nijhuis - van der Sanden, M W G , Van Goor-Dıjkstra, B , Engelbert, R , \& Heerkens, Y (2001) Functieprofiel Kinderfysiotherapeut Amersfoort Nederlandse Verenıging voor Fysıtherapıe in de Kınder- en Jeugdgezondheidszorg

Nıjhuıs - van der Sanden, M W G , \& Vermaas, A (1998) Multıdısciplınaire protocollen zin of onzin? Ziekenhuisbrede protocollen in het AZN Onderwys en Gezondhetdszorg, 22, 184-188

Smits - Engelsman, B C M , Nıhhus - van der Sanden, M W G , \& Duysens, J (in press) An exploratory Study of the kinematics of girls with Turner Syndrome in a visuo-motor task Infant and Chuld Development

Van Empelen, Ron, Nijhuıs-van der Sanden, Ria en Annelıes Hartman (Eds)

Kinderfysiotherapıe Maarsssen Elsevier Gezondheidszorg

Van Kessel-Feddema, B J M, Sondaar, M, Maassen, B A M, Knuit, S , Nıhuıs - van der Sanden, M W G, Kollée, L A A (2001) Determınanten van gedrags- en schoolproblemen bij ex-premature kınderen met een zeer laag geboortegewıcht Tydschrift voor Kindergeneeskunde, 69, 37-43

Van Kuyk, E M , Wissınk-Essink, M L , Brugman-Boezeman, A T, Oerlemans, H M , Nijhuıs - van der Sanden, M W G, Sevenjnen, R S, Festen, C, Bleıjenberg, G A (2001) Multidisciplinary behavioural treatment of defecation problems A controlled study in children with anorectal malformatıons Pediatric Surgery Internatıonal, 36, $1350-1356$

Willemsen, M A A P, Lutt, M A J, Steijlen, P M, Cruysberg, J R M, van der Graaf, M, Nuhhuis - van der Sanden, M W G, Pasman, J W , Mayatepek, E, Rotteveel, J J (2001) Clinical and biochemical effects of zileuton in patıents with the Sjogren-Larsson syndrome European Journal of Pediatrics, 160, 711-717 

Stellingen

behorende bij het proefschrift

\section{The Turning Point}

Localizing the motor performance deficit in Turner Syndrome

Ria Nijhuis - van der Sanden

Nijmegen, 24 april 2003 
Motorische problemen bij meisjes met het Syndroom van Turner worden niet gekenmerkt door een accuratesse probleem maar door een snelheidsprobleem, onafhankelijk van de visuo-spatiële eisen in een taak. (dit proefschriff)

Bij meisjes met het Syndroom van Turner is de tragere bewegingssnelheid bij eenvoudige doelgerichte taken niet een gevolg van problemen in de planning, maar direct gerelateerd aan de dynamica van de beweging. (dit proefschriff)

Interventieprogramma's voor motorische dysfuncties dienen gebaseerd te zijn op goed onderbouwde theoretische modellen, die inzicht geven in de wijze waarop het normale bewegingscontrolesysteem omgaat met interne en externe constraints.

Psychologische theorieën over motorische controle kunnen zonder een gedegen biologische kennis van het bewegingssysteem en van de biomechanica niet goed ontwikkeld worden.

Consensus-based richtlijnen in de fysiotherapie zijn een formalisering van de "sensus communis"; dit brengt het risico met zich mee dat de impliciete axiomata, die aan de inhouden ten grondslag liggen niet of zelden systematisch getoetst worden. ( $J$. Linschoten, 1964: De idolen van de psychologie. Utrecht: erven J. Bijleveld)

Evidence-based richtlijnen zijn in het algemeen gebaseerd op het black-box model: bekend is welke prikkels of manipulaties zijn toegediend en het effect is gemeten aan de hand van de outputvariabelen; echter het detecteren van het inhoudelijk werkingsmechanisme door middel van deductie ontbreekt, hetgeen implicaties heeft voor het bepalen van de doelmatigheid. 
Kinderfysiotherapie is een dialogisch spel: je speelt het samen met kind en ouders, je verstaat en begrijpt elkaar en vult elkaar aan, ook al spreek je niet dezelfde taal: een dialoog, die op logica getoetst moet kunnen worden.

Het menselijk verstand fingeert constantie waar veranderlijkheid heerst en houdt daarmee grip op de wereld. (Francis Bacon, 1620: Novum Organum, geciteerd in J. Linschoten, 1964: De idolen van de psychologie. Utrecht: erven J. Bijleveld, b/z. 56)

Er leven vele ikken in mijzelf. Om de beste uit te zoeken heb ik goede vrienden en leermeesters nodig. (Toon Hermans, 1980: Alles is Heimwee. Amsterdam: Elsevier, p. 72.)

De wetmatige relatie tussen snelheid en accuratesse (Fitts' law) lijkt niet op te gaan in management: hoe meer tijd hoe minder accuraat.

Titels of kwaliteitskeurmerken zijn geen garantie voor wijze besluiten.

Mèt elkaar dansen verrijkt je leven, maar van om elkaar heen dansen word je alleen maar moe.

Slechts weinigen beseffen, dat een leidinggevende noch een op buit beluste wolf, noch een uit te melken koe is, maar een paard dat de kar moet trekken. (Peter Camp en Funs Erens, 1997: De gekookte kikker. Amsterdam:Contact)

Ook professoren moeten leren leren. (Dick Jungst, 14 september 2002) 

